 \\ Universidade de São Paulo \\ Instituto de Física
}

\section{Métodos de Análise de Mapeamentos Não-Lineares com Aplicações à Física}

sberétuix Calolas

\section{de Plasmas}

Tese apresentada ao

Instituto de Física da

Universidade de São Paulo

para a obtenção do título

de Doutor em Ciências

Banca Examinadora:

Prof. Dr. Iberê Luiz Caldas (Orientador / IF-USP)

Prof. Dr. José Carlos Sartorelli (IF-USP)

Prof. Dr. Felipe Rizzatto (UFRGS)

Prof. Dr. Sylvio Ferraz de Mello (IAG-USP)

Prof. Dr. Pisardo Egydio (UNESP-Rio Claro)
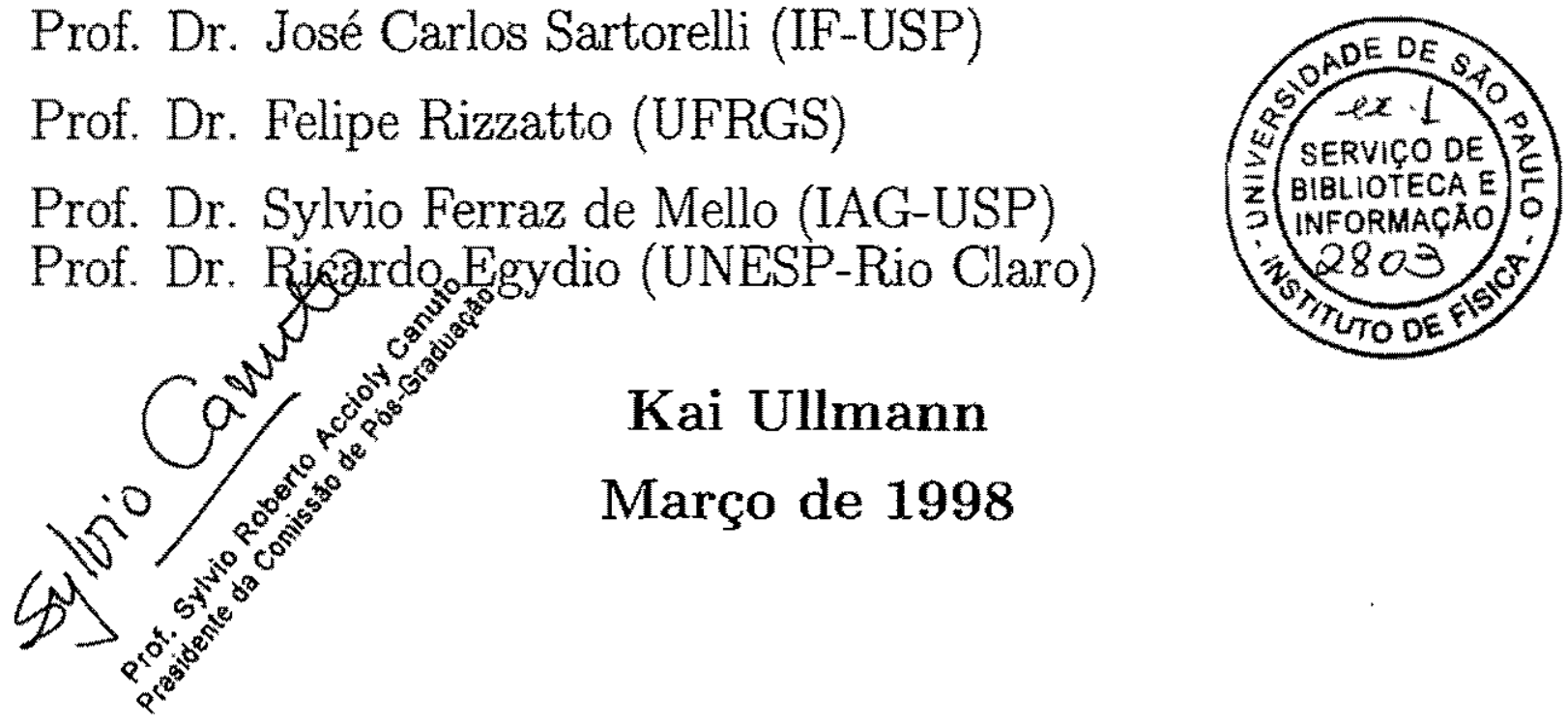
"Take then good note of it. Nothing is too small. I counsel you to see how true you guess. We learn from failure, not from success!" - Bram Stoker (Dracula).

"Ah, it is fault of our science that it wants to explain all; and if it explains not, then it says there is nothing to explain. But yet we see around us every day the growth of new beliefs, which think themselves new; and which are yet but the old, which pretend to be young - like the fine ladies at the opera." - Bram Stoker (Dracula). 


\section{Agradecimentos}

À minha família.

Ao meu orientador.

Ao professor e amigo Júlio, que foi um dos primeiros a me levar ao caminho da Física.

Aos amigos Maurício, Alê, Paula, Serginho, e tantos outros, por seu constante apoio e amizade durante a escrita desta tese.

Ao Dr. Wanderley Pires de Sá e ao Prof. Dr. Aluisio Neves Fagundes, pela inestimável ajuda em relação aos incontáveis probleminhas de informática.

Aos professores Dr. Constantino Ferro-Fontan (Universidade de Buenos Aires) e Dr. Ricardo Luiz Viana (Universidade Federal do Paraná) pelas discussões e sugestões, fundamentais para o desenvolvimento deste trabalho.

Às sempre prestativas Eleonora Lo Duca, Sylvia R. F. da Silva e Maria M. Vara (Lia).

A todos os meus amigos, colegas e professores do Laboratório de Física de Plasma, cuja convivência tornou o trabalho desta tese mais agradável.

Ao coordenador do Laboratório de Física de Plasma da USP, Dr. Ivan C. Nascimento.

Ao Sylvio Luiz Thomaz de Souza pela leitura da tese e importantes sugestoẽs.

E, "last but not least", à FAPESP pelo auxílio financeiro. 


\section{Índice}

$\begin{array}{ll}\text { Agradecimentos } & 5\end{array}$

$\begin{array}{ll}\text { Resumo } & 11\end{array}$

$\begin{array}{lr}\text { Abstract } & 13\end{array}$

1 Introdução $\quad 15$

2 O Mapa Unidimensional Dissipativo $\quad 19$

2.1 Osciladores suaves . . . . . . . . . . . . . . . . . 19

2.2 Perturbações impulsivas . . . . . . . . . . . . . . . . . . . 21

2.3 O mapa bidimensional dissipativo . . . . . . . . . . . . . 23

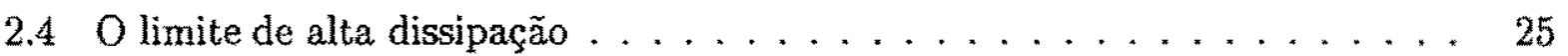

3 Análise Dinâmica do Mapa Unidimensional 29

3.1 Diagramas de bifurcação . . . . . . . . . . . . . . . . 29

3.2 A análise espectral . . . . . . . . . . . . . . . . . 31

3.3 Números de rotação $\ldots \ldots \ldots \ldots \ldots \ldots$

3.4 Expoentes de Lyapunov . . . . . . . . . . . . . . . . . . . . 38

3.5 Resumo da caracterização de trajetórias . . . . . . . . . . . . . . 40

3.6 Estudos no plano de parâmetros . . . . . . . . . . . . . . . 40

4 As Transições Entre os Diversos Regimes de Comportamento Dinâmico 47

4.1 A transição entre regiōes de regimes periódicos e quase-periódicos $\ldots 47$

4.2 A transição entre regimes periódicos e caóticos . . . . . . . . . . . . 52

4.3 A transição entre regimes periódicos de períodos incomensuráveís . . . . . 58

4.4 A regiāo em torno de $a=1 / 2 \ldots \ldots \ldots 1$ 
4.5 Resumo das principais características das transiçōes entre diferentes regimes

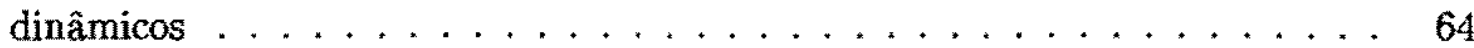

5 Trajetórias Periódicas Instảveis e Parâmetros Variando no Tempo $\quad 67$

5.1 Trajetórias periódicas instáveis e sua determinação $\ldots \ldots 7$

5.2 Trajetórias optimais . . . . . . . . . . . . . . . 72

5.3 O comportamento das trajetórias periódicas instáveis na transição entre regimes periódicos e caóticos ....................... 75

5.4 Perturbações com intensidade alternando entre dois valores de forma regular

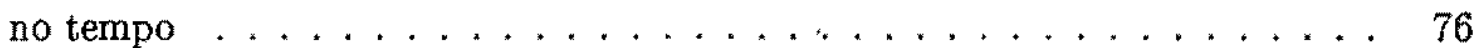

5.5 Pequenas oscilações irregulares dos parâmetros no tempo . . . . . . . 78

5.6 Oscilaçōes harmônicas da intensidade de perturbação no tempo . . . . . . 82

6 Limitadores ergódicos magnéticos $\quad 89$

6.1 O campo magnético de equilíbrio . . . . . . . . . . . . . 89

6.2 A geometria dos limitadores ergódicos . . . . . . . . . . . . . . 92

6.3 O modelo de Martin-Taylor . . . . . . . . . . . . . . . . . . . . 94

6.4 O modelo de Viana e Caldas . . . . . . . . . . . . . . . . . 96

$\begin{array}{lll}7 & \text { O mapeamento bidimensional conservativo } & 101\end{array}$

7.1 O mapeamento do equilíbrio das linhas de campo magnético . . . . . . . 101

7.2 O mapeamento da perturbação introduzida pelo limitador ergódico . . . . . 104

7.3 Seções de Poincaré . . . . . . . . . . . . . . . . . . . 105

7.4 Análise de Fourier do mapeamento bidimensional conservativo . . . . . . 107

7.5 Expoentes de Lyapunov do mapeamento bidimensional conservativo . . . . 109

7.6 Fatores de segurança do mapeamento bidimensional conservativo . . . . . . . 112

7.7 Dimensões de mergulho das trajetórias das linhas de campo magnéticas . . . 114

7.8 Resumo da classificação das linhas de campo do mapa bidimensional conservativo

8 Análise do mapeamento conservativo do limitador ergódico 117

8.1 Planos de parâmetros do mapeamento bidimensional conservativo . . . . . 117

8.2 Cortes nos planos de parâmetros . . . . . . . . . . . . . . . . . . 119

8.3 Planos espectrais do mapeamento bidimensional conservativo . . . . . . . 124

8.4 Padrōes de escape . . . . . . . . . . . . . . . . . . . . 125 
8.5 Análise da difusão local . . . . . . . . . . . . . . . . . . . 128

8.6 Pequenas flutuaçôes na corrente das hélices do limitador $\ldots \ldots \ldots \ldots 131$

9 Conclusōes

135

Bibliografia 


\section{Resumo}

Inicialmente, deduzimos um mapeamento unidimensional dissipativo a dois parâmetros que representa um protótipo de osciladores suaves perturbados periodicamente, de forma impulsiva, por uma força externa de intensidade, direção, e período constantes. Passamos a analisar os possíveis tipos de trajetória deste sistema, utilizando expoentes de Lyapunov, análise espectral, e números de rotação, entre outros algoritmos. Introduzimos também uma nova ferramenta de análise, denominada "diagrama de bifurcação no espaço de frequências". Fazemos então uma análise do sistema no plano de parâmetros, identificando as diversas regiões de distintos comportamentos dinâmicos (trajetórias periódicas, quase-periódicas, e caóticas). Em seguida fazemos um estudo mais aprofundado das transições entre estas regiōes, em especial das suas caracteristicas gerais no espaço de frequências. Apresentamos um algoritmo para determinar as órbitas periódicas instáveis deste mapeamento, cujo estudo é de grande relevância para os métodos de controle de caos por pequenas perturbações, e fazemos uma análise estatística destas. Finalmente, fazemos um estudo do comportamento do sistema para parâmetros variando no tempo, tanto de forma regular, o que nos leva à detecção de atratores estranhos näo-caóticos e aos problemas envolvidos em sua caracterização, quanto de forma irregular, reproduzindo pequenas flutuaçôs aleatórias, sempre presentes em situaçôes experimentais.

Na segunda parte da tese passamos a estudar modelos para a o estudo das configurações de linhas de campo magnético no interior de um tokamak, quando perturbadas por um limitador ergódico magnético. Fazemos primeiro uma análise de alguns modelos já existentes e mostramos porque estes são inadequados para o tipo de estudo que pretendemos realizar. Em seguida, deduzimos um mapeamento bidimensional conservativo para descrever a evolução das línhas de campo magnético. Passamos então à análise das seções de Poincaré obtidas através deste mapa, utilizando expoentes de Lyapunov, fatores de segurança, e análise espectral, entre outros métodos. Finalmente, fazemos uma análise da difusão destas linhas de campo magnético, utilizando coeficientes locais de difusâo e desenvolvendo uma representação gráfica que denominamos "diagramas de escape". 


\section{Abstract}

Initially, we derive an unidimensional dissipative mapping with two parameters, which represents a prototype for soft oscillators perturbed periodically by an external force of constant intensity, direction, and periodicity. We procede then to analyze the possible trajectory classes of this system, using Lyapunov exponents, spectral analysis, and winding numbers, among other algorithms. We also introduce a new analysis tool, called "bifurcation diagrams in the frequency space". Then we perform a system analysis on the parameter plane, identifying the different regions of dynamical behaviour (periodical, quasi-periodical, and chaotical). We also perform a more detailed analysis of the transitions between these regions, specially their main characteristics in the frequency space. An algorithm to find unstable periodic orbits of this mapping, which are of great importance for studying chaos control with small perturbations, is also introduced, and a statistical study of these orbits presented. Finally, we study the behaviour of this system with time-dependent parameters, both regularly, which leads us to the detection of nonchaotic strange attractors and the problems involved in their caracterization, and irregularly, reproducing small random fluctuations, always present in experimental situations.

In the second section of this thesis we procede to study the modelling of the magnetic field line configuration in a tokamak vessel, perturbed by ergodic magnetic limiters. First, we analyze some already existing models and show their inadequacies for the kind of study we intend to perform. Then we deduce a conservative bidimensional mapping describing the magnetic field line evolution. The Poincaré sections obtained with this mapping are analyzed using Lyapunov exponents, safety factors, and spectral analysis. Finally, we study the field line diffusion, using local diffusion coefficients and introducing a graphical representation we called "escape diagrams". 


\section{Capítulo 1}

\section{Introdução}

Ao longo dos últimos anos o caos instalou-se na ciência. Em praticamente todas as áreas foram relatados casos de sistemas com comportamento rotulado como caótico. Sistemas tão diversos como a atmosfera terrestre [1], o movimento de uma bolinha de pingue-pongue perturbada periodicamente de forma impulsiva [2], circuitos elétricos [3], ou o crescimento populacional $[4]$, foram declarados possivelmente caóticos. Nem sequer o movimento dos corpos celestes, antes um paradigma da ordem e regularidade, foi poupado [5]. Pesquisadores de todas as áreas juntaram-se em um coro aliviado dizendo: "A culpa não é nossa; a evolução temporal destes sistemas ê imprevisivel, não devido aos nossos modelos e observações insuficientes, mas sim devido ao seu caráter intrínseco não-linear."

E assim surgiu o caos determinístico, um aparente paradoxo. Como a evolução de um sistema com as equaçōes de movimento perfeitamente conhecidas pode ser imprevisível? A resposta está na sensibilidade às condições iniciais, uma das primeiras tentativas de definição de caos. No caso de um sistema apresentando caos determinístico temos trajetórias perfeitamente determinadas para uma condição inicial conhecida com precisão absoluta, mas as trajetórias de pontos iniciais arbitrariamente próximos se afastam com velocidade exponencial no decorrer da evolução temporal, e o sistema torna-se imprevisível se tivermos a menor imprecisão na condição inicial, o que sempre ocorre em sistemas fisicos reais.

Mas de fato, caos é um pouco mais do que isso. De uma idéia inicial pouco nítida, associando caos a movimentos irregulares e imprevisiveis, surgiram conceitos mais definidos e métodos os mais diversos para a identificação, análise, e, em última instância, rotulação das trajetórias caóticas. Recentemente, até foram desenvolvidos algoritmos para controle do caos, eliminando-o ou provocando-o no sistema estudado, conforme a necessidade $[6,7]$.

Neste trabalho, estudamos alguns exemplos de sistemas submetidos a perturbações im- 
pulsivas, ou perturbações que podem ser aproximadas por estas, e que em consequência deste fato podem ser representados por mapeamentos de evolução discretizada. Como grande parte dos trabalhos publicados nos últimos anos sobre dinâmica não-linear utilizou-se de mapas unidimensionais como exemplo, pelo menos para o estudo de sistemas dissipativos $[8,9,10,11,12,13]$ começamos o trabalho com o estudo de um sistema proposto por Ding para estudos de dinâmica simbólica [8]. Analisamos os diversos tipos de comportamentos que as trajetórias deste sistema podem apresentar, e diversos métodos para caracterizar estes comportamentos, entre eles o cálculo de planos de parâmetros, um método muito utilizado em estudos recentes $[14,12,11]$. Como aplicação mais prática, desenvolvemos um modelo para descrever a evoluçăo das linhas de campo magnéticas no interior de um tokamak sob influência de um limitador ergódico [15], na forma de um mapa bidimensional conservativo, que consiste em um aperfeiçoamento de modelos já existentes $[16,17]$. Em seguida, analisamos as possibilidades da aplicação de algoritmos da análise não-linear a este modelo, uilizando tanto técnicas já conecidas de análise de sistemas não-lineares, como análise de Fourier [18] e expoentes de Lyapunov [10], quanto técnicas novas introduzidas por nós, como os diagramas de bifurcação no espaço de frequências, os planos espectrais, e os diagramas de escape.

Esta tese divide-se, basicamente, em duas grandes partes. A primeira parte, que se estende do capítulo 2 ao capítulo 5 , trata da obtenção e análise dinâmica de um mapa unidimensional dissipativo [8] que representa um protótipo de osciladores suaves, ou seja, osciladores que possuem um ciclo-limite estável contendo um ponto de equilíbrio instável [9]. A segunda parte, que compreende do capítulo 6 ao capítulo 8 , é dedicada ao desenvolvimento de um modelo para descrever a evolução das linhas de campo magnético no vaso de um tokamak sob a influência das correntes elétricas externas de um dispositivo denominado limitador ergódico, e à análise dinâmica das trajetórias obtidas através deste modelo.

No capítulo 2, introduzimos o conceito de mapas para descrever a evolução de sistemas dinâmicos e apresentamos as perturbações impulsivas e a sua representação através de funções delta de Dirac. Representamos então um oscilador suave padrão, submetido a perturbações impulsivas de intensidade $(a)$, período $(b)$, e direção constantes, por um mapa bidimensional dissipativo, e mostramos como, no limite de alta dissipatividade, o sistema pode ser reduzido a um mapa unidimensional dissipativo a dois parâmetros, na váriavel $\theta$, em coordenadas polares no plano de movimento do oscilador [8].

No capítulo 3, passamos a fazer a análise dinâmica do mapa obtido no capítulo anterior. Fazemos a análise espectral das trajetórias utilizando algoritmos de FFT (Fast Fourier 
Transform) [18] e calculamos números de rotação, expoentes de Lyapunov, e diagramas de bifurcação $[10,19]$. Passamos então a utilizar estes resultados para caracterizar os diversos regimes de movimento possíveis (periódico, quase-periódico e caótico) e para estudar o comportamento mais geral do sistema no plano de parâmetros $a \times b$ [14]. Introduzimos também os diagramas de bifurcação no espaço de frequências, uma técnica desenvolvida por nós que permite uma melhor visualização do comportamento espectral do sistema para um grande intervalo de parâmetros.

No capítulo 4 utilizamos as ferramentas do capítulo 3 para estudar as transiçōes possíveis entre estes regimes no plano de parâmetros $a \times b$ : a transição periódico/quase-periódico, a transição periódico/caótico e a transição entre regimes periódicos de períodos incomensuráveis. Mostramos as principais características de cada transição, e damos um enfoque particular em como diferenciá-las no espaço de frequências. Finalmente, fazemos uma análise detalhada do comportamento do sistema na região em torno da intensidade de perturbação $a=\frac{1}{2}$, região peculiar, pois é neste eixo que o mapa deixa de ser inversivel, ou seja, começa a apresentar a possibilidade de trajetórias caóticas [11].

No capítulo 5 passamos a estudar o comportamento do mapa unidimensional dissipativo com parâmetros variando no tempo, de forma regular (periódica ou quase-periódica) ou com pequenos ruídos irregulares. Damos ênfase à análise da estabilidade do sistema diante de pequenas oscilações aleatórias introduzidas na intensidade e no período da perturbaçăo, como fatalmente seria o caso para sistemas experimentais, nunca completamente isentos de ruídos externos. Apresentamos também um algoritmo para localizar de forma exaustiva as órbitas periódicas instáveis de um dado período, coexistentes com qualquer atrator caótico, e fazemos uma análise destas [20].

No capítulo 6, introduzimos o conceito de limitador ergódico magnético e analisamos os modelos já existentes e suas límitações. Primeiro, introduzimos o modelo de MartinTaylor [17], que consiste em uma descrição qualitativa em coordenadas retangulares, mas que não permite a introdução de correções toroidais. Depois apresentamos o modelo de Viana e Caldas [21, 22], que é baseado diretamente na equação de evolução das linhas de campo magnético $(\vec{B} \times d \vec{l}=0)$ e apresenta correçōes toroidais de primeira ordem, porém possui pequenos termos dissipativos nāo realistas que alteram de forma bastante profunda a análise dinâmica que pretendemos realizar neste trabalho. De fato, estes termos dissipativos tornam-se cada vez mais relevantes à medida que elevamos a corrente, levando a fenômenos não realistas tais como a "difusão inversa" e a "implosão" das ilhas magnéticas periféricas.

Passamos então, no capítulo 7, a deduzir um mapeamento conservativo bidimensional 
para descrever a evolução das linhas de campo magnético no vaso do tokamak sob influência da ação de limitadores magnéticos no capítulo 6. Este modelo apresenta uma configuração de ilhas magnéticas semelhante ao de Viana e Caldas, porém nāo há problemas de dissipatividade e ainda descreve o deslocamento do eixo magnético em relação ao eixo geométrico ("shift de Shafranov") conforme previsto por resoluçōes numéricas da equação de Grad-Shafranov. Fazemos, também neste capítulo, a análise dinâmica deste novo modelo, calculando espectros de Fourier, expoentes de Lyapunov, e transformadas rotacionais.

No capítulo 8 aprofundamos a análise do mapeamento conservativo, apresentando os diagramas de escape e cálculo de expoentes de Lyapunov e transformadas rotacionais nos planos de parâmetros, que permite estudar de forma genérica o crescimento das bandas de comportamento caótico, à medida que cresce a corrente nas hélices do limitador. Estudamos também o comportamento do modelo sob a infiuência de pequenas oscilaçöes aleatórias na corrente elétrica dos limitadores e a influência destas em sua dinâmica. Fazemos ainda uma análise da difusão local das linhas de campo magnético e introduzimos os "diagramas de escape" que foram desenvolvidos por nós como uma forma de melhor visualizar as limitações para o cálculo de coeficientes de difusão em sistemas limitados na direção de difusão.

Finalmente, deixamos para apresentar as conclusões relativas à análise dos dois modelos, o mapa unidimensional dissipativo e o mapa bidimensional conservativo, no capítulo 9, que encerra a tese.

Todos os resultados numéricos apresentados nesta tese foram obtidos por programas computacionais desenvolvidos em Fortran pelo autor. Um dos testes feitos para prevenir erros foi a comparação de resultados parciais destes programas com programas análogos desenvolvidos em Turbo Pascal. Como os resultados obtidos foram coincidentes, apenas resultados dos programas em Fortran são apresentados aqui. Para a confeç̧ão dos gráficos foram utilizados dois programas distintos: o "XMGR", desenvolvido por Paul J. Turner, e a "PGPLOT GRAPHICS SUBROUTINE LIBRARY Version 5.0", desenvolvida por T.J. Pearson. 


\section{Capítulo 2}

\section{O Mapa Unidimensional Dissipativo}

Neste capítulo introduzimos o conceito de osciladores suaves e deduzimos um mapeamento unidimensional dissipativo que representa a evolução temporal de um tipo de oscilador suave, perturbado por pulsos periódicos de intensidade constante, no limite de relaxação rápida. Observamos numericamente que as trajetórias deste mapa podem ser periódicas, quase-periódicas, ou caóticas, dependendo dos valores do período e da intensidade da perturbação aplicada.

\subsection{Osciladores suaves}

Os sistemas dinâmicos e suas aplicações foram bastante estudados nos últimos anos, dando-se particular atenção a sistemas não-lineares levando ao possivel surgimento de comportamento caótico $[10,23,24,25,26]$. Entre estes sistemas destacaram-se os osciladores de relaxação submetidos a perturbações externas, periódicas ou não $[27,9]$. Uma classe de sistemas dinârnicos que aparece em muitas áreas é a do oscilador suave ("soft oscillator"), que consiste em um sistema bidimensional de equações diferenciais com um ciclo-limite estável contendo um ponto fixo instável [8]. Este tipo de oscilador aparece, por exemplo, nos sistemas de Lorenz e Rössler e o seu estudo auxilia a compreensảo topológica de outros osciladores destes sistemas.

Um modelo simples de oscilador suave, mas que preserva todas as principais características deste tipo de sistema, é um ciclo-limite estável de raio unitário centrado na origem, onde se localiza o ponto fixo instável. Se supormos que a atração para o ciclo-limite ocorre de uma forma mais definida (por exemplo, $\dot{r} \propto r\left(1-r^{2}\right)$ ), então o sistema dinâmico pode 


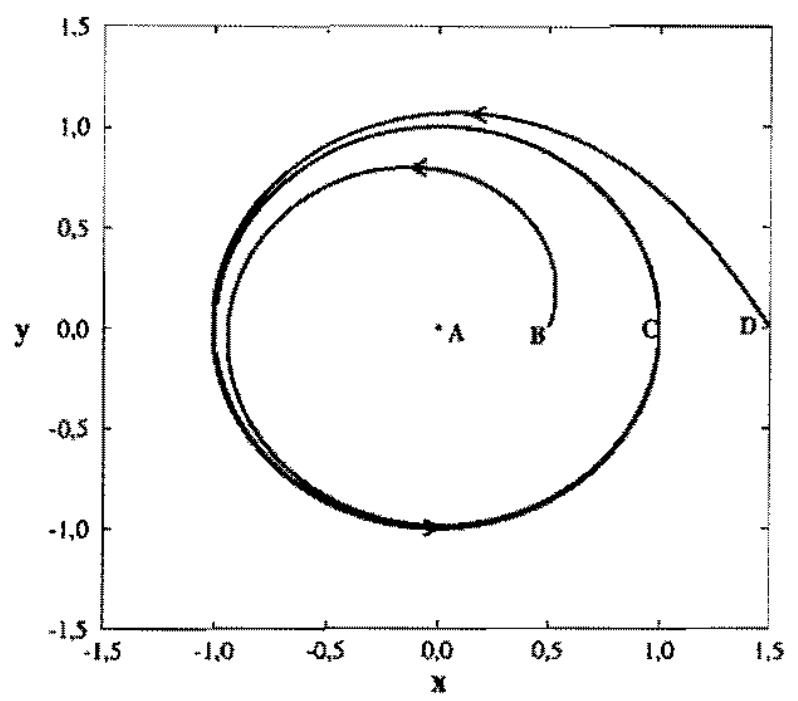

Figura 2.1: Os vários tipos de trajetórias do oscilador suave no plano $x \times y$.

ser descrito pelas equações:

$$
\begin{aligned}
& \dot{x}=-y+s x\left(1-x^{2}-y^{2}\right) \\
& \dot{y}=x+s y\left(1-x^{2}-y^{2}\right)
\end{aligned}
$$

onde $x$ e $y$ são as coordenadas cartesianas usuais e $s>0$ é um parâmetro de dissipatividade do sistema que mede a velocidade com que o sistema tende ao ciclo-limite (quanto maior o valor de $s$, mais rapidamente o sistema tende ao ciclo-limite estável).

Introduzindo as coodenadas polares $r$ e $\theta$ definidas de maneira habitual:

$$
\begin{aligned}
& x=r \cos \theta \\
& y=r \sin \theta
\end{aligned}
$$

as equações que descrevem o sistema dinâmico 2.1-2.2 podem ser reescritas na forma:

$$
\begin{aligned}
& \dot{r}=s r\left(1-r^{2}\right) \\
& \dot{\theta}=1 .
\end{aligned}
$$

As equações são desacopladas uma da outra e portanto fica evidente que o sistema é integrável. De fato, integrando 2.5 e 2.6 obtemos:

$$
r(t)=\frac{1}{\sqrt{1+\left(\frac{1}{r_{0}^{2}}-1\right) e^{-2 s t}}}
$$



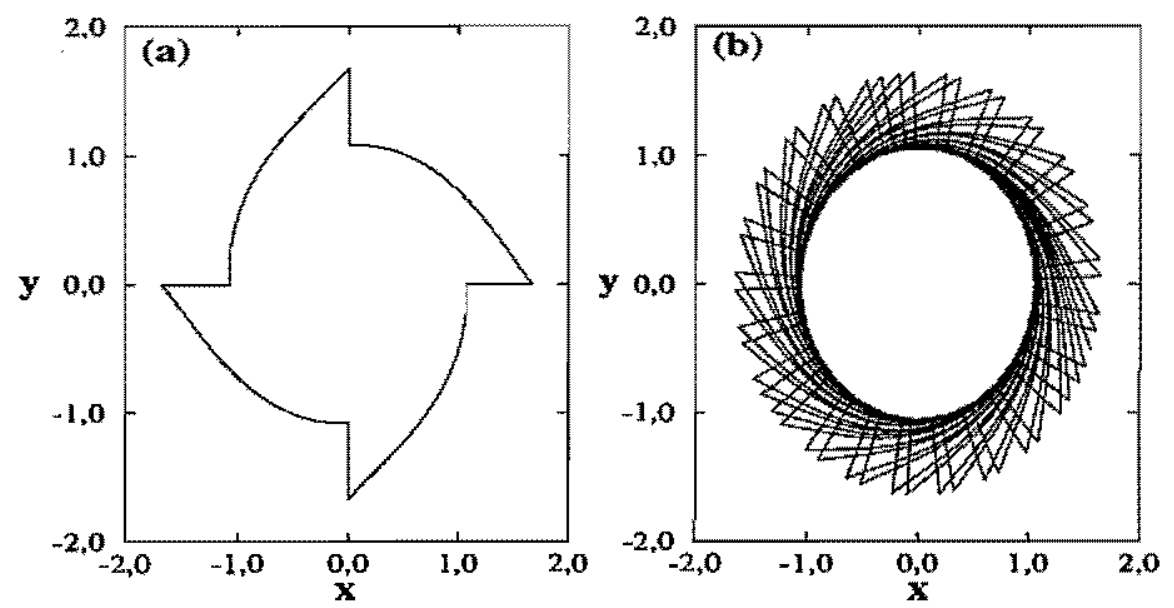

Figura 2.2: As trajetórias do sistema 2.10-2.11 (a) periódica com $a=0,30, b=0,25$ e $s=0,50$; (b) quase-periódica com $a=0,30, b=0,3194837 \ldots$ e $s=0,50$.

$$
\theta(t)=\theta_{0}+t
$$

Fazendo um gráfico das trajetórias no plano $x \times y$ (fig. 2.1), vemos que é possível dividilas em quatro grupos distintos, dependendo da posição radial inicial. Para $r_{0}=0$ (A) a trajetória está exatamente sobre o ponto fixo instável e permanece neste indefinidamente; para $0<r_{0}<1$ (B) a trajetória vai espiralando para fora e se aproxima do ciclo-limite estável em $r_{c-l}=1$ para $t \rightarrow \infty$. Para $r_{0}=r_{c-l}=1(\mathrm{C})$ estamos exatamente sobre o ciclolimite e a trajetória segue sobre ele, rodando com velocidade angular $\omega=1$; para $\tau_{0}>1$ (D) a trajetória espirala para dentro, também tendendo a $r_{c-l}=1$ para $t \rightarrow \infty$.

\subsection{Perturbações impulsivas}

O estudo do comportamento de sistemas dinâmicos na presença de perturbaçōes externas periódicas $[11,12]$ tem sido um tópico de grande relevância, devido, entre outras coisas, à sua importância no controle de caos [28]. Deu-se particular ênfase ao estudo das perturbaçōes impulsivas, ou seja, perturbaçōes que apenas possuem intensidade diferente de zero durante intervalos de tempo muito menores que a escala de tempo na qual o sistema passa por mudanças significativas [29]. Muitas vezes estas perturbaçöes podem ser representadas pela 
função delta de Dirac, ou, para perturbações periódicas, por uma somatória infinita de funções delta de Dirac do tipo :

$$
\alpha \sum_{n=-\infty}^{\infty} \delta(t-n \tau)
$$

onde $\alpha$ é a intensidade das perturbações e $\tau$ é o seu período.

Submetendo o sistema dinâmico 2.5-2.6 obtido no item anterior a pertubações impulsivas de intensidade $2 a$ e período $2 \pi b$ na direção radial obtemos:

$$
\begin{aligned}
\dot{r} & =s r\left(1-r^{2}\right)+2 a \sum_{n} \delta(t-2 \pi n b) \\
\dot{\theta} & =1 .
\end{aligned}
$$

Fazendo um gráfico das trajetórias deste sistema (fig. 2.2) observamos que há duas possibilidades: para $b$ racional $\left(b=\frac{p}{q}, q \neq 0\right)$ a trajetória torna-se periódica de período $\tau=2 \pi b q$, após o regime transitório, enquanto que para $b$ irracional a trajetória é quaseperiódica, nunca retornando exatamente ao mesmo lugar no espaço de fase [11].

Este tipo de sistema, que pode ser integrado analiticamente na maior parte do tempo (no caso do sistema 2.10-2.11 em qualquer instante de tempo fora das perturbações impulsivas), é denominado quase-integrável. Em geral, um sistema quase-integrável de equações diferenciais pode ser transformado em um mapa, ou seja uma aplicação que evolui o sistema em intervalos de tempo discretos, fornecendo assim uma amostra discreta do estado do sistema a dados intervalos de tempo, descrevendo, na maioria das vezes, de forma bastante completa todas as características dinâmicas do sistema estudado [23]. Este tipo de discretização não deve ser confundido com os métodos numéricos de integração de sistemas de equações diferenciais, que consistem em uma aproximação das equações contínuas por discretas. No caso dos sistemas quase-integráveis a discretização temporal é um processo exato.

O mapa equivalente ao sistema $2.10-2.11$ é dado pelas equações:

$$
\begin{aligned}
& r_{n+1}=\frac{1}{\sqrt{1+\left(\frac{1}{r_{n}^{2}}-1\right) e^{-4 \pi s b}}+2 a} \\
& \theta_{n+1}=\theta_{n}+2 \pi b
\end{aligned}
$$

onde $\left(r_{n}, \theta_{n}\right)$ é a posição do sistema em coordenadas polares imediatamente após a $n$-ésima perturbação impulsiva. Na figura 2.3 podemos ver as trajetórias do mapa 2.12-2.13, equivalentes às trajetórias contínuas do sistema 2.10-2.11 representadas na figura 2.2. Devemos ressaltar que, neste caso, apesar de conhecermos apenas alguns pontos da trajetória, estes nos fornecem ainda informação suficiente para classificar o comportamento do sistema como sendo periódico ou quase-periódico. 

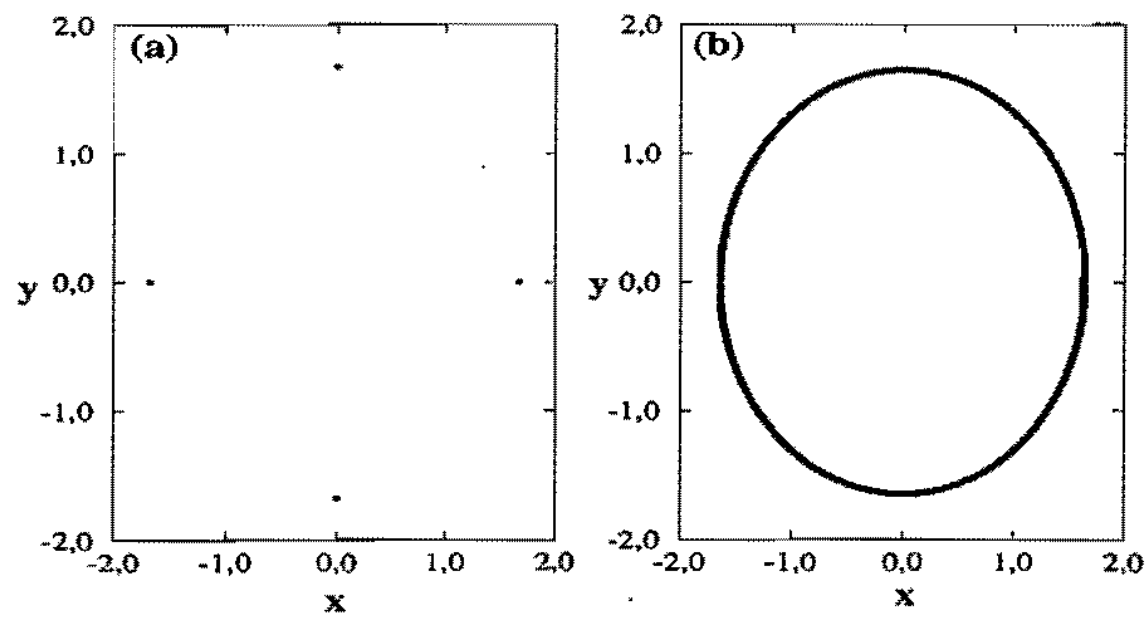

Figura 2.3: As trajetórias do mapa 2.12-2.13 (a) periódica para $a=0,30, b=0,25$ e $s=0,50$; (b) quase-periódica para $a=0,30, b=0,3194837 \ldots$ e $s=0,50$.

\subsection{O mapa bidimensional dissipativo}

No item anterior perturbamos o nosso protótipo de oscilador suave com perturbações impulsivas na direção radial e constatamos que as equações em coordenadas polares continuavam desacopladas uma da outra. Uma outra possibilidade é perturbarmos o sistema com perturbaçōes impulsivas de direção cartesiana constante [8]. Como o sistema não perturbado tem simetria radial, podemos escolher, por exemplo, a direção do eixo $x$, sem perda de generalidade, para aplicarmos a perturbação. Neste caso, as equaçōes diferenciais que descrevem o sistema quase-integrável em coordenadas cartesianas são:

$$
\begin{aligned}
& \dot{x}=-y+s x\left(1-x^{2}-y^{2}\right)+2 a \sum_{n} \delta(t-2 \pi n b) \\
& \dot{y}=x+s y\left(1-x^{2}-y^{2}\right)
\end{aligned}
$$

Integrando a parte não perturbada entre dois impulsos sucessivos, utilizando $2.7-2.8$, obtemos o mapa bidimensional, em coordenadas cartesianas, equivalente ao sistema quaseintegrável de equações diferenciais $2.14-2.15$ :

$$
x_{n+1}=\frac{\cos \left(\arctan \left(\frac{y_{n}}{x_{n}}\right)+2 \pi b\right)}{\sqrt{1+\left(\frac{1}{x_{n}^{2}+y_{n}^{2}}-1\right) e^{-4 \pi s b}}}+2 a
$$



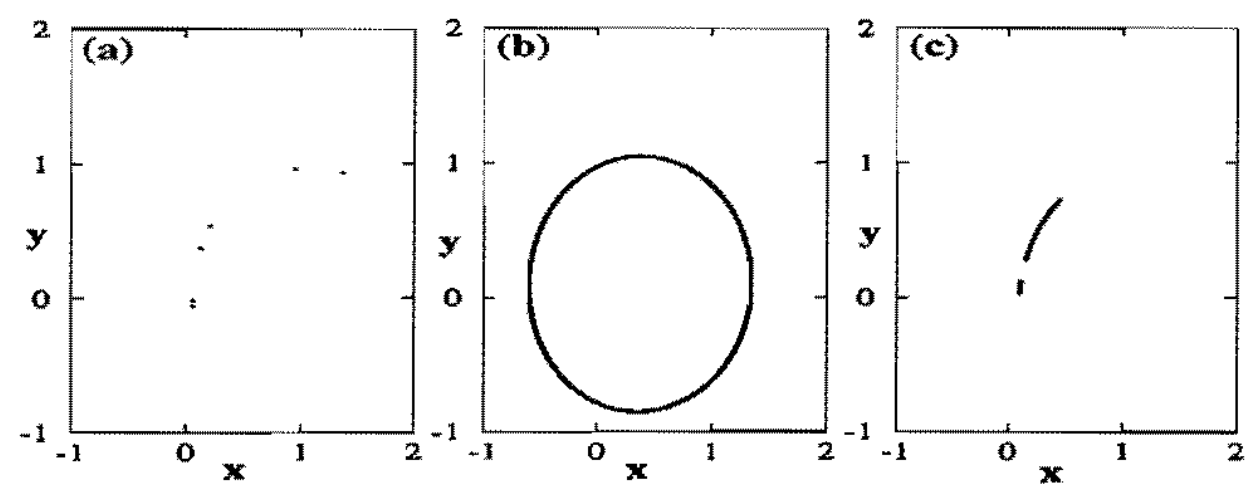

Figura 2.4: As trajetórias do mapa 2.16-2.17 (a) periódica para $a=0,532, b=0,315 \mathrm{e}$ $s=2,0 ;$ (b) quase-periódica para $a=0,20, b=0,25$ e $s=0,50$; (c) caótica para $a=0,55$, $b=0,32$ e $s=1,80$.

$$
y_{n+1}=\frac{\sin \left(\arctan \left(\frac{y_{n}}{x_{n}}\right)+2 \pi b\right)}{\sqrt{1+\left(\frac{1}{x_{n}^{2}+y_{n}^{2}}-1\right) e^{-4 \pi s b}}}
$$

Já em coordenadas polares o mapa bidimensional $2.16-2.17$ pode ser reescrito como:

$$
\begin{aligned}
& r_{n+1}=\left[\frac{1}{1+\left(r_{n}^{-2}-1\right) e^{-4 \pi s b}}+\frac{4 a \cos \left(\theta_{n}+2 \pi b\right)}{\sqrt{1+\left(r_{n}^{-2}-1\right) e^{-4 \pi s b}}}+4 a^{2}\right]^{1 / 2} \\
& \theta_{n+1}=\arctan \left[\frac{\sin \left(\theta_{n}+2 \pi b\right)}{\cos \left(\theta_{n}+2 \pi b\right)+2 a \sqrt{1+\left(r_{n}^{-2}-1\right) e^{-4 \pi s b}}}\right]
\end{aligned}
$$

Vemos assim que as equações do mapa não são desacopladas em nenhum dos sistemas de coordenadas, o que indica que neste caso podemos ter trajetórias caóticas, além das periódicas e quase-periódicas. De fato, podemos observar todos estes tipos de trajetórias para determinados conjuntos de parâmetros $(a, b, s)$ na figura 2.4. Mostraremos mais adiante neste trabalho que a trajetória irregular vista na figura 2.4.c é de fato caótica. 

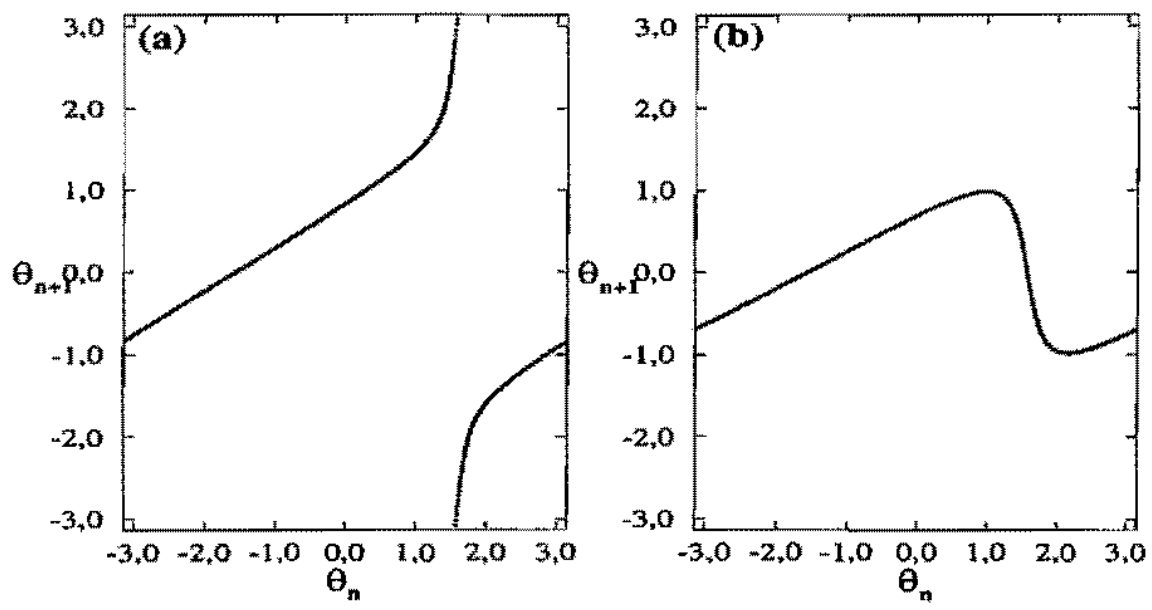

Figura 2.5: Diagramas de retorno do mapa 2.22 para (a) $a=0,45$ e $b=0,25$ (inversível, pois a cada valor de $\theta_{n+1}$ pode ser associado apenas um valor de $\theta_{n}$ ); (b) $a=0,60$ e $b=0,25$ (não inversível, pois a alguns valores de $\theta_{n+1}$ podemos associar dois valores de $\theta_{n}$ ).

\subsection{O limite de alta dissipação}

Um dos regimes de maior interesse no mapa bidimensional obtido no item anterior é a regiẫo de alta dissipação no espaço de parâmetros $(s \gg 1)$. Neste caso, o sistema sempre acaba retornando ao ciclo-limite estável em $r=r_{c-t}=1$ entre dois impulsos sucessivos e portanto a coordenada radial torna-se irrelevante para a dinâmica do sistema, que se concentra toda na variável angular $\theta$. Tomando o limite $s \rightarrow \infty$ no mapa $2.18-2.19$ obtemos as equações:

$$
\begin{aligned}
& r_{n+1}=\left[1+4 a \cos \left(\theta_{n}+2 \pi b\right)+4 a^{2}\right]^{1 / 2} \\
& \theta_{n+1}=\arctan \left[\frac{\sin \left(\theta_{n}+2 \pi b\right)}{\cos \left(\theta_{n}+2 \pi b\right)+2 a}\right]
\end{aligned}
$$

É importante observarmos que, de fato, a variável $r_{n}$ não entra em lugar nenhum no lado direito das equaçōes, ou seja, a posição $\left(r_{n+1}, \theta_{n+1}\right)$ é completamente independente da posição radial $r_{n}$. Assim sendo, podemos estudar a evolução do sistema apenas através da 


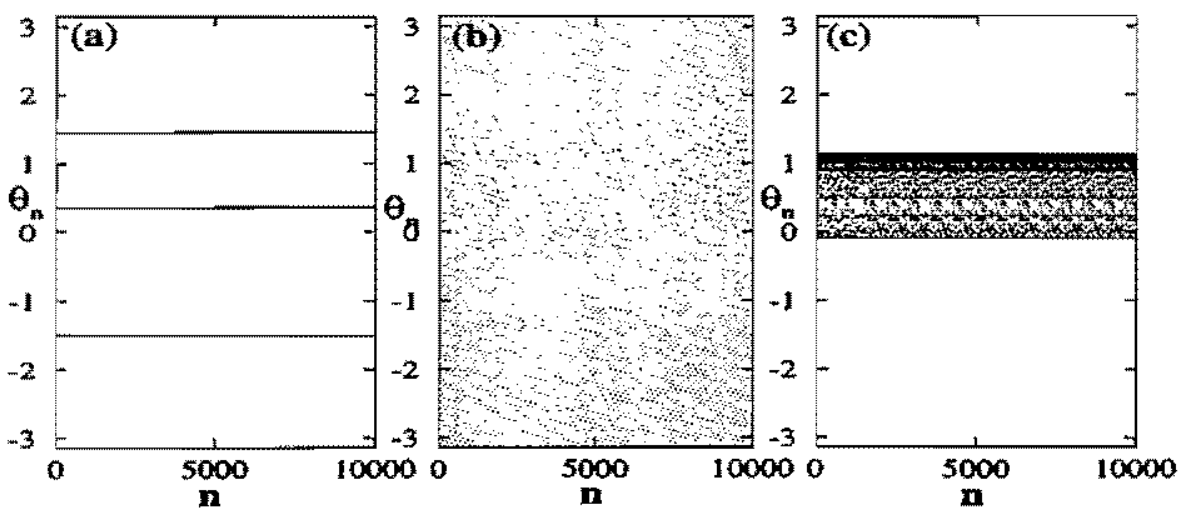

Figura 2.6: Trajetórias do mapa 2.22: (a) periódica de período 3 para $a=0,45$ e $b=0,35$; (b) quase-periódica para $a=0,25$ e $b=0,30$; (c) caótica para $a=0,55$ e $b=0,32$.

parte angular representada pelo mapa unidimensional dissipativo $[8]^{1}$ :

$$
\tan \theta_{n+1}=\frac{\sin \left(\theta_{n}+2 \pi b\right)}{\cos \left(\theta_{n}+2 \pi b\right)+2 a}
$$

Este mapa tem algumas características globais interessantes: o comportamento dinâmico dele possui um eixo de simetria em $b=1 / 2$ e basta, portanto, estudarmos a região de parâmetros $0 \leq b \leq 1 / 2$. Temos também que para $a>1$ as perturbações são tão fortes que ele sempre tem comportamento periódico de período 1, e portanto basta estudarmos a região $0 \leq a \leq 1$. Para $0 \leq a \leq 1 / 2$ o mapa é de fato inversível, como podemos observar no mapa de retorno da figura 2.5.a, apesar de não existir nenhuma expressão analítica de sua função inversa. Isto quer dizer que nesta região do plano de parâmetros há apenas trajetórias periódicas e quase-periódicas. Já para $a>1 / 2$ o mapa deixa de ser inversível (fig. 2,5.b) e temos regiōes de regime periódico e de comportamento caótico. Na figura

\footnotetext{
1 Preferimos colocar a tangente no lado esquerdo da equação ao invés da arco-tangente do lado direito para ressaltarmos uma característica importante deste sístema ao realizarmos simulaçōes numéricas: a imagem da funçăo arco-tangente é o intervalo $(-\pi / 2, \pi / 2]$ enquanto que o ângulo $\theta$ é definido sobre $(-\pi, \pi]$. É preciso portanto fazer urn ajuste, baseado em considerações físicas, no ângulo $\theta_{n+1}$ após o cálculo da arco-tangente, somando ou subtraindo $\pi$ quando ele corresponde a um valor negativo de $x$. De fato, temos que verificar sempre que $\sin \left(\theta_{n}+2 \pi b\right) * \sin \left(\theta_{n+1}\right) \geq 0$.
} 
2.6 podemos observar trajetórias periódicas, quase-periódicas e caóticas do mapa 2.22 para diferentes valores de parâmetros $(a, b)$.

Outra característica interessante do mapa 2.22 é que para perturbações impulsivas de baixa intensidade $(a \ll 1)$ podemos expandi-lo em série de potências de $a$ em torno de $a=0$ e, retendo apenas os termos até primeira ordem obter:

$$
\theta_{n+1}=\theta_{n}+2 \pi b-2 a \sin \left(\theta_{n}+2 \pi b\right)
$$

que, definindo $\psi \equiv \theta+2 \pi b, \Omega \equiv b$, e $K \equiv 2 a$, é exatamente o mapa do círculo [30, 31]:

$$
\psi_{n+1}=\psi_{n}+2 \pi \Omega-K \sin \psi_{n}
$$

Este é um dos mapas unidimensionais dissipativos mais utilizados na literatura para estudar fenômenos como "sincronização de fase" (phase locking) [13] e as "línguas de Arnold" [32], por exemplo. 


\section{Capítulo 3}

\section{Análise Dinâmica do Mapa Unidimensional}

Neste capitulo passamos a uma análise dinâmica mais detalhada do mapa unidimensional dissipativo obtido no capítulo anterior, apresentando várias maneiras de classificar suas trajetórias em regulares (periódicas ou quase-periódicas) ou irregulares (caóticas). Em seguida utilizamos os algoritmos apresentados para fazer uma análise geral do sistema utilizando os gráficos de coeficientes no plano de parâmetros $a \times b$.

\subsection{Diagramas de bifurcação}

Ao estudarmos um sistema físico, em geral estamos interessados em analisar o comportamento deste em uma grande variedade de situações. O mesmo ocorre para o mapa unidimensional dissipativo obtido no capítulo anterior. Nós já mostramos algumas trajetórias deste mapa para valores fixos dos parâmetros $a$ e $b$, mas estamos interessados em estudar o comportamento dele para $a$ e $b$ genéricos, e, mais ainda, as mudanças no comportamento dinâmico à medida que os parâmetros variam. Um primeiro passo em direção a essa análise mais geral é a obtenção dos diagramas de bifurcação.

Os diagramas de bifurcação são definidos na literatura $[25,33,10]$ como um gráfico cujo eixo horizontal representa um dado intervalo de um dos parầmetros de controle do sistema (no nosso caso a intensidade de perturbação $a$ ou o período de perturbação $b$ ). Para um grande número de valores igualmente espaçados deste parâmetro, calculamos a trajetória do sistema e colocamos no gráfico todos os pontos de uma das variáveis de posição da trajetória 

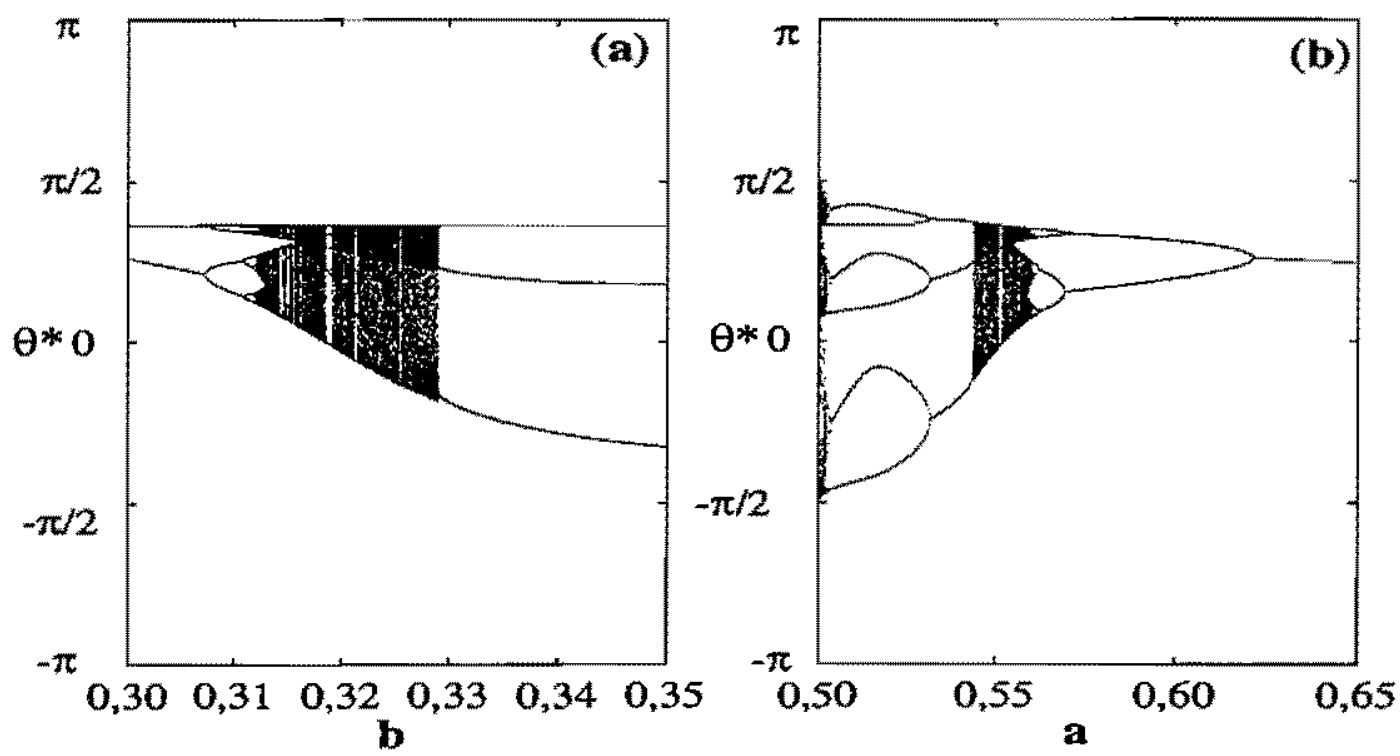

Figura 3.1: Diagramas de bifurcação do mapa unidimensional dissipativo 2.22 para (a) $a=0,55$ e (b) $b=0,32$

(como o nosso mapa é unidimensional, temos apenas o ângulo $\theta$ ) atingidos após o transitório ao longo da direção vertical. No caso do nosso mapa unidimensional dissipativo 2.22 , como estamos no limite de alta dissipaçäo, os transitórios são bastante curtos, tipicamente da ordem de algumas dezenas de iterações. Mesmo assim, em todos os exemplos numéricos apresentados nesta tese trabalhamos com transitórios de $N_{t}=1000$ iterações para termos certeza do sistema estar sobre o atrator.

Na figura 3.1.a vemos, por exemplo, o diagrama de bifurcação do mapa 2.22 fixando a intensidade da perturbação em $a=0,55$ e variando o período da perturbação no intervalo $0,30<b<0,35$. Vemos ali que, por exemplo, para $b=0,30$ a trajetória passa apenas por dois ângulos distintos, ou seja, é de período 2. Já para $b=0,32$, a trajetória preenche todo um intervalo angular, sendo uma trajetória caótica (conforme mostraremos mais adiante). Para $b=0,34$, observamos uma trajetória de periodo três. Na figura 3.1.b vemos uma figura semelhante, só que desta vez fixamos o período da perturbação $(b=0,32)$ e variamos a intensidade $(0,50<a<0,65)$. Observamos que, para certos valores críticos do parâmetro 

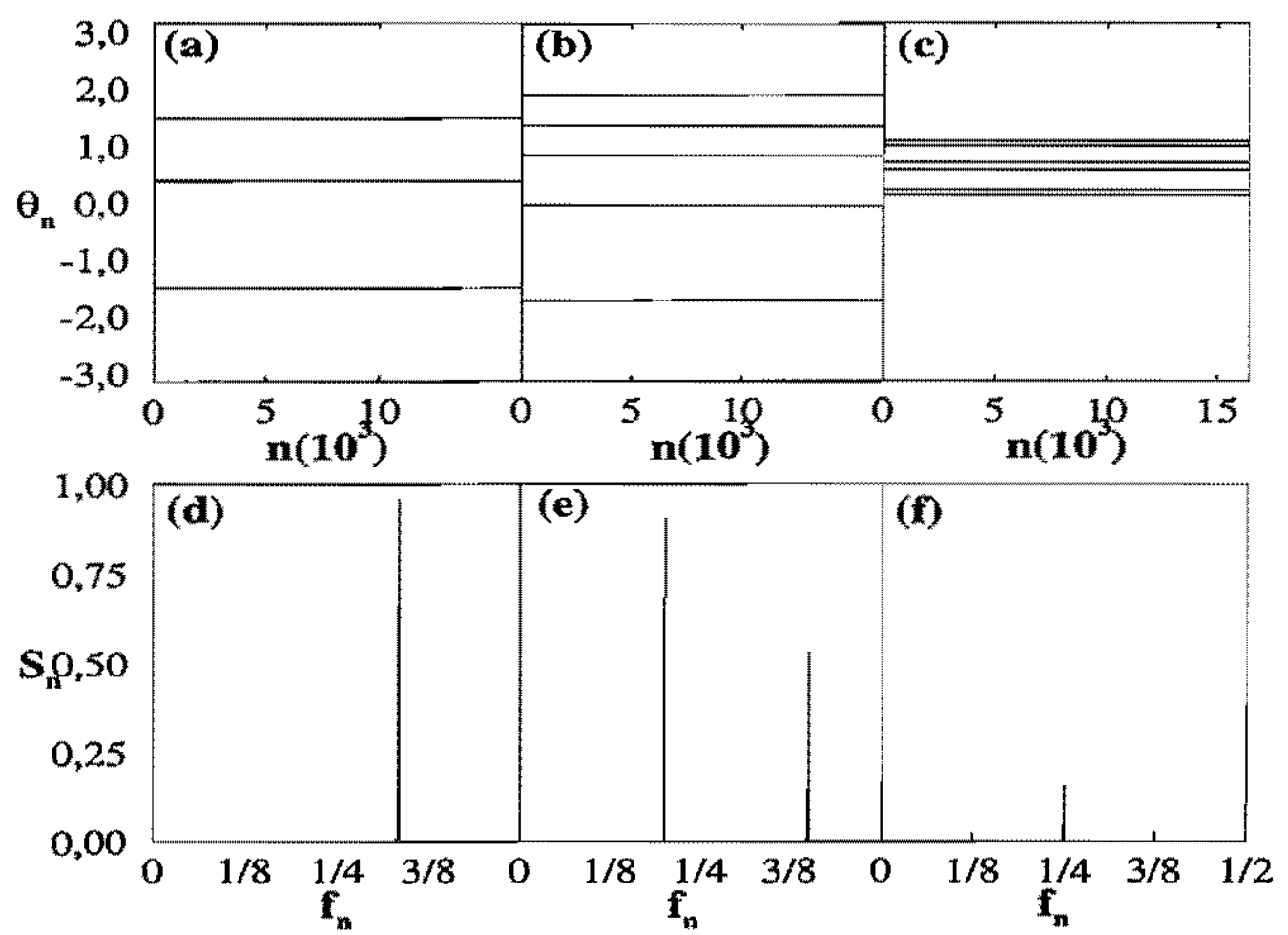

Figura 3.2: As trajetórias do mapa 2.22 para (a) $a=0,45$ e $b=0,35$ (período 3) ; (b) $a=0,45$ e $b=0,252$ (período 5); (c) $a=0,57$ e $b=0,327$ (período 8); e seus respectivos espectros de potência em unidades normalizadas ((d)-(f)).

variado, as trajetórias periódicas mudam de período, passando, por exemplo, de período 2 para 4 , ou de 3 para 6 . Este fenômeno é denominado bifurcação e consequentemente o diagrama apresentado é denominado "diagrama de bifurcação". Na verdade a duplicação sucessiva de periodos conforme aí observada é uma das rotas para o caos (rota de Feigenbaum) e ocorre em muitos sistemas [27, 34, 24], sendo um fenômeno universal que aparece em muitos fenômenos físicos e no qual nos aprofundaremos mais adiante.

\subsection{A análise espectral}

Uma das ferramentas comumente utilizadas na literatura para a análise de trajetórias é a análise espectral, em particular a análise espectral de Fourier, que consiste em descrever a trajetória como sendo uma superposição de funções senoidais, e analisar as frequências destas. Através desta decomposição é possível identificar trajetórias aparentemente muito 
complexas como uma superposição de apenas algumas frequências bem definidas, ou, no caso de trajetórias caóticas ou quase-periódicas, descobrir as frequências mais importantes, que muitas vezes estão ligadas a trajetórias periódicas próximas no espaço de parâmetros, conforme veremos a seguir. Como estamos trabalhando com um mapa, as nossas trajetórias consistem em conjuntos discretos de dados, e por isso podemos utilizar o algoritmo da "Fast Fourier Transform" (FFT) para o cálculo da transformada de Fourier [18].

Calculando algumas trajetórias periódicas de períodos diversos para o mapa 2.22, e os seus respectivos espectros de Fourier (fig.3.2), podemos observar que estes espectros consistem sempre de um ou mais picos espectrais bem definidos, sendo que fora da posição destes picos a intensidade espectral normalizada $\left(S_{n}\right)$ é nula.

A posição destes picos espectrais no eixo de frequências é diretamente relacionada com o período da trajetória. Para a trajetória de periodo 3 (fig. 3.2.a) o único pico do espectro encontra-se na posição $f_{n}=\frac{1}{3}$, ou seja na própria posição $f_{n}=\frac{1}{P}$ onde $P$ é o período (fig. 3.2.d). Já para a trajetória de período 5 (fig. 3.2.b) vemos que o espectro consiste em dois picos (fig. 3.2.e), um principal na posição $f_{n}=\frac{1}{P}=\frac{1}{5}$, e um secundário, de intensidade menor, no harmônico $f_{n}=\frac{2}{5}$. Finalmente, temos que para a trajetória de período 8 (fig. 3.2.c) ocorrem três picos espectrais distintos (fig. 3.2.f): o maior na posição $f_{n}=\frac{1}{4}$, pois os oito ângulos percorridos pela trajetória periódica agrupam-se em quatro conjuntos de dois ângulos cada, e dois picos menores em $f_{n}=\frac{1}{8}$ e $f_{n}=\frac{3}{8}$.

Para trajetórias quase-periódicas do mapa (fig. 3.3.a), temos que o espectro de Fourier consiste em um grande número de picos discretos mais acentuados, com espaçamento aparentemente igual entre eles, e um fundo contínuo de intensidade muito baixa distribuído ao longo de toda a faixa de frequências. Mais adiante mostraremos de que forma a posição dos picos mais intensos está ligada ao período, ou períodos, mais próximos dos quais esta trajetória é "quase"-periódica.

$\mathrm{Na}$ figura 3.3.b vemos uma trajetória caótica que ainda está dividida em várias faixas distintas entre as quais o sistema fica alternando, ou seja, uma trajetória que, apesar de ser caótica, ainda preserva uma regularidade de período fixo. Ao calcularmos o espectro de potência desta trajetória (fig. 3.3.e) vemos que ainda há picos predominantes relacionados ao comportamento regular com o qual o sistema visita as faixas caóticas, mas também há uma faixa contínua e irregular de frequências, característica de regimes caóticos. Uma trajetória completamente caótica, sem faixas regularmente separadas, pode ser vista na figura 3.3.c, e, ao calcularmos o espectro desta trajetória (fig. 3.3.f), não observamos mais picos discretos de comportamento regular, mas apenas uma faixa contínua e bastante irregular de picos ao 

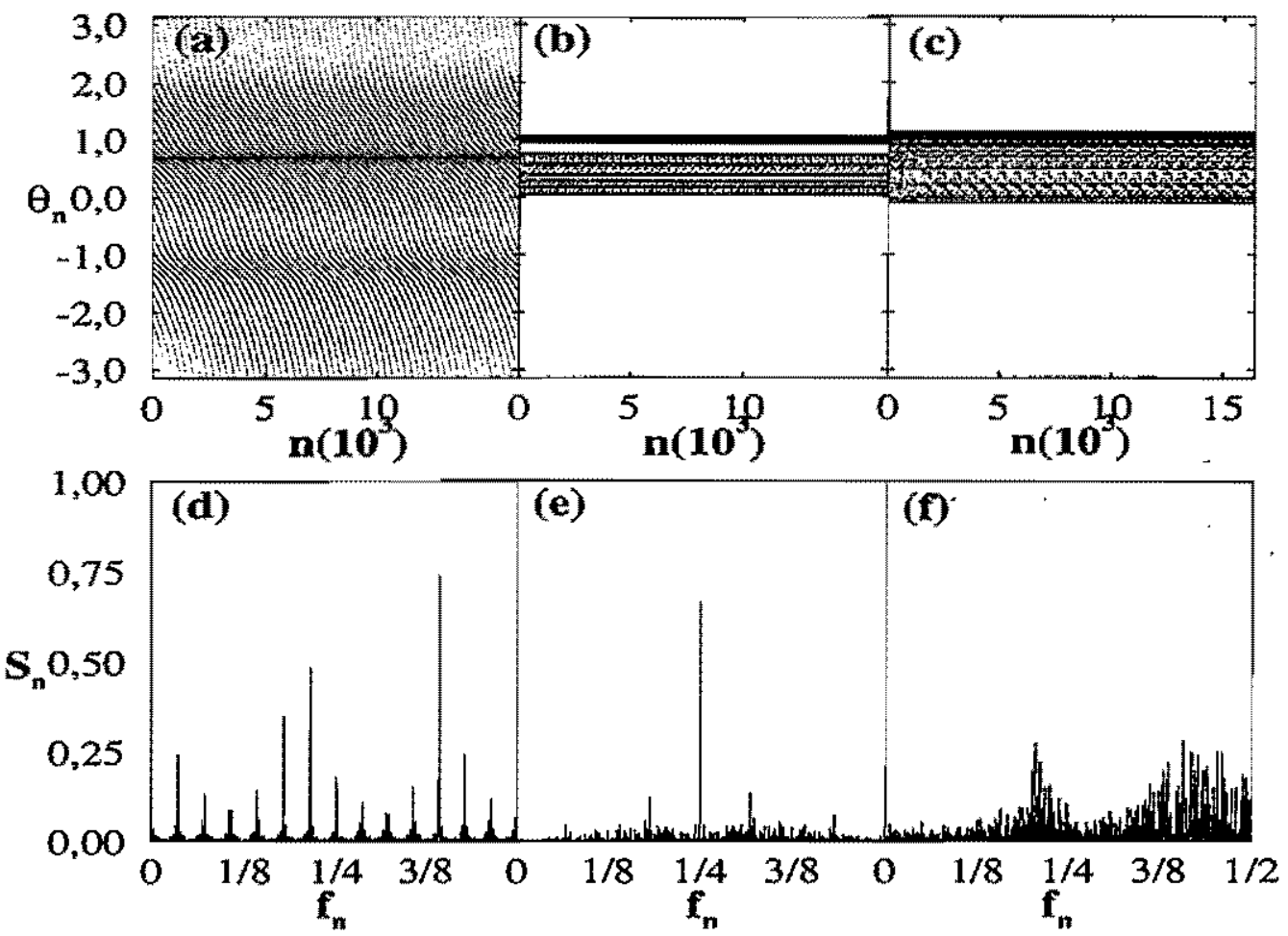

Figura 3.3: As trajetórias do mapa 2.22 para (a) $a=0,45$ e $b=0,40$ (quase-periódica); (b) $a=0,57$ e $b=0,329$ (caótica) ; (c) $a=0,55$ e $b=0,32$ (caótica) ; e seus respectivos espectros de potência em unidades normalizadas ((d)-(f)).

longo de todo o eixo de frequências. Em algumas regiōes de frequências estas intensidades espectrais são mais acentuadas, sendo que estas frequências estão associadas aos periodos das trajetórias periódicas mais próximas no espaço de parâmetros.

Como neste trabalho estamos interessados nāo apenas na análise de trajetórias isoladas a parâmetros fixos, mas também na mudança gradual das características das trajetórias à medida que um ou mais parâmetros de controle são variados continuamente, resolvemos introduzir, em nosso trabalho, uma nova forma de apresentar uma série de espectros de potência para uma faixa de parâmetros. No tipo de gráfico que desenvolvemos, o eixo horizontal representa o parâmetro a ser variado e o eixo vertical é o eixo de frequências. Para cada valor do parâmetro no eixo horizontal calculamos então um espectro de potências e marcamos as suas frequências mais intensas (picos) em preto e as frequências que não ocorrem em branco, sendo que intensidades intermediárias são marcadas em tons graduais de cinza. Denominamos este tipo de gráfico "diagrama de bifurcação no espaço de frequências", 
pois ele é construído de forma muito semelhante ao diagrama de bifurcação tradicional, só que no eixo vertical temos frequências em vez de posições, o que nos permite, na maioria das vezes, uma visão mais clara do tipo de trajetória, especialmente nas regiōes de regime caótico.
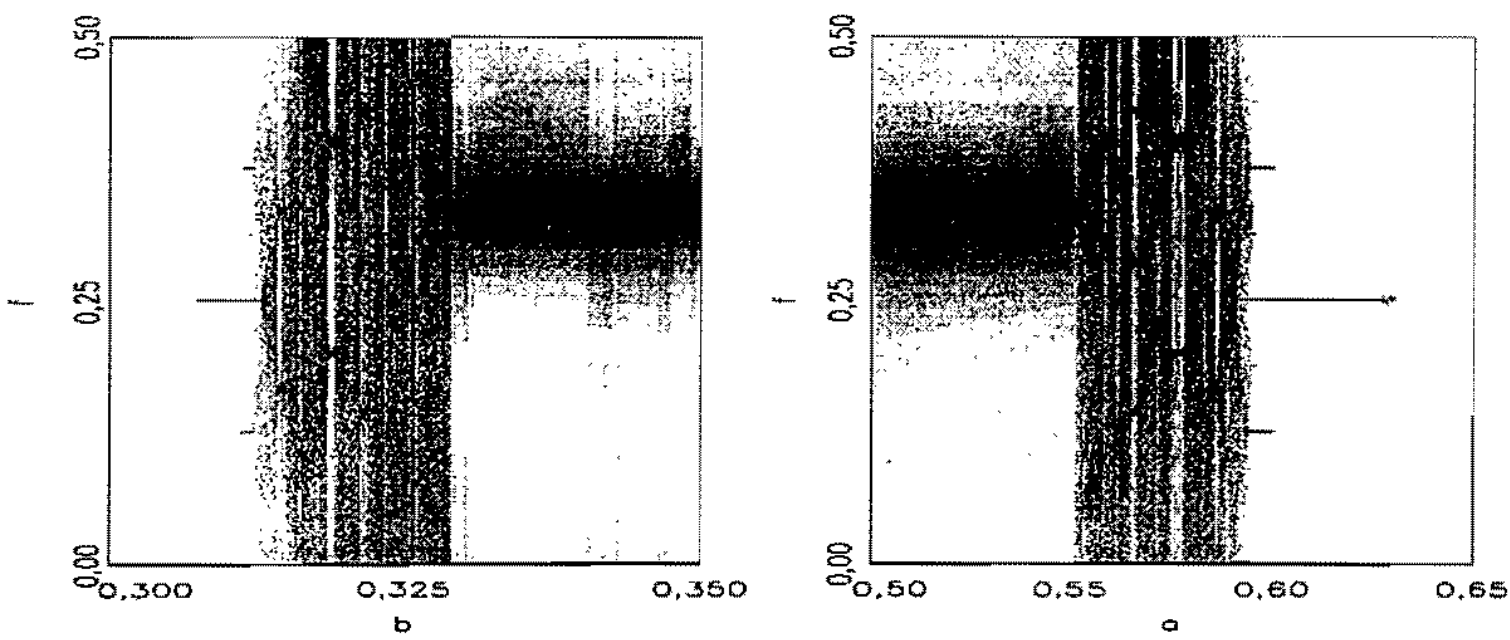

Figura 3.4: Diagramas de bifurcação no espaço de frequências para (a) $a=0,55$ e (b) $b=0,37$.

Fazendo um gráfico com o diagrama de bifurcação no espaço de frequências para $0,30<$ $b<0,35$ e $a=0,55$ (fig.3.4.a) e comparando com o diagrama de bifurcação comum para os mesmos parâmetros (fig. 3.1.a), observamos que nas regiōes de parâmetros correspondentes aos regimes periódicos as faixas de frequência são mais restritas ${ }^{1}$ em torno das frequências características do período (por exemplo, $f_{n}=\frac{1}{6}$ e $f_{n}=\frac{1}{3}$ para período 6 ), mas mesmo nas regiōes caóticas ainda podemos observar as frequências predominantes em cada caso, e a evolução das faixas espectrais. Apresentamos ainda o gráfico correspondente a uma variação da intensidade de perturbação $(0,50<a<0,65)$ para um período fixo $(b=0,37)$ (fig: 3.4.b). É importante ressaltarmos que quando não há nenhuma frequência predominante visível estamos com regimes periódicos de período 1 ou 2 , cujas frequências localizam-se sobre os eixos laterais do gráfico $\left(f=0\right.$ e $\left.f=\frac{1}{2}\right)$.

\footnotetext{
${ }^{1} \mathrm{Para}$ períodos $P=2^{n}$ reduzem-se a linhas, pois neste caso o algoritmo de FFT é mais eficiente por construção.
} 

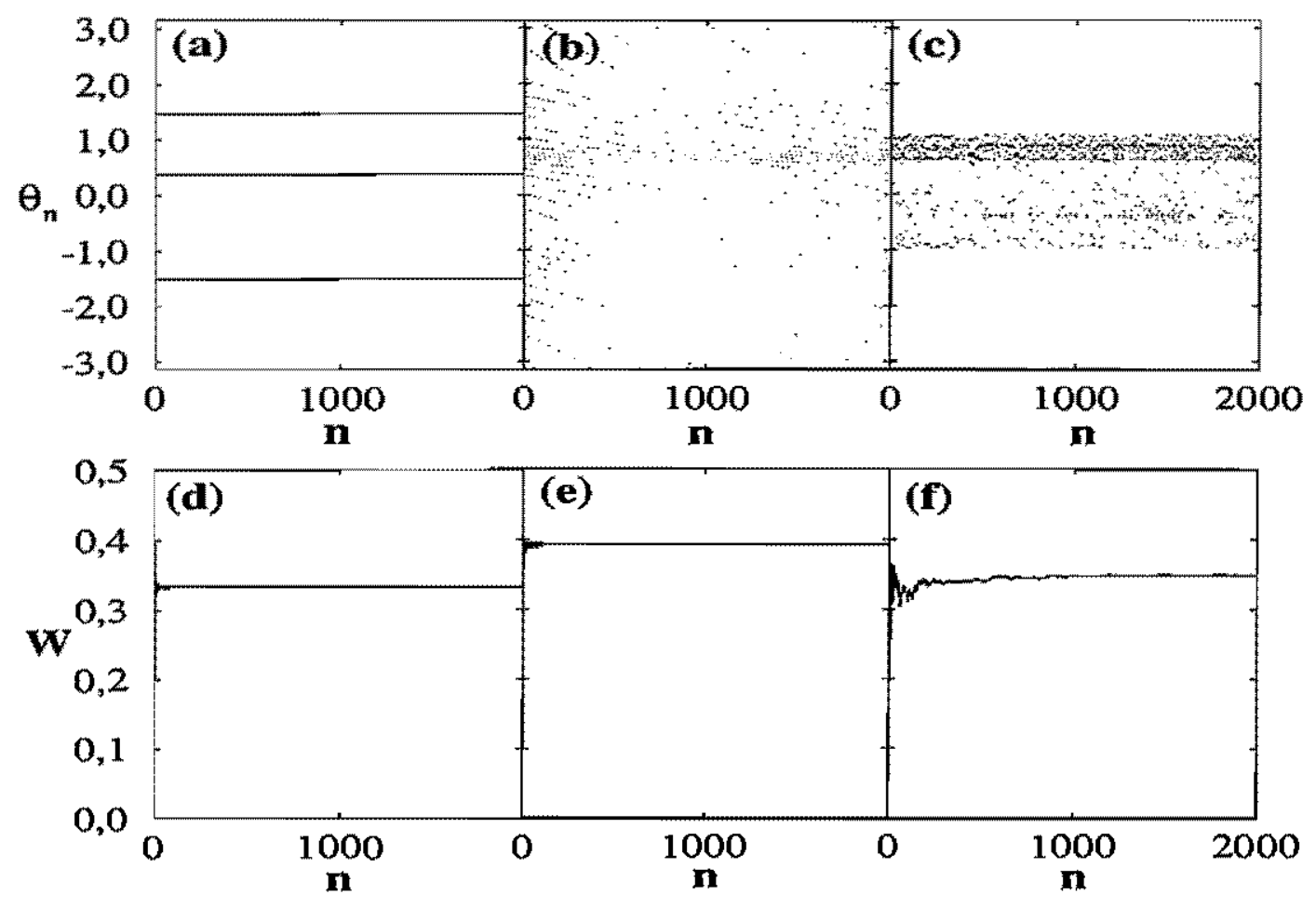

Figura 3.5: As trajetórias do mapa 2.22 para (a) $a=0,45$ e $b=0,35$ (periódica) ; (b) $a=0,45$ e $b=0,40$ (quase-periódica); (c) $a=0,57$ e $b=0,331$ (caótica); e a convergência de seus respectivos números de rotação ((d)-(f)).

\subsection{Números de rotação}

O próximo algoritmo de análise das trajetórias que nós consideramos é o cálculo de números de rotação (winding numbers), que nada mais são do que uma medida do deslocamento angular médio associado a cada trajetória. A definição do número de rotação de uma dada trajetória é $[13,25,10]$ :

$$
W \equiv \lim _{N \rightarrow \infty} \frac{1}{2 \pi N} \sum_{j=0}^{N}\left(\theta_{j+1}-\theta_{j}\right)
$$

onde é necessário tomar o cuidado de não normalizar o ângulo $\theta_{n}$ entre duas iterações antes de calcular a diferença. No cálculo de $W$ para uma trajetória há três resultados possíveis: (i) se a série convergir para um número racional $W=\frac{p}{q}$, a trajetória é periódica de período $q$ e dá $p$ voltas na direção angular, antes de voltar à posição original; (ii) se a série convergir 

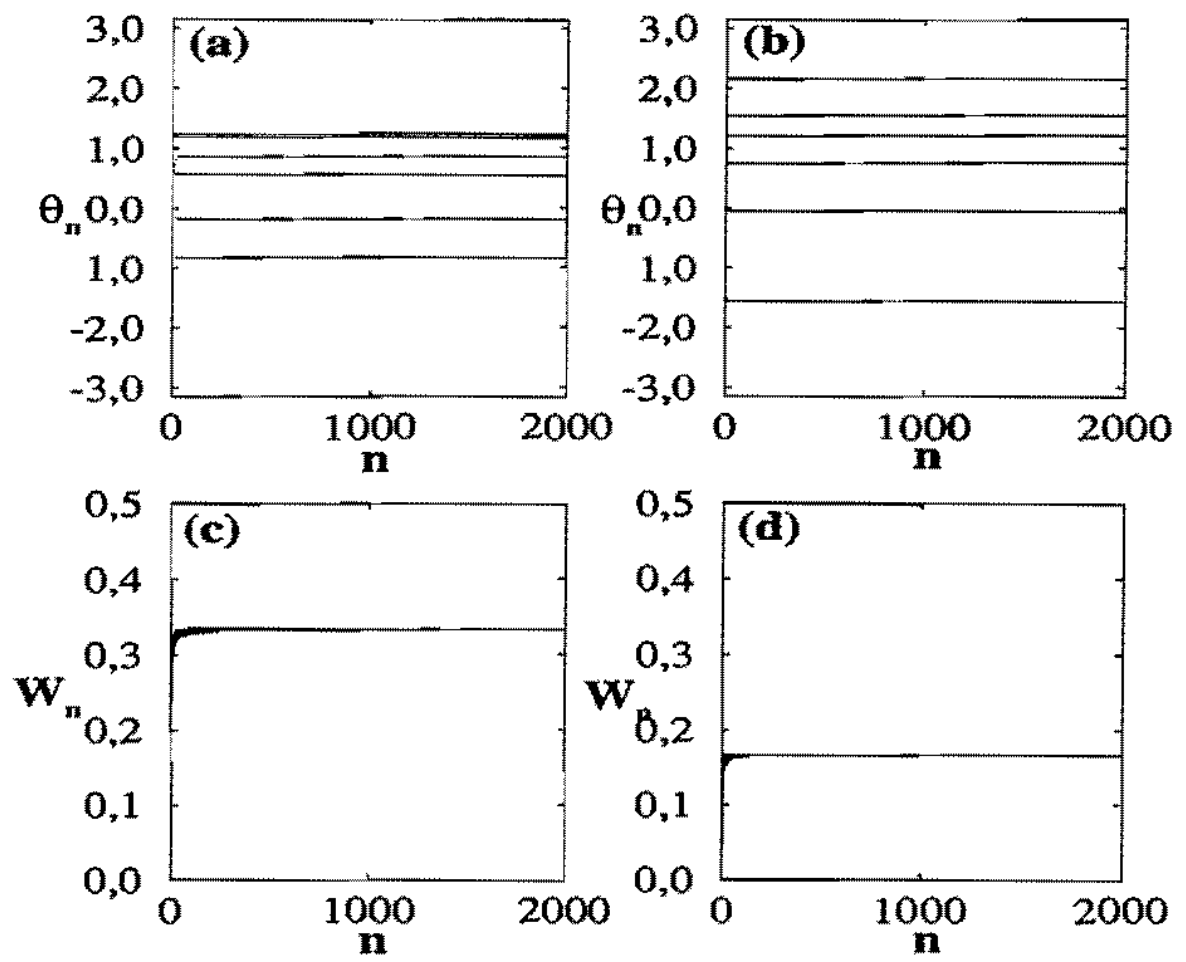

Figura 3.6: As trajetórias periódicas de período 6 do mapa 2.22 para (a) $a=0,53 \mathrm{e} b=0,315$; (b) $a=0,45$ e $b=0,232$; e a convergência de seus respectivos nứmeros de rotação ((c)-(d)).

para um número irracional, a trajetória é quase-periódica; (iii) se a série não convergir, a trajetória é caótica.

É importante ressaltarmos aqui que esta definição está relacionada à convergência no sentido estritamente numérico e não no sentido numérico aproximado. Para muitas trajetórias caóticas há uma aparente convergência numérica, mas basta continuarmos iterando as trajetórias para que apareçam pequenas variações na série do número de rotação e não existe, de fato, limite quando esta tende ao infinito, devido à irregularidade da trajetória caótica.

$\mathrm{Na}$ figura 3.5.a temos uma trajetória periódica de período 3 , e ao calcularmos o seu número de rotação (fig. 3.5.d) observamos que este converge muito rapidamente a $W=\frac{1}{3}$, conforme esperado para uma trajetória de período 3. Já para uma trajetória quase-periódica (fig. 3.5.b) o número de rotação converge igualmente rápido (fig. 3.5.e) para um número irracional, enquanto que para uma trajetória caótica (fig. 3.5.c) $W$ não converge, mesmo após um grande número de iterações.

É importante ressaltarmos aqui que nem sempre o número de rotação define de maneira 
inequívoca o período da trajetória, nos casos em que este é um número racional. Isto se deve ao fato de que se tivermos, por exemplo, $W=\frac{1}{3}$, o que parece indicar uma trajetória de período 3 que se completa após uma volta na direção angular, temos igualmente que $W=\frac{2}{6}=\frac{3}{9}=\ldots$, ou seja, podemos ter uma trajetória de período 6 se repetindo a cada duas voltas, uma de período 9 que se repete a cada três voltas, e assim por diante. $\mathrm{Na}$ figura 3.6 temos, por exemplo, duas trajetórias de período 6. Porém ao passo que para a primeira trajetória (fig. 3.6.a), que se fecha após percorrer uma volta angular, o número de rotação converge rapidamente para $W=\frac{1}{6}$ (fig. 3.6.c), conforme esperado, temos que para a trajetória que leva dois ciclos para se fechar (fig. 3.6.b) $W$ converge para $\frac{1}{3}$, ou seja, $W=\frac{2}{6}$ (fig. 3.6.d).

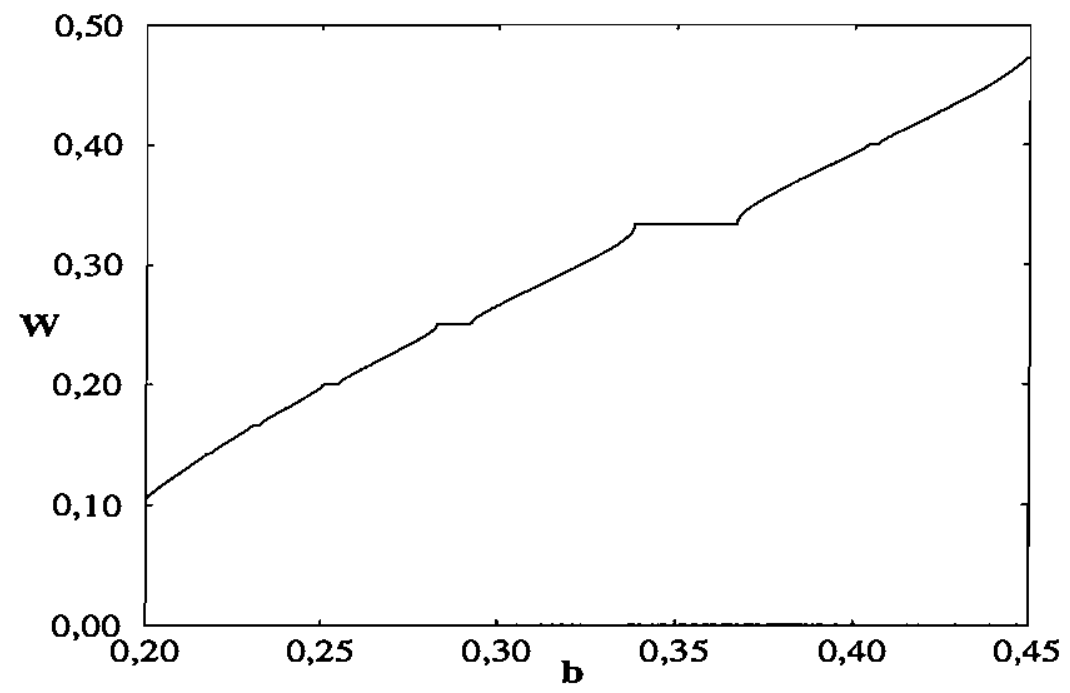

Figura 3.7: Números de rotação para trajetórias do mapa unidimensional dissipativo com $a=0,45$.

Como nos casos anteriores, estamos interessados em observar também o comportamento de $W$ à medida que variamos um dos parâmetros de controle. Na figura 3.7 vemos uma série de números de rotação pára uma intensidade de perturbação fixa $(a=0,45)$ e uma faixa de valores do período da perturbação. Podemos observar que o gráfico consiste em uma curva contínua e crescente com degraus constantes nos números racionais de baixos denominadores. De fato, se fizermos ampliações sucessivas desta curva começamos a observar que há um degrau para cada $W$ racional ao longo dela, sendo a largura do degrau cada vez 
menor, à medida que aumenta o denominador de $W$. Esta estrutura é observada em um grande número de sistemas, particularmente nos mapas da família do mapa do círculo, e é comumente denominada "escada do diabo "(devil's staircase) na literatura, pois lembra uma escada, mas se subirmos de degrau em degrau nunca saímos do lugar, uma vez que em qualquer intervalo de números reais, por menor que seja, há infinitos números racionais.
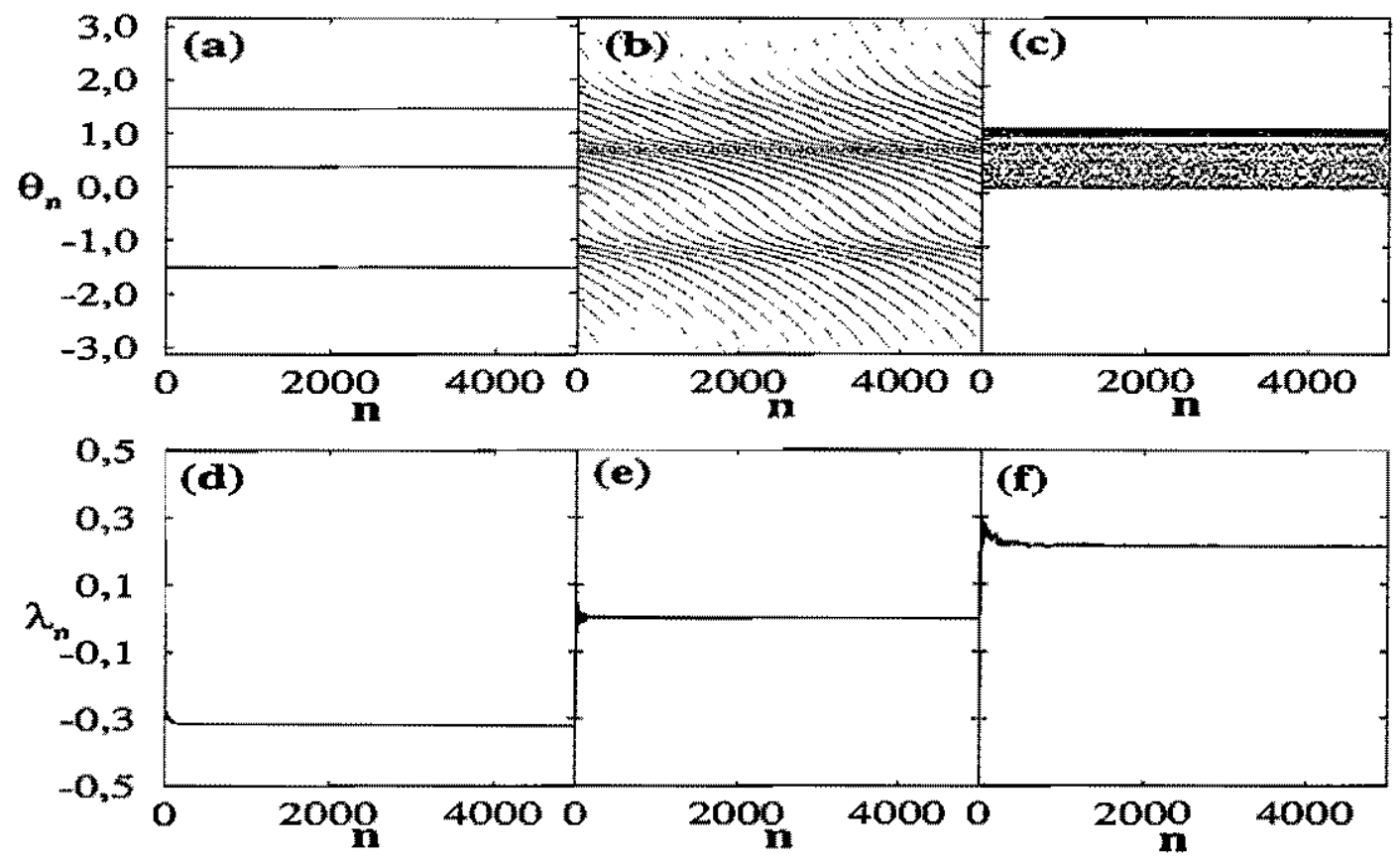

Figura 3.8: As trajetórias do mapa 2.22 para (a) $a=0,45$ e $b=0,35$ (periódica); (b) $a=0,45$ e $b=0,40$ (quase-periódica); (c) $a=0,57$ e $b=0,331$ (caótica); e a convergência de seus respectivos expoentes de Lyapunov ((d)-(f)).

\subsection{Expoentes de Lyapunov}

Outro coeficiente muito importante na análise dinâmica de trajetórias é o expoente de Lyapunov $(\lambda)$. Ele é de fato tão importante que muitos consideram a definição de uma trajetória caótica como sendo aquela que tem $\lambda$ positivo (ou no caso de sistemas com mais de uma dimensão, a trajetória cujo expoente de Lyapunov máximo é positivo). Qualitativamente, ele mede o afastamento exponencial, ou não, de trajetórias com pontos iniciais infinitamente próximos porém não coincidentes. Ou seja, temos que uma trajetória de pon- 


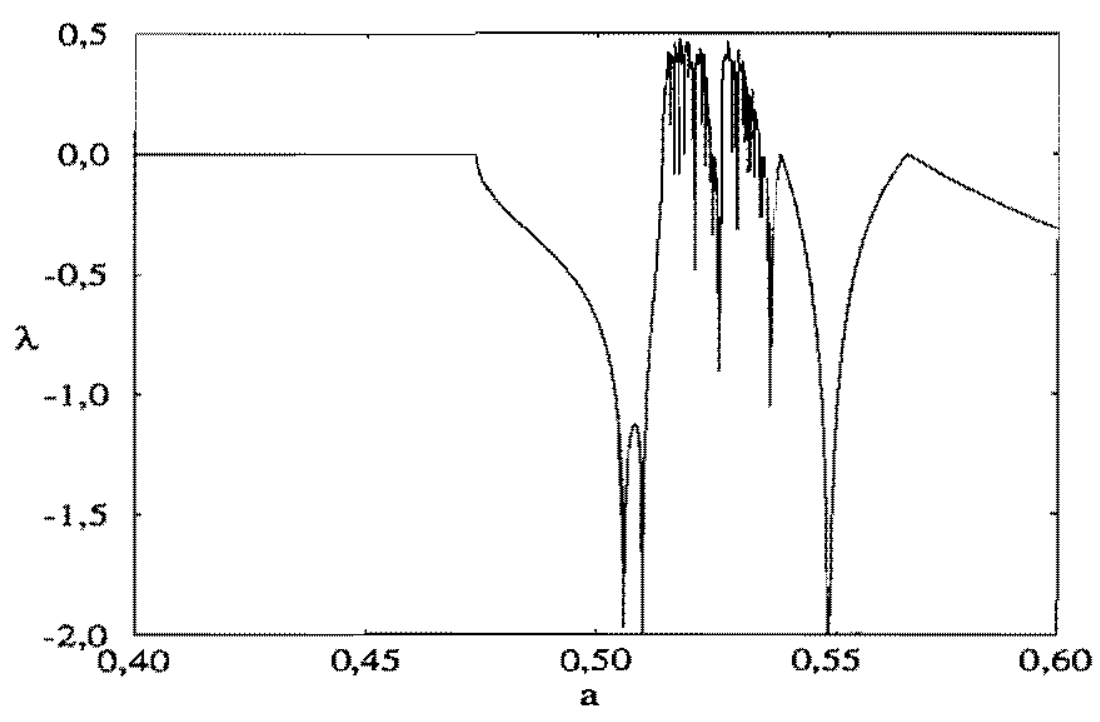

Figura 3.9: Expoentes de Lyapunov do mapa 2.22 para $b=0,30$

to inicial vizinho a outra com expoente de Lyapunov $\lambda$ se afasta desta no tempo de uma distância aproximadamente proporcional a $d_{0} e^{\lambda t}$. A definição do expoente de Lyapunov para mapas unidimensionais é dada por [10]:

$$
\lambda \equiv \lim _{N \rightarrow \infty} \frac{1}{N} \ln \sum_{j=0}^{N}\left\|\frac{d \theta_{n+1}}{d \theta_{n}}\right\|
$$

onde temos que $\frac{d \hat{d}_{n+1}}{d \hat{\theta}_{n}}$ representa a derivada da função iterativa do mapa no ponto $\theta_{n}$. Para sistemas unidimensionais dissipativos temos que se $\lambda<0$ a trajetória é periódica, se $\lambda=0$ a trajetória é quase-periódica, e se $\lambda>0$ a trajetória é caótica.

Para uma trajetória periódica (fig. 3.8.a) vemos que a convergência do seu expoente de Lyapunov (fig. 3.8.d) ocorre de forma muito rápida para um número inequivocamente negativo. Já para uma trajetória quase-periódica (fig. 3.8.b) temos que a convergência para zero ocorre de forma igualmente rápida (fig. 3.8.e), mas há sempre uma certa indefinição no método devido à imprecisão numérica, e o resultado poderia ser um número positivo muito próximo de zero (caracterizando uma trajetória fracamente caótica) ou um número negativo próximo de zero, caracterizando uma trajetória periódica de baixa estabilidade, que para uma pequena variação paramétrica pode se romper. Já para uma trajetória caótica (fig. 3.8.c) a convergência é mais lenta do que nos casos anteriores (fig. 3.8.f), porém o resultado 
é distintamente um número positivo.

Como nos casos anteriores, estamos interessados também no estudo do comportamento dos expoentes de Lyapunov à medida que um dos parầmetros é variado. Fazendo um gráfico de $\lambda$ para um período de perturbação fixo e variando a intensidade de perturbação (fig. 3.9), observamos os três típos de trajetórias. Para a próximo de 0,40 (lado esquerdo do gráfico) temos uma região onde $\lambda=0$, ou seja, as trajetórias são todas quase-periódicas. Depois entramos numa regiāo de regime periódico $(\lambda<0)$, permeada por pequenas regiōes de trajetórias caóticas. Na proximidade destas regiões vemos que o expoente de Lyapunov, que em outras regiōes constitui uma curva contínua e suave, apresenta variações bastante abruptas.

\subsection{Resumo da caracterização de trajetórias}

Nas seções anteriores apresentamos vários métodos de caracterização das trajetórias de um mapa unidimensional. Apresentamos aqui um resumo de todas as características de cada tipo de trajetória (periódica, quase-periódica, e caótica);

\begin{tabular}{|c|c|c|c|}
\hline Trajetória & Periódica & Quase-periódica & Caótica \\
\hline & & & \\
\hline Expoente de Lyảpunov $(\lambda)$ & negativo & nulo & positivo \\
\hline Número de rotação $(W)$ & racional & irracional & não converge \\
\hline Espectro de potência & poucos picos & muitos picos & fundo contínuo \\
\hline Diagrama de bifurcação & alguns pontos & linha cheia em $[0,2 \pi)$ & algumas regiôes cheias \\
\cline { 2 - 4 }
\end{tabular}

Tabela 3.1: Resumo da classificaçâo de trajetórias.

\subsection{Estudos no plano de parâmetros}

Apresentamos até aqui uma série de métodos que permitem classificar o comportamento de uma trajetória de um mapa unidimensional para um dado conjunto de parâmetros fixos. Mas, em geral, não estamos interessados no comportamento do sistema apenas para alguns conjuntos de parâmetros fixos, mas sim para qualquer valor dos parâmetros (dentro dos limites onde ele representa de forma adequada o comportamento do sistema a ser estudado, 
é claro). Para isso passamos a estudar de forma mais completa o espaço de parâmetros do sistema, que no caso do nosso mapa unidimensional dissipativo a dois parâmetros se reduz a um plano de parâmetros $a \times b$ [14]. Para tanto fazemos uma série de gráficos associando o valor de um parâmetro (por exemplo, o expoente de Lyapunov) a um tom de cinza proporcional ao seu valor numérico para uma "rede" de valores dos parâmetros no plano $a \times b$ (tipicamente $500 \times 500$ valores).

No caso do nosso mapa basta estudarmos a regiäo onde $0<b \leq 1$, pois para valores fora desta faixa o comportamento se repete (o sistema simplesmente dá mais voltas no ciclo-limite antes da próxima perturbação impulsiva). De fato, para $\bar{b}=b+n$, onde $n$ é inteiro, temos que:

$$
\tan \theta_{n+1}=\frac{\sin \left(\theta_{n}+2 \pi \bar{b}\right)}{\cos \left(\theta_{n}+2 \pi \bar{b}\right)+2 a}=\frac{\sin \left(\theta_{n}+2 \pi b+2 \pi n\right)}{\cos \left(\theta_{n}+2 \pi b+2 \pi n\right)+2 a}=\frac{\sin \left(\theta_{n}+2 \pi b\right)}{\cos \left(\theta_{n}+2 \pi b\right)+2 a}
$$

O intervalo de estudo do sistema pode ser reduzido mais ainda se observarmos que há uma simetria em torno do eixo $b=\frac{1}{2}$, uma vez que para $\vec{b}=1-b$ o sistema tem o mesmo comportamento dinâmico, porém nâo as mesmas trajetórias, que para $b$. Temos que :

$$
\begin{array}{r}
\sin \left(\theta_{n}+2 \pi \tilde{b}\right)=\sin \left(\theta_{n}+2 \pi-2 \pi b\right)=\sin \left(\theta_{n}-2 \pi b\right)=-\sin \left(-\theta_{n}+2 \pi b\right) \\
\cos \left(\theta_{n}+2 \pi \bar{b}\right)=\cos \left(\theta_{n}+2 \pi-2 \pi b\right)=\cos \left(\theta_{n}-2 \pi b\right)=\cos \left(-\theta_{n}+2 \pi b\right)
\end{array}
$$

e introduzindo $\psi_{n}=-\theta_{n}$ e utilizando o fato de que $\tan \theta_{n+1}=-\tan \psi_{n+1}$ temos que o mapa 2.22 para $\vec{b}$ é equivalente a:

$$
\tan \psi_{n+1}=\frac{\sin \left(\psi_{n}+2 \pi b\right)}{\cos \left(\psi_{n}+2 \pi b\right)+2 a}
$$

ou seja, para $\bar{b}=1-b$ tudo que muda na trajetória é uma reflexão em torno do ângulo $\theta=0$. Basta portanto limitarmos o nosso estudo ao intervalo $b \leq 0 \leq \frac{1}{2}{ }^{2}$

O mapa também tem uma simetria em torno do eixo $a=0$, pois para $a<0$ basta trocarmos a direção da perturbação de $\hat{e}_{x}$ para $-\hat{e}_{x}$ e obtemos um mapa equivalente, e portanto nos restringimos ao estudo da região $a>0$. Mas para perturbaçōes muito fortes o nosso mapa perde o sentido físico, pois não é possível imaginar um mapa que depois de ser muito afastado por uma perturbação impulsiva volte "imediatamente" para o ciclo-limite, por

\footnotetext{
${ }^{2}$ De fato, para $b=\frac{1}{2}$ todos os atratores sâo, portanto, simétricos em torno de $\theta=0$.
} 
mais forte que seja a dissipação. De qualquer forma, para $a>1$ todas as trajetórias do nosso mapa unidimensional sāo periódicas de período 1, o que torna o seu estudo desinteressante do ponto de vista dinâmico, e portanto nós nos limitamos ao estudo do intervalo $0 \leq a<1$.

Passamos agora a estudar quatro características das trajetórias no plano de parâmetros $a \times b$ delimitado por $a \in[0,1]$ e $b \in\left[0, \frac{1}{2}\right]$ : os períodos das trajetónias periódicas (diagramas isoperiódicos), os expoentes de Lyapunov, os números de rotação, e a intensidade de determinadas frequências espectrais.
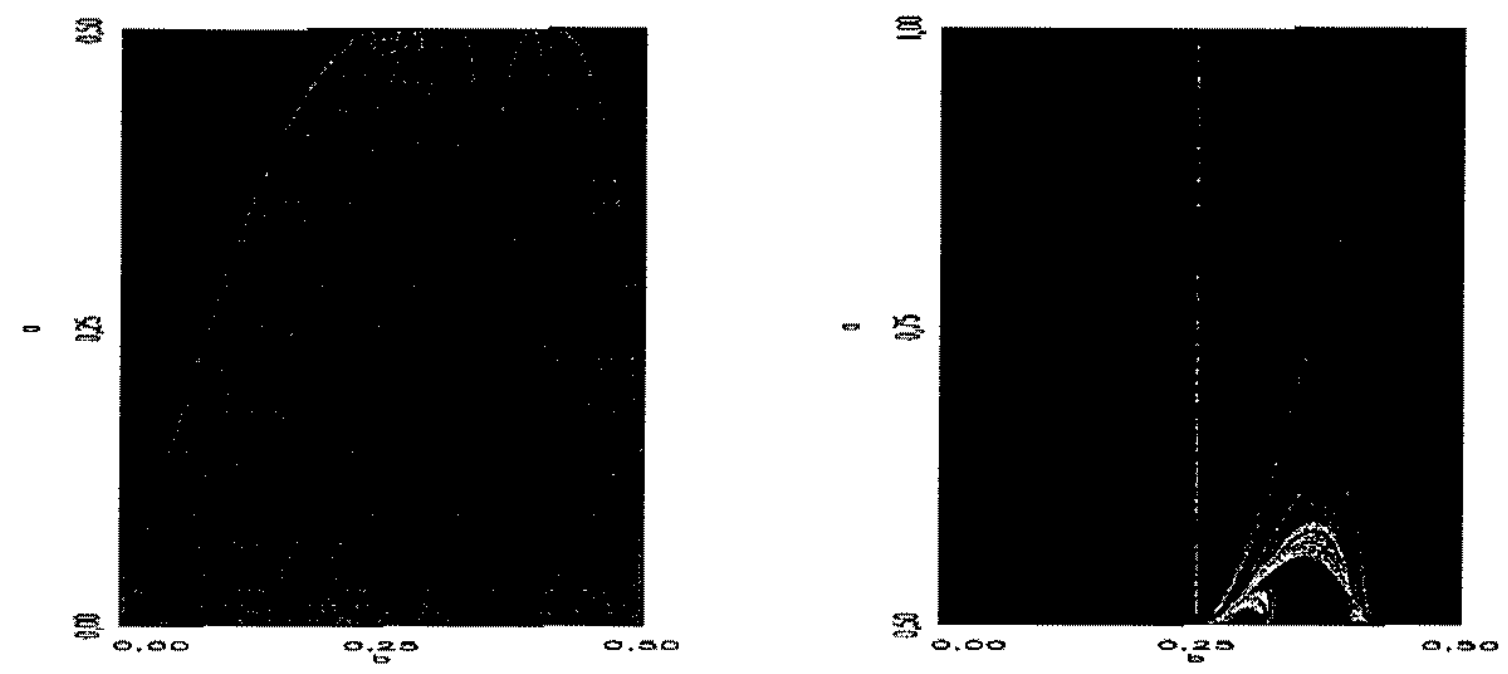

Figura 3.10: Expoentes de Lyapunov no plano de parâmetros. Quanto mais claro o ponto, maior é o expoente de Lyapunov.

Fazendo um gráfico com os expoentes de Lyapunov no plano dos parâmetros para a região de pertubações de baixa intensidade (fig. 3.10.a), observamos que para $a \approx 0, \lambda$ é praticamente constante. Na verdade quase todas as trajetórias nesta região sâo quaseperiódicas e portanto têm $\lambda=0$. À medida que aumentamos a surgem faixas cada vez mais largas com expoentes de Lyapunov negativos, correspondentes a regiōes de comportamento periódico. Estas faixas são conhecidas na literatura como "línguas de Arnold". Ao nos aproximarmos de $a=\frac{1}{2}$, estas faixas ocupam todo o espaço de parâmetros. De fato, não temos mais nenhuma trajetória quase-periódica para $a=\frac{1}{2}$, conforme mostraremos mais adiante.

Já na regiāo com $a>\frac{1}{2}$ (fig. 3.10.b) temos expoentes bastante negativos na maior parte do plano e apenas uma pequena região de pontos muito claros (correspondentes às trajetórias caóticas) logo acima do eixo $a=\frac{1}{2}$. Esta região tem contornos bastante complexos. 


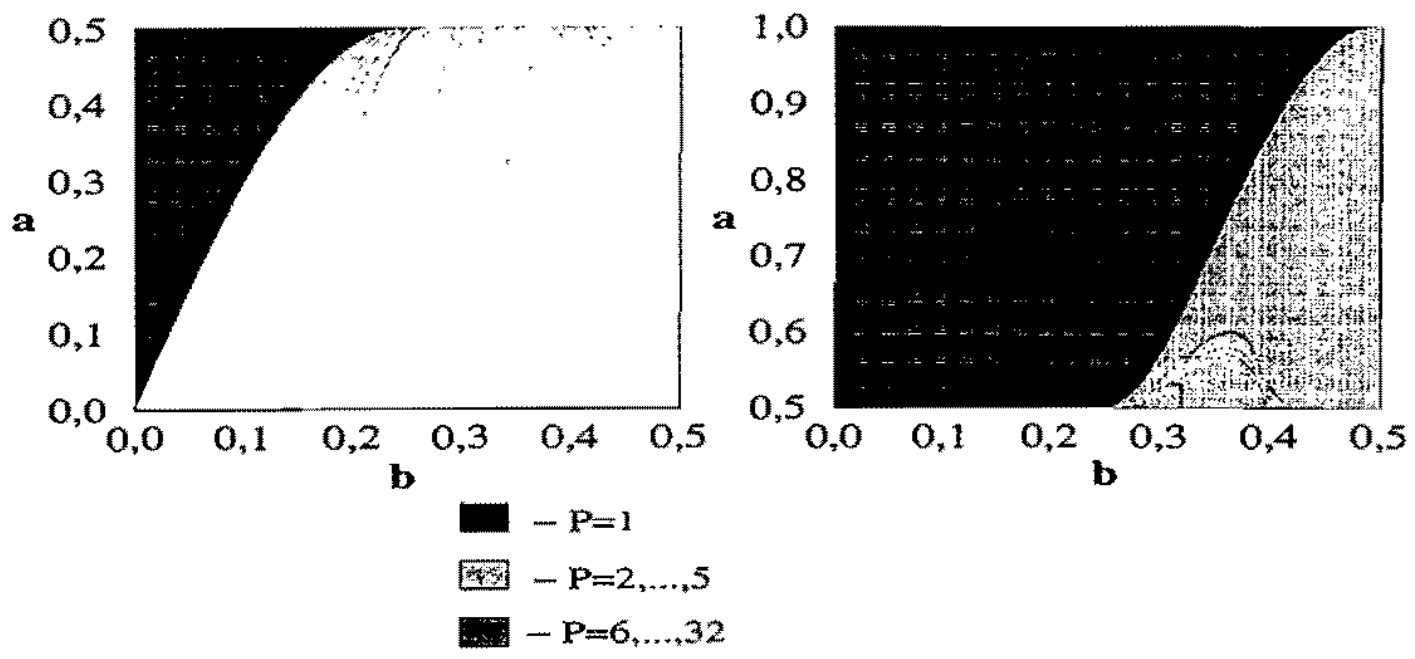

Figura 3.11: Diagramas isoperiódicos do mapa unidimensional dissipativo.

Temos também faixas mais claras de aparência bastante regular imersas nas regiōes escuras (periódicas) que correspondem a uma fronteira de duplicação de períodos, onde temos que, exatamente na fronteira, $\lambda=0$. Estas transiçōes de duplicaçāo de períodos serão analisadas em detalhe no próximo capítulo. Observamos também que a região caótica é permeada de ilhas de regimes periódicos, correspondentes às janelas nos diagramas de bifurcação. Esta estrutura é fractal, ou seja, quanto mais ampliarmos a região caótica, mais ilhas periódicas cada vez menores (e de periodos cada vez mais altos) nós observaremos.

Fazendo agora os diagramas isoperiódicos para as mesmas regiōes do plano de parâmetros que os expoentes de Lyapunov (fig. 3.11) podemos observar de forma mais nítida as línguas de Arnold de diversos periodos. Algumas propriedades das línguas de Arnold podem ser obtidas analiticamente. Em $a=0$, por exemplo, o nosso mapa unidimensional dissipativo se reduz a $\theta_{n+1}=\theta_{n}+2 \pi b$ e portanto existe uma trajetória periódica de período $Q$ para cada $b=\frac{P}{Q}$ racional. Ou seja, para cada valor racional de $b$ "nasce" uma língua de Arnold em $a=0$. Temos assim uma língua de Arnold de período 1 nascendo em $b=0$, uma língua de período 2 nascendo em $b=1 / 2$, uma de periodo $3 \mathrm{em} b=1 / 3$ e assim por diante. Assim sendo, verificamos que há línguas de Arnold de qualquer período.

É possivel também determinar de maneira precisa as fronteiras das línguas de Arnold 


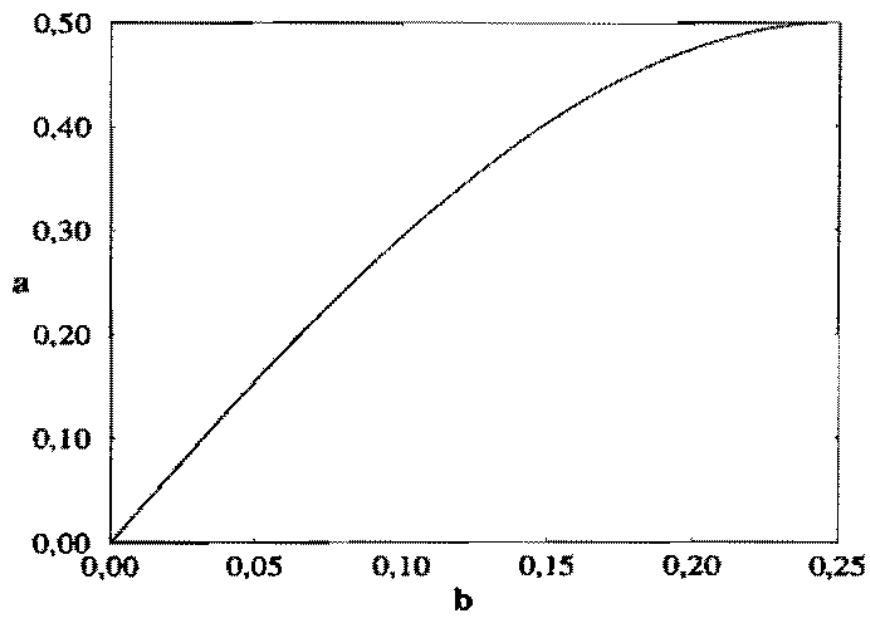

Figura 3.12: Curva limitante da língua de Arnold de período 1 obtida analiticamente.

com as regiões quase-periódicas. Damos aqui como exemplo a determinação da curva que limita a língua de Arnold de período 1. Temos que as trajetórias de período 1 são definidas por $\theta_{n+1}=\theta_{n} \equiv \theta^{*}$ e portanto temos do mapa que:

$$
\tan \left(\theta^{*}\right)=\frac{\sin \left(\theta^{*}+2 \pi b\right)}{2 a+\cos \left(\theta^{*}+2 \pi b\right)}
$$

que pode ser reescrita como:

$$
\sin \left(\theta^{*}\right)=\frac{\sin (2 \pi b)}{2 a}
$$

e, como $\left\|\sin \theta^{*}\right\| \leq 1$ por definição, obtemos a condição que nos fornece a regiăo ocupada no plano de parâmetros pela língua de Arnold cuja fronteira (à direita) é dada pela equação:

$$
a=\frac{\sin (2 \pi b)}{2}
$$

A curva descrita pela equação 3.9 encontra-se na figura 3.12 e comparando com a língua de Arnold da figura 3.11 vemos que de fato ela representa a borda desta. As fronteiras para as outras línguas de Arnold podem ser obtidas de maneira análoga, porém as curvas são descritas por funçōes implícitas envolvendo $a \mathrm{e} b$.

Outros coeficientes de interesse a serem analisados no plano de parâmetros são os números de rotação (fig. 3.13). Podemos observar que para $0<a<1 / 2$, correspondente à região das línguas de Arnold, os números de rotação variam de forma contínua, aumentando com 
o parâmetro $b$. Para $a$ próximo de zero este aumento se dá de forma linear $W \propto b$, mas conforme aumentamos $a$ a variação passa a se concentrar cada vez mais em torno de $b \approx 0,30$.
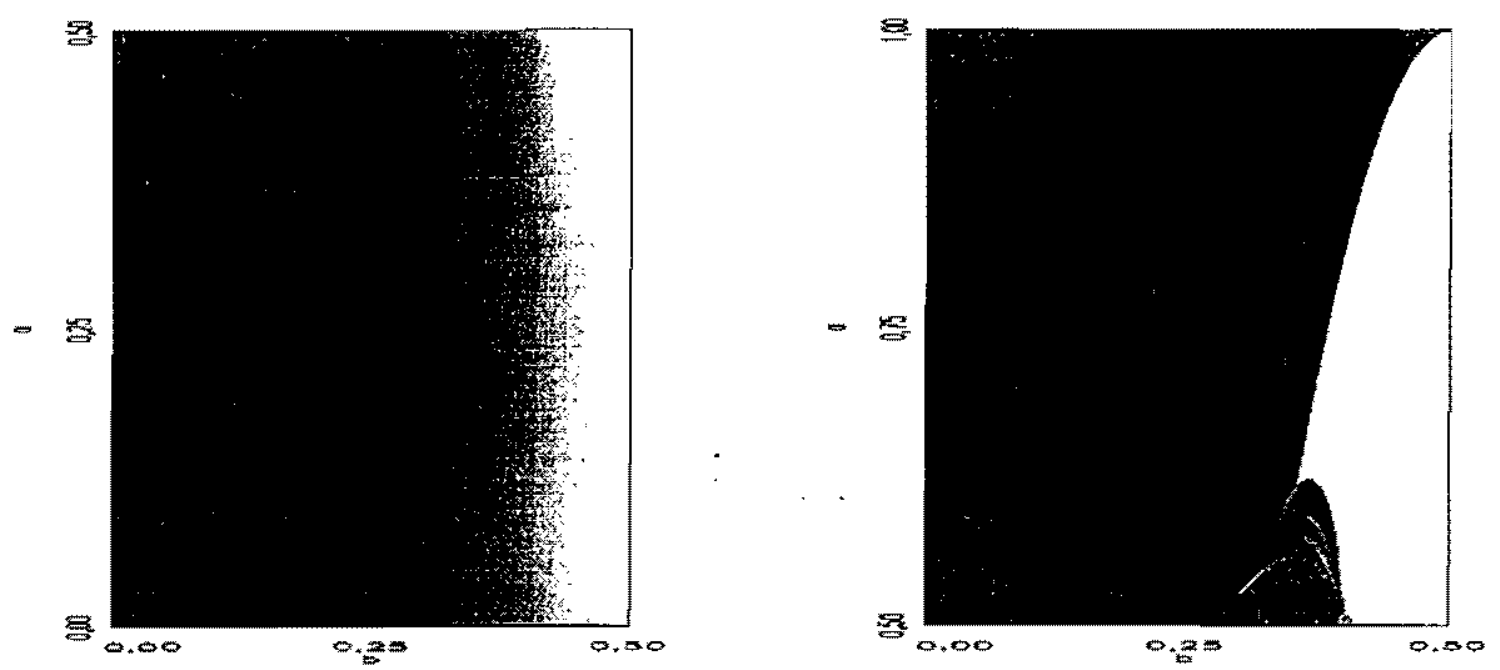

Figura 3.13: Números de rotação no plano de parâmetros. Quanto mais claro o ponto, maior é o número de rotação.

Já na região $a>1 / 2$ vemos que existem grandes regiōes com número de rotação constante e variaçöes abruptas em seu valor ao passar de uma região para outra. Veremos mais adiante que estas fronteiras onde ocorrem as mudanças no valor de $W$ correspondem a duplicações de período nos diagramas de bifurcação.

Finalmente, apresentamos ainda os planos espectrais, como uma última forma de representarmos o sistema no plano de parâmetros. Os planos espectrais foram desenvolvidos para observar a distribuição de certas frequências relevantes no espaço de parâmetros do sistema. Um plano espectral é construído tomando-se uma rede de valores $(a, b)$ no plano de parâmetros (tipicamente da ordem de $500 \times 500$ valores e calculando a trajetória do sistema para cada par de parâmetros. Em seguida tiramos o espectro de Fourier de cada uma das trajetórias, utilizando o algoritmo da FFT( $F_{a s}$ Fourier Transform), e colocamos no gráfico um ponto cujo tom de cinza é proporcional à intensidade espectral de uma certa frequência a ser analisada neste plano. Quanto maior a intensidade espectral, mais escuro o ponto.

Na figura 3.14 vemos os planos espectrais do mapa unidimensional dissipativo em torno da região de regime caótico $(0,50<a<0,70 \mathrm{e} 0,25<b<0,45)$ para as frequências $f=1 / 3$, $f=1 / 4, f=1 / 5$, e $f=1 / 7$, respectivamente. Temos que para cada frequência aparecem regiōes maiores de grande intensidade espectral correspondentes às regiôes periódicas com 

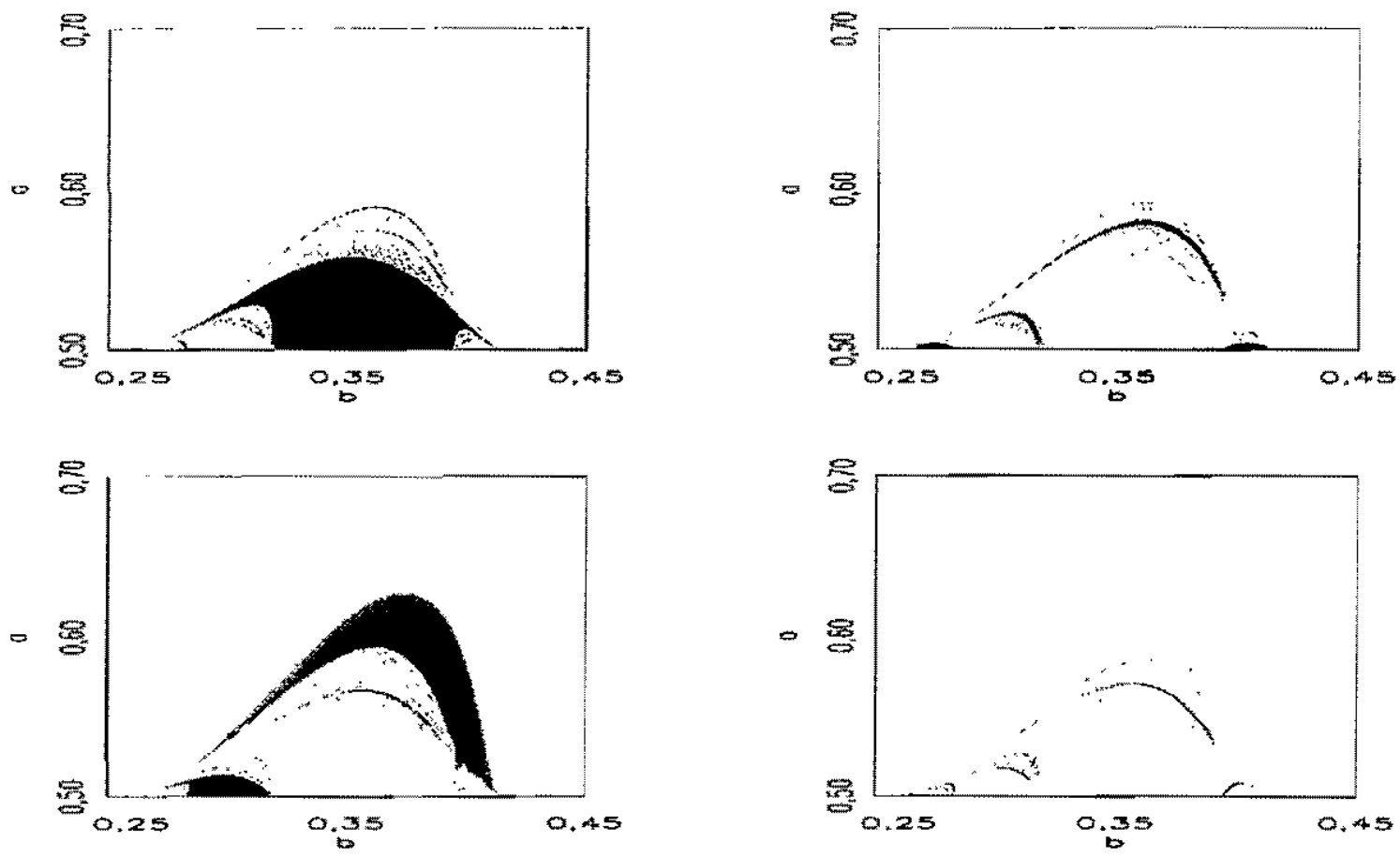

Figura 3.14: Planos espectrais para (a) $f=1 / 3$; (b) $f=1 / 4$; (c) $f=1 / 5$; (d) $f=1 / 7$.

períodos relacionados com a frequência analisada (para $f=1 / 3, P=3,6,12,24, \ldots$, para $f=1 / 4, P=4,8,16,32, \ldots$ e assim por diante). Já na região caótica todas as frequências aparecem de forma mais fraca e irregular, devido ao fato de trajetórias caóticas apresentarem um espectro de fundo contínuo em toda a faixa de frequências. Observamos também de forma bastante distinta estreitas faixas escuras imersas na região caótica, correspondentes às janelas periódicas já observadas nos diagramas de bifurcação. É ainda interessante notarmos que dentro de uma regiâo periódica de mesmo período a intensidade espectral não é constante, mas varia suavemente com os parâmetros.

Uma vez identificadas as diversas regiōes de comportamento dinâmico e algumas de suas características no plano dos parâmetros, passamos entäo a fazer uma análise mais rigorosa das características do sistema ao passar de uma região para a outra à medida que os parâmetros são variados. Esta análise encontra-se no capitulo seguinte. 


\section{Capítulo 4}

\section{As Transições Entre os Diversos Regimes de Comportamento Dinâmico}

Neste capítulo utilizamos os algoritmos de classificação das trajetórias, introduzidos no capítulo anterior, para um estudo mais detalhado dos diversos tipos de transiçōes possíveis entre os regimes dinâmicos no plano de parâmetros [11]: a transição entre regimes periódicos e quase-periódicos, a transição entre regimes periódicos e caóticos, e a transição entre regimes periódicos de períodos incomensuráveis. Mostramos também que no nosso sistema não há nenhuma transiçạa direta. entre regimes quase-periódicos e caóticos.

\subsection{A transição entre regiões de regimes periódicos e quase-periódicos}

Ao analisarmos os planos de parâmetros no capítulo anterior, vimos que para $a<1 / 2$ o mapa unidimensional dissipativo 2.22 não apresenta trajetórias caóticas, uma vez que ele é inversivel, e temos portanto apenas trajetórias periódicas, de diversos períodos, e quaseperiódicas. Vimos tambérn que estas se distribuem no plano dos parâmetros formando uma estrutura conhecida na literatura como "línguas de Arnold". Passamos agora a analisar esta estrutura mais a fundo. Na verdade, vamos dar enfoque não às características de cada regime dinâmico ern si, mas sim às fronteiras entre eles, analisando como uma mudança infinitesimal nos parâmetros de controle na vizinhança das fronteiras entre estes regimes pode afetar de 


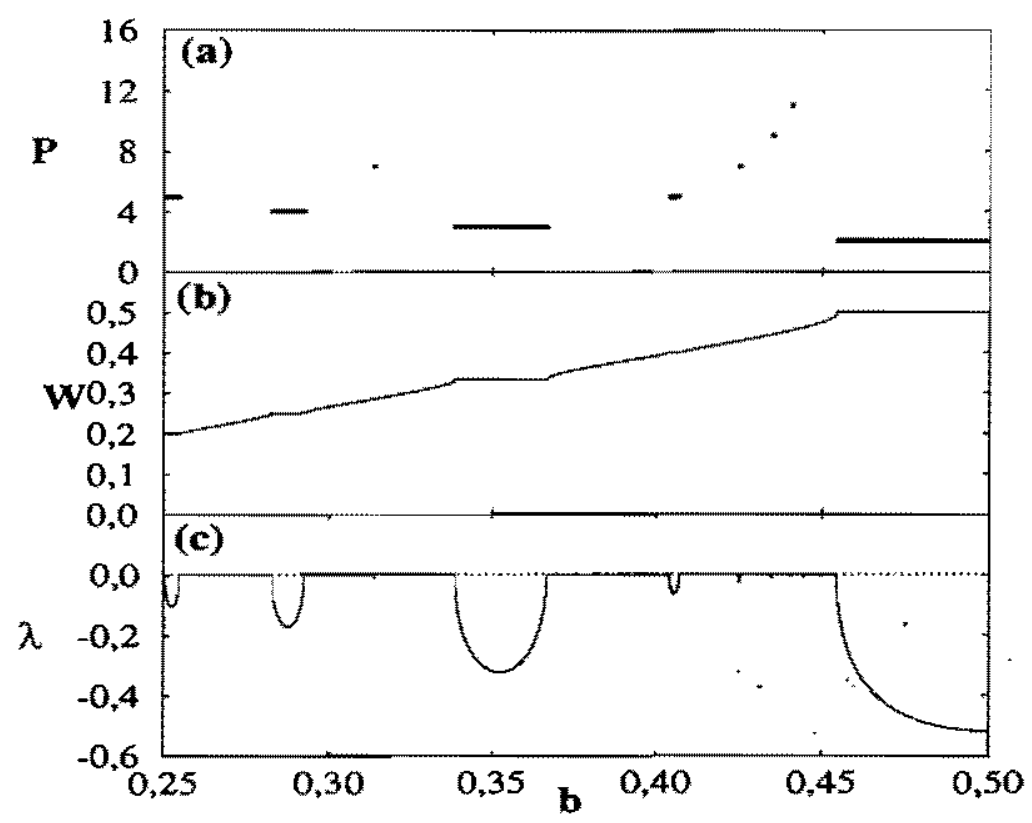

Figura 4.1: (a) Períodos das órbitas periódicas; (b) números de rotação; (c) expoentes de Lyapunov para o mapa unidimensional dissipativo 2.22 com $a=0,45$.

maneira tão profunda a dinâmica do sistema.

Para tanto, vamos estudar a dinâmica das trajetórias ao longo de um segmento de reta no plano dos parâmetros, fixando a intensidade de perturbação $(a)$ e variando o seu período $(b)$. Assim sendo, calculamos os expoentes de Lyapunov, os números de rotação, e os períodos das trajetórias (caso elas sejam periódicas) ao longo deste segmento de reta (fig.4.1). Os intervalos de trajetórias periódicas são caracterizados por degraus constantes indicando o período das trajetórias na figura 4.1.a, por outros degraus constantes indicando seus números de rotação na figura 4.1.b, e por reentrâncias de expoentes de Lyapunov negativos na figura 4.1.c. Já os intervalos de trajetórias quase-periódicas não são indicados no diagrama de periodos, têm números de rotação irracionais, que crescem proporcionalmente ao período da perturbação $b$, e expoentes de Lyapunov nulos.

Ampliando sucessivamente, por exemplo, o gráfico dos números de rotação (fig.4.2), vemos que surge um número crescente de faixas cada vez mais estreitas de regimes periódicos. De fato, esta estrutura é fractal e deve-se ao fato de que em cada intervalo de números reais há infinitos números racionais, cada um levando a um degrau no gráfico dos números de rotação e uma reentrância no gráfico dos expoentes de Lyapunov. A curva fractal assim 
formada pelos números de rotação é conhecida na líteratura como escada do diabo ("devil's staircase") [13], pois se subirmos de degrau em degrau nunca saímos do lugar.

Surge agora a questão: como se dá a transição entre os dois tipos de regime observados, periódico e quase-periódico? $\mathrm{O}$ que acontece com a dinämica do sistema quando um parâmetro (no nosso exemplo, o período da perturbaçāo externa, $b$ ) é variado continuamente? Para entendermos este fenômeno, vamos analisar em detalhe a regiäo de transição entre as línguas de Arnold de período 4 e 3 (fig.4.3).
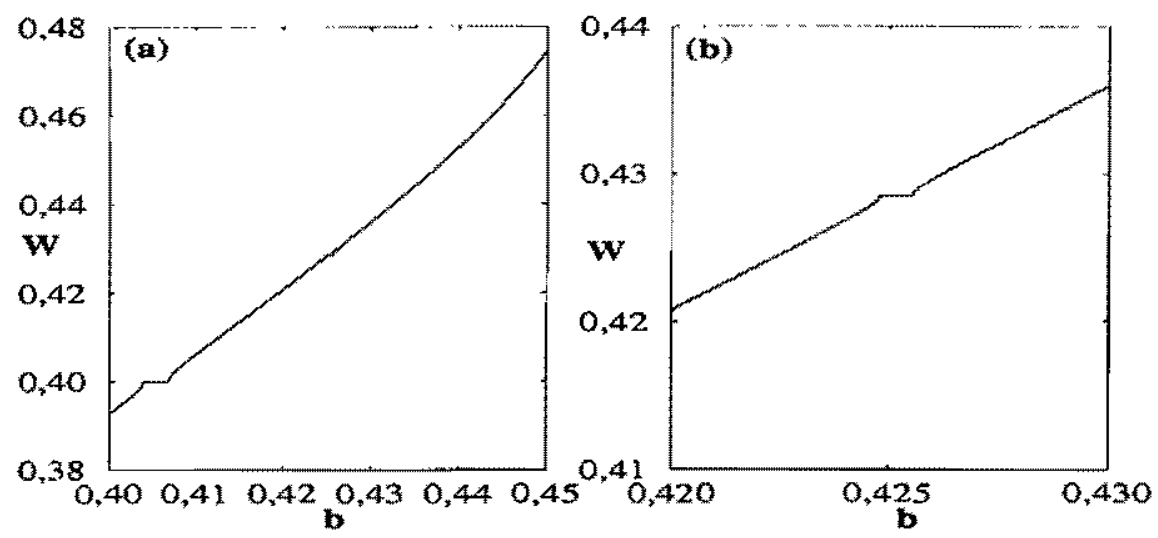

Figura 4.2: Ampliações sucessivas da curva de números de rotação da figura 4.1.b

Tirando alguns espectros de Fourier ao longo desta transição para certos valores de parâmetros fixos (fig.4.4), vemos no primeiro espectro (fig.4.4.a), tirado na região de parâmetros correspondente à língua de Arnold de período 4, que existe apenas um pico espectral intenso e bastante bem definido em $f_{4}=\frac{1}{4}$, conforme esperado. $\grave{A}$ medida que aumentamos o período da perturbação $b$ (fig.4.4.b) e entramos na região quase-periódica, observamos agora um grande número de picos espectrais, mas dentre estes picos dois se destacam com maior intensidade. Um deles está com frequência um pouco maior que $f_{4}$ e o outro está com frequência um pouco menor que $f_{2}=\frac{1}{2}$. Aumentando ainda mais o parâmetro $b$ e seguindo no regime quase-periódico (fig.4.4.c), continuamos observando os dois picos mais acentuados, que agora já estão mais próximos. Ao entrarmos finalmente na língua de Arnold de período 3 (fig.4,4,d) passamos a ter novamente um espectro com apenas um pico definido (desta vez em $f_{3}=\frac{1}{3}$ ) localizado na regiào entre os picos anteriores. Observamos assim que, à medida que em que variamos $b$, os picos correpondentes às principais frequencias se deslocam de forma 
contínua e quando eles chegam em um número racional entramos em uma língua de Arnold. Este fenômeno é conhecido na literatura como sincronização de fase ("phase-locking").

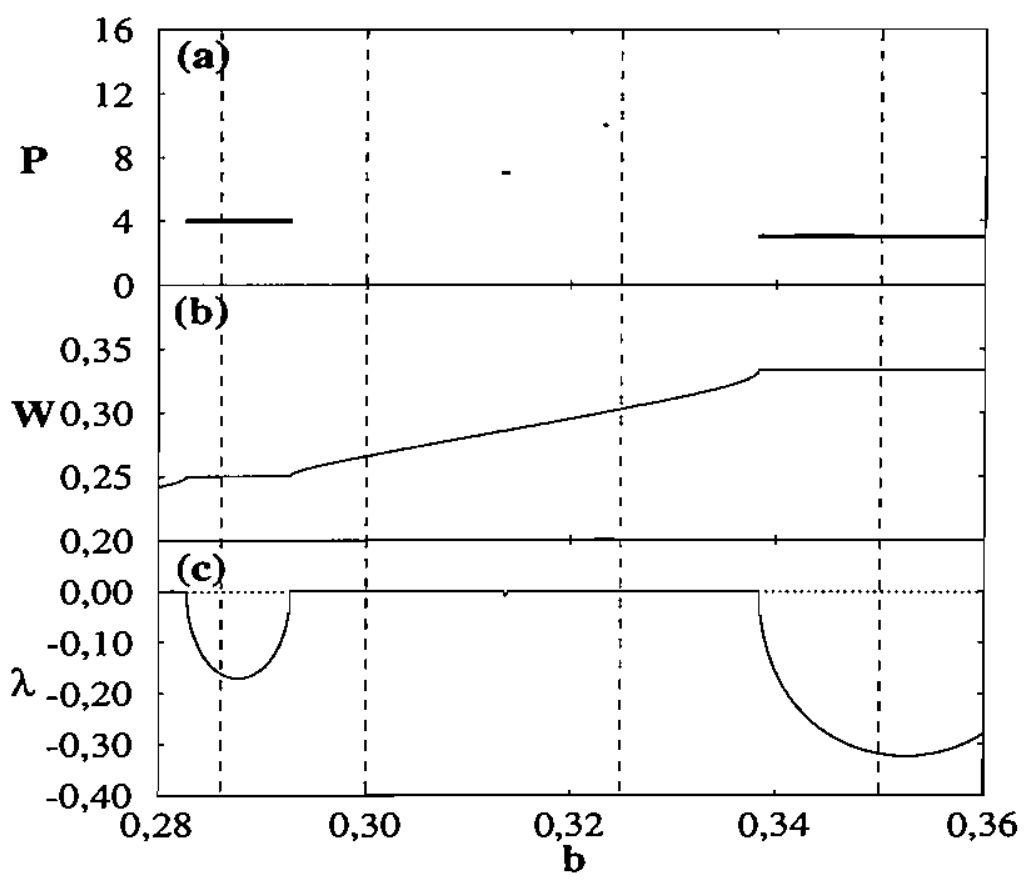

Figura 4.3: Ampliação da figura 4.1 na região entre as línguas de Arnold de período $4 \mathrm{e}$ período 3 , respectivamente.

De fato, este deslocamento de picos espectrais ocorre não apenas com os picos principais, mas também com os picos secundários de todas as intensidades. Ele pode ser observado melhor em diagramas de bifurcação no espaço de frequências. Fazendo um diagrama de bifurcação no espaço de frequências correpondente à região analisada na figura 4.3 (fig. 4.5.a), podemos observar uma série de curvas pretas, cada uma correspondendo a um pico de frequência que se desloca de forma contínua ao longo do eixo de frequências, à medida que o parâmetro $b$ é variado. É importante notarmos que nenhuma destas curvas surge ou desaparece em pontos quaisquer, mas todas elas ligam picos espectrais correspondentes às faixas periódicas. Ampliando uma faixa deste diagrama correspondente à região quaseperiódica logo antes do regime periódico de período 3 (fig. 4.5.b), vemos que a estrutura de curvas torna-se mais regular e que de fato todas as curvas espectrais se dirigem às bordas do espectro ou a $f_{3}=\frac{1}{3}$ quando entramos no regime periódico de período 3 .

Temos ainda que os cruzamentos entre estas linhas espectrais ocorrem ao longo de algu- 


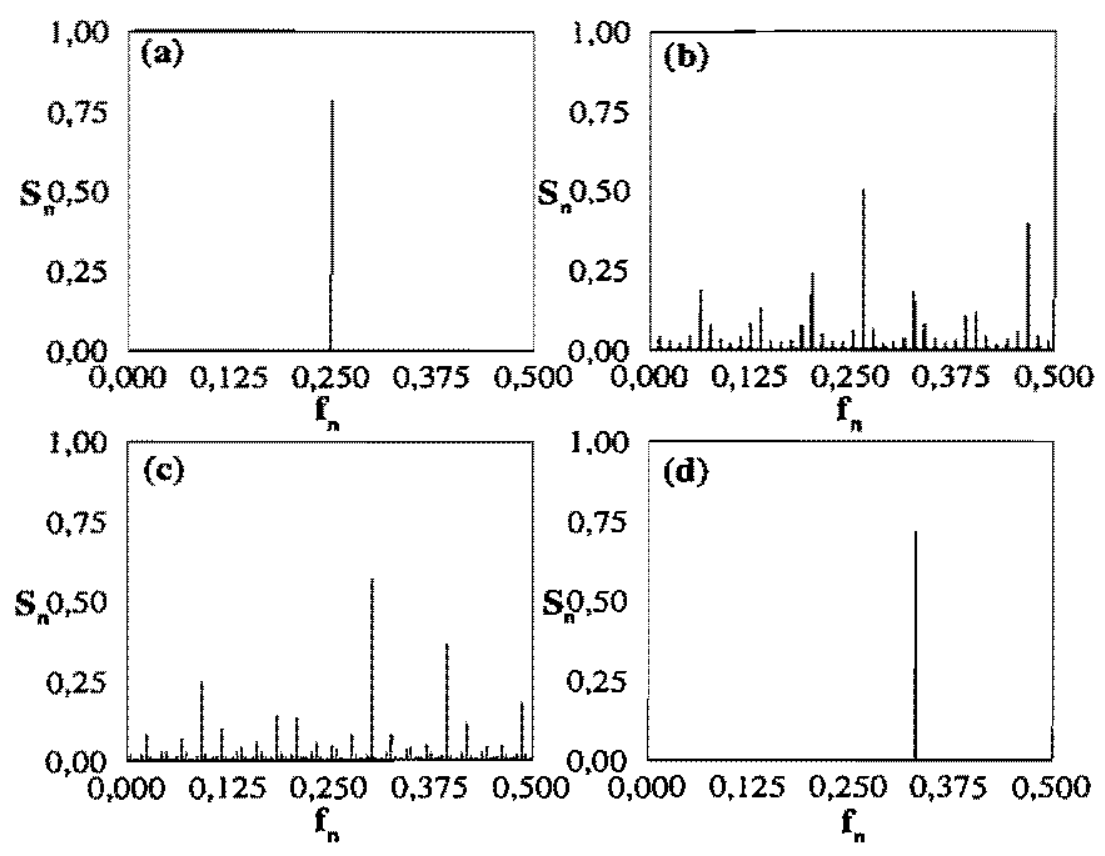

Figura 4.4: Espectros de Fourier para trajetórias com parâmetros fixos marcados pelas linhas pontilhadas na fig.4.3((a) $b=0,287$, (b) $b=0,300$, (c) $b=0,325$, (d) $b=0,350$ ).

mas linhas verticais bem definidas, cada uma delas correspondendo a uma língua de Arnold muito estreita de período elevado. De fato, não ocorrem cruzamentos de curvas espectrais em valores de parâmetros do regime quase-periódico.

Vimos assim, que a transição entre regimes periódicos e quase-periódicos correponde a um deslocamento contínuo das frequências dominantes da trajetória e que, para certos conjuntos de parâmetros, estas frequências sāo sincronizadas formando estruturas correspondentes às regiōes periódicas no plano de parâmetros, que no caso do nosso sistema (e de toda uma classe de mapas conhecidos como mapas do círculo e seus derivados) são denominadas "línguas de Arnold".

Outra forma de analisarmos a transiçāo entre regimes periódicos e quase-periódicos é utilizando a própria definição de trajetória periódica. Temos que, se um mapa apresenta uma trajetória periódica estável de período $P$, então existem por definição $P$ posiçōes $\theta_{j}(j=$ $1, \ldots, P)$ tais que $f^{P}\left(\theta_{j}\right)=\theta_{j}$ com $\left\|\frac{d f^{P}\left(\theta_{j}\right)}{d \theta_{j}}\right\|<1$. Fazendo uma série de gráficos de $f^{3}(\theta) \times \theta$ na região da figura 4.3 correspondente à entrada na língua de Arnold de período 3 (fig.4.6), podemos ver que no regime quase-periódico perto da língua de Arnold a curva não cruza a reta $f^{3}(\theta)=\theta$. Quando passamos pela borda do regime periódico de período 3 a curva encosta 

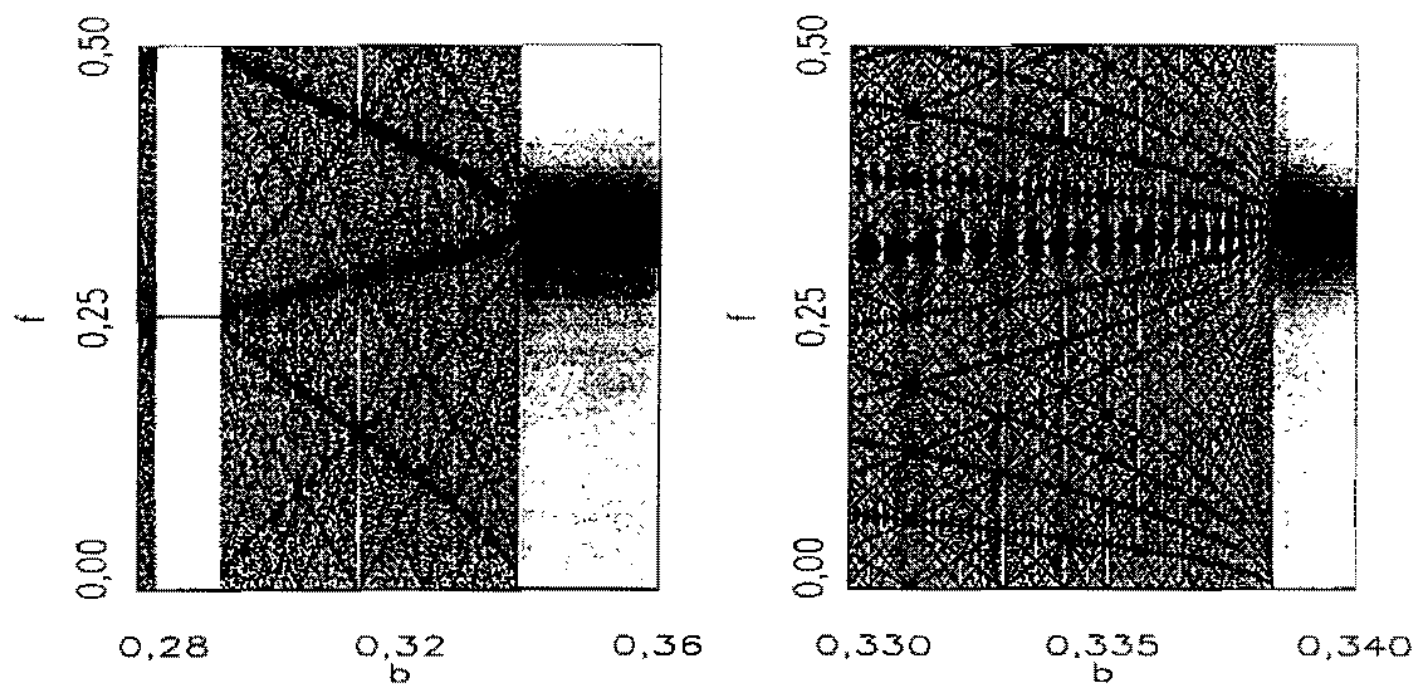

Figura 4.5: Diagramas de bifurcação no espaço de frequências para $a=0,45$.

na reta em 3 pontos distintos e a medida que entramos na língua temos 6 cruzamentos: 3 em pontos com derivada menor que 1 , correspondentes à órbita estável, e 3 com derivada maior que 1, correspondentes à órbita instáyel. Quanto mais nos aproximamos do centro da região periódica mais os pontos das órbitas estáveis e instáveís se afastam. Assim sendo, podemos utilizar a distância entre uma órbita estável e uma órbita instável como uma medida aproximada da proximidade de órbitas quase-periódicas no plano dos parâmetros. Temos também que as órbitas no centro das línguas de Arnold são as mais estáveis pois têm as menores derivadas médias, conforme também já foi observado nos diagramas de expoentes de Lyapunov, que têm os valores mais negativos nos pontos mais afastados das regiōes quaseperiódicas.

\subsection{A transição entre regimes periódicos e caóticos}

Passamos agora à análise das transiçōes entre os diversos regimes na regiāo do plano de parâmetros com $a>\frac{1}{2}$. Nesta região observamos apenas trajetórias periódicas ou caóticas, mas nāo existem trajetórias quase-periódicas. Isto nos leva a dois tipos possíveis de transiçōes: as transições entre regimes periódicos e caóticos, das quais trataremos em detalhe neste item, e as transições entre regimes periódicos de periodos não comensuráveis, que serão analisadas no próximo item. 


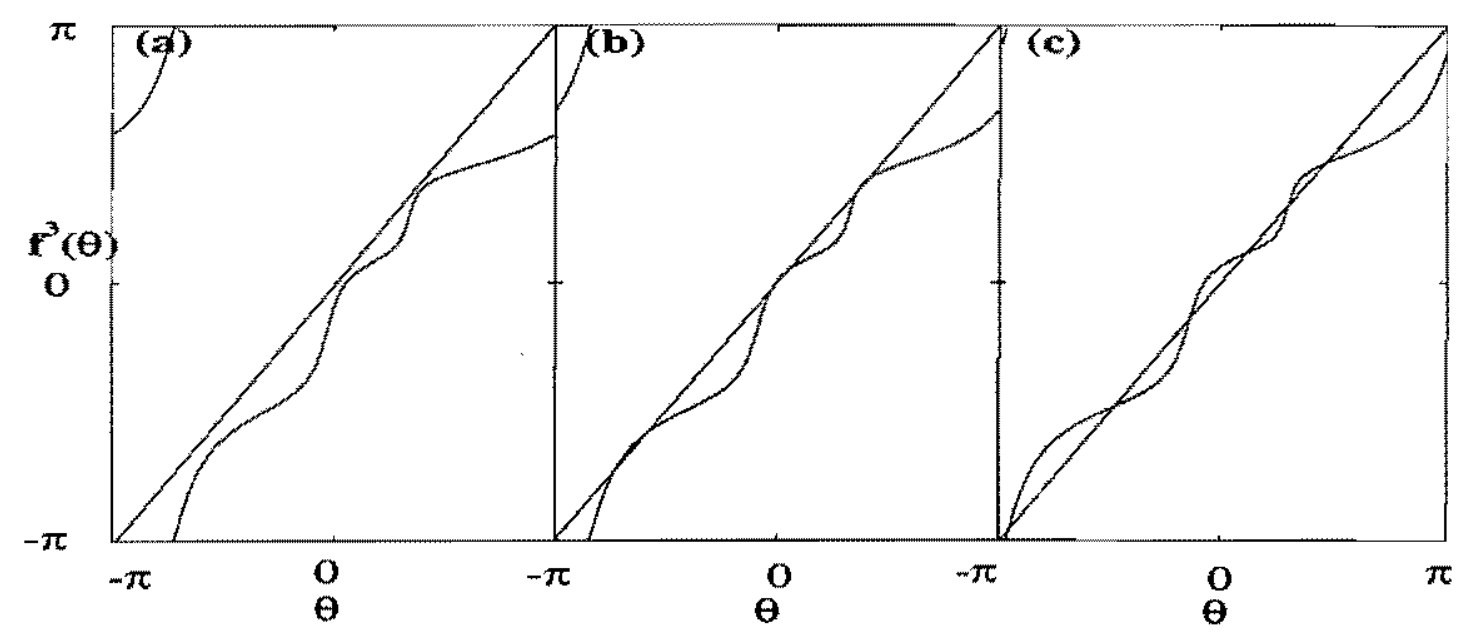

Figura 4.6: Diagramas de iteração do mapa 2.22 para período $P=3 \operatorname{com} a=0,45$ e (a) $b=0,33$; (b) $b=0,34$; (c) $b=0,35$.

Para a análise da transição entre regimes periódicos e caóticos vamos tomar novamente como exemplo o comportamento do mapa unidimensional dissipativo ao longo de um segmento de reta no plano de parâmetros $a \times b$. Fixamos a intensidade da perturbação periódica em $a=0,57$ e fazemos o diagrama de bifurcação, os expoentes de Lyapunov, e os períodos das órbitas periódicas (fig.4.7). Vemos nestes diagramas que começamos em um regime periódico para perturbações com $b=0,25 \mathrm{e}$, à medida que aumentamos $b$, ocorrem duplicações de período até entrarmos no regime caótico, permeado por janelas de trajetórias regulares; finalmente saímos de novo do regime caótico para o periodico por um processo de bifurcaçôes reversas.

Para um estudo mais detalhado da transição entre regimes periódicos e caóticos ampliamos a parte da figura 4.7 correspondente ao primeiro conjunto de bifurcações (fig.4.8). Podemos observar aí alguns detalhes do processo de bifurcação, que é uma das rotas mais comuns para o caos, conforme foi descoberto por Feigenbaum. Na verdade, tudo que precisamos para que este processo ocorra em um mapa unidimensional dissipativo, é que o mapa de retorno deste apresente um único ponto de máximo local, como é o nosso caso. Temos ainda que se o mapa de retorno tiver comportamento quadrático na vizinhança deste ponto de máximo (o que ocorre para o nosso mapa), as bifurcaçôes do sistema são caracteriza- 


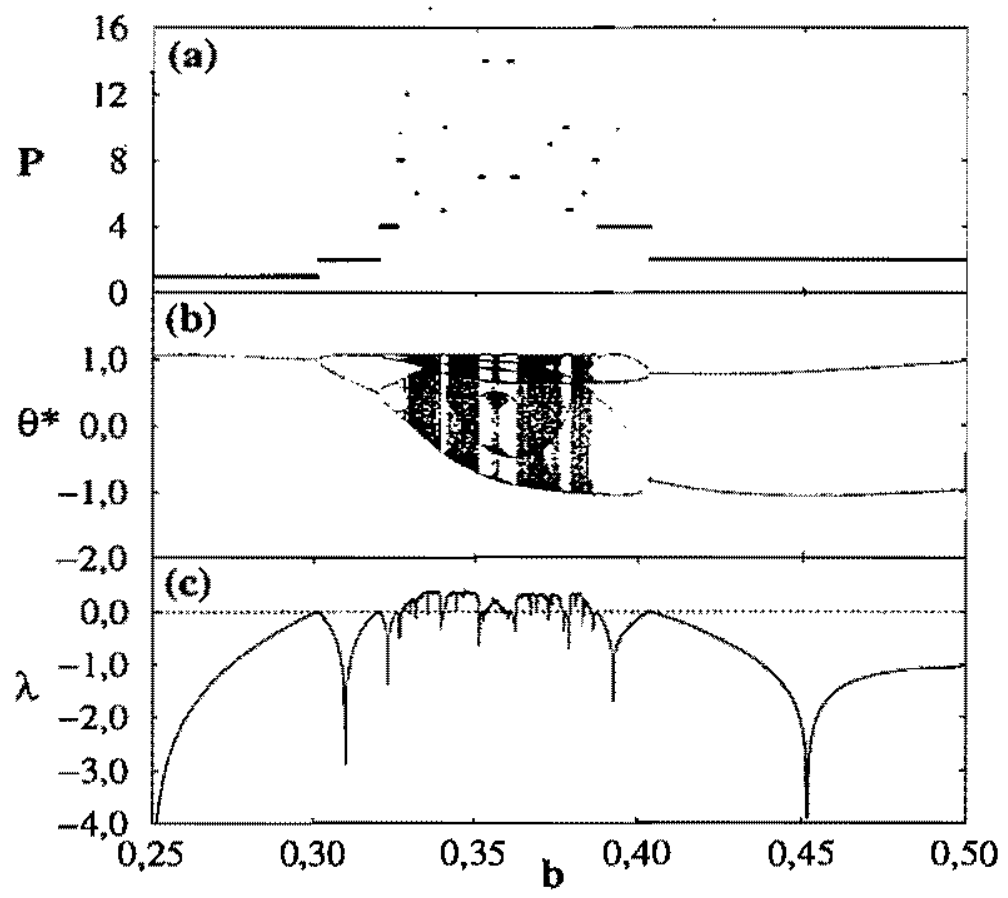

Figura 4.7: (a) Períodos das órbitas periódicas; (b) diagrama de bifurcação; (c) expoentes de Lyapunov para o mapa unidimensional dissipativo 2.22 com $a=0,57$.

das por uma constante universal (para comportamento quártico, por exemplo, existe outra constante). Esta constante é definida como:

$$
\delta \equiv \lim _{k \rightarrow \infty} \delta_{k}=\lim _{k \rightarrow \infty} \frac{\mu_{k}-\mu_{k-1}}{\mu_{k+1}-\mu_{k}}=4.669201 \ldots
$$

onde definimos $\mu_{k}$ como o valor do parâmetro no diagrama de bifurcação no ponto da $k$ ésima bifurcação, e $\delta$ é conhecida na literatura como constante de Feigenbaum. Na tabela 4.1 temos os valores de $b_{k}, b_{k}-b_{k-1}, \mathrm{e} \delta_{k}$ para as primeiras bifurcações do exemplo do gráfico 4.8 , e vemos que estas de fato vão se aproximando da constante universal esperada.

Outra forma de analisar a transição entre os regimes periódico e caótico é calcular uma série de espectros ao longo da transição, como também foi feito no caso da transição quaseperiódico-periódico no item anterior. Calculando os espectros para a bifurcação da figura 4.8 (fig.4.9) observamos que para $b=0,325$ (trajetória periódica de período 4) o espectro é discreto, apresentando apenas o pico correspondente ao período em $f=1 / 4=1 / P$. Aumentando para $b=0,327$ passamos ao regime de período 8 no diagrama de bifurcação e 


\begin{tabular}{|c|c|c|c|}
\hline$k$ & $b_{k}$ & $\Delta_{k} \equiv b_{k}-b_{k-1}$ & $\delta_{k} \equiv \frac{\Delta_{k}}{\Delta_{k+1}}$ \\
\hline 1 & 0,30115 & - & - \\
\hline 2 & 0,32035 & 0,01920 & 3,4470 \\
\hline 3 & 0,32592 & 0,00557 & 4,1880 \\
\hline 4 & 0,32725 & 0,00133 & 4,5392 \\
\hline 5 & 0,327543 & 0,000293 & 4,7258 \\
\hline 6 & 0,327605 & $6,20 \times 10^{-5}$ & - \\
\hline
\end{tabular}

Tabela 4.1: Valores de $b$ para sucessivas bifurcaçöes com $a=0,57$ e a convergência para a constante de Feigenbaum.

no espectro surgem picos discretos menores nas frequências correspondentes $f=(1 / 8 ; 3 / 8)$ (fig.4.9.b). Aumentando mais um pouco o parâmetro $b$ para $b=0,329$ já entramos em uma região caótica no diagrama de bifurcação, mas as regiôes percorridas de forma caótica pela trajetória ainda se encontram divididas em faixas bem definidas que são visitadas de forma periódica. Consequentemente, o espectro (fig.4.9.c) apresenta um fundo contínuo, correspondente ao caos, e alguns picos discretos fortemente acentuados, correspondentes à visitação periódica das faixas.

Passando agora para $b=0,331$, vemos no diagrama de bifurcação que a regiäo caótica está dividida em apenas duas faixas, e portanto o pico de período 4 desaparece do espectro, conforme vemos na figura 4.9.d, se bem que a região em torno de $f=1 / 4$ ainda apresenta um espectro contínuo mais intenso. Entrando ainda mais na região caótica (fig.4.9.e-f) as últimas faixas se juntam e temos espectros contínuos sem picos definidos, onde as regiōes de maior intensidade espectral vão variando ao longo do eixo de frequências, conforme os periodos das janelas periódicas mais próximas.

Assim sendo, vemos que a transição do regime periódico para o caótico se dá por duas etapas: primeiro temos uma série de duplicações de períodos, que ocorrem a intervalos de parâmetro cada vez menores, levando a um número cada vez maior de picos discretos distribuídos ao longo do eixo de frequências do espectro de Fourier. A um certo ponto ocorreram "infinitas" bifurcações e o espectro passa a apresentar fundo contínuo. Este é o ponto exato da fronteira entre regime periódico e caótico e ele pode ser calculado de forma bastante precisa com a ajuda da constante de Feigenbaum. Mas neste ponto o caos está ainda confinado em infinitas faixas de largura infinitesimal e portanto os picos discretos ainda dominam o espectro. À medida que entramos na região caótica estas faixas se fundem 


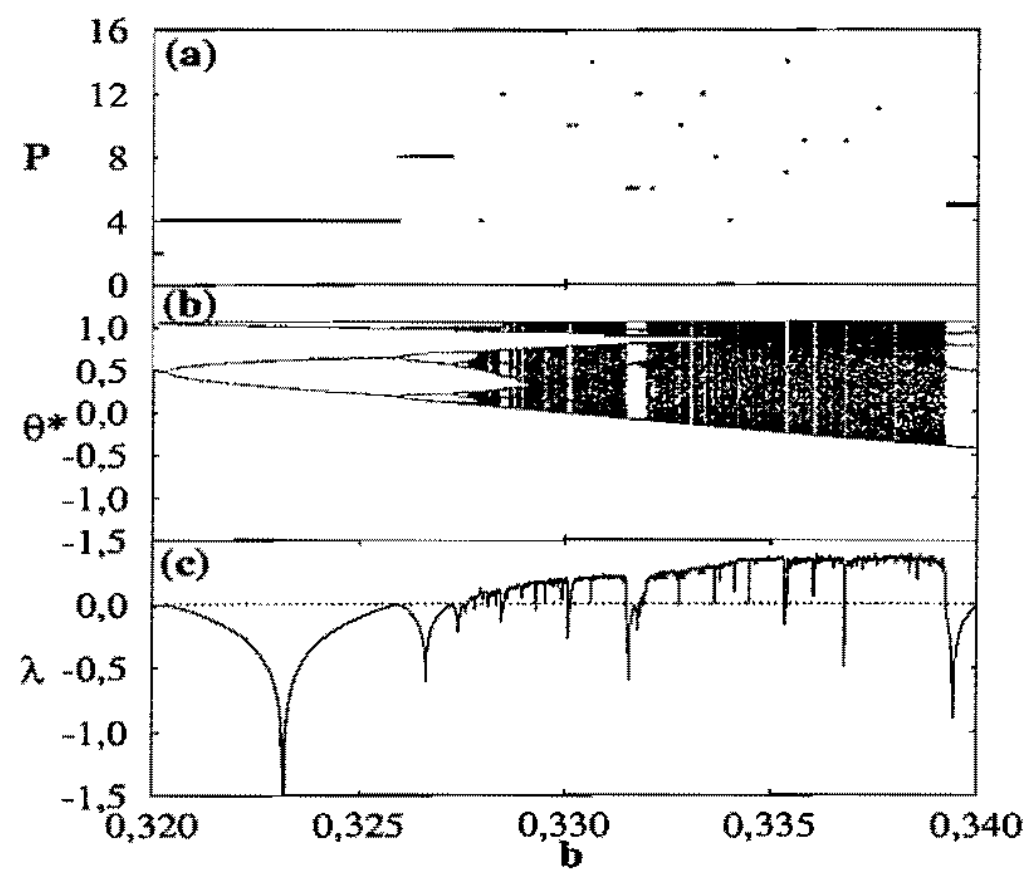

Figura 4.8: Ampliação dos gráficos da figura 4.7.

duas a duas num processo denominado de "crises" na literatura (os pontos de fusão de faixas são os pontos de "crise"). Assim temos cada vez menos faixas caóticas cada vez mais largas e os picos discretos acentuados no espectro vão diminuindo em número e intensidade. Finalmente, após a última crise temos uma larga banda caótica e o espectro é totalmente contínuo, sem picos discretos predominantes.

Fazendo o diagrama de bifurcação no espaço de frequências correspondente a esta transição (fig.4.10), podemos observar de forma mais detalhada o surgimento e desaparecimento dos picos discretos durante as bifurcaçôes e crises, e também o surgimento e crescimento do fundo contínuo à medida que entramos na região caótica. Podemos também observar os picos espectrais correspondentes às duas janelas maiores de regimes periódicos dentro da região caótica: uma de período $6 \mathrm{em}$ torno de $b=0,332$, e uma de período $5 \mathrm{em}$ torno de $b=0,340$. Vemos também que à medida em que aumentamos $b$ a transição do caos para estes regimes periódicos se dá de forma abrupta, e não através de um processo de bifurcações reversas.

Para entendermos a diferença entre estas duas formas de passagem do regime caótico ao periódico (ou vice-versa) vamos analisar o mapa de retorno do sistema em torno da região 


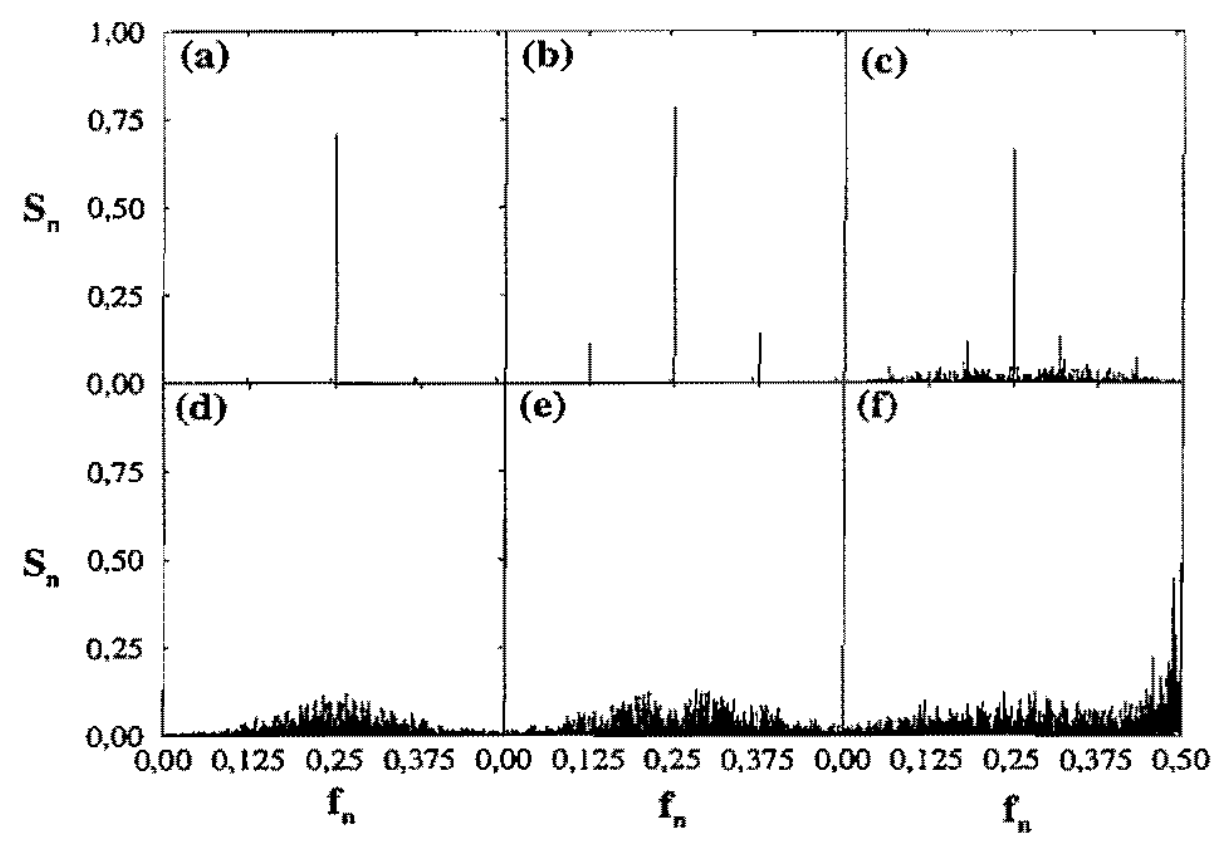

Figura 4.9: Espectros de Fourier para trajetórias com parâmetros fixos $a=0,57$ e (a) $\mathrm{b}=0,325$; (b) $b=0,327$; (c) $b=0,329$; (d) $b=0,331$; (e) $b=0,333$; (f) $b=0,335$.

em que passamos do regime cátítico ao régime periódico de período 5 . Analisando os mapas de retorno de $f^{5}(\theta)$ para vários valores de $b$ em torno da transição caos-período 5 (fig. 4.11) vemos que a curva $\theta_{n+5} \times \theta_{n}$ não cruza a linha $\theta_{n+5}=\theta_{n}$ dentro da regiāo de regime caótico, mas vai se aproximando desta à medida em que aumentamos $b$. A partir do momento em que ocorre o cruzamento surgem duas órbitas periódicas de período 5 a estável e a instável. Aumentando mais ainda o parâmetro $b$ estas duas órbitas se afastam e começa o processo de transição para o regime caótico na outra borda da janela através do processo já analisado de sucessivas duplicaçōes de período.

Vimos portanto, neste item, que as transiçōes de regime periódico-caos são caracterizadas por crescimento e decrescimento de picos espectrais de frequências fixas, ao contrário do processo de deslocamento e sincronização de frequências que caracteriza a transição entre os regimes periódicos e quase-periódicos. 


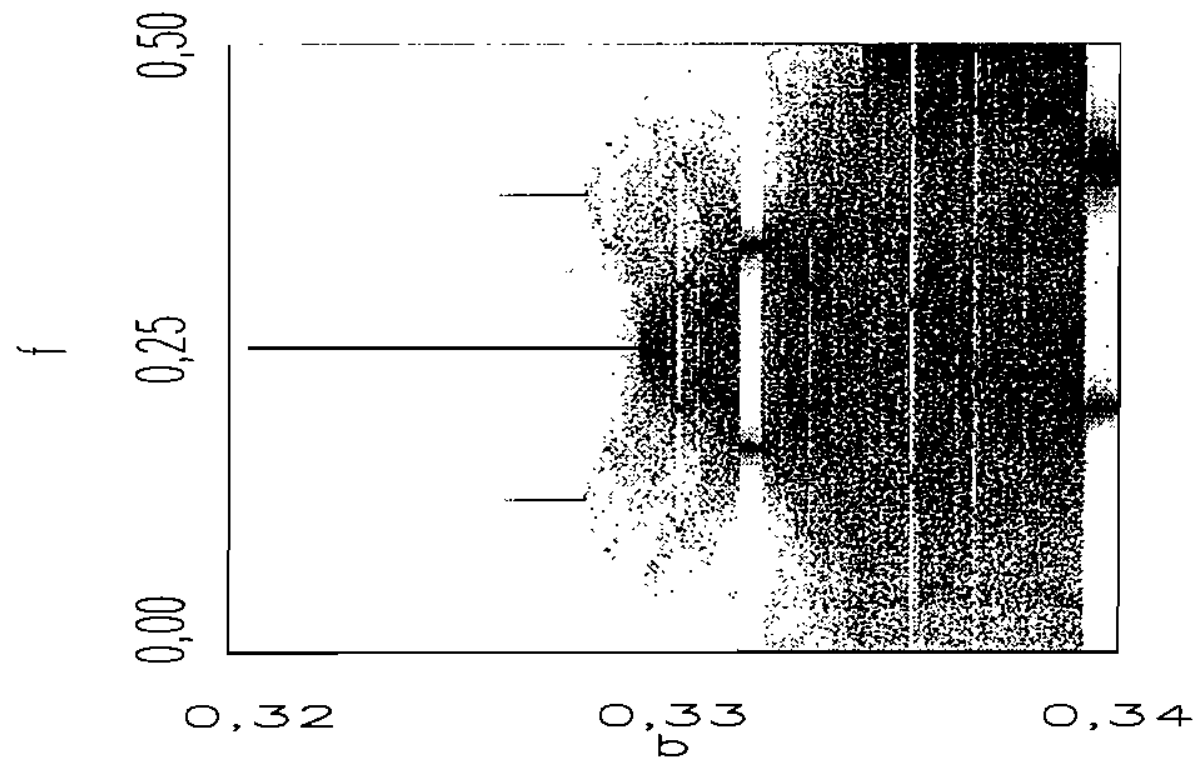

Figura 4.10: Diagrama de bifurcação no espaço de frequências do mapa unidimensional dissipativo para $a=0,57$.

\subsection{A transição entre regimes periódicos de períodos incomensuráveis}

Neste item passamos a analisar o último tipo de transição possível no plano de parâmetros: a transição entre dois regimes periódicos de períodos incomensuráveis, ou seja períodos $P$ e $Q$ tais que $P \neq n Q$, onde $n$ é um número natural. Esta restrição é imposta para eliminarmos o caso do fenômeno da duplicação de períodos já analisada no item anterior.

De fato, a região do plano de parâmetros onde temos regiões vizinhas de períodos incomensuráveis é bastante restrita, ocorrendo apenas em uma estreita faixa acima do eixo $a=1 / 2$. Nesta região as faixas periódicas de períodos incomensuráveis se "cruzam" como pode ser visto na figura 4.12. É importante observarmos que esta é a única região do plano de parâmetros onde o atrator final para o qual a trajetória se dirige depende da posição inicial do sistema, devido à existência de mais de um atrator estável para os mesmos valores de parâmetros. Comparando as figuras 4.12.a e 4.12.b, que diferem apenas no valor do ângulo inicial do sistema, vemos que no segundo caso é muito maior o número de trajetórias que se 

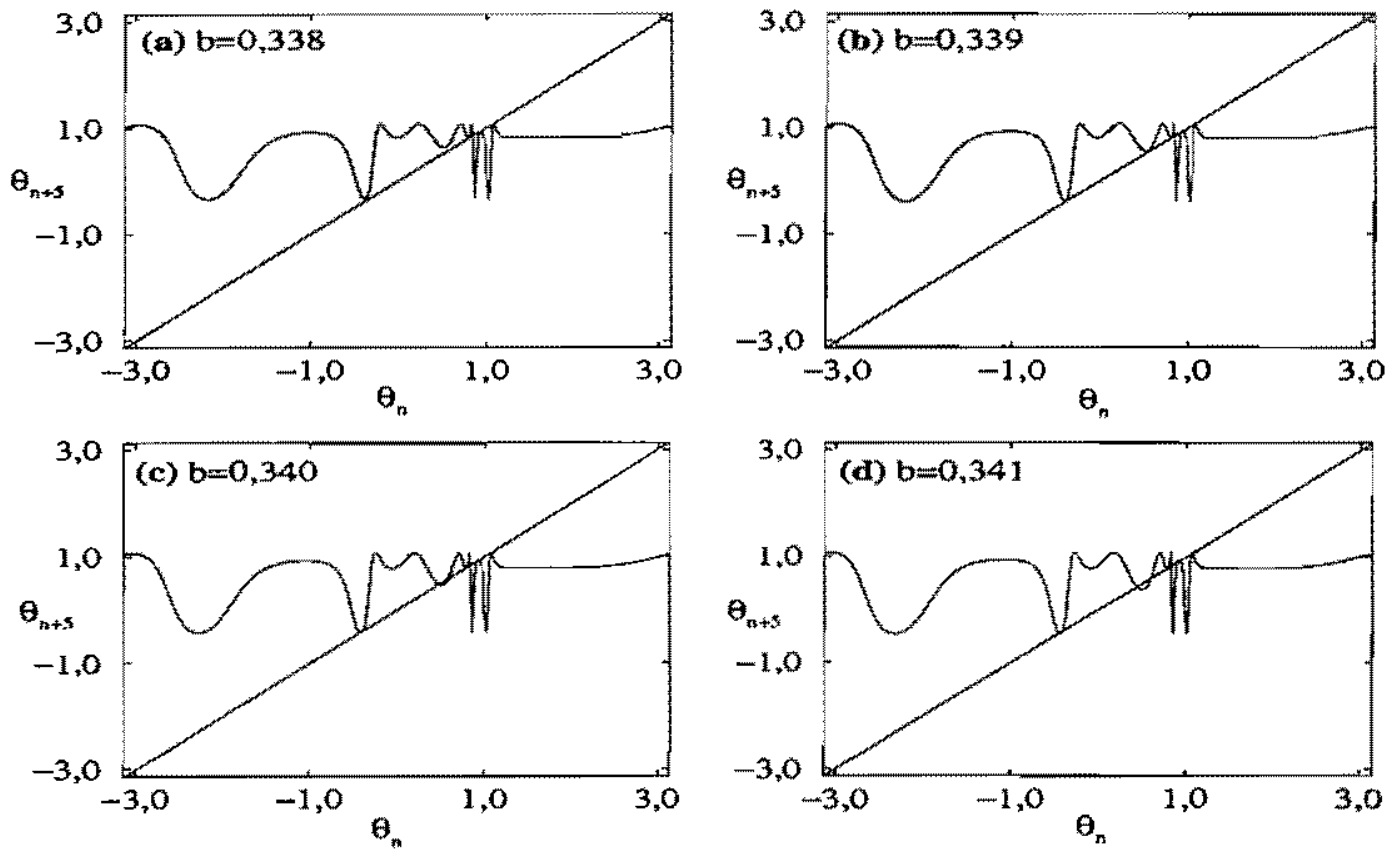

Figura 4.11: Mapas de retorno do mapa unidimensional dissipativo para $a=0,57$

dirige aos atratores periódicos de período $P=3 \times 2^{n}$.

Para analisarmos a transição do sistema entre os regimes periódicos de períodos incomensuráveis fazemos novamente um corte no plano de parâmetros, fixando a intensidade da perturbação em $a=0,520$ e variando o periodo no intervalo $0,397<b<0,398$. Passamos então a calcular os expoentes de Lyapunov, os números de rotação, e o diagrama de bifurcação ao longo deste segmento de reta no plano de parâmetros (fig.4.13). O que obternos então na região de superposição das línguas periódicas é uma alternância fractal entre os dois regimes: o periódico de período 3 e a bifurcaçäo $2-4-8-16-\ldots$ que leva ao caos, observado para os valores de $b$ mais elevados. Vemos que existem tanto regiōes onde um só regime predomina em uma larga faixa do parâmetro $b$ (para um ângulo inicial $\theta_{0}$ constante), como regiōes de grande alternância entre os regimes. O que acontece é que em toda esta região os dois atratores periódicos estão sempre presentes, mas as suas bacias de atração, de carăter fractal vão se deslocando à medida que variamos o parâmetro $b$. Na figura 4.14 podemos observar um exemplo típico de uma destas bacias de atração para um valor fixo do parâmetro $b$, em função do ângulo inicial.

Para comprovarmos o caráter fractal da fronteira entre os dois regimes periódicos em função do ângulo inicial calculamos a dimensão fractal desta através do algoritmo de con- 

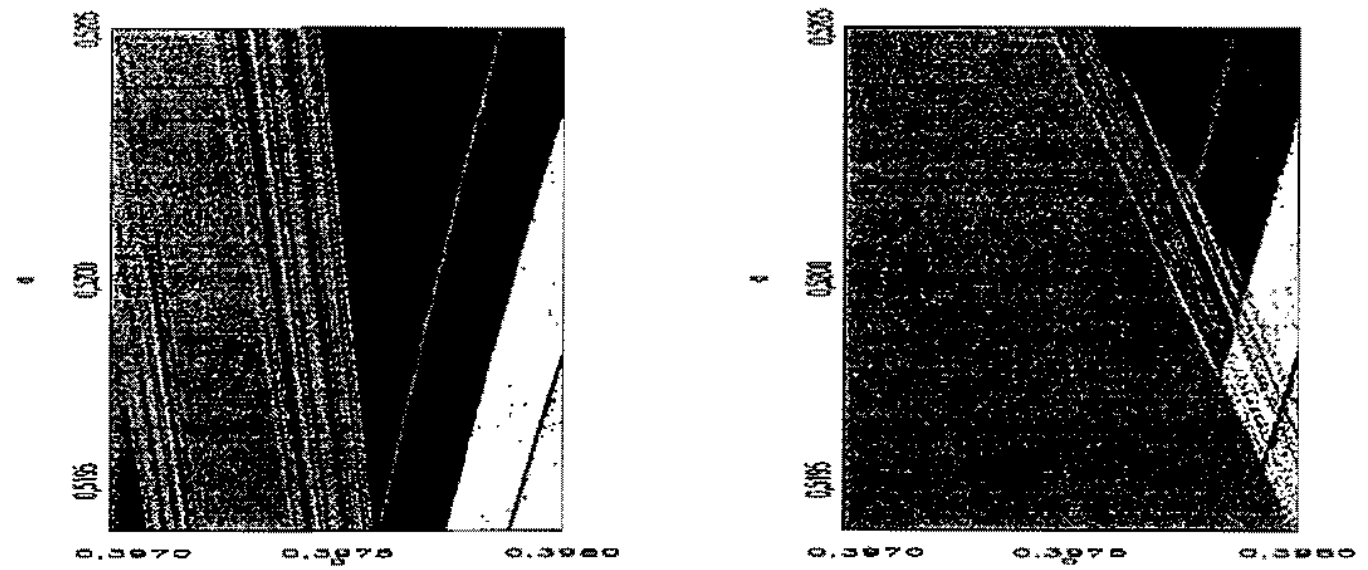

Figura 4.12: Diagramas isoperiódicos do mapa unidimensional com (a) $\theta_{0}=0,0$ e (b) $\theta_{0}=3,0$. Pontos brancos correspondem a regimes não-periódicos, e pontos cinzas e pretos a regimes periódicos. Quanto maior o período destes, mais escuro o ponto.

tagem de caixas ("box counting dimension")[33,30]. Esta dimensão é calculada utilizando o seguinte algoritmo: nós cobrimos o espaço dentro do qual a nossa curva está contida (no nosso caso o segmento de reta dos ângulos iniciais entre 0 e $2 \pi$ ) com $N$ cubos $K$-dimensionais de aresta $\epsilon$ (no nosso caso segmentos de reta de comprimento $\epsilon$ ) e contamos o número de cubos $R$ que contêm um pedaço da curva a ser analisada (no caso, os segmentos de reta onde ocorre mudança de atrator). A dimensão fractal é então definida como sendo:

$$
D_{0} \equiv \lim _{\epsilon \rightarrow 0} \frac{\ln R(\epsilon)}{\ln N(\epsilon)}
$$

Fazendo o cálculo desta dimensão fractal para os valores de parâmetros correspondentes à figura 4.14 e para vários valores de $N(\epsilon)$ (fig.4.15) observamos que a convergência é rápida e o valor obtido $\left(D_{0} \approx 0,73\right)$ aponta indubitavelmente o caráter fractal da fronteira entre as bacias de atração periódicas, no caso de períodos 3 e 8 .

Para completarmos o estudo da fronteira entre as bacias de atração de atratores coexistentes fizemos ainda um gráfico da evolução da bacia de atração do atrator de período 3 à medida em que o parâmetro $b$ é variado (fig.4.16). Vemos que apesar da intrincada natureza complexa desta a parâmetros fixos ela apresenta deslocamentos contínuos e suaves à medida que o parâmetro de controle é variado. Ou seja, se considerarmos um ângulo inicial fixo e investigarmos o atrator ao qual o sistema se dirige, após o transitório, para uma pequena faixa de variação de um parâmetro, podemos obter que para uma grande faixa ele se dirige 


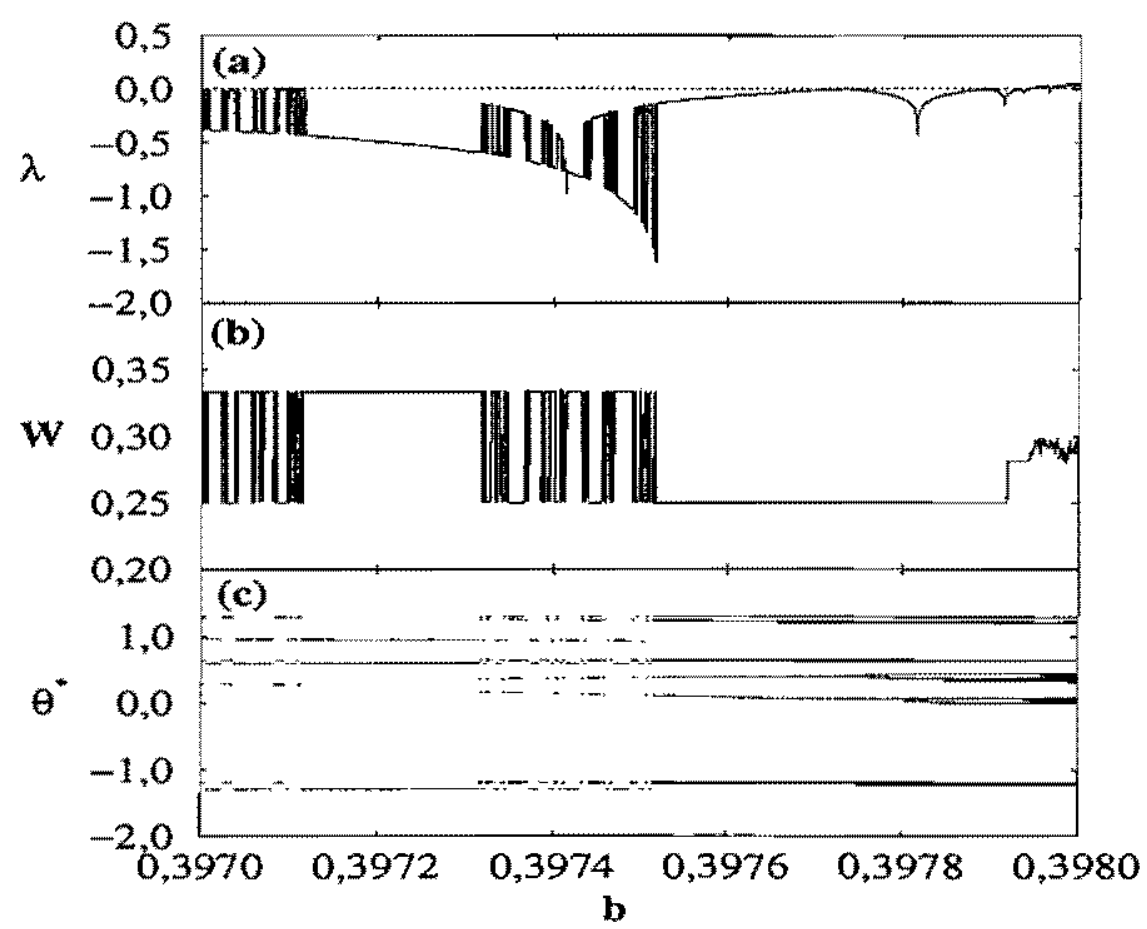

Figura 4.13: (a) Expoentes de Lyapunov; (b) números de rotação; (c) diagrama de bifurcação para $a=0,520$.

ao mesmo atrator (como observamos para uma grande região $\operatorname{com} \theta_{0}=3,0$ na figura $4.12 . b$, onde predomina o atrator de periodo 3 ), ou podemos observar um comportamento acentuadamente fractal (como para $\theta_{0}=0,0$ na figura $4.12 \mathrm{a}$ ), dependendo de estarmos numa faixa mais ou menos fractal das bacias de atração em função de $\theta_{0}$.

Foi visto então neste item que a transição entre regimes periódicos de períodos nãocomensuráveis ocorre apenas em uma região muito pequena do plano de parâmetros, que é caracterizada pela existência de mais de uma atrator periódico estável para cada conjunto fixo de parâmetros. As transiçōes ocorrem então de forma abrupta e podem apresentar uma estrutura fractal no plano de parâmetros, que é induzida pela distribuição fractal das bacias de atração no espaço das condiçōes iniciais.

\subsection{A região em torno de $a=1 / 2$}

Analisamos até aqui três típos possíveis de transiçōes no plano dos parâmetros: a transição regime periódico-caos, a transição regime periódico-quase-periódico, e a transição en- 


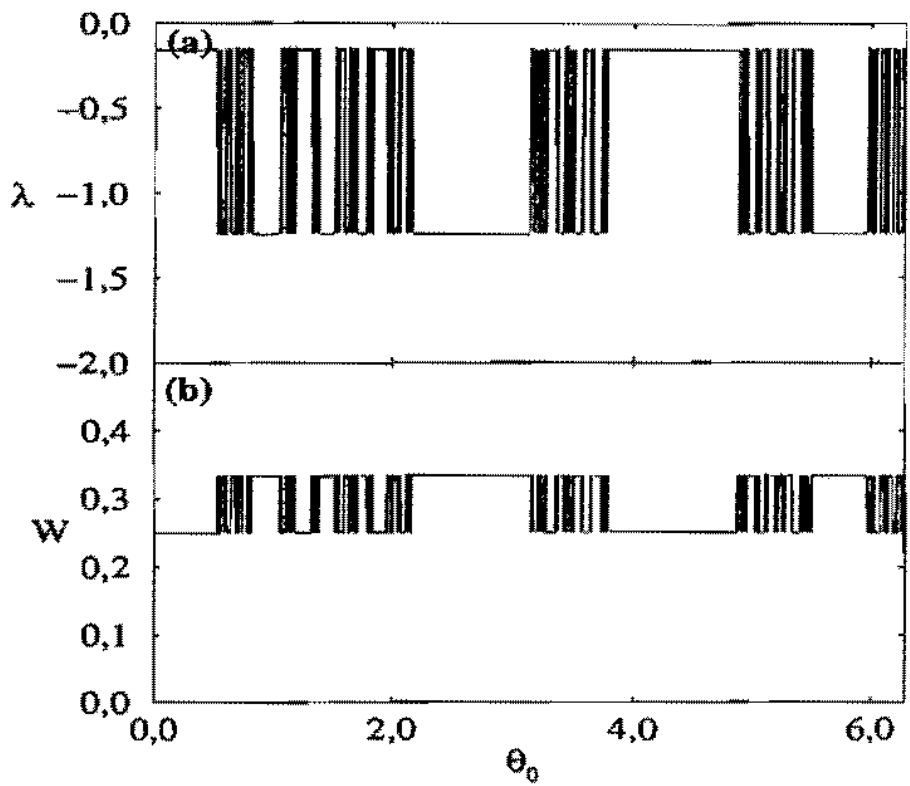

Figura 4.14: (a) Expoentes de Lyapunov e (b) Números de rotação em função do ângulo inicial $\theta_{0}$ para $a=0,520$ e $b=0,3975$.

tre regimes periódicos de períodos não comensuráveis. Falta então apenas nos perguntarmos: será que existe no mapa unidimensional analisado uma transição entre regimes quaseperiódicos e caóticos, sem a passagem por regimes periódicos intermediários no plano dos parâmetros? Como o comportamento quase-periódico é observado apenas para $a<1 / 2$ e o regime caótico apenas para $a>1 / 2$, o único lugar possivel de observarmos uma transição destas seria sobre o eixo $a=1 / 2$ que, de qualquer forma, é uma das regiōes mais interessantes do sistema, pois é sobre ele que o mapa passa de inversível para não inversível. Passamos então, neste item, a analisar a regiāo do plano de parâmetros em torno de $a=1 / 2$.

Calculando diagramas isoperiódicos cada vez mais ampliados em torno do eixo $a=1 / 2$, e mais especificamente em torno dos parâmetros $b$ para os quais ocorrem trajetórias caóticas ou quase-periódicas nesta regiäo (fig. 4.17), observamos trajetórias caóticas para valores de $a=1 / 2+\epsilon(\epsilon>0)$ com $\epsilon$ tão pequeno quanto quisermos. O mesmo ocorre para trajetórias quase-periódicas abaixo do eixo $a=1 / 2$. Mais ainda, as regiōes quase-periódicas entre as línguas de Arnold vão estreitando à medida em que nos aproximamos de $a=1 / 2 \mathrm{e}$ acabam "convergindo" para alguns valores discretos de $b$, que são precisamente aqueles onde "nascem" as regiōes caóticas assim que cruzamos o eixo $a=1 / 2$.

Para melhor investigarmos o que acontece neste eixo, calculamos diagramas de bifur- 


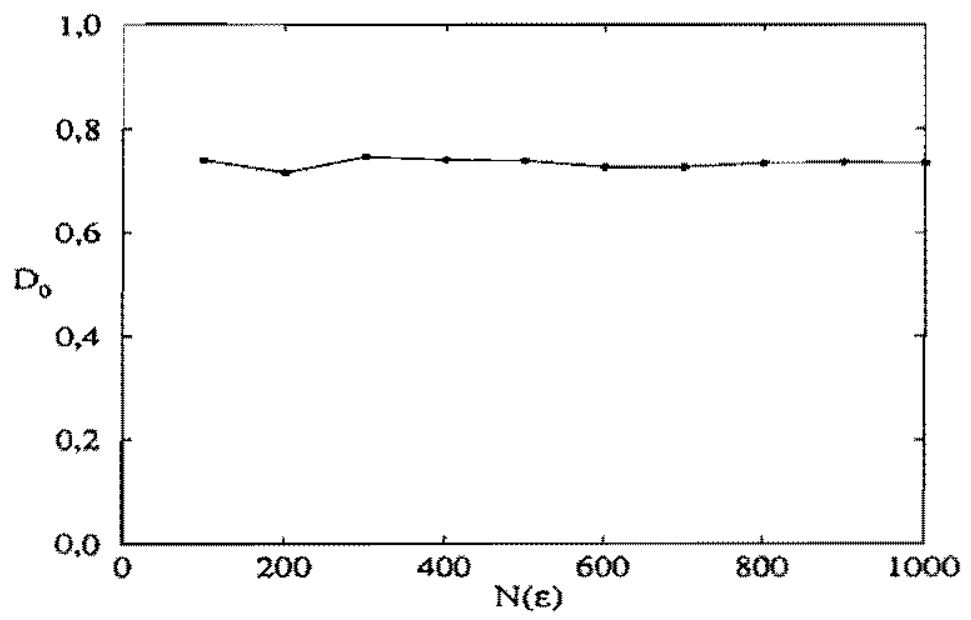

Figura 4.15: Convergência da dimensão fractal $D_{0}$ da fronteira entre as bacias de atração para $a=0,520$ e $b=0,3975$

cação logo abaixo, sobre, e logo acima do eixo $a=1 / 2$, para uma pequena faixa de valores de $b$ (fig.4.18), e observamos que apesar de ainda termos regióes bastante significativas de comportamento quase-periódico logo abaixo do eixo e de comportamento caótico logo em cima do eixo, sobre o eixo o sistema é completamente periódico (no intervalo observado, de período 8 ).

De fato o período das trajetórias periódicas não é constante ao longo de todo o eixo $a=1 / 2$ e as transiçôes ocorrem de forma abrupta justamente nos pontos onde se "acumulam" as regiōes quase-periódicas logo abaixo de $a=1 / 2$. Os pontos onde ocorrem estas transiçöes podem ser obtidos numericamente com uma precisão arbitrária, mas não dispomos de indicações sobre uma forma de determiná-los de forma analítica. Assim sendo, não é possivel calcular as trajetórias exatamente sobre estes pontos. De qualquer forma, como temos pontos dos mais diversos períodos arbitrariamente próximos, o que supomos é que à medida em que nos aproximamos do ponto um dos ângulos se aproxima cada vez mais de

$$
\theta_{c r}=2 \pi(1-b)+\arccos (-2 a)
$$

que é o ângulo crítico para o qual o denominador de 2.22 se anula e portanto o atrator é destruido apenas naquele exato ponto do plano de parâmetros, o que nos parece uma explicaçäo plausível para o tipo de mudança abrupta observada.

De qualquer forma, observamos que não existe em nenhum ponto do plano de parâmetros 


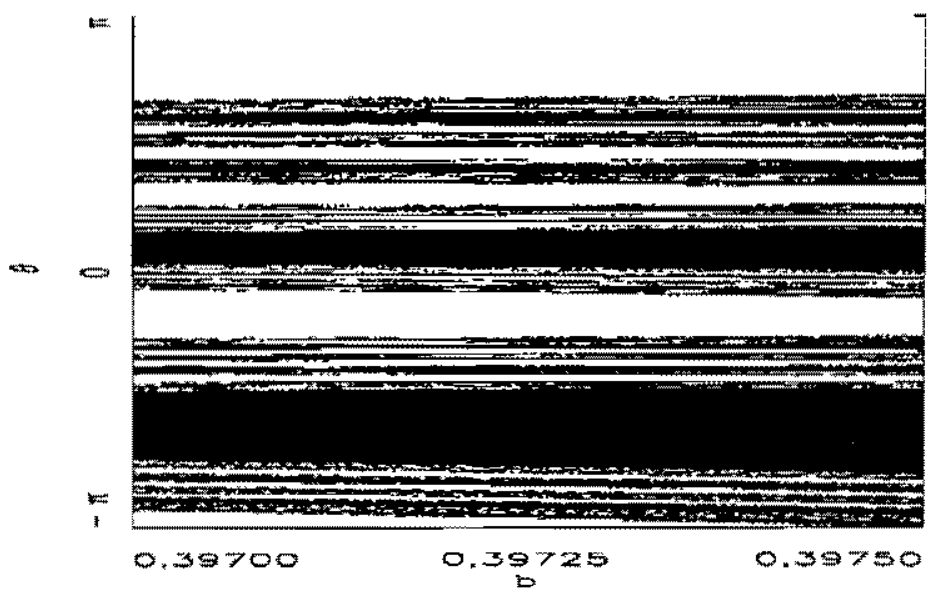

Figura 4.16: Bacia de atraçāo do atrator periódico de período 3 (marcado por pontos pretos) em função do parâmetro $b$ para $a=0,52$.

uma transição do tipo quase-periódico-caótico, apesar da estrutura complexa da distribuiçāo de tipos de trajetórias nas proximidades do eixo $a=1 / 2$.

\subsection{Resumo das principais características das transições entre diferentes regimes dinâmicos}

Neste capítulo analisamos as diversas transições observadas entre os diversos tipos de trajetórias (periódicas, quase-periódicas, e caóticas) no plano de parâmetros $a \times b$ do mapa unidimensional dissipativo 2.22. Vimos que existem três tipos possíveis de transição: entre regimes periódicos e quase-periódicos, entre regimes periódicos e caóticos, e entre regimes periódicos de períodos não-comensuráveis.

As transições entre regimes periódicos e quase-periódicos ocorrem na região de baixas intensidades de perturbação $(a<1 / 2)$ do plano de parâmetros onde observamos as línguas de Arnold, estrutura característica de mapas do círculo, que são um limite do nosso mapa para $a \rightarrow 0$. Vimos que, no espaço das frequências, esta transiçăo é caracterizada por um deslocamento dos principais picos espectrais e as línguas de Arnold (correspondentes às diversas regiôes de regimes periódicos) ocorrem quando estes picos chegam nas frequências racionais correspondentes ao período da língua. Observamos ainda que os números de rotação 


\subsection{Resumo das principais características das transições entre diferentes regimes}

dinâmicos
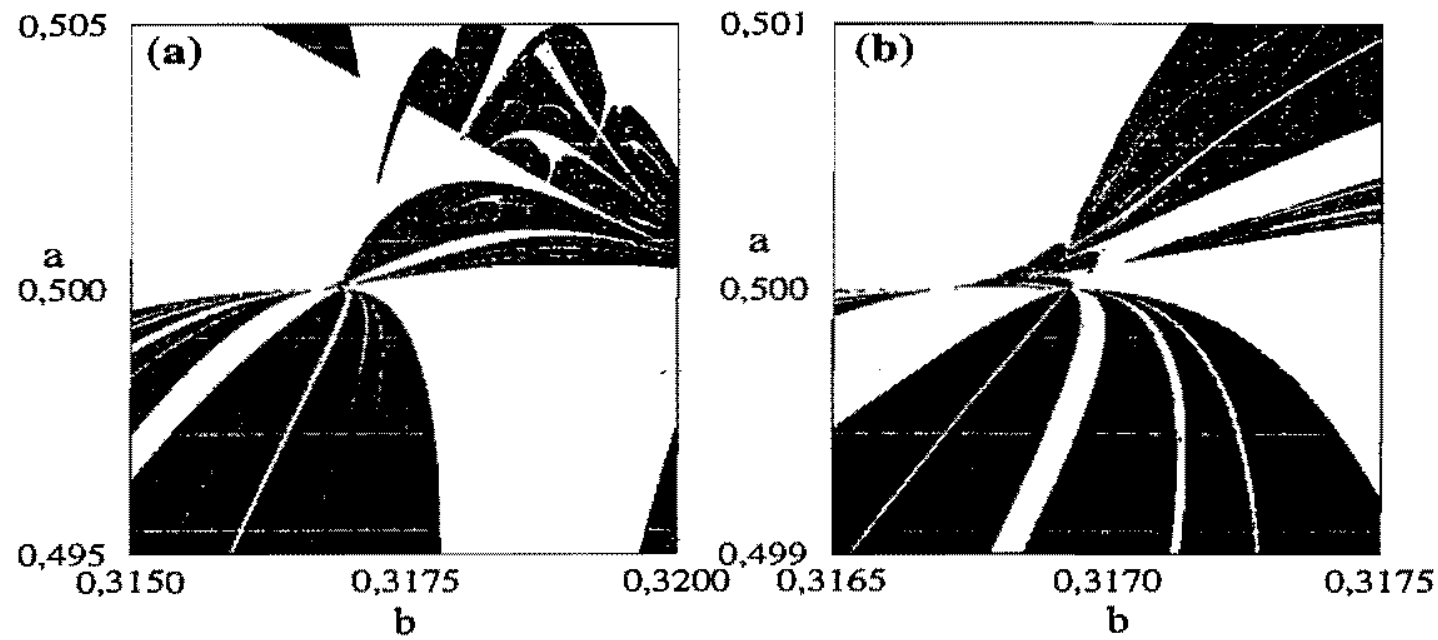

Figura 4.17: Detalhes do diagrama isoperiódico do mapa $2.22 \operatorname{com} \theta_{0}=0$ - pontos brancos correspondem a órbitas periódicas e pontos pretos correspondem a órbitas quase-periódicas $(a<1 / 2)$ ou órbitas caóticas $(a>1 / 2)$.

formam uma estrutura conhecida como "escada do diabo" ao longo dos segmentos de reta que cruzam as línguas de Arnold, e os expoentes de Lyapunov sobre as línguas ficam cada vez mais negativos quanto mais longe estiver a região quase-periódica mais próxima.

Já as transiçōes entre regimes periódicos e caóticos ocorrem na região do plano de parâmetros correspondente a altas intensidades de perturbação ( $a>1 / 2)$. Este tipo de transição se dá pela rota de Feigenbaum (duplicação sucessiva de períodos) comum a um grande número de sistemas näo-lineares. Vimos que a estrutura das bifurcações sucessivas é de fato regida pela constante universal de Feigenbaum, o que já era esperado, uma vez que os mapas de retorno do mapa apresentam pontos de máximo quadráticos. No espaço de frequências temos que durante este tipo de transição os picos principais não se deslocam mas surge um número cada vez maior de picos discretos à medida que ocorrem as duplicações de período, e depois estes picos decrescem até se confundirem com o fundo contínuo à medida que ocorrem as crises na borda da regiāo de regime caótico. Vỉmos também que em alguns 


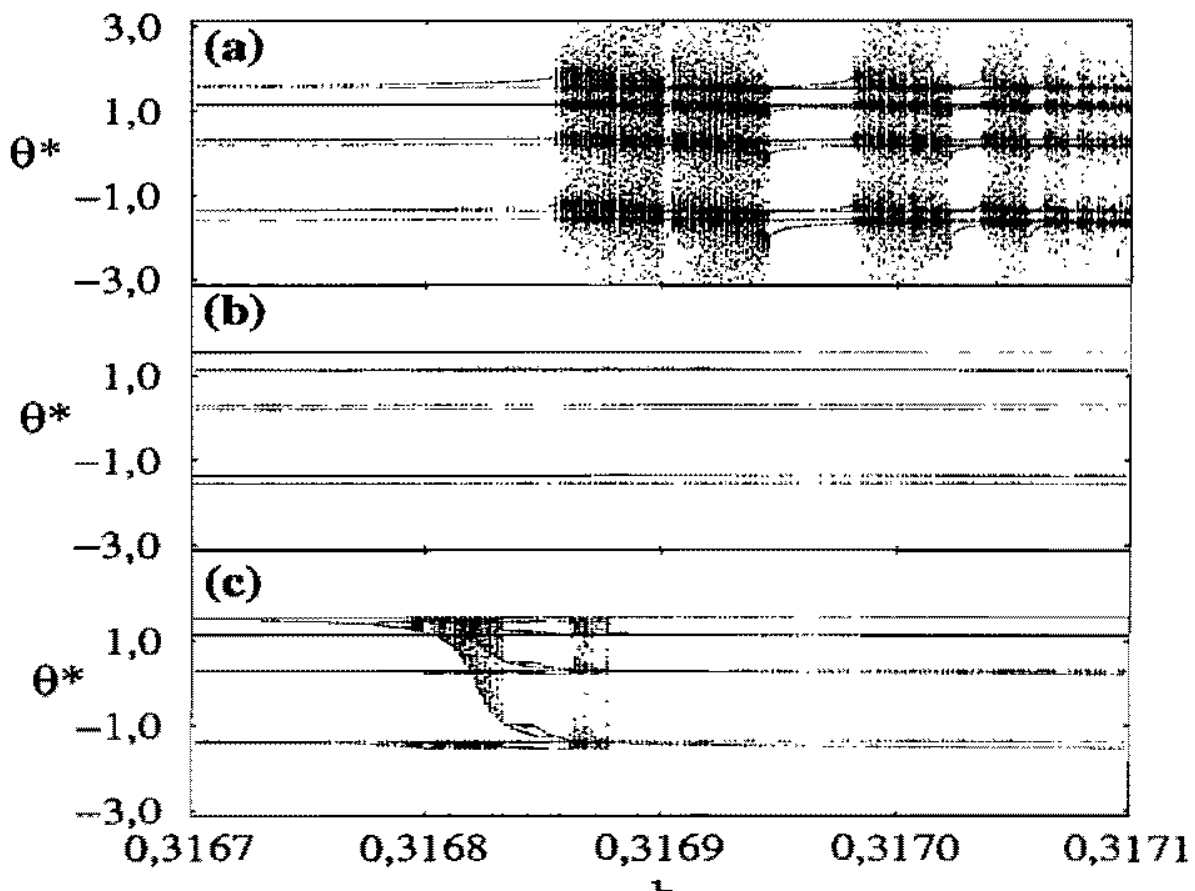

b

Figura 4.18: Diagramas de bifurcação do mapa $2.22 \operatorname{com} \theta_{0}=0$ e (a) $a=0,49995$, (b) $a=0,50000$, e (c) $a=0,50005$.

casos a transiçāo entre regimes periódicos e caóticos ocorre de forma abrupta na borda das janelas periódicas, sem passar pelo processo acima.

O último tipo de transição observado é a transição entre regimes periódicos de períodos incomensuráveis, que ocorre em uma pequena região do plano de parâmetros imediatamente acima do eixo $a=1 / 2$. Esta região é a única do espaço de parâmetros onde coexistem vários atratores periódicos estáveis de período diverso para um mesmo conjunto de parämetros fixos, sendo que o atrator a ser percorrido pela trajetória depende do ângulo inicial. Vimos que este tipo de transiçäo ocorre de forma abrupta e apresenta uma estrutura fractal no plano de parâmetros, que provém da estrutura fractal das bacias de atração que são deslocadas de forma contínua à medida que variamos os parâmetros. 


\section{Capítulo 5}

\section{Trajetórias Periódicas Instáveis e Parâmetros Variando no Tempo}

$\mathrm{Na}$ análise das trajetórias do mapa unidimensional dissipativo feita nos capítulos anteriores levamos em conta apenas as trajetórias estáveis, ou seja, aquelas trajetórias para as quais o sistema se dirige naturalmente, após o transitório, para um certo conjunto de parâmetros fixos $(a, b)$. Mas em muitos casos coexistem, para o mesmo conjunto de parâmetros, trajetórias periódicas instáveis, que são muito relevantes para uma análise mais completa do sistema $[35,20]$. Neste capítulo introduzimos um método para determiná-las e depoís passamos a estudar a influência destas sobre a dinâmica do sistema.

Na segunda parte do capítulo passamos a usar as mesmas ferramentas já utilizadas para estudar as trajetórias do sistema a parâmetros fixos, para analisarmos o que acontece quando estes parâmetros são variados ao longo de uma mesma trajetória. Estudamos basicamente três casos de interesse: parâmetros modulados de forma senoidal no tempo, parâmetros alternando entre dois valores de forma regular no tempo, e parâmetros com pequenas variações aleatórias no tempo. Este último caso é de grande importância em sistemas experimentais, onde muitas vezes temos um ruído nos parâmetros de controle.

\subsection{Trajetórias periódicas instáveis e sua determinação}

Definimos como trajetória periódica de período $P$ de um mapa unidimensional $x_{n+1}=$ $f\left(x_{n}\right)$ a trajetória que, após o regime transitório, obedece a relaçẫo $x_{n+P}=x_{n}$ para todo $n$ inteiro. De forma intuitiva, dizemos que a trajetória é estável se o sistema tende a voltar 
para ela após sofrer pequenas perturbações e que ela é instável se o sistema tende a se afastar dela sob a influência das mesmas perturbaçōes. Uma maneira mais rigorosa de definirmos a trajetória periódica de período $P$ como estável é dizer que ela tem que obedecer a relação:

$$
\left\|\frac{d x_{n+P}}{d x_{n}}\right\|<1
$$

Acontece porém que ao realizarmos simulações numéricas para obtermos trajetórias de um mapa unidimensional, jamais obtemos as órbitas periódicas instáveis, por duas razões. Em primeiro lugar, o conjunto das posiçōes $x_{n}$ (ou, no nosso caso, ângulos $\theta_{n}$ ) que se localiza sobre uma trajetória periódica instảvel tem medida nula, ou seja, a probabilidade de começarmos exatamente sobre uma trajetória periódica instável (condição necessária para seguir sobre ela) é nula. Em segundo lugar, mesmo se, por um remoto acaso, escolhessemos uma destas posiçōes como sendo a inicial, a trajetória logo seria afastada da trajetória periódíca instável devido aos erros de arredondamento numérico cometidos na iteração do sistema, e que atuam como as pequenas perturbaçōes para desviar a trajetória.

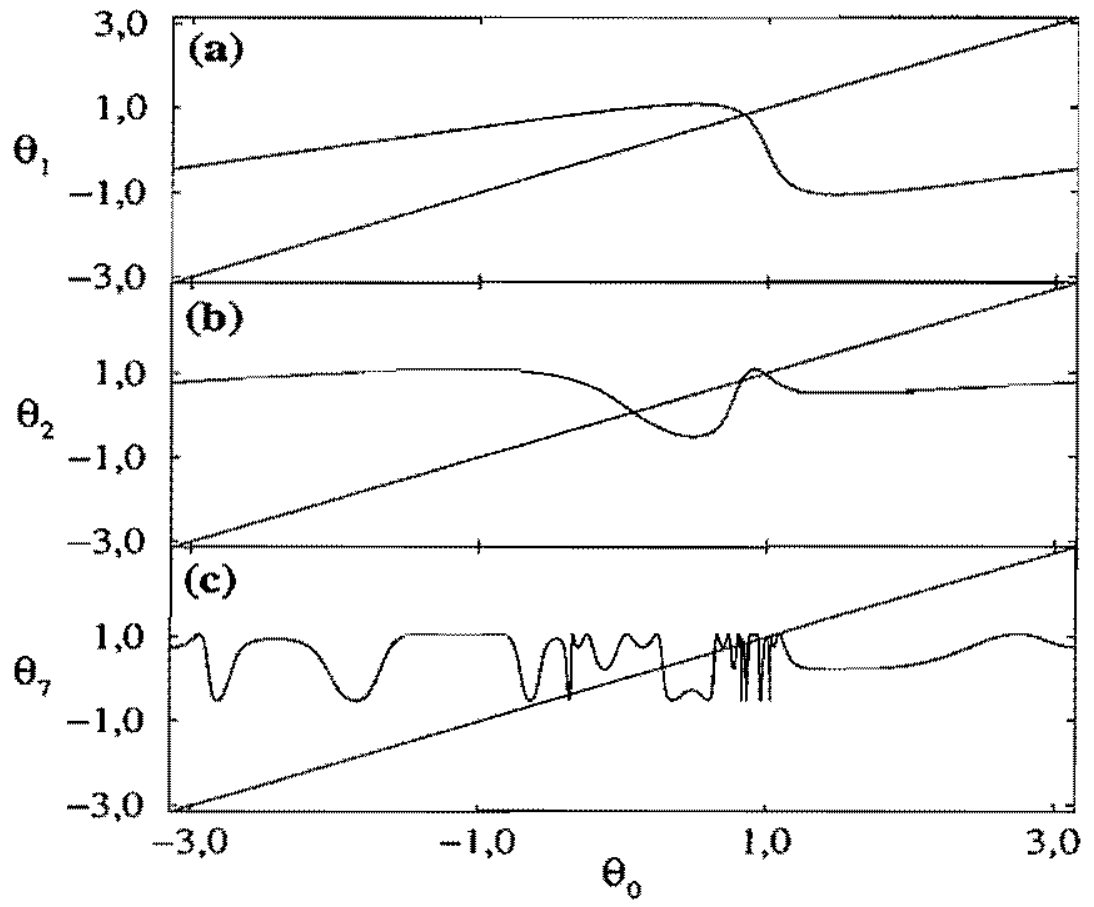

Figura 5.1: Curvas de iteração do mapa unidimensional dissipativo 2.22 para $a=0,570$, $b=0,343$ e (a) 1 iteração; (b) 2 iteraçöes; (c) 7 iterações. 
Mesmo assim, estas trajetórias, que a princípio parecem "invisíveis" aos nossos olhos de simulador numérico, são de fundamental importância em muitos casos, como o controle de caos por pequenas perturbaçōes [28], a sincronização de circuitos caóticos, o cálculo do limite semiclássico para sistemas quânticos com potenciais não-lineares, e a análise da bifurcação para bacias de atraçāo "embaralhadas" (riddled basins of attraction) [20]. De fato, uma trajetória caótica pode ser vista como uma trajetória oscilando entre as bacias de atração de infinitas órbitas periódicas instáveis, conforme observaremos mais adiante.

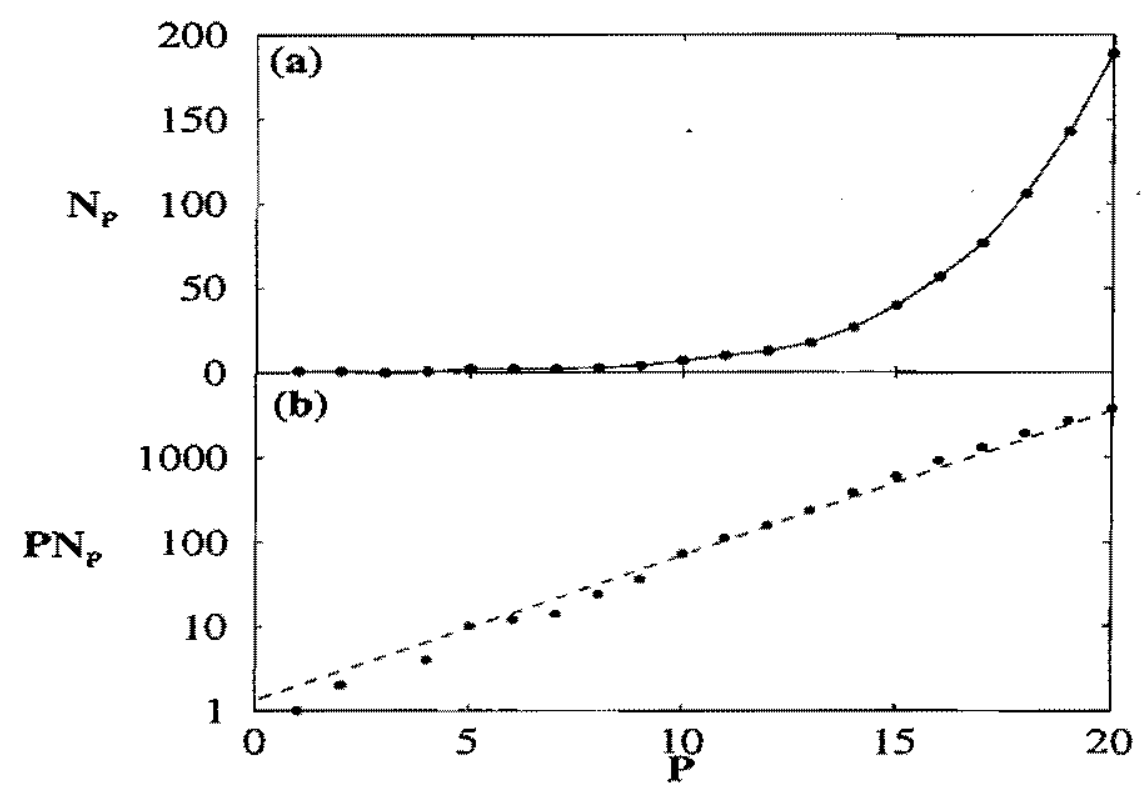

Figura 5.2: (a) Número de órbitas periódicas instáveis $\left(N_{P}\right)$ em funçāo do período e (b) $P N_{p}$ em função do período para $a=0,570$ e $b=0,343$.

Observando algumas curvas de iteração ${ }^{1}$ para o nosso mapa unidimensional dissipativo (fig. 5.1), vemos que estas tornam-se mais complexas à medida que aumentamos o número de iterações, mas jamais deixam de ser contínuas. Acontece porém que, se existír uma trajetória periódica instável de período $P$, então a $P$-ésima curva de iteração tem que cortar a reta $\theta_{P}=\theta_{0}$, por definição, e portanto o problema de determinar todos os ângulos pertencentes a trajetórias periódicas instáveis de periodo $P$ se reduz a determinarmos os zeros de uma

\footnotetext{
${ }^{1}$ Definimos como $n$-ésima curva de iteração a curva que nos dá o ângulo obtido após $n$ iterações do mapa em função do àngulo inicial em $[0,2 \pi)$.
} 
função contínua e limitada, $g(\theta)=f^{P}(\theta)-\theta$, o que pode ser feito utilizando métodos numéricos, como o da biseç̧ão ou o método de Newton.

Para fazermos uma contagem do número de órbitas periódicas instáveis de período $P$ para um conjunto fixo de parâmetros $(a, b)$ basta então contarmos o número de zeros da função descrita acima, subtrairmos o número de zeros das funçōes dos períodos sub-múltiplos (pois as trajetórias de período 1,2, e 3, também são de período 6, por exemplo, mas não estamos interessados em contá-las novamente), e dividir o resultado por $P$.

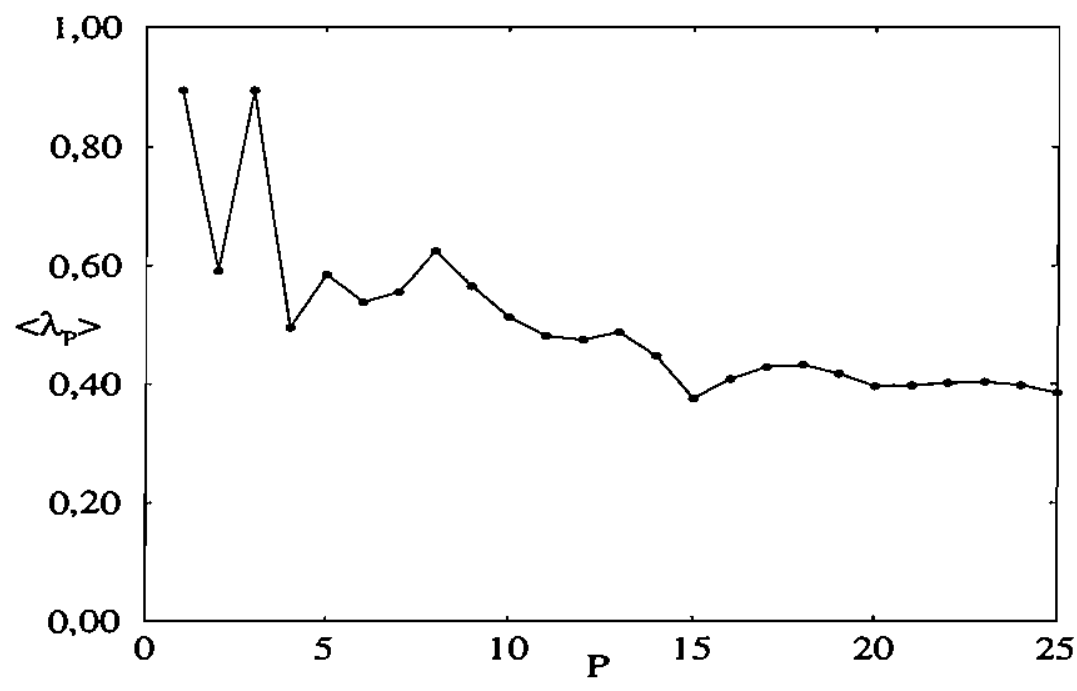

Figura 5.3: Expoentes de Lyapunov médios das órbitas periódicas instáveis em função do período para $a=0,570$ e $b=0,343$.

Na figura 5.2.a podemos ver o número de órbitas periódicas instáveis em função do período para um conjunto de parâmetros $(a, b)$ correspondentes a uma órbita caótica. Observamos que este número, a princípio bastante baixo, logo começa a crescer de forma considerável, formando uma curva que se assemelha a uma exponencial. De fato, estima-se teoricamente que esta curva, para valores elevados de $P$ deve se aproximar assintoticamente da função:

$$
N_{P} \propto \frac{e^{\gamma P}}{P}
$$

onde $\gamma$ é um parâmetro positivo a ser ajustado que varia de caso a caso. De fato, fazendo um gráfico da curva $P N_{P} \times P$ para o mesmo exemplo (fig. 5.2.b) em escala mono-logarítmica, ob- 
servamos que ela tende realmente a uma curva exponencial para valores de $P$ suficientemente elevados, que permitam uma boa estatística.

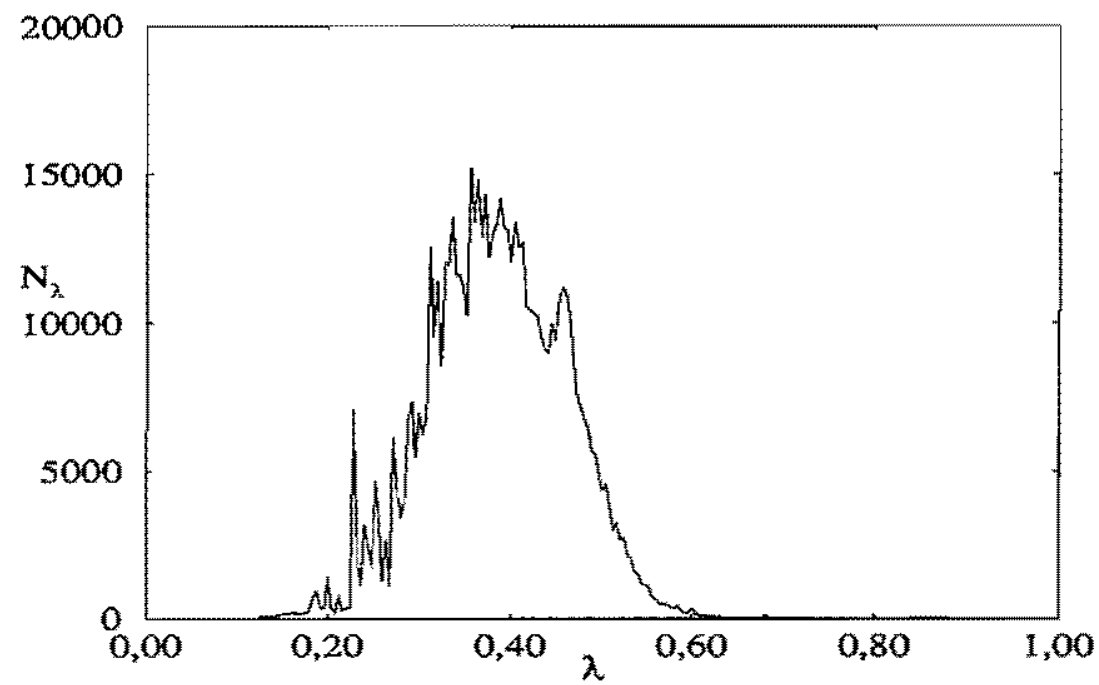

Figura 5.4: Histograma dos expoentes de Lyapunov das órbitas periódicas instáveis com período $P \leq 20$ para $a=0,570$ e $b=0,343$.

Outra propriedade importante destas órbitas periódicas instáveis a ser investigada é a dependência da sua instabilidade com o período, ou seja, será que as órbitas de período alto tendem a ser mais ou menos instáveis que as de período baixo? Ou será que a instabilidade independe do período? Este tipo de análise é bastante relevante, pois para muitas aplicações, como por exemplo o controle de caos por estabilização de órbitas periódicas instáveis, é preferível escolhermos órbitas as menos instáveis possível. Uma medida da instabilidade de uma órbita é o seu expoente de Lyapunov. Quanto mais alto este for, mais instável será a órbita. Fazendo um gráfico do expoente de Lyapunov médio das órbitas versus o seu período (fig. 5.3) observamos que para períodos elevados o suficiente para termos uma estatística significativa, o expoente de Lyapunov é aproximadamente constante, ou seja, a instabilidade independe do período, o que justifica a utilização de órbitas de baixo período para o controle de caos, conforme é feito usualmente. Mais do que uma constância na média dos expoentes, temos ainda que o desvio dos expoentes de uma órbita isolada tem um desvio pequeno da média, conforme podemos observar no histograma da distribuição de expoentes de Lyapunov (fig. 5.4) onde todos os expoentes formam um aglomerado razoavelmente bem definido em 


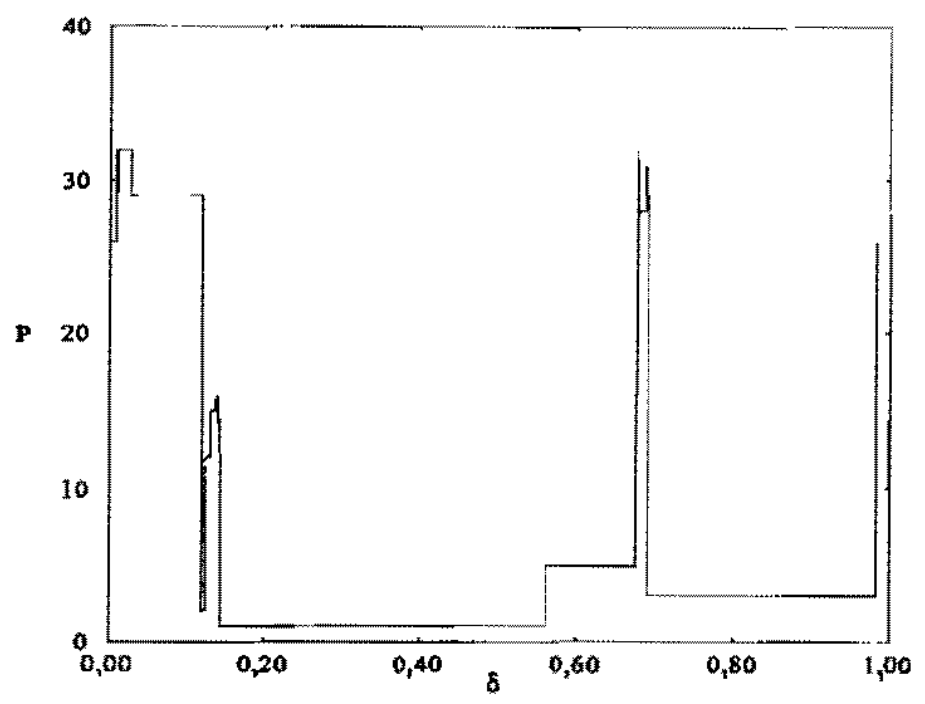

Figura 5.5: O período das órbitas optimais para a função $F_{\delta}^{(1)}(\theta)$ para o mapa unidimensional dissipativo com $a=0,52$ e $b=0,30$.

torno do valor médio. De fato este valor médio é bastante próximo ao expoente de Lyapunov da trajetória caótica $\left(\lambda_{c}=0,34\right)$, o que é razoável uma vez que a órbita caótica consiste na oscilação do sistema entre as diversas órbitas periódicas instáveis.

\subsection{Trajetórias optimais}

Um dos tópicos mais relevantes do estudo da dinâmica não-linear é a determinação das órbitas optimais de um sistema. Uma órbita é definida como optimal se ela pertencer ao conjunto invariante do sistema e for tal que a média de uma função suave e dependente apenas das variáveis de estado (como, por exemplo, a energia) for máxima sobre ela. Maximizar funçōes como energia ou desempenho de um sistema dinâmico é de grande importância em uma série de aplicações.

Estudos recentes mostraram que as órbitas periódicas instáveis de baixo período são excelentes candidatos a órbitas optimais em muitos casos. Por enquanto há apenas estudos numéricos corroborando esta afirmação, não foram realizadas ainda demonstraçōes mais formais.

Para estudar as órbitas optimais do nosso mapa unidimensional dissipativo, utilizamos 
primeiro a funçāo teste a um parâmetro $(\delta)$ dada por:

$$
F_{\delta}^{(1)}(\theta)=\cos (\theta-2 \pi \delta)
$$

para ser maximizada. Esta função foi escolhida como um protótipo de função periódica e limitada. Calculando a média desta função $\left(\left\langle F_{\delta}^{(1)}\right\rangle\right)$ sobre todas as órbitas periódicas instáveis com período $P \leq 32$, variando o parâmetro da função $(\delta)$ no intervalo de 0 a 1, e determinando o período para qual cada uma destas médias é maximizada (fig. 5.5), observamos que, para a maior parte dos parâmetros, o período da órbita optimal é bastante baixo. No exemplo que mostramos os períodos mais frequentes são $P=1,3,5$.

É importante ressaltarmos que a curva deste gráfico é formada por um número reduzido de degraus, ou seja, a optimalidade de uma determinada órbita periódica instável é pouco afetada por pequenas variações na função teste a ser otimizada. Não há comportamento fractal ou outras estruturas mais complexas. Isto mostra que muitas vezes uma única órbita pode ser utilizada para otimizar um sistema dinâmico em um grande intervalo de operação.

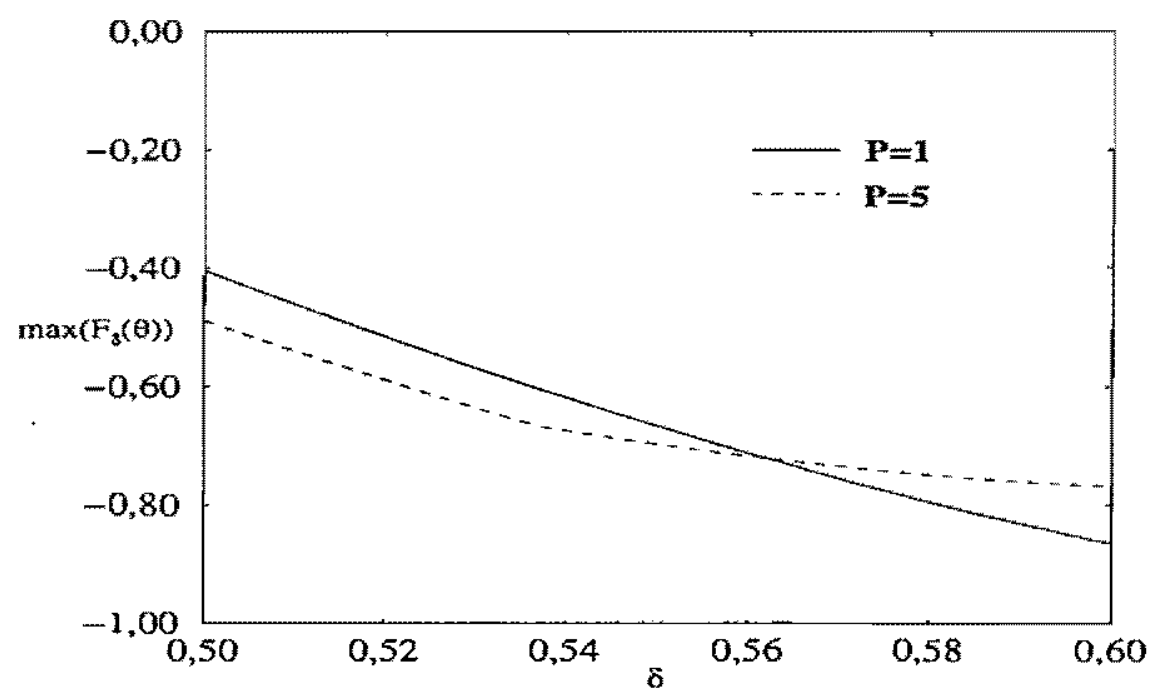

Figura 5.6: Médias da função $F_{\delta}^{(1)}$ sobre as trajetórias periódicas instáveis de período 1 e $5 \mathrm{em}$ torno da mudança da órbita optimal, que ocorre em $\delta \approx 0,56$, para o mapa unidimensional dissipativo com $a=0,52$ e $b=0,30$.

Observando ainda os valores médios da função a ser otimizada em torno de uma mudança de trajetória optimal, por exemplo a passagem de uma órbita de período 1 para uma de 
período 5 (fig. 5.6), vemos que as médias para cada trajetória variam lentamente com o parâmetro. Disto podemos concluir que mesmo numa região próxima à região em que ela é optimal, uma trajetória ainda chega muito perto de otimizar o sistema, e portanto não há necessidade de se preocupar com o caráter abrupto das transiçōes de um período para outro.

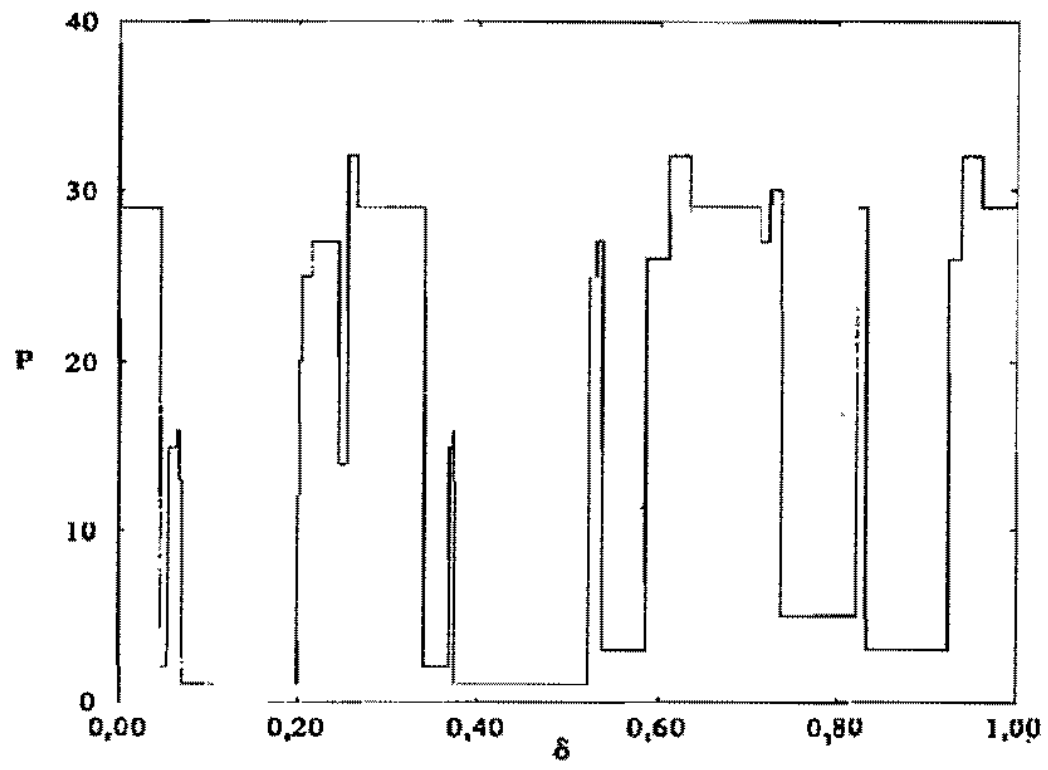

Figura 5.7: O periodo das órbitas optimais para a função $F_{b}^{(2)}(\theta)$ para o mapa unidimensional dissipativo com $a=0,52$ e $b=0,30$.

Fazendo o cálculo do período das órbitas optimais para uma outra função teste, dada por:

$$
F_{\delta}^{(2)}=\cos (\theta-2 \pi \delta)+\sin (3 \theta-6 \pi \delta)
$$

e utilizando os mesmos parâmetros do caso anterior (fig. 5.7), obtemos um dos poucos casos em que pudemos observar o fato de uma órbita de período mais elevado (no caso, $P=29$ ) ser optimal para um conjunto significativo de parâmetros. Mesmo assim, tirando este período particular, ainda predominam órbitas optimais de períodos baixos.

Os resultados apresentados nesta seção mostram que o controle de órbitas caóticas através de pequenas perturbaçōes, que mantêm o sistema sobre uma trajetória periódica instável de baixo período, tem ainda a vantagem adicional de que as grandezas macroscópicas do sistema, que dependem unicamente de seu estado dinâmico, são muitas vezes otimizadas de forma automática. 
5.3 O comportamento das trajetórias periódicas instáveis na transição entre regimes periódicos e caóticos

\subsection{O comportamento das trajetórias periódicas instáveis na transição entre regimes periódicos e caóticos}

Analisamos até aqui as propriedades das órbitas periódicas instáveis para um conjunto de parâmetros fixos. Surge agora a questão: como é que estas órbitas surgem no plano de parâmetros? Ou seja, o que caracteriza a fronteira, no plano de parâmetros, entre uma região que apresenta uma certa órbita instável de período $P$ e uma outra região que não apresenta a mesma órbita?

Sabemos que ao longo de uma transiçāo ordem-caos caracterizada por uma bifurcação do tipo $1-2-4-8-16-32-\ldots$, por exemplo, a cada duplicação de período a órbita de período menor torna-se instável. Isto explica o surgimento de órbitas instáveis com períodos $2^{n}$, neste exemplo. Mas como surgem as órbitas de outros períodos?

Para investigar esta questão utilizamos um exemplo numérico de uma transição entre regime periódico e caótico, fixando $a=0,57$ e tomando o intervalo $0,30<b<0,35$. Plotamos então o diagrama de bifurcação e os expoentes de Lyapunov para as trajetórias estáveis e as instáveis de período 2 e 5 , respectivamente (fig.5.8). Podemos observar que no caso do período $P=2$, de fato a órbita instável nada mais é do que um prolongamento da órbita estável que é destruída na bifurcação $2-4$. De fato, o expoente de Lyapunov desta órbita torna-se positivo após a bifurcação, conforme esperado para uma órbita que se torna instável.

Já para a órbita de período $P=5$, temos que esta apenas surge quando o sistema já se encontra na região de regime cátíco do plano de parâmetros. De fato, ela aparece primeiro como uma órbita estável que dá origem a uma transição abrupta do regime caótico para uma janela periódica de periodo $P=5$. Em seguida ocorre uma bifurcação do tipo $5-10-20-40-\ldots$, e a órbita de período 5 torna-se instável na bifurcação $5-10$. Analisamos muitos outros exemplos numéricos e verificamos que todas as outras órbitas periódicas instáveis dentro da região caótica surgem pelo mesmo processo descrito acima. Isto mostra que a existência de uma órbíta periódica instável de período $P$ em um certo ponto de regime caótico no plano de parâmetros implica na existência de uma janela periódica de período $P / 2^{n}$ entre este ponto e qualquer região periódica externa à região caótica e que não seja de período $P / 2^{n}$. Esta propriedade é de grande importância para a localizaçâo de janelas periódicas no plano de parâmetros, especialmente no caso de períodos mais elevados que ocorrem muitas vezes em janelas extremamente estreitas e portanto de difícil localização por métodos convencionais. 


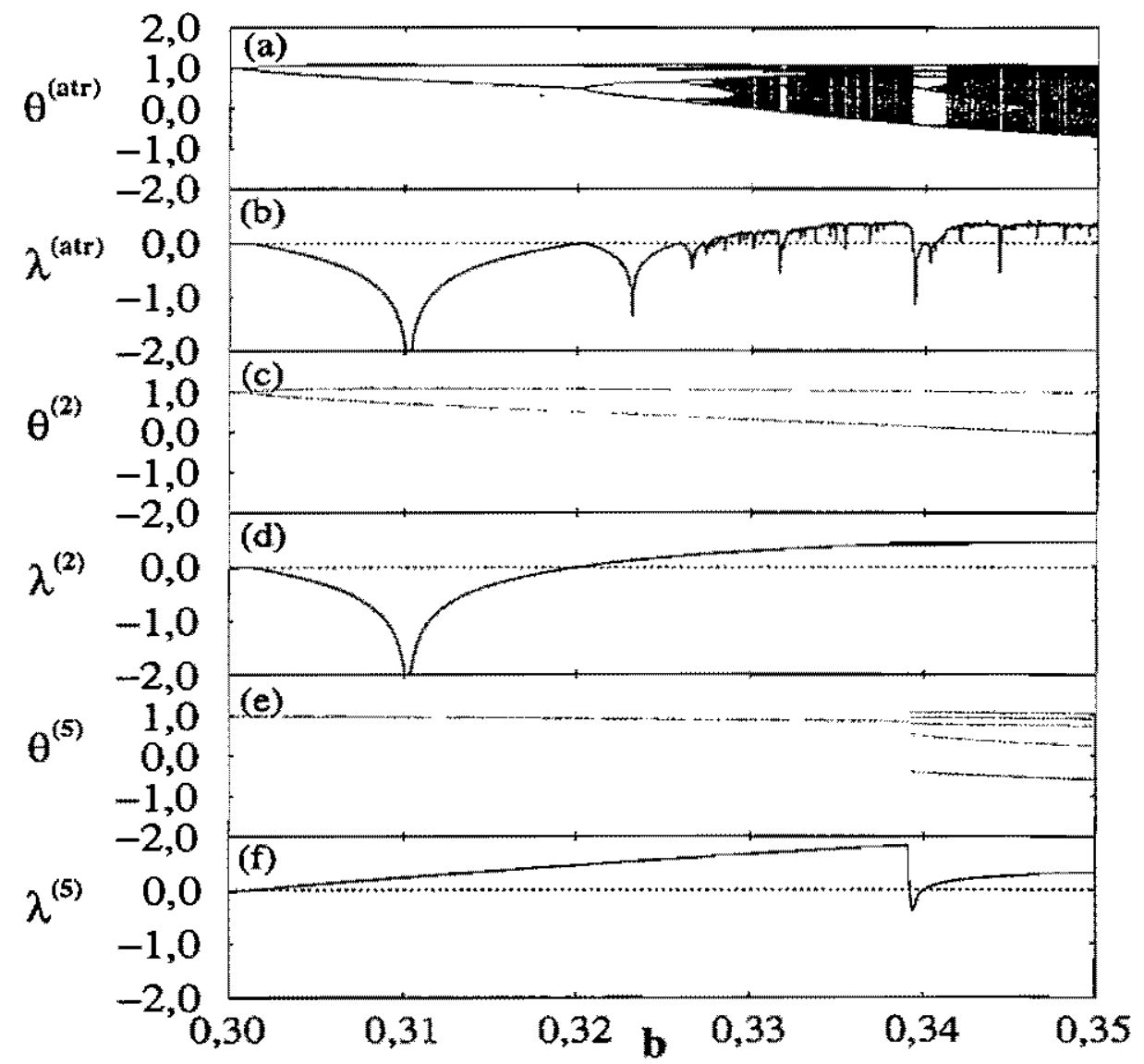

Figura 5.8: (a) Diagrama de bifurcação dos atratores estáveis, (b) expoentes de Lyapunov dos atratores estáveis, (c) diagrama de bifurcação das órbitas de período 2, (d) e seus expoentes de Lyapunov, (e) diagrama de bifurcação das órbitas de período 5, (f) e seus expoentes de Lyapunov para $a=0,57$.

\subsection{Perturbações com intensidade alternando entre dois valores de forma regular no tempo}

Passamos agora, nesta segunda parte deste capítulo, a estudar alguns casos do mapa unidimensional dissipativo 2.22 com parâmetros variando no tempo. Neste item vamos considerar o mapa unidimensional dissipativo 2.22 com a intensidade de perturbação $a$ variando entre dois valores fixos no tempo. Conisideramos que para iterações impares a intensidade de perturbação é dada por $a_{1}$ e para iterações pares a intensidade é dada por $a_{2}$. Concentramos este estudo na região $a>1 / 2$ onde o mapa original apresenta regiões de comportamento caótico. 
5.4 Perturbaçōes com intensidade alternando entre dois valores de forma regular no tempo
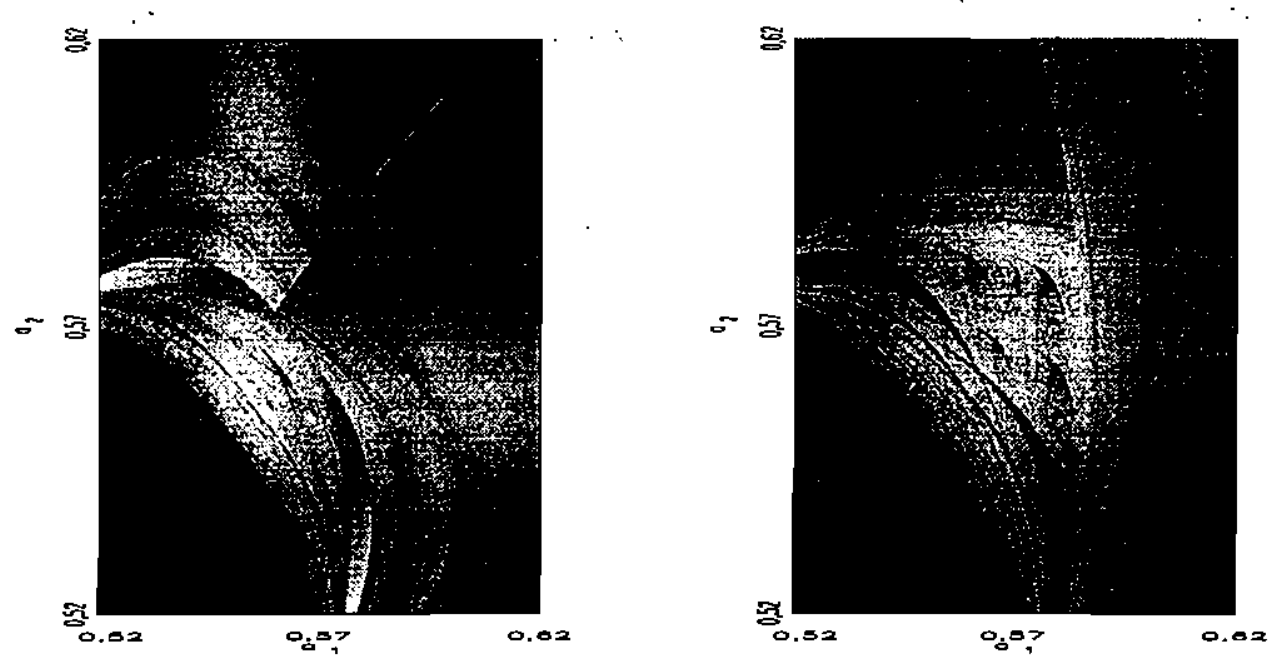

Figura 5.9: Expoentes de Lyapunov no plano de parâmetros $a_{1} \times a_{2}$ para (a) $b=0,33$ e (b) $b=0,37$. Todas as trajetórias foram calculadas a partir da posição inicial $\theta_{0}=0$.

Calculamos alguns planos de parâmetros $a_{1} \times a_{2}$ para valores fixos do período de perturbação $b$ utilizando expoentes de Lyapunov (fig.5.9). É interessante observarmos que os planos de parâmetros apresentam uma assimetria em torno do eixo $a_{1}=a_{2}$, ou seja, o atrator para o qual o sistema se dirige depende de qual perturbação é aplicada primeiro. Isto mostra que existe uma dependência da posição inicial do sistema. Temos aqui a coexistência de atratores caóticos e atratores periódicos estáveis para os mesmos valores de parâmetros que o mapa unidimensional original não apresentava.

Fazemos então cortes no segundo plano de parâmetros para valores fixos de $a_{2}$ e calculamos os expoentes de Lyapunov e os diagramas de bifurcação (fig.5.10) para uma análise mais detalhada. Em ambos os casos observamos bifurcações reversas análogas às observadas para o mapa original. Mas também observamos uma transição abrupta do período 4 para o caos, e linhas correspondentes a atratores periódicos se cruzando, o que não era observado antes.

Um fato bastante interessante deste tipo de mapeamento, é que os atratores do novo mapa com parâmetros $\left(a_{1}, a_{2}, b\right)$, não estão necessariamente ligados aos atratores dos sistemas originais com parâmetros $\left(a_{1}, b\right)$ e $\left(a_{2}, b\right)$. Temos que dois conjuntos correspondentes originalmente ambos a atratores caóticos podem resultar em atrator periódico, ou vice-versa. E quando os valores de $a_{1}$ e $a_{2}$ estão muito próximos, temos muitas vezes a superposição dos dois atratores originais, entre os quais o sistema fica oscilando a cada iteração. 

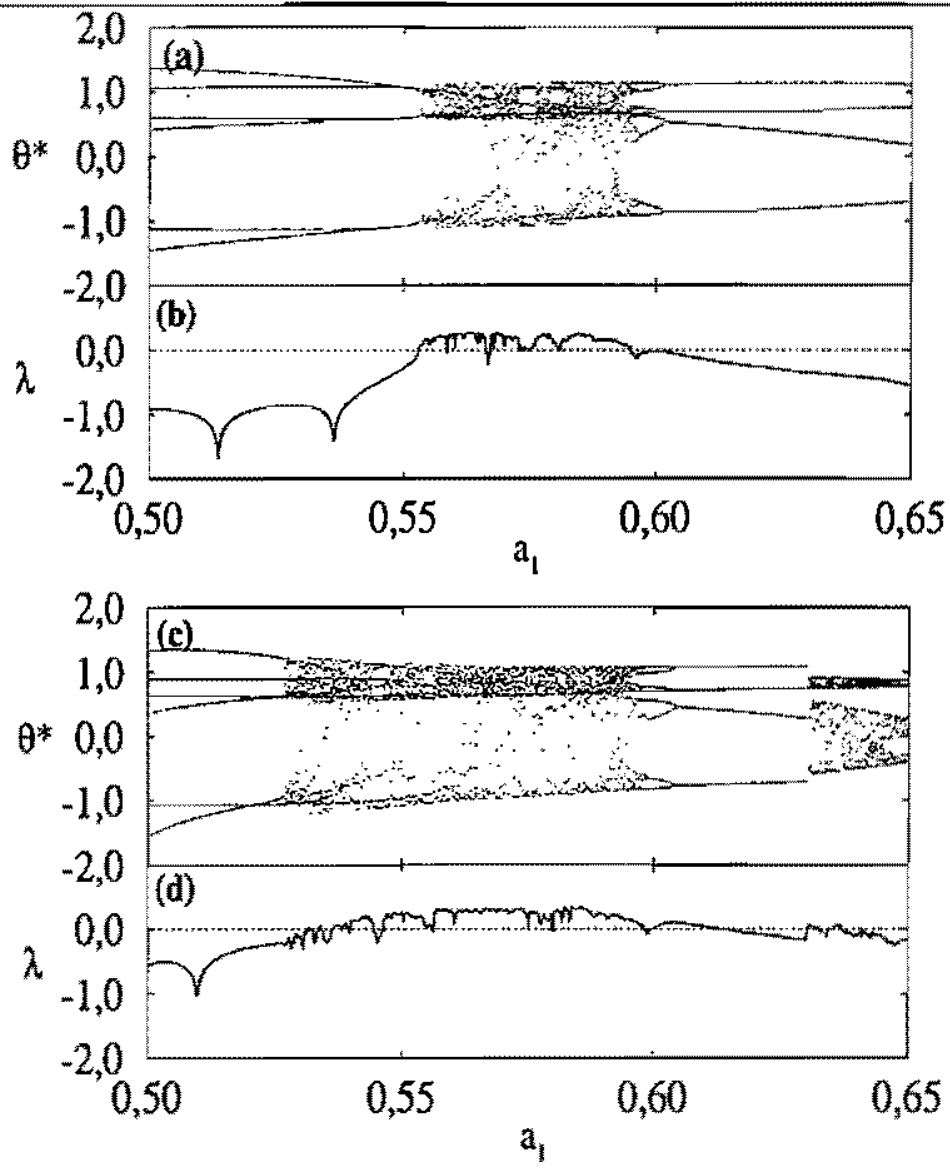

Figura 5.10: Diagramas de bifurcação fixando $b=0,37$ e (a) $a_{2}=0,55$ e (b) $a_{2}=0,57$, e os respectivos expoentes de Lyapunov ((b) e (d)). Todas as trajetórias foram calculadas a partir da posição inicial $\theta_{0}=0$.

\subsection{Pequenas oscilações irregulares dos parâmetros no tempo}

Analisamos até aqui os diversos aspectos da dinâmica do mapa unidimensional 2.22 , sempre supondo que os parâmetros $a$ e $b$ fossem grandezas perfeitamente bem determinadas. Mas em sistemas experimentais os parâmetros de controle em geral apresentam pequenas flutuações aleatórias. Passamos então a analisar agora o comportamento do sistema estudado quando ocorrem pequenas flutuações randômicas na intensidade da perturbaçāo. Neste caso, 

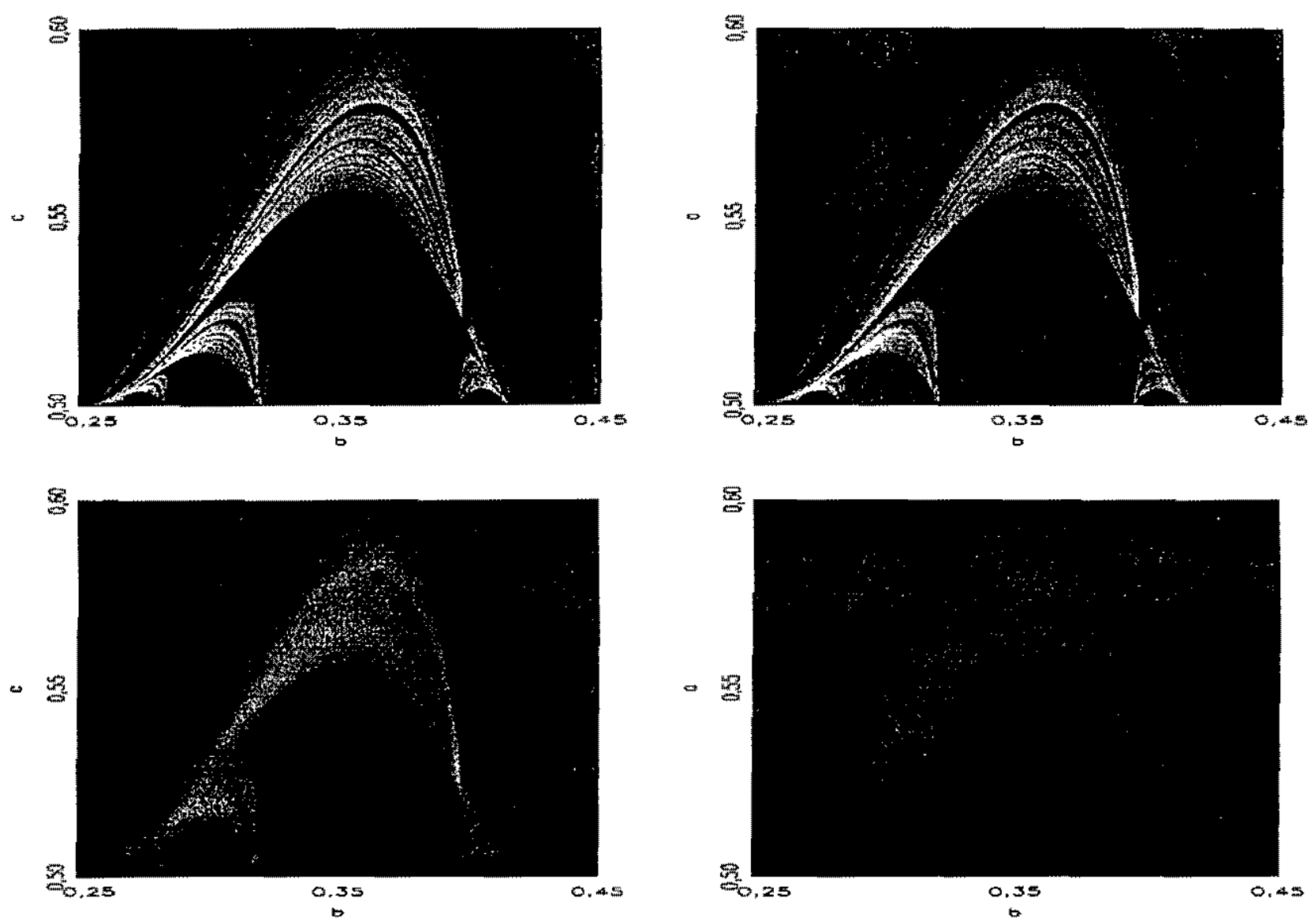

Figura 5.11: Expoentes de Lyapunov no plano dos parâmetros com pequenas variaçóes aleatórias na intensidade de perturbação com amplitude máxima (a) $\Delta a=0$, (b) $\Delta a=$ 0,0005 , (c) $\Delta a=0,0050$ e (d) $\Delta a=0,0250$.

o mapa 2.22 pode ser reescrito como:

$$
\tan \left(\theta_{n+1}\right)=\frac{\sin \left(\theta_{n}+2 \pi b\right)}{\cos \left(\theta_{n}+2 \pi b\right)+2\left(a+\Delta a R_{n}\right)}
$$

onde $R_{n}$ é um número real no intervalo $[-1,1]$ escolhido randomicamente a cada iteração $n$ e $\Delta a$ é a intensidade máxima da flutuação (para $\Delta a=0$ o mapa 5.5 se reduz ao mapa original 2.22).

Para fazermos a análise dinâmica das trajetórias no plano dos parâmetros, a ferramenta mais adequada para distinguirmos entre trajetórias caóticas e regimes ordenados é o expoente de Lyapunov, uma vez que no regime ordenado o sistema não apresenta mais trajetórias 


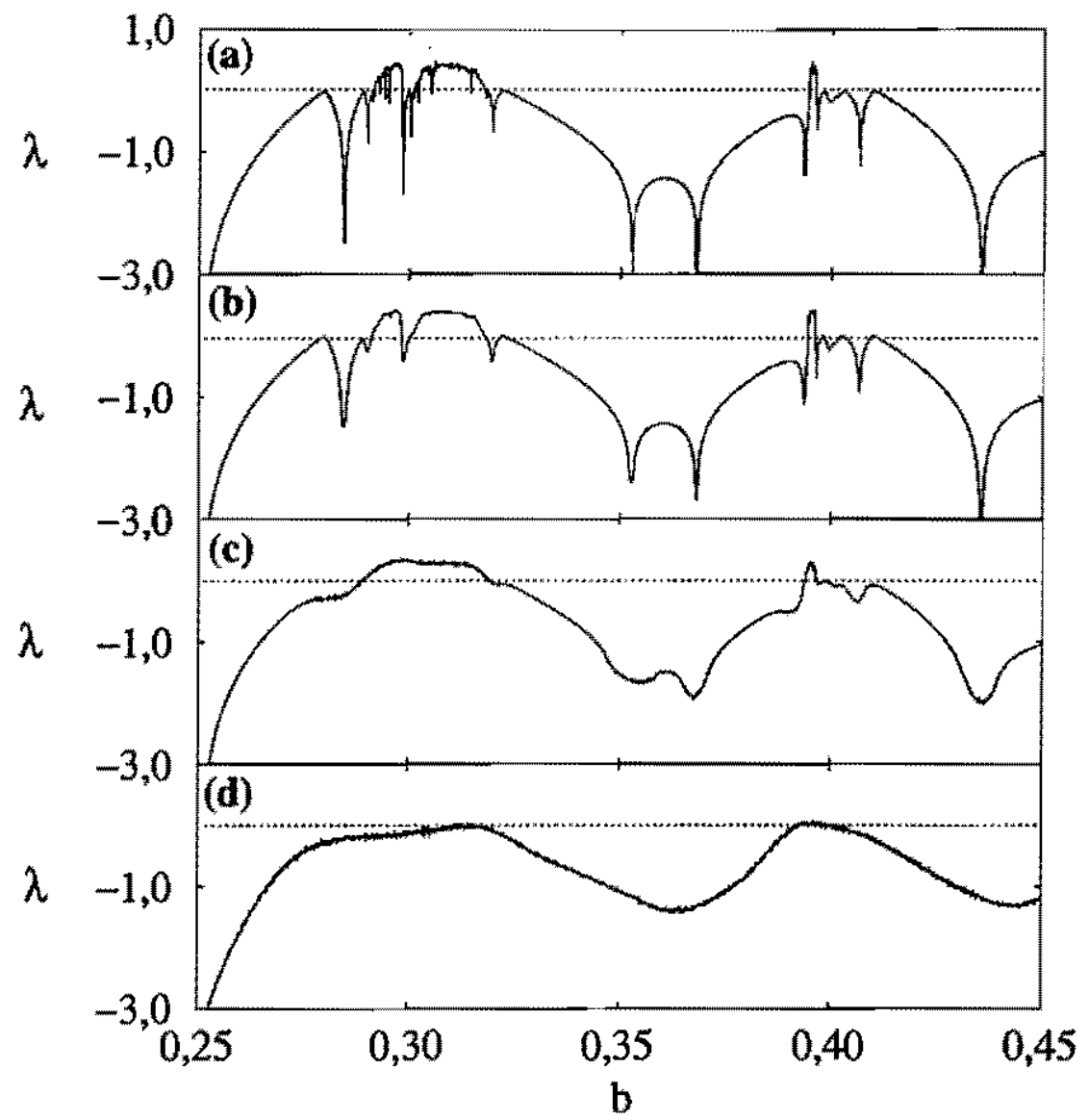

Figura 5.12: Expoentes de Lyapunov do mapa unidimensional dissipativo para $a=0,525 \mathrm{e}$ (a) $\Delta a=0$, (b) $\Delta a=0,0005$, (c) $\Delta a=0,0050$ e (d) $\Delta a=0,0250$.

exatamente periódicas, mas trajetórias oscilando entre atratores periódicos extremamente próximos. Observando a distribuição dos expoentes de Lyapunov no plano de parâmetros em torno da região caótica para vários valores de $\Delta a$ (fig.5.11), parece-nos à primeira vista que o efeito das flutuaçōes consiste em "borrar" as estruturas no plano de parâmetros.

De fato, à medida que para $\Delta a=0$ ainda temos as regiōes caóticas percorridas por um número muito grande de ilhas periódicas (fig.5.11.a), quando passamos a flutuações de amplitude $\Delta a=5 \times 10^{-4}$ (fig5.11.b), uma boa parte das ilhas mais finas já são destruídas. A medida em que aumentamos ainda mais a intensidade (fig.5.11.c) praticamente todas as ilhas periódicas são destruídas e as bordas entre as regiôes caóticas e regulares se tornam extremamente difusas (fig.5.11.d). Mesmo assim, durante todo este processo as grandes regiões de ordem e caos são mantidas fixas no plano de parâmetros, e a proporção entre 


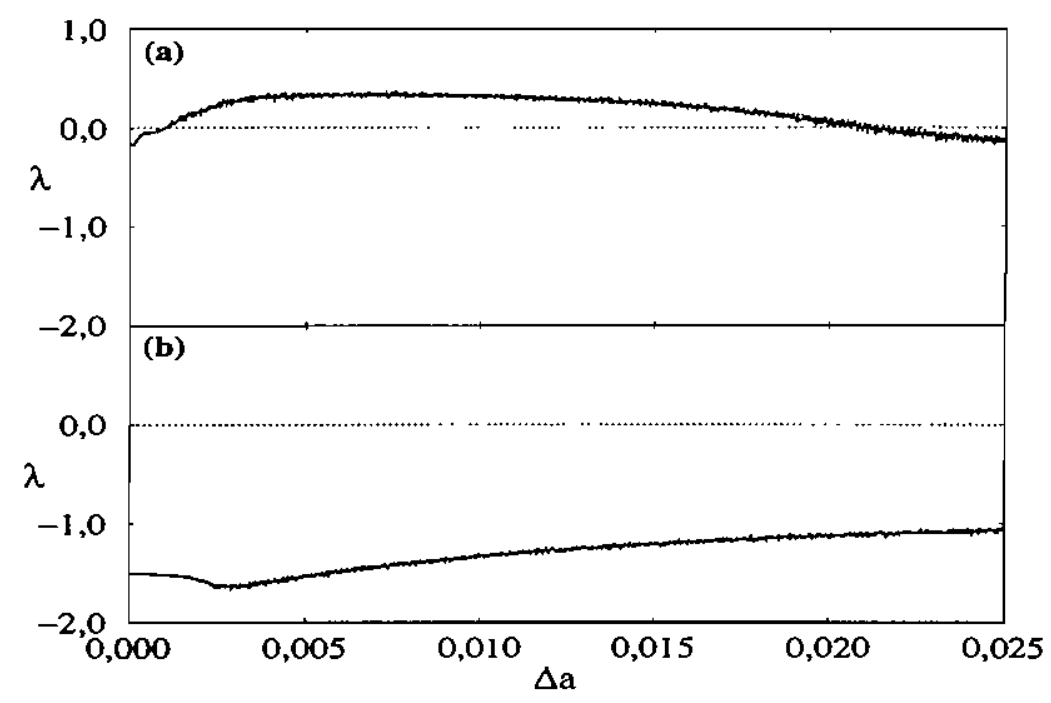

Figura 5.13: Expoentes de Lyapunov do mapa unidimensional dissipativo para $a=0,525$, e (a) $b=0,30$ e (b) $b=0,35$.

pontos regulares e caóticos não é afetada de maneira significativa.

Para entendermos o processo acima de forma mais detalhada, passamos à análise de alguns cortes nos planos de parâmetros da figura 5.11, fixando a intensidade média da perturbação em $a=0,525$ e calculando expoentes de Lyapunov para vários valores de $\Delta a$ sobre o intervalo $0,25<b<0,45$ (fig.5.12). Observamos neste caso que, à medida em que aumentamos o valor de $\Delta a$, os detalhes da curva vão sendo progressivamente eliminados, levando a uma curva cada vez mais suave. De fato, verificamos que o expoente de Lyapunov em um ponto $a$ com incerteza $\Delta a$ corresponde aproximadamente a uma média de todos os expoentes de Lyapunov no intervalo $[a-\Delta a, a+\Delta a]$. Isto se deve ao fato do sistema em questão ser fortemente dissipativo e portanto o sistema tende praticamente de forma imediata ao atrator correspondente ao valor de $a^{\prime}=a+\Delta a R_{n}$ a cada iteração do mapa.

Isto pode ser observado de forma mais detalhada se calcularmos os expoentes de Lyapunov para parâmetros fixos $(a, b)$ em função do valor de $\Delta a$ (fig.5.13). No primeiro caso $(a=0,525$; $b=0,30$ ) temos uma órbita periódica com expoente de Lyapunov muito fracamente negativo próxima a uma região caótica. Por isso, o expoente de Lyapunov aumenta e se torna positivo à medida em que aumentamos $\Delta a$ a ponto de incluirmos a regiāo caótica. Já para valores muito grandes de $\Delta a$ incluimos uma região de expoentes de Lyapunov fortemente negativos, 
e $\lambda$ diminui de novo até se tornar negativo. Já no segundo exemplo $(a=0,525 ; b=0,35)$ temos uma órbita periódica de expoente de Lyapunov bem mais negativo, mas rodeada por regióes caóticas de ambos os lados. Por isto mesmo o expoente de Lyapunov tende a aumentar cada vez mais à medida que aumentamos $\Delta a$ e englobamos faixas cada vez maiores de regime caótico.

Verificamos, enfim, que eventuais oscilações aleatórias nos parâmetros de controle não destroem as características fundamentais do sistema. Elas apenas impossibilitam observarmos estruturas cuja dimensão no plano de parâmetros seja menor do que $\Delta$, onde $\Delta$ é a ordem de grandeza das flutuaçôes nos parâmetros de controle.

\subsection{Oscilações harmônicas da intensidade de pertur- bação no tempo}

Neste item analisamos mais um caso relevante de parâmetros variáveis no tempo para o mapa unidimensional dissipativo, que consiste em modular a amplitude de perturbação do mapa unidimensional dissipativo de forma harmônica no tempo. O mapa unidimensional 2.22 passa então a ser descrito por:

$$
\tan \left(\theta_{n+1}\right)=\frac{\sin \left(\theta_{n}+2 \pi b\right)}{\cos \left(\theta_{n}+2 \pi b\right)+2 a \cos (\omega t / b)}
$$

onde introduzimos um terceiro parâmetro $\omega$ que representa a frequência com a qual a intensidade de perturbação é modulada no tempo. Este novo mapa unidimensional dissipativo a três parâmetros apresenta agora uma dependência temporal explícita, o que dificulta o cálculo de expoentes de Lyapunov, entre outras coisas. Eliminamos então a dependência temporal explícita representando a evolução do sistema 5.6 pelo mapa bidimensional equivalente:

$$
\begin{aligned}
\tan \left(\theta_{n+1}\right) & =\frac{\sin \left(\theta_{n}+2 \pi b\right)}{\cos \left(\theta_{n}+2 \pi b\right)+2 a \cos \Psi_{n}} \\
\Psi_{n+1} & =\Psi_{n}+2 \pi \omega
\end{aligned}
$$

onde foi introduzida uma segunda variável angular $\Psi$ diretamente proporcional ao tempo, mas que pode ser modulada no intervalo $(-\pi, \pi]$ uma vez que ela só entra no cosseno da primeira equação.

$\hat{E}$ importante notarmos aqui que no mapa 5.8 a variável $\Psi_{n+1}$ nāo depende de $\theta_{n}$ (ou seja, $\left.\frac{\partial \Psi_{n+1}}{\partial \theta_{n}}=0\right)$, e portanto o Jacobiano do sistema $\left(J \equiv \frac{\partial\left(\theta_{n+1}, \Phi_{n+1}\right)}{\partial\left(\theta_{n}, \Psi_{n}\right)}\right)$ é triangular. Isto facilita o 

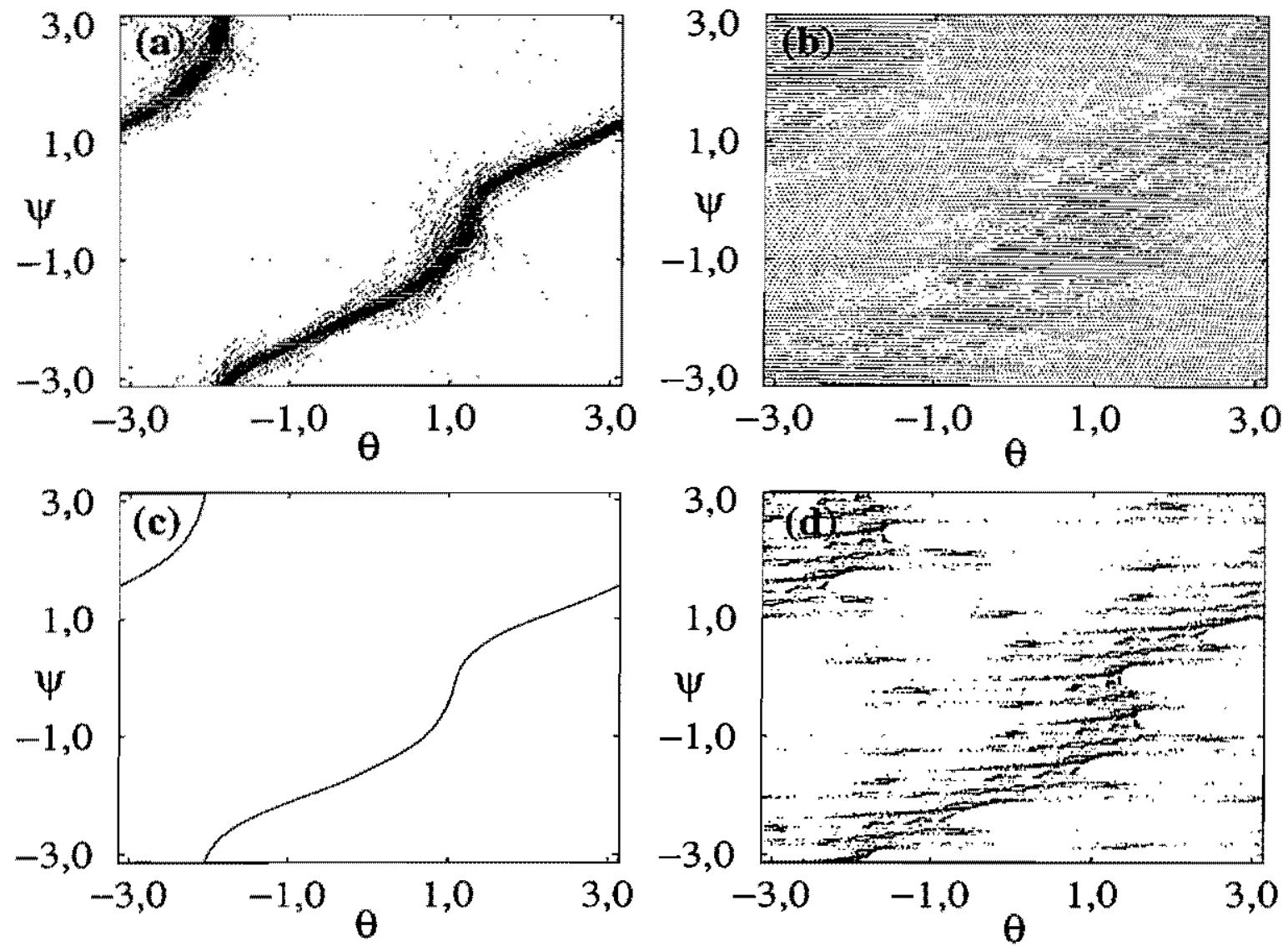

Figura 5.14: Trajetórias do mapa bidimensional dissipativo a três parâmetros para (a) $a=$ $0,48, b=0,25$, e $\omega=0,155$; (b) $a=0,20, b=0,25$, e $\omega=0,15915$; (c) $a=0,52, b=0,23$, e $\omega=0,127323$; (d) $a=0,513, b=0,25$, e $\omega=0,127323$.

cálculo dos expoentes de Lyapunov, que para um mapa bidimensional são definidos como:

$$
\lambda_{j} \equiv \lim _{N \rightarrow \infty} \frac{1}{N} \ln \left\|a_{j}\left(\prod_{k=0}^{N} J^{k}\right)\right\|
$$

com $j=1,2$. Nesta definiçăo, $a_{j}$ é o j-ésimo autovalor da matriz produtória dos jacobianos $J^{k}$, onde $J^{k}$ é dado por:

$$
J^{k} \equiv \frac{\partial\left(\theta_{k+1}, \Psi_{k+1}\right)}{\partial\left(\theta_{k}, \Psi_{k}\right)}
$$

Como para o mapa 5.8 os jacobianos $J^{k}$ são triangulares, e consequentemente a sua produtória é triangular também, os expoentes de Lyapunov associados a cada uma das variáveis 
$\theta$ e $\Psi$ podem ser calculados separadamente como se cada equação fosse um mapa unidimensional. Para a variável $\Psi$ em particular, este cálculo pode ser feito analiticamente. Temos que:

$$
\lambda_{2}=\lim _{N \rightarrow \infty} \frac{1}{N} \sum_{j=0}^{N} \ln \left\|\frac{\partial \Psi_{j+1}}{\partial \Psi_{j}}\right\|=\lim _{N \rightarrow \infty} \frac{1}{N} \sum_{j=0}^{N} \ln \|1\|=0
$$

Isto nos leva a três possibilidades distintas: (i) para $\lambda_{\mathbf{l}}>0$ a trajetória do sistema é caótica e forma um atrator estranho que ocupa parte do plano $\theta \times \Psi$ (fig.5.14.a); (ii) para $\lambda_{1}=0$ temos trajetórias quase-periódicas de três frequências que percorrem todo o plano de fase sem jamais voltarem exatamente ao ponto inicial (fig.5.14.b); (iii) para $\lambda_{1}<0$ temos trajetórias quase-periódicas de duas frequências, também denominadas ciclos-limite, cujos atratores formam uma curva contínua e fechada no plano de fase (fig.5.14.c), ou podemos ter atratores estranhos näo-caóticos (fig.5.14.d)[36, 37].

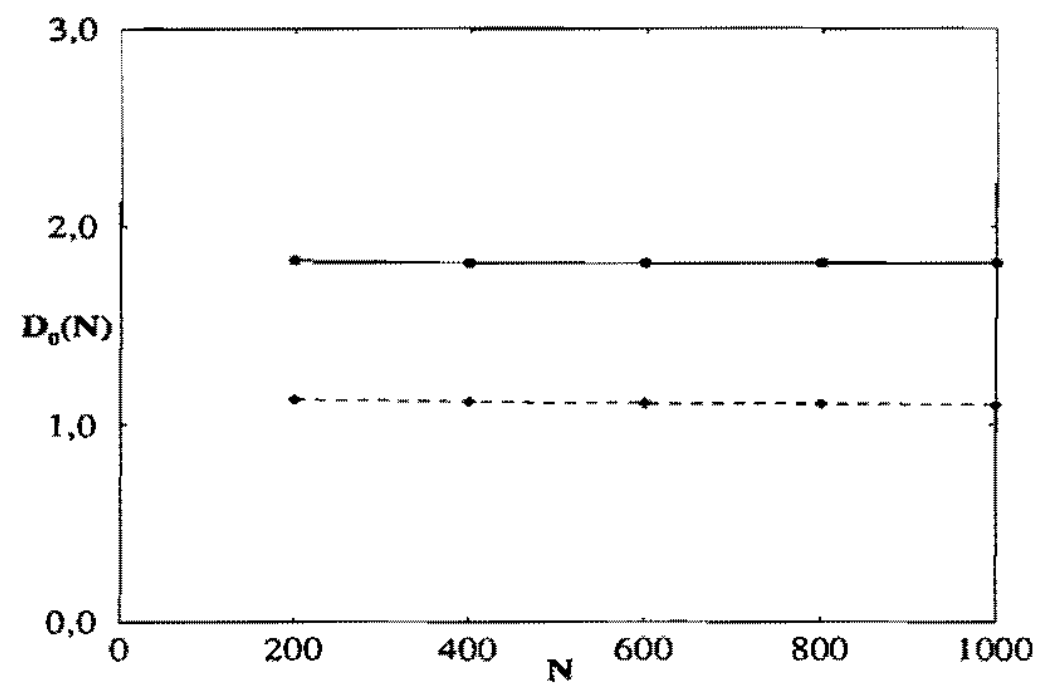

Figura 5.15: Convergência de $D_{0}$ para o atrator estranho da figura 5.14.d (linha cheia, círculos) e para o ciclo-limite da figura 5.14.c (linha tracejada, losangos). Foram utilizadas trajetórias com $k=5 \times 10^{7}$ iteraçōes nos cálculos.

Para diferenciarmos entre atratores estranhos não caóticos e ciclos-limite (ambos com $\lambda_{1}<0$ ), calculamos a dimensão fractal ("box counting dimension"), conforme definida em 4.2. Temos que para trajetórias do tipo ciclo-limite $D_{0}(\epsilon) \rightarrow 1$ à medida em que $\epsilon$ tende a zero, enquanto que atratores estranhos não-caóticos apresentam uma dimensão fractal 
$\left(1<D_{0}<2\right)$, que em geral é nitidamente maior que 1. Na figura 5.15 podemos ver a convergência de $D_{0}$ para o ciclo-limite da figura 5.14.c e o atrator estranho da figura 5.14.d, respectivamente. Vemos claramente que no caso do ciclo-limite $D_{0} \rightarrow 1$, ainda que a convergência seja lenta, enquanto que para $o$ atrator estranho não-caótico a convergência é muito boa e temos $D_{0} \approx 1,8$, ou seja, o valor obtido é distintamente maior que 1 . Isto mostra que $D_{0}$ pode de fato ser utilizado para distinguir entre estes dois tipos de atratores.
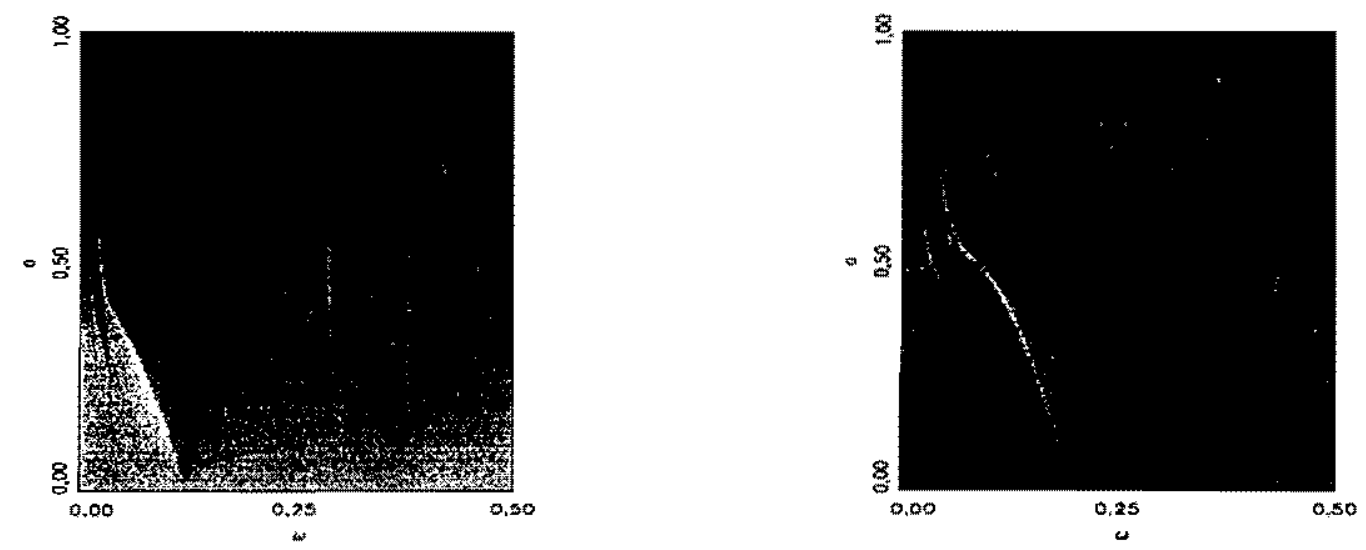

Figura 5.16: Expoentes de Lyapunov $\lambda_{1}$ nos planos de parâmetros para o mapa bidimensional dissipativo fixando (a) $b=0,1225$ e (b) $b=0,20$. Os pontos mais escuros correspondem a expoentes de Lyapunov maiores.

Como este é um sistema a três parâmetros $(a, b, e \omega)$, não é possível representá-lo de forma completa em apenas um plano de parâmetros, mas podemos obter uma série de planos de parâmetros realizando cortes no espaço mantendo um parâmetro fixo. Nos exemplos aqui apresentados decidimos fixar o valor de $b$. Variamos $a$ no intervalo $0<a<1$, como no caso unidimensional, e $\omega$ no intervalo $0<\omega<1$, uma vez que verificamos que o sistema apresenta comportamento dinâmico similar para $(a, b, \omega)$ e $(a, b, 1-\omega)$. A estrutura complexa destes planos de parâmetros pode ser observada na figura 5.16. Observamos que para baixas intensidades de perturbação $(a \ll 1)$ o sistema apresenta praticamente sempre $\lambda_{1}=0$, ou seja, temos trajetórias quase-periódicas de 3 frequências. Já para altas intensidades de perturbação $(a \approx 1)$ o sistema sempre apresenta $\lambda_{1}>1$, ou seja existem apenas trajetórias caóticas (de fato existem também valores de parâmetros nesta região correspondentes a trajetórias periódicas, mas eles ocupam um conjunto de medida nula). Já na região intermediária (em torno de $a=1 / 2$ ) temos todos os tipos de comportamento dinâmico distribuido nos planos 

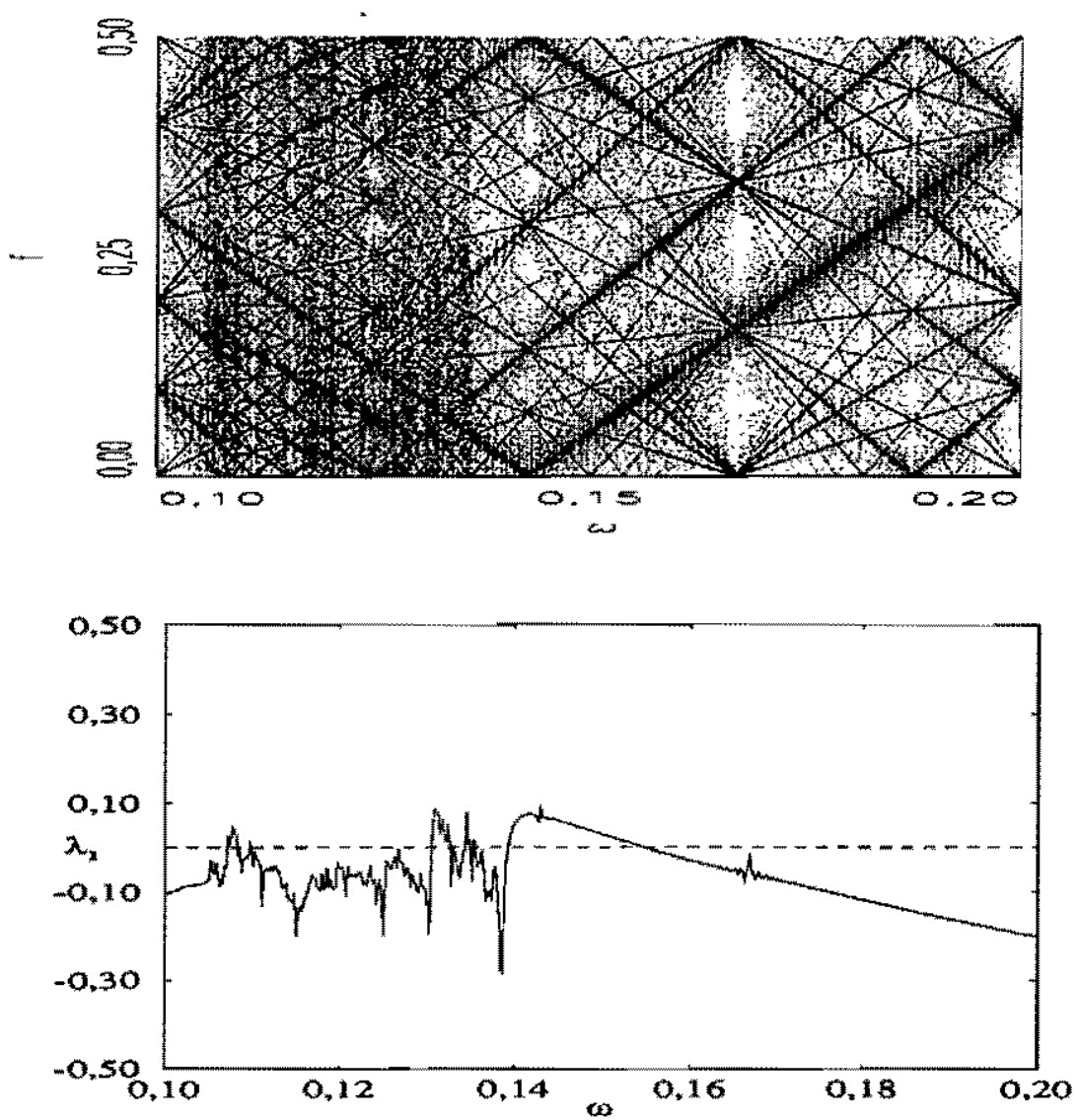

Figura 5.17: Diagrama de bifurcação no espaço de frequências e expoentes de Lyapunov para o mapa bidimensional dissipativo com $a=0,513$ e $b=0.25$.

de parâmetros de forma bastante complexa.

Fazendo agora um corte no plano de parâmetros para o mapa bidimensional dissipativo 5.8, fixando os parâmetros $a$ e $b$ e variando apenas $\omega$, e calculando $\lambda_{1}$ e o diagrama de bifurcação no espaço de frequências ao longo deste corte (fig. 5.17), observamos duas regiōes distintas ao longo deste corte: na regiâo de $\omega$ menor a maioria dos espectros apresenta fundo contínuo e temos dois tipos de comportamento predominante: caos (nas regiōes com $\lambda_{1}>0$ ) e atratores estranhos não-caóticos (nas regiōes de $\lambda_{1}$ negativo). Já para valores maiores de $\omega$ temos apenas alguns picos discretos bem-definidos se destacando nos espectros cujas frequências variam de forma linear com $\omega$ e nesta região temos ciclos-limite com $\lambda_{1}<0$, conforme era de se esperar.

Observamos ainda que a variação de $\lambda_{1}$ é bastante irregular na região dos atratores 
estranhos não-caóticos, ao contrário da variação praticamente linear (pelo menos localmente) na regiäo dos ciclos-limite. Esta é uma outra forma de distínguir entre regiões com estes dois tipos de comportamento que têm ambos $\lambda_{1}<0$. Finalmente, ressaltamos ainda o fato de que os pontos com $\omega$ mais racional apresentam uma variação local abrupta de regime dinâmico, como pode ser observado na figura para $\omega=1 / 6$. Observamos ainda que para todos os tipos de regime observados existem picos espectrais discretos bastante acentuados e que tendem a variar de forma bastante linear com o parâmetro $\omega(\Delta f \propto \Delta \omega)$. 


\section{Capítulo 6}

\section{Limitadores ergódicos magnéticos}

Neste capítulo inicia-se a segunda parte da tese, que consiste em desenvolver um modelo para descrever a evolução das linhas de campo magnético no vaso de um tokamak, sob a influência das correntes elétricas externas de um dispositivo denominado limitador ergódico, e analisar as trajetórias deste modelo utilizando os algoritmos apresentados na primeira parte da tese.

Apresentamos neste capítulo uma descrição do limitador ergódico e analisamos os modelos já existentes para descrevê-lo e as suas vantagens e desvantagens. Primeiro, descrevemos o modelo proposto por Martin e Taylor, e depois o modelo introduzido por Viana e Caldas. Em seguida mostramos porque estes modelos não são apropriados para o tipo de estudo que pretendemos fazer.

\subsection{O campo magnético de equilíbrio}

Em um tokamak, o plasma é confinado em um vaso toroidal que é caracterizado por seu raio maior $R_{0}$ e seu raio menor $b$ (fig. 6.1). Costuma-se definir a razão de aspecto do tokamak como sendo $\epsilon=R_{0} / b$. Para tokamaks de grande razão de aspecto $(\epsilon \gg 1)$ é comum desprezar os efeitos toroidais, pelo menos em uma primeira aproximação, e adotar uma geometria cilíndrica, de periodicidade $2 \pi R_{0}$ (fig. 6.2).

Consideremos agora uma coluna de plasma em equilíbrio magnetohidrodinâmico estático dentro do vaso deste tokamak, sendo que no nosso modelamento trabalhamos com colunas de seção circular de raio a. Para os modelos a seguir, consideramos que esta coluna de plasma 
é confinada por um campo magnético de equilíbrio do tipo:

$$
\vec{B}=B_{\theta}(r) \hat{e}_{\theta}+B_{0} \hat{e}_{\phi}
$$

onde $B_{0}$ é o campo toroidal de equilíbrio gerado por bobinas externas ao vaso. Na aproximação cilíndrica este campo é uniforme e paralelo ao eixo geométrico do vaso. $B_{\theta}(r)$ é o campo poloidal, gerado pela corrente de plasma $I_{p}$. Existem vários modelamentos teóricos para o perfil deste campo poloidal, sendo que para os cálculos a serem apresentados aqui vamos utilizar o modelo parabólico generalizado, que é descrito por uma densidade de corrente de plasma, dada por:

$$
\vec{j}_{\phi}(r)=j_{0}\left[1-\left(\frac{r}{a}\right)^{2}\right]^{\gamma} \Theta(a-r) \hat{e}_{\phi}
$$

onde $\Theta(x)$ é a função escada de Heavyside, e $j_{0}$ e $\gamma$ são parâmetros positivos ajustáveis para a descrição de descargas típicas no tokamak.

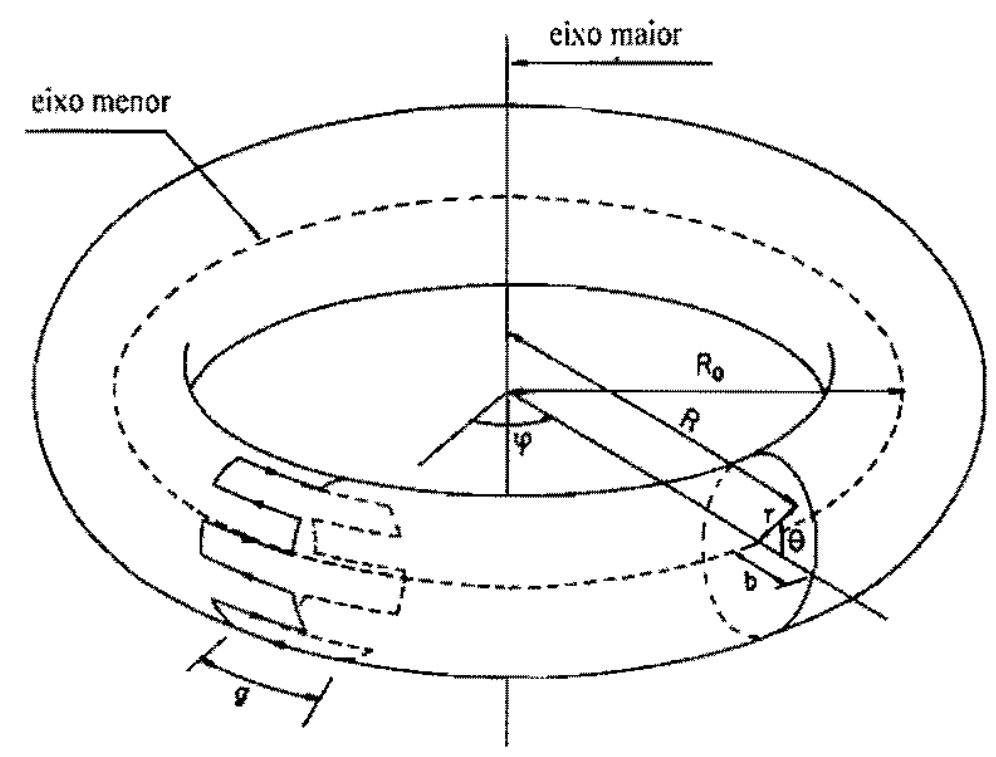

Figura 6.1: Coordenadas utilizadas na descriçāo das linhas de campo magnético.

Utilizando a lei de Ampère, o perfil de densidade de corrente 6.2 leva ao perfil de campo magnético poloidal:

$$
B_{0}(r)=\frac{a B_{\theta}(a)}{r}\left[1-\left[1-\left(\frac{r}{a}\right)^{2}\right]^{\gamma+1} \Theta(a-r)\right]
$$

onde $B_{\theta}(a)$ é a intensidade de campo poloidal na borda da coluna de plasma. 

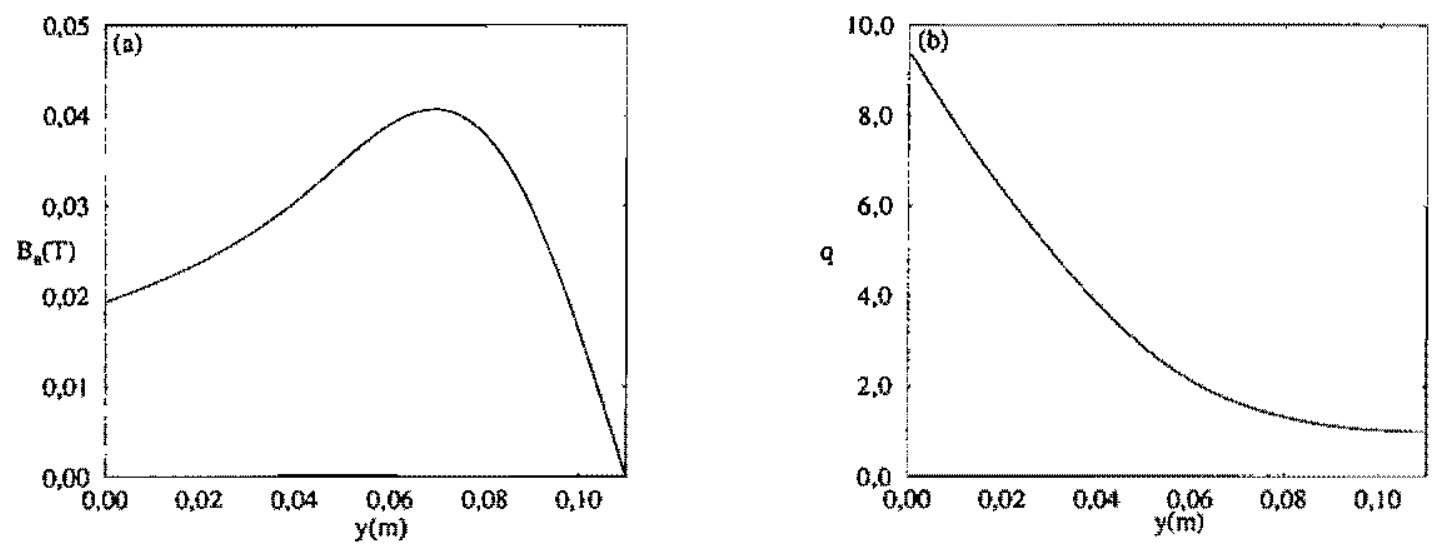

Figura 6.3: Perfis radiais do campo magnético poloidal 6.3 e do fator de segurança 6.7 para um tokamak de grande razão de aspecto com os parâmetros do TBR-1. Adotamos aqui a coordenada radial $y$, definida como sendo $y=b-r$.

A relação $\frac{d \theta}{d \phi}$ está diretamente ligada à definição do fator de segurança, que consiste em uma integração desta quantidade ao longo de uma volta no tokamak e representa a evolução média da linha de campo na direção poloidal em relação à evolução na direção toroidal. O perfil de fator de segurança ainda pode ser relacionado diretamente ao perfil de campo magnético poloidal através da relação:

$$
q(r) \equiv \frac{B_{0} r}{R_{0} B_{\theta}(r)}
$$

Ambos os perfis podem ser vistos na figura 6.3 para parâmetros correspondentes ao tokamak TBR-1 (vide tabela 6.1) [16, 38]. Adotamos os parâmetros do tokamak TBR-1 para todos os cálculos numéricos a seguir, mas os modelos propostos têm validade geral.

No caso toroidal a equação 6.4 não pode ser integrada analiticamente, e mais adiante vamos analisar aproximaçōes para esta integração.

\subsection{A geometria dos limitadores ergódicos}

Um dos grandes problemas no confinamento de plasma em tokamaks é a presença de impurezas. Mas uma das principais fontes de impurezas são as colisões de partículas com a parede do vaso do tokamak. No final da década de 70 alguns autores sugeriram criar então uma camada de linhas de campo caóticas na borda do tokamak, que servisse como 


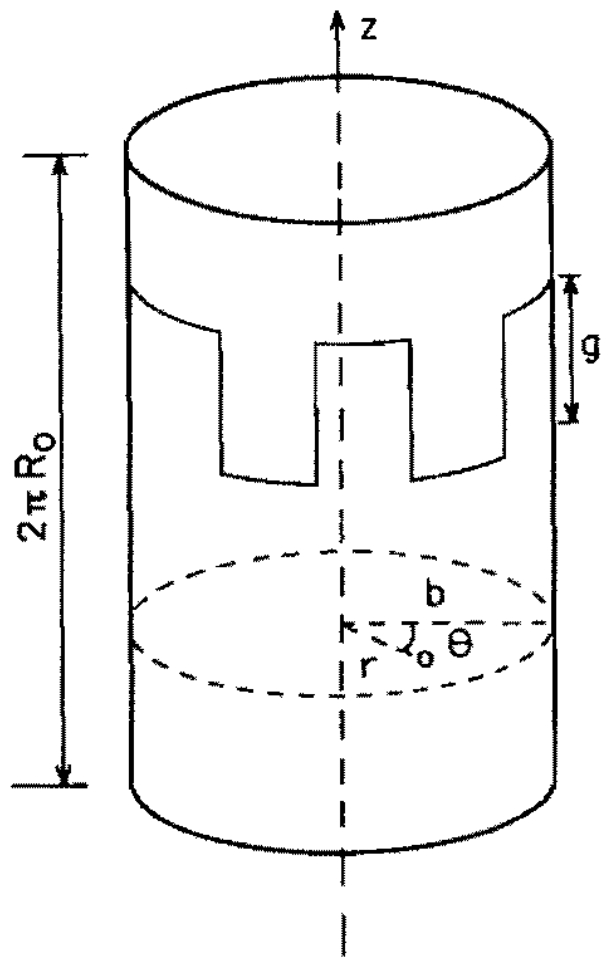

Figura 6.2: A geometria do tokamak na aproximação cilíndrica.

A partir das expressões 6.1 e 6.3 para o campo magnético podemos obter as linhas de campo magnético de equilíbrio através da equação:

$$
\vec{B} \times d \vec{l}=0
$$

onde $d \vec{l}$ é um deslocamento ao longo da lina de campo. No caso da aproximação cilíndrica esta equação pode ser resolvida de forma analítica, pois ela pode ser escrita como:

$$
\frac{d r}{B_{r}}=\frac{r d \theta}{B_{\theta}}=\frac{R_{0} d \phi}{B_{0}}
$$

Para obtermos as linhas de campo de equilíbrio basta integrarmos a equação:

$$
\frac{d \theta}{d \phi}=\frac{R_{0} B_{\theta}\left(r_{0}\right)}{r B_{0}}
$$

a partir da condição inicial $\left(r_{0}, \theta_{0}\right)$ desejada. Temos neste caso que as linhas de campo magnético de equilíbrio localizam-se sobre superfícies cilíndricas de raio fixo $r_{0}$. A variável $\phi$ desempenha, neste caso, o papel de um tempo canônico ao longo do qual calculamos a evolução das linhas de campo magnético. 

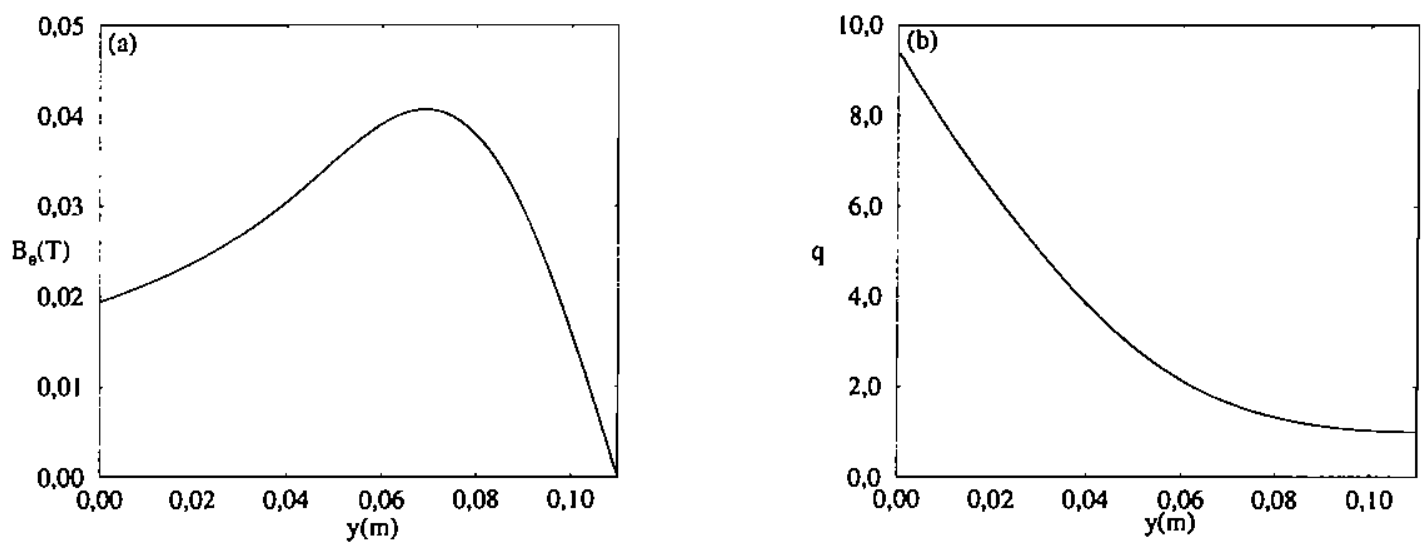

Figura 6.3: Perfis radiais do campo magnético poloidal 6.3 e do fator de segurança 6.7 para um tokamak de grande razão de aspecto com os parâmetros do TBR-1. Adotamos aqui a coordenada radial $y$, definida como sendo $y=b-r$.

A relação $\frac{d \theta}{d \phi}$ está diretamente ligada à definição do fator de segurança, que consiste em uma integração desta quantidade ao longo de uma volta no tokamak e representa a evolução média da linha de campo na direção poloidal em relação à evolução na direção toroidal. O perfil de fator de segurança ainda pode ser relacionado diretamente ao perfil de campo magnético poloidal através da relação:

$$
q(r) \equiv \frac{B_{0} r}{R_{0} B_{\theta}(r)} .
$$

Ambos os perfis podem ser vistos na figura 6.3 para parâmetros correspondentes ao tokamak TBR-1 (vide tabela 6.1)[16, 38]. Adotamos os parâmetros do tokamak TBR-1 para todos os cálculos numéricos a seguir, mas os modelos propostos têm validade geral.

No caso toroidal a equação 6.4 não pode ser integrada analiticamente, e mais adiante vamos analisar aproximações para esta integração.

\subsection{A geometria dos limitadores ergódicos}

Um dos grandes problemas no confinamento de plasma em tokamaks é a presença de impurezas. Mas uma das principais fontes de impurezas são as colisões de partículas com a parede do vaso do tokamak. No final da década de 70 alguns autores sugeriram criar então uma camada de linhas de campo caóticas na borda do tokamak, que servisse como 
de linhas de campo magnético caóticas desejada na borda do tokamak[40].

\subsection{O modelo de Martin-Taylor}

O modelo de Martin-Taylor foi um dos primeiros modelos para descrever a evolução das linhas de campo magnético em um tokamak perturbado por limitadores ergódicos magnéticos[17, $21,41]$. Ele não é derivado diretamente das equações de evolução do campo magnético, mas em vez disso propõe uma descrição mais qualitativa dos fenômenos envolvidos. O mapeamento de Martin-Taylor foi desenvolvido em coordenadas retangulares e é composto por dois mapas sucessivos: o primeiro descreve a evolução do campo magnético de equilíbrio ao longo do vaso, e o segundo descreve a perturbação sobre as linhas na região do anel do limitador.

A parte do mapeamento que descreve a evolução das linhas de campo magnético de equilíbrio é dada por:

$$
\begin{aligned}
& x_{n}^{*}=x_{n}+s y_{n} \\
& y_{n}^{*}=y_{n}
\end{aligned}
$$

onde $\vec{r}_{n} \equiv\left(x_{n}, y_{n}\right)$ é a posição inicial da linha de campo, logo após sair da regiäo de influência do limitador, e $\vec{r}_{n}^{*} \equiv\left(x_{n}^{*}, y_{n}^{*}\right)$ é a posiçäo da linha de campo após dar a volta no vaso, logo antes de entrar novamente na região do limitador. O parâmetro $s$ (do inglês "shear" deslocamento) é a intensidade de deslocamento poloidal da linha causado pela corrente de plasma (nas coordenadas retangulares de Martin-Taylor, $x$ corresponde à direção poloidal e $y$ à direção radial). Em termo dos parâmetros do tokamak, $s$ é definido como:

$$
s \equiv-\frac{2 \pi b}{q^{2}} \frac{d q}{d y}
$$

onde $b$ é o raio menor do tokamak e $q(y)$ é o perfil radial do fator de segurança, que é inversamente proporcional ao perfil de campo poloidal.

A segunda parte do mapeamento, que descreve a evolução da linha de campo magnético na regiāo do limitador de comprimento de onda $\frac{2 \pi b}{m}$, carregando uma corrente $I_{h}$, e de largura 9 , é dada por:

$$
\begin{aligned}
& x_{n+1}=x_{n}^{*}-p e^{-y_{n}^{*}} \cos x_{n}^{*} \\
& y_{n+1}=y_{n}^{*}+\ln \left(\cos \left(x_{n}^{*}-p e^{-y_{n}^{*}} \cos x_{n}^{*}\right)\right)-\ln \left(\cos x_{n}^{*}\right)
\end{aligned}
$$


onde o parâmetro $p$ mede a intensidade da perturbação em relação ao campo toroidal de equilíbrio $B_{0}$, definido como sendo:

$$
p \equiv \frac{\pi m^{2} g I_{h}}{b^{2} B_{0}}
$$
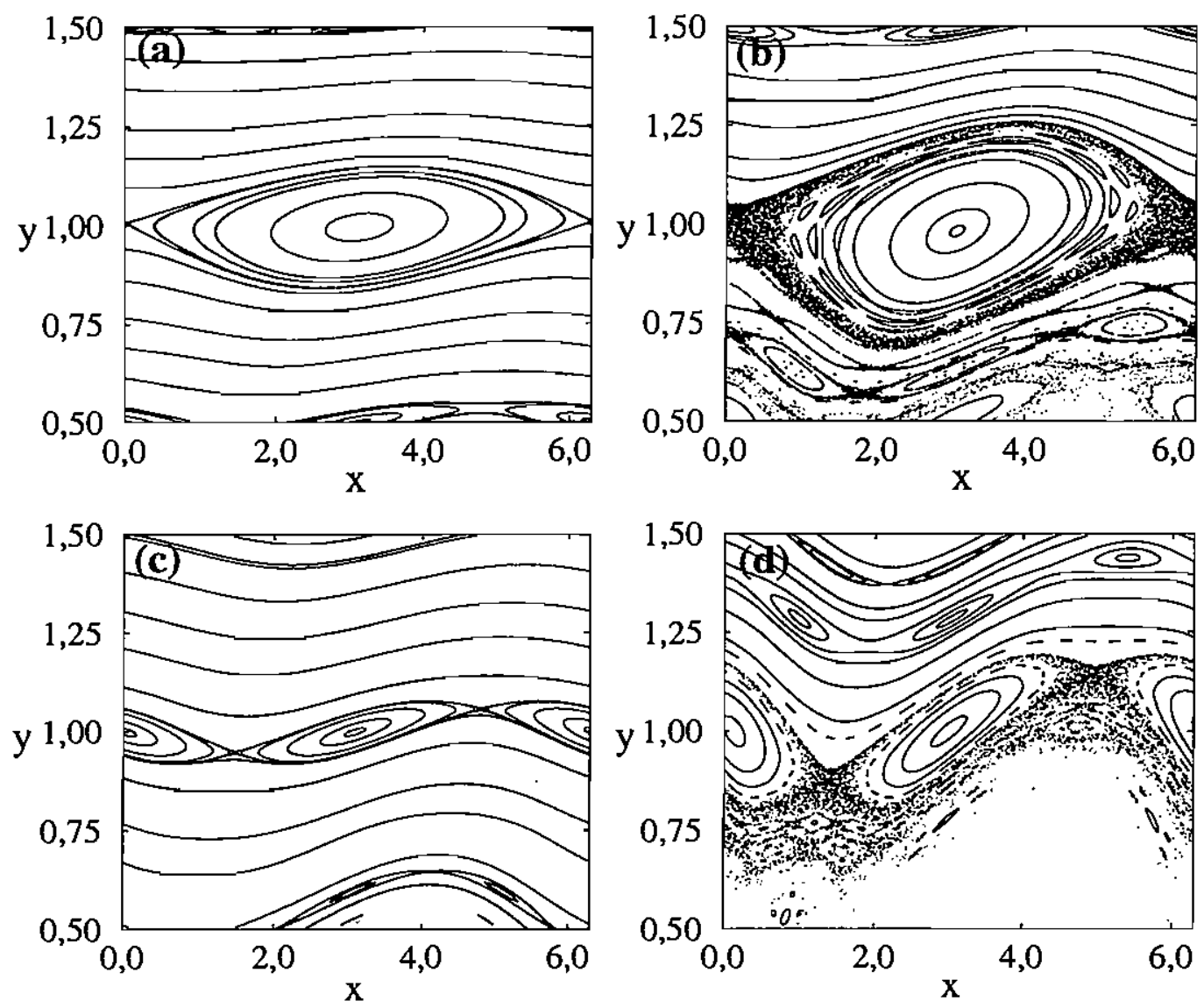

Figura 6.4: Seções de Poincaré para o mapa de Martin-Taylor com (a) $p=0,10$ e $s=2 \pi$; (b) $p=0,30$ e $s=2 \pi$; (c) $p=0,30$ e $s=\pi$; (d) $p=0,75$ e $s=\pi$.

Aplicando estes dois mapas sucessivamente a um dado conjunto de condições iniciais, obtemos seções de Poincaré das linhas de campo magnético no interior do tokamak. Na maioria dos estudos numéricos apresentados na literatura considerou-se apenas uma faixa radial para a análise, e nesta faixa o fator de deslocamento $s$ foi considerado como sendo constante. Neste caso, temos um mapeamento conservativo ${ }^{1}$ a dois parâmetros ( $p$ e $s$ ).

\footnotetext{
${ }^{1}$ De fato, este mapeamento é conservativo, pois temos que os jacobianos dos dois mapeamentos parciais são unitários, e portanto o jacobiano do mapeamento total também o é.
} 
Na figura 6.4 vemos alguns exemplos de seções de Poincaré para o mapa de MartinTaylor. Na figura 6.4.a temos uma baixa intensidade de perturbação (equivalente a uma baixa corrente $I_{h}$ no limitador) e portanto as cadeias de ilhas ainda são bastante achatadas e não há grandes regiôes de regime caótico, mesmo em torno da ilha principal em $y=1$. Já na figura $6.4 . \mathrm{b}$ vemos o que acontece para o mesmo deslocamento $s$ quando aumentamos a corrente nos limitadores: as cadeias de ilhas magnéticas ressonantes ficam mais largas, acabam se superpondo, e assim dão origem a regiôes de linhas de campo caóticas. Também podemos observar um grande número de cadeias de ressonâncias secundárias. $\mathrm{O}$ mesmo tipo de fenômeno pode ser observado nas figuras 6.4.c-d, onde alteramos o parâmetro $s$, obtendo agora outras cadeias de ilhas em outras posições ressonantes.

\subsection{O modelo de Viana e Caldas}

Apesar do modelo de Martin-Taylor oferecer uma boa descrição qualitativa do crescimento e da superposição de cadeias de ilhas magnéticas, levando ao surgimento de regiões caóticas, ele não considera os efeitos toroidais, bastante relevantes em máquinas cuja razão de aspecto não seja muito grande, e tampouco pode ser associado diretamente às coordenadas de um tokamak de forma quantitativa, por não ser derivado diretamente das equações de campo magnético.

Neste item passamos a apresentar um modelo derivado por Viana e Caldas[16, 22, 42], que procede diretamente das equações do campo magnético $(6.1,6.3,6.4$, e 6.9) e admite correções toroidais. Assim como o modelo de Martin-Taylor, este modelo propõe um mapeamento bidimensional composto por dois mapeamentos sucessivos: o primeiro descreve a evolução da linha de campo magnético no equilibrio ao longo do vaso; o segundo descreve a perturbação introduzida pelo limitador ergódico.

Começamos apresentando um mapeamento para a seção de Poincaré do campo magnético de equilíbrio no caso cilíndrico. Conforme já constatamos acima, neste caso as linhas de campo magnético estão situadas sobre superfícies magnéticas de raio constante, e portanto:

$$
r_{n}^{*}=r_{n}
$$

onde $r_{n}$ é a coordenada radial da linha dé campo magnético antes da volta no tokamak, e $r_{n}^{*}$ a mesma coordenada radial ao final da volta. Substituindo a equação $6.3 \mathrm{em} 6.6$ e integrando ao longo de uma volta na coordenada toroidal $\phi$, obtemos:

$$
\theta_{n}^{*}=\theta_{n}+\frac{2 \pi R_{0}}{B_{0}} \frac{B_{\theta}\left(r_{n}\right)}{r_{n}}
$$


O conjunto de equaçōes $6.16-6.17$ compōe então um mapeamento que descreve a seção de Poincaré das linhas de campo magnético de equilíbrio na aproximação cilíndrica.

Para introduzir correçōes toroidais de primeira ordem, este modelo adota um campo magnético toroidal de equilíbrio do tipo:

$$
B_{\phi}(r, \theta)=\frac{B_{0}}{1+\frac{r}{R_{0}} \cos \theta}
$$

que, substituído em 6.6 , nos leva a:

$$
\frac{d \theta}{d \phi}=\frac{B_{\theta}(r)\left(1+\frac{r}{R_{0}} \cos \theta\right) R_{0}}{r B_{0}}
$$

Integrando esta equação, obtemos que:

$$
\theta_{n}^{*}=2 \arctan \left[\lambda\left(r_{n}\right) \tan \left(\Omega\left(r_{n}\right)+\arctan \Xi\left(r_{n}, \theta_{n}\right)\right)\right]+2 \pi
$$

onde definimos as seguintes variáveis auxiliares:

$$
\begin{aligned}
\epsilon\left(r_{n}\right) & =\frac{r_{n}}{R_{0}} \\
\lambda\left(r_{n}\right) & =\frac{1-\epsilon\left(r_{n}\right)}{\sqrt{1-\epsilon^{2}\left(r_{n}\right)}} \\
\Omega\left(r_{n}\right) & =\frac{\pi R_{0} B_{\theta}\left(r_{n}\right)\left(1-\epsilon\left(r_{n}\right)\right)}{B_{0} r_{n} \lambda\left(r_{n}\right)} \\
\Xi\left(r_{n}, \theta_{n}\right) & =\frac{1}{\lambda\left(r_{n}\right)} \tan \left(\frac{\theta_{n}}{2}\right) .
\end{aligned}
$$

Como continuamos com o campo radial nulo nesta aproximação, a equação 6.16 continua válida para a iteração da coordenada radial, e em conjunto com a equação 6.20 fornece um mapeamento para a seção de Poincaré das linhas de campo magnético de equilíbrio com correções toroidais de primeira ordem.

Para obtermos um mapeamento para a perturbação introduzida pelos campos magnéticos do limitador ergódico, vamos supor que este seja suficientemente estreito em relação à dimensão toroidal $\left(\frac{g}{2 \pi R_{0}} \ll 1\right)$ de forma a poder ser considerado como uma perturbação impulsiva sobre as linhas de campo do equilíbrio. Esta suposição leva a resultados numéricos válidos, conforme foi mostrado através da comparação com integrações numéricas dos campos originais em [43]. Temos então que os campos magnéticos perturbativos devido ao limitador 
ergódico podem ser representados, de forma aproximada, por[16]:

$$
\begin{aligned}
& B_{r}^{(1)}(r, \theta, \phi)=-\frac{\mu_{0} g m I_{h}}{\pi b}\left(\frac{r}{b}\right)^{m-1} \sin (m \theta) \sum_{j=-\infty}^{\infty} \delta(\phi-2 \pi j) \\
& B_{j}^{(1)}(r, \theta, \phi)=-\frac{\mu_{0} g m I_{h}}{\pi b}\left(\frac{r}{b}\right)^{m-1} \cos (m \theta) \sum_{j=-\infty}^{\infty} \delta(\phi-2 \pi j)
\end{aligned}
$$

onde $\delta(x)$ representa a função delta de Dirac. Integrando, chegamos ao mapeamento bidimensional:

$$
\begin{aligned}
& r_{n+1}=r_{n}^{*}-\frac{\mu_{0} g m I_{h}}{\pi b B_{0}}\left(\frac{r_{n}^{*}}{b}\right)^{m-1} \sin \left(m \theta_{n}^{*}\right) \\
& \theta_{n+1}=\theta_{n}^{*}-\frac{\mu_{0} g m I_{h}}{\pi b^{2} B_{0}}\left(\frac{r_{n}^{*}}{b}\right)^{m-2} \cos \left(m \theta_{n}^{*}\right)
\end{aligned}
$$

que representa a perturbação introduzida pelo anel do limitador ergódico.

O conjunto de equações apresentado nos permite obter uma série de seções de Poincaré para as linhas de campo magnético, sendo que os parâmetros a serem variados são o número $m$ de pares de espiras no anel e a corrente $I_{h}$ do limitador ergódico.

Na figura 6.5 vemos um exemplo de uma seção de Poincaré com os parâmetros do TBR-1, incluíndo correções toroidais de primeira ordem, e utilizando um limitador ergódico com $m=$ 6 pares de espiras e conduzindo uma corrente de $I_{h}=300 \mathrm{~A}$. Para uma melhor visualização da borda do tokamak, que é a nossa regiäo de maior interesse neste caso, utilizamos as coordenadas retangulares definidas por:

$$
\begin{aligned}
& x=b \theta \\
& y=b-r
\end{aligned}
$$

para fazermos a seção de Poincaré. Observamos a formação de uma série de cadeias de ilhas magnéticas, sendo que mais na borda do tokamak (próximo a $y=0$ ) já houve superposição destas cadeias de ilhas, levando à criação de uma faixa radial percorrida por linhas de campo cáticas.

Este modelo, deduzido diretamente das equaçöes de campo magnético, representa de forma bastante fiel as posições radiais e as larguras das cadeias de ilhas magnéticas criadas devido às ressonâncias provocadas pelo limitador ergódico. Mesmo assim, não é adequado para o tipo de análise dinâmica que pretendemos efetuar (cálculo de expoentes de Lyapunov, espectros de Fourier, fatores de segurança, e assim por diante). Isto se deve ao fato do mapeamento de Viana e Caldas apresentar pequenos termos dissipativos que provêm das 


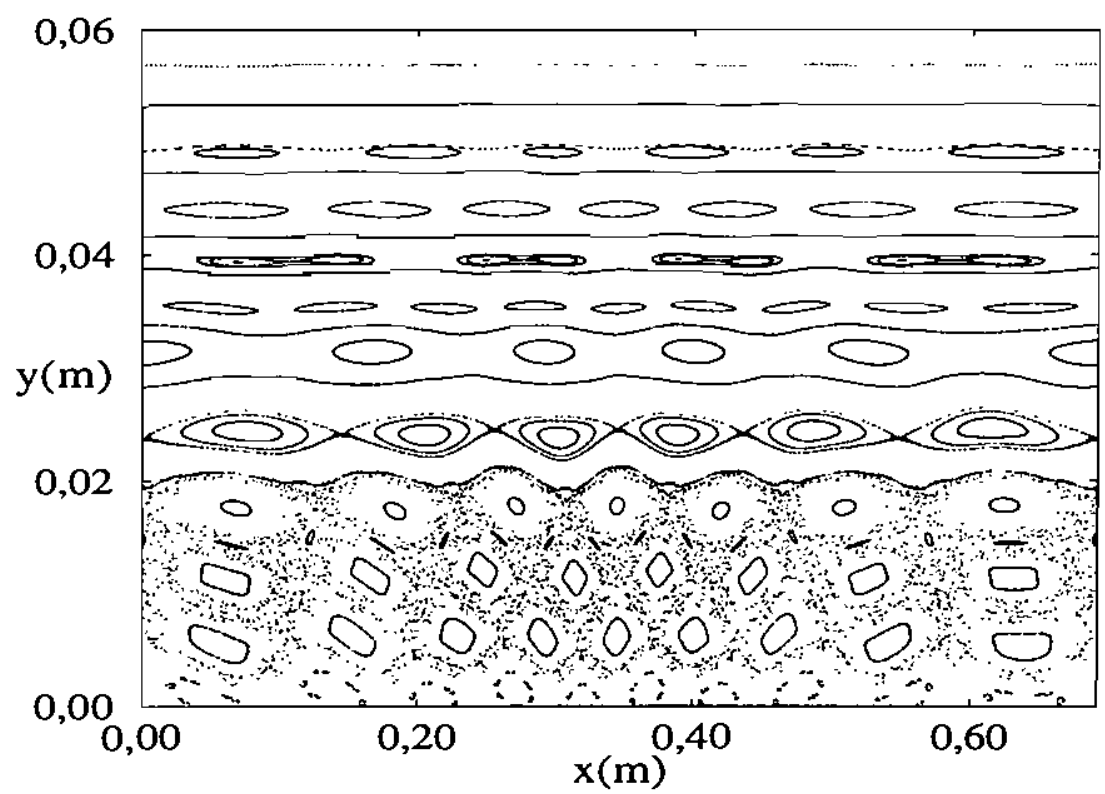

Figura 6.5: Seção de Poincaré do mapeamento de Viana-Caldas para $m=6$ e $I_{h}=300 \mathrm{~A}$ com correções toroidais, utilizando os parâmetros do TBR-1.

aproximações efetuadas em sua dedução. Temos que estes termos contradizem a equação da divergência nula das linhas de campo magnético $(\nabla \cdot \vec{B}=0)$, uma das equações fundamentais da física clássica, segundo a qual todo mapeamento, para descrever a evolução das linhas de campo magnético, deve ser conservativo.

Apesar do fato dos termos dissipativos no mapeamento de Viana e Caldas serem muito pequenos, eles acabam se tornando relevantes para um grande número de iterações, necessário para o cálculo preciso de expoentes de Lyapunov, por exemplo, e eles também geram fenômenos que não correspondem à realidade, como pode ser observado na figura 6.6, onde, para altas correntes no limitador ergódico, uma linha de campo começa a se dissipar para dentro das ilhas magnéticas durante a sua iteração.

Para contornarmos este tipo de problemas, vamos introduzir, no próximo capítulo, um mapeamento conservativo, baseado em parte no mapeamento de Viana e Caldas, para descrevermos a seção de Poincaré das linhas de campo magnético no interior de um tokamak, sob influência de um limitador ergódico magnético. 


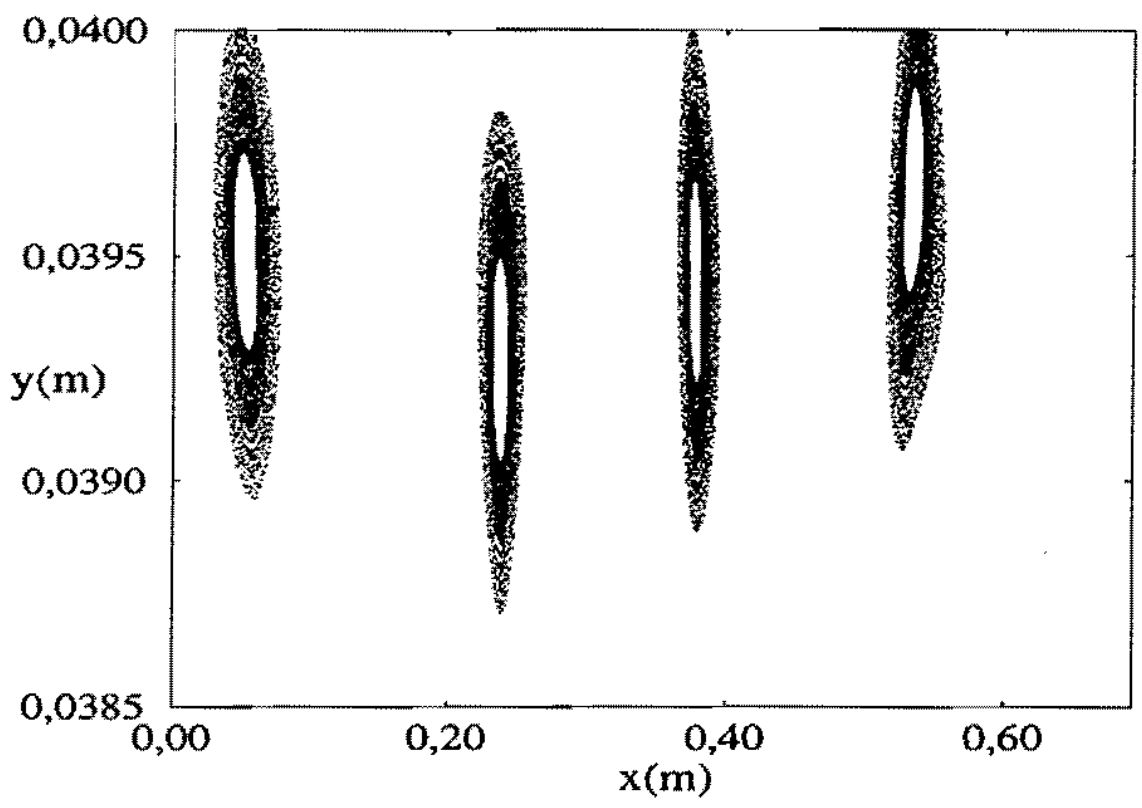

Figura 6.6: $O$ efeito dos termos dissipativos do mapeamento de Viana-Caldas sobre uma linha de campo magnético das ilhas da cadeia $8 / 2$ para $m=8$ e $I_{h}=1000 A$.

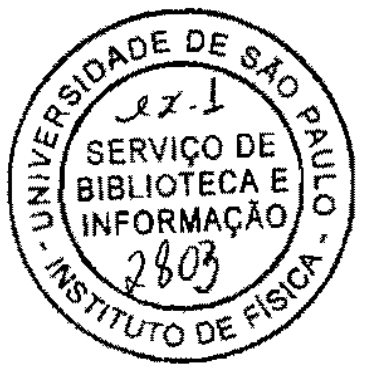




\section{Capítulo 7}

\section{O mapeamento bidimensional conservativo}

Neste capítulo é apresentada a dedução de um mapeamento bidimensional conservativo que fornece as seções de Poincaré das linhas de campo magnético no vaso de um tokamak, sob influência de limitadores ergódicos. Este novo mapa é desenvolvido retendo as características relevantes do mapa de Viana e Caldas, como a posição e largura das cadeias de ilhas magnéticas, mas eliminando os pequenos termos dissipativos que dão origem aos problemas na análise dinâmica das linhas de campo magnético, conforme visto no capítulo anterior.

Em seguida introduzimos os métodos utilizados na análise dinâmica deste mapeamento, consistindo nos espectros de Fourier, expoentes de Lyapunov, fatores de segurança, e no método dos falsos vizinhos para determinação da dimensão de mergulho.

\subsection{O mapeamento do equilíbrio das linhas de campo magnético}

Para o caso do equilíbrio cilíndrico, o mapeamento de Viana e Caldas em coordenadas cilíndricas é dado por:

$$
\begin{aligned}
r_{n}^{*} & =r_{n} \\
\theta_{n}^{*} & =\theta_{n}+\frac{2 \pi}{q\left(r_{n}\right)}
\end{aligned}
$$




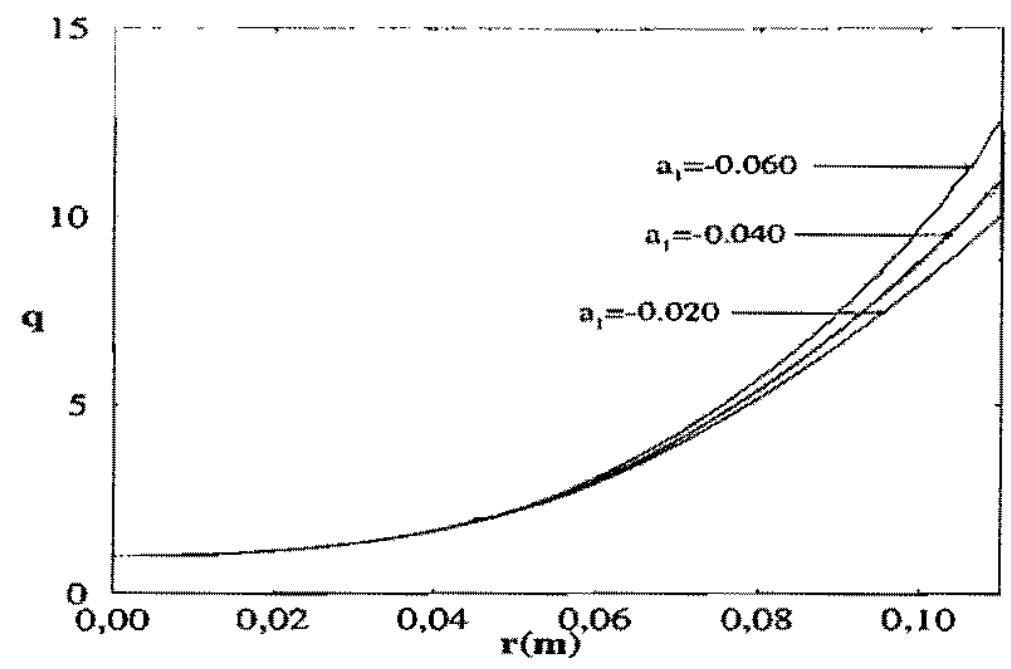

Figura 7.1: Perfis do fator de segurança para o equilíbrio toroidal do mapeamento de VianaCaldas (linha pontilhada) e para o mapeamento conservativo com vários valores de $a_{1}$ (linhas cheias).

onde $q(r)$ é o perfil do fator de segurança. Temos que a matriz jacobiana deste mapeamento é dada por:

$$
J_{c i l .} \equiv\left(\begin{array}{ll}
\frac{\partial r_{n}^{*}}{\partial r_{n}} & \frac{\partial r_{n}^{*}}{\partial \theta_{n}} \\
\frac{\partial \theta_{n}^{n}}{\partial r_{n}} & \frac{\partial \theta_{n}^{n}}{\partial \theta_{n}}
\end{array}\right)=\left(\begin{array}{cc}
1 & 0 \\
-\frac{2 \pi}{q^{2}} \frac{d q}{d r} & 1
\end{array}\right)
$$

e portanto temos que:

$$
\operatorname{det}\left(J_{\text {cil. }}\right)=1
$$

ou seja, o mapeamento é conservativo. Como todo mapeamento conservativo ele pode ser derivado de uma função geratriz, e escolhendo a função geratriz nas coordenadas $\left(r_{n}^{*}, \theta_{n}\right)$ vemos que ela pode ser escrita como sendo:

$$
G_{\text {cil. }}\left(r_{n}^{*}, \theta_{n}\right)=\theta_{n} r_{n}^{*}+2 \pi \int_{0}^{r_{n}^{*}} \frac{d \xi}{q(\xi)}
$$

O mapeamento do equilíbrio cilíndrico pode ser derivado desta função geratriz através das relações:

$$
\begin{aligned}
& r_{n}=\frac{\partial G_{c i l .}\left(r_{n}^{*}, \theta_{n}\right)}{\partial \theta_{n}} \\
& \theta_{n}^{*}=\frac{\partial G_{c i l .}\left(r_{n}^{*}, \theta_{n}\right)}{\partial r_{n}^{*}}
\end{aligned}
$$



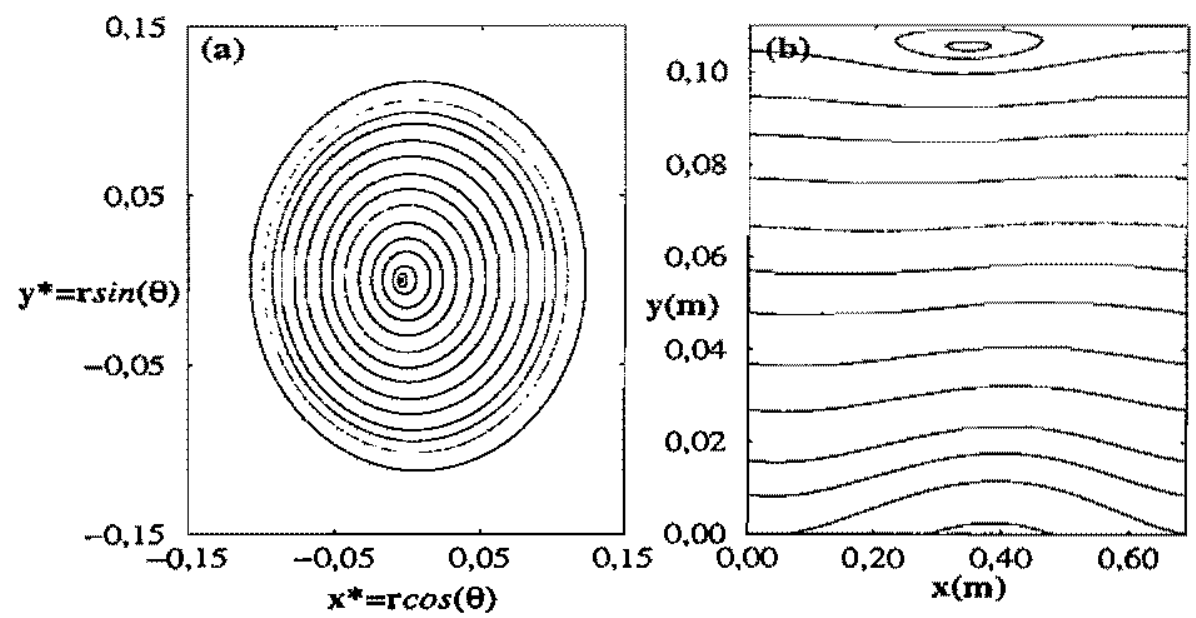

Figura 7.2: Seções de Poincaré das linhas de campo do equilíbrio toroidal (a) em coordenadas cilíndricas e (b) em coordenadas retangulares

Por outro lado, o mapeamento introduzido por Viana e Caldas, para a descrição do equilibrio com correçōes toroidais, apresenta pequenos termos dissipativos, o que nos obriga a desenvolver um novo mapeamento conservativo para uma descrição mais acurada. Este novo mapa deve apresentar as seguintes propriedades:

(a) para $\eta \equiv \frac{r}{R_{0}} \rightarrow 0$ ele deve se reduzir ao mapeamento do caso cilíndrico, que sabemos ser válido para grandes razões de aspecto;

(b) Os perfis de campo poloidal, transformada rotacional, e fator de segurança devem ser semelhantes ao modelo de Viana e Caldas, pois este descreve de forma satisfatória a posição e a largura das cadeias de ilhas magnéticas;

(c) ele deve ser derivável de uma função geratriz, o que nos garante que ele é conservativo.

Propomos entāo uma função geratriz genérica que leva a um mapeamento com as propriedades acima:

$$
G_{t o r .}\left(r_{n}^{*}, \theta_{n}\right)=G_{c i l .}\left(r_{n}^{*}, \theta_{n}\right)+\sum_{l=1}^{\infty} a_{l}\left(\frac{r_{n}^{*}}{R_{0}}\right)^{l} \cos ^{l} \theta_{n}
$$

onde os coeficientes $a_{i}$ são coeficientes genéricos a serem ajustados para satisfazermos a propriedade imposta (b). Numa primeira tentativa retemos apenas o primeiro termo da 
somatória, impondo $a_{l}=0(l \geq 2)$, e derivando a função geratriz obtemos o mapa:

$$
\begin{aligned}
r_{n}^{*} & =\frac{r_{n}}{1-a_{1} \sin \theta_{n}} \\
\theta_{n}^{*} & =\theta_{n}+\frac{2 \pi}{q\left(r_{n}^{*}\right)}+a_{1} \cos \theta_{n} .
\end{aligned}
$$

Comparando o perfil do fator de segurança deste novo mapa, para vários valores de $a_{1}$, com o perfil do fator de segurança do modelo de Viana-Caldas (fig.7.1) vemos que para $a_{1}=-0.04$ os perfis são praticamente idênticos. Assim sendo, uma expansão até primeira ordem é satisfatória para os nossos propósitos.

Calculando a seção de Poincaré deste mapeamento para o equilibrio (fig.7.2) vemos que em coordenadas cilíndricas o eixo magnético é ligeiramente deslocado do eixo geométrico. Este deslocamento não era observado em modelos anteriores, mas existe de fato e pode ser observado em soluçöes numéricas da equação de Grad-Shafranov[44, 45]. Na literatura, ele é conhecido como "shift de Shafranov". No caso do nosso mapeamento este deslocamento varia com $a_{1}$ e pode ser tomado como um critério alternativo para o ajuste desta constante. Já em coordenadas retangulares $(x=b \theta, y=b-r)$ vemos que as superfícies de equilíbrio já não são mais representados por retas, mas sim por curvas mais complexas, e surge uma pseudo-ilha próxima do centro, devido ao deslocamento do eixo magnético. Para contornar este problema poderiamos definir um novo sistema de coordenadas retangulares $\left(x^{\prime}, y^{\prime}\right)$ centrado no eixo magnético, mas não adotamos esta técnica, uma vez que nos estudos numéricos subsequentes estamos interessados na borda do plasma, e não na região central.

\subsection{O mapeamento da perturbação introduzida pelo limitador ergódico}

Passamos agora a desenvolver um mapeamento bidimensional conservativo para a perturbação efetuada sobre as linhas de campo magnético pelos anéis do limitador ergódico. Novamente nos baseamos no mapeamento de Viana e Caldas, onde esta perturbação é descrita pelo par de equaçôes:

$$
\begin{aligned}
& r_{n+1}=r_{n}^{*}-b C\left(\frac{r_{n}^{*}}{b}\right)^{m-1} \sin \left(m \theta_{n}^{*}\right) \\
& \theta_{n+1}=\theta_{n}^{*}-C\left(\frac{r_{n}^{*}}{b}\right)^{m-2} \cos \left(m \theta_{n}^{*}\right)
\end{aligned}
$$

onde definimos a constante adimensional $C=\frac{\mu_{0} m I_{h} g}{B_{0} \pi b^{2}}$. 
Para as regiōes de interesse das coordenadas $r$ e $\theta$, temos que em geral $\left\|\frac{\theta_{n+1}-\theta_{n}^{*}}{r_{n+1}-r_{n}^{*}}\right\| \gg 1$, ou seja, a perturbação angular é muito mais relevante do que a perturbação radial. Na dedução de um mapeamento conservativo retemos então a equação angular dentro da qual fazemos a aproximação $r_{n+1} \approx r_{n}^{*}$, e integramos esta para obter a funçäo geratriz. Já que $\theta_{n+1} \equiv \frac{\partial G_{p e r i}}{\partial r_{n+1}}$ temos que:

$$
G_{p e r t .}\left(r_{n+1}, \theta_{n}\right)=\int d r_{n+1} \theta_{n+1}\left(r_{n+1}, \theta_{n}^{*}\right)
$$

o que nos leva a:

$$
G_{p e r t .}\left(r_{n+1}, \theta_{n}^{*}\right)=r_{n+1} \theta_{n}^{*}-\frac{C b}{m-1}\left(\frac{r_{n+1}}{b}\right)^{m-1} \cos \left(m \theta_{n}^{*}\right)
$$

e utilizando a definição adicional $r_{\pi}^{*} \equiv \frac{\partial G_{\text {pert. }}}{\partial \theta_{n}^{*}}$ obtemos as equações para o mapeamento bidimensional conservativo da perturbação do limitador ergódico magnético:

$$
\begin{aligned}
r_{n}^{*} & =r_{n+1}+\frac{m C b}{m-1}\left(\frac{r_{n+1}}{b}\right)^{m-1} \sin \left(m \theta_{n}^{*}\right) \\
\theta_{n+1} & =\theta_{n}^{*}-C\left(\frac{r_{n+1}}{b}\right)^{m-2} \cos \left(m \theta_{n}^{*}\right)
\end{aligned}
$$

Ressaltamos aqui o fato da equação radial ser obtida em forma inversa, e podemos isolar o valor de $r_{n+1}$ apenas para alguns valores especiais de $m$ de pouco interesse prático. $\dot{E}_{\text {, }}$ portanto, necessário utilizarmos um método para determinar os zeros de uma função, como por exemplo o método de Newton, a cada iteração do mapeamento. Como $r_{n+1}-r_{n}^{*} \ll 1$ observamos numericamente que, se utilizarmos $r_{n}^{*}$ como estimativa inicial no método de Newton, temos uma ótima convergência para cerca de 10 iterações.

$O$ conjunto das equações $7.9,7.10,7.15$, e 7.16 compöe entäo um mapeamento bidimensional conservativo que descreve as seçōes de Poincaré das linhas de campo magnético dentro de um tokamak sob influência de limitadores ergódicos. Nos próximos itens deste capítulo vamos analisar os resultados numéricos obtidos com este mapeamento utilizando os parâmetros do tokamak TBR-1 da Universidade de São Paulo.

\subsection{Seções de Poincaré}

Passamos agora à análise das seções de Poincaré do mapeamento bidimensional conservativo obtido. Para tanto calculamos alguns exemplos numéricos para vários valores de $m$ e $X_{h}$, todos incluindo correções toroidais (fig.7.3). No cálculo de cada seção de Poincaré foram utilizadas de 20 a 30 condições iniciais, e a partir de cada uma destas condiçōes foram 

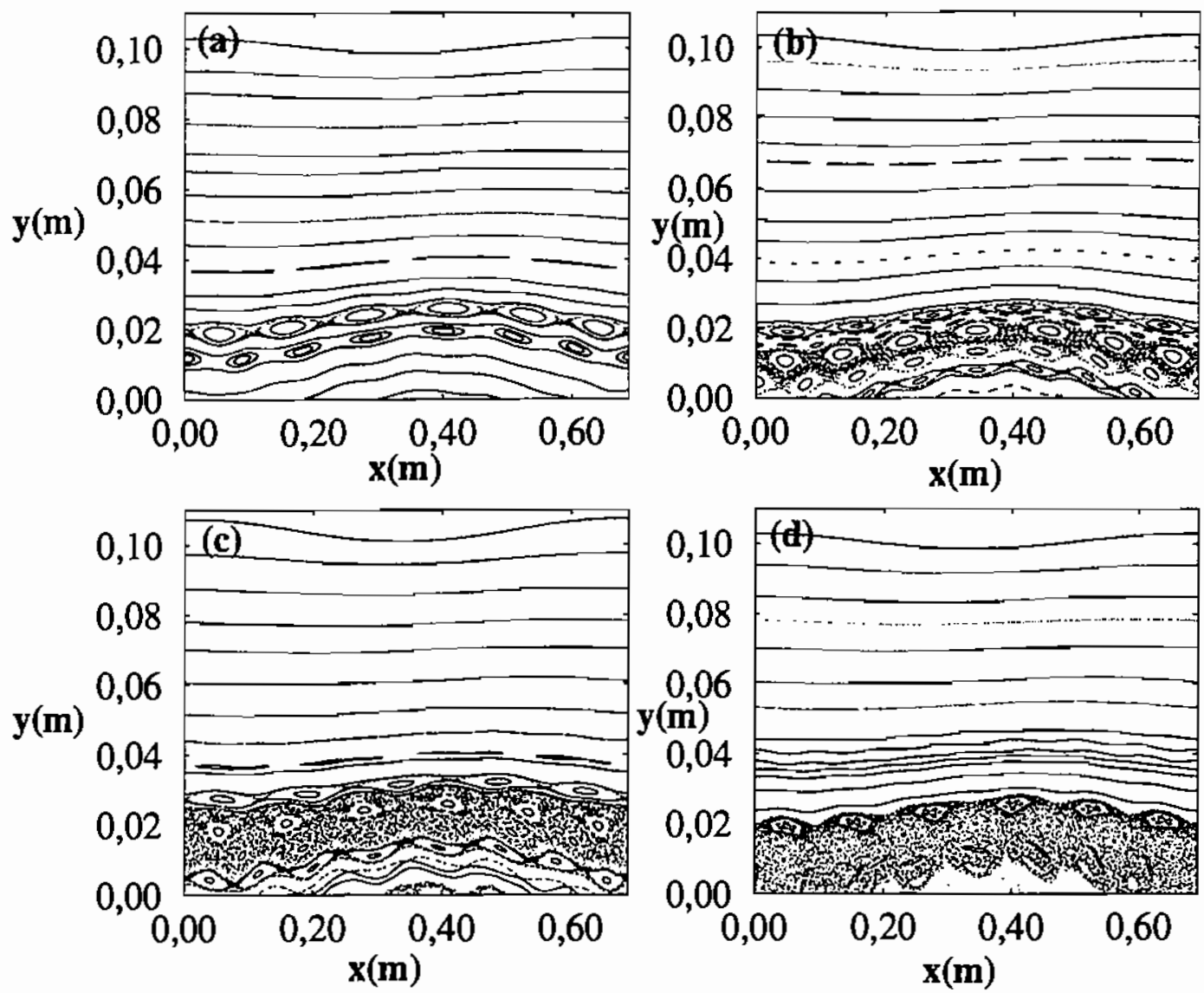

Figura 7.3: Seções de Poincaré do mapeamento bidimensional conservativo com correções toroidais para (a) $m=6$ e $I_{h}=200 A$, (b) $m=7$ e $I_{h}=200 A$, (c) $m=6$ e $I_{h}=600 A$, (d) $m=7$ e $I_{h}=600 A$.

calculadas 2000 iterações do mapeamento. Para possibilitar uma escolha mais eficiente de condições iniciais significativas, foi desenvolvido um programa interativo que permite a escolha de condições iniciais de forma gráfica, à medida que a seção de Poincaré é gerada. Em todos os exemplos observamos a formação de cadeias de ilhas magnéticas e surgimento de regiões de linhas de campo caóticas (a caoticidade destas linhas irregulares será verificada mais adiante) na borda do tokamak (valores baixos de $y$ ). Já o centro do plasma (valores de $y$ mais elevados) não é afetado de forma significativa pelas perturbações.

Para correntes mais baixas $\left(I_{h}=200 A\right)$ e $m=6$ (fig.7.3.a) vemos que apenas duas cadeias de ilhas apresentam largura significativa: a cadeia principal $6 / 1^{1}$, em torno da qual já existe

\footnotetext{
${ }^{1}$ Esta convençāo para definir as cadeias de ilhas magnéticas tem a seguinte interpretaçāo: o numerador
} 
uma estreita faixa de regime caótico, devido à superposição de suas cadeias secundárias mais externas, e, de forma menos acentuada, a sua cadeia vizinha 7/1. Observamos que para este valor de corrente estas duas cadeias de ilhas ainda se encontram separadas por superfícies magnéticas regulares fechadas.

Analisando agora o mesmo exemplo para uma corrente mais elevada $\left(I_{h}=800 \mathrm{~A}\right.$ fig.7.3.c), vemos que as cadeias $6 / 1$ e $7 / 1$ já estão bastante destruídas e várias outras cadeias de ilhas $(5 / 1,8 / 1,9 / 1)$ assumiram larguras significativas. Temos já uma larga faixa caótica no sistema, englobando as cadeias de ilhas $6 / 1$ a $8 / 1$.

Para $m=7$ (fig.7.3.b e fig.7.3.d), fenômenos semelhantes são observados, sendo que agora a cadeia principal de ilhas é a cadeia $7 / 1$, e temos que a superposição desta com sua vizinha $8 / 1$ já acontece a correntes baixas, devido à proximidade destas cadeias.

\subsection{Análise de Fourier do mapeamento bidimensional conservativo}

A primeira ferramenta que nós vamos introduzir para a análise das linhas de campo magnético é a análise de Fourier. Como no caso do mapeamento unidimensional dissipativo utilizamos o algoritmo da FFT ("Fast Fourier Transform") para o cálculo dos espectros. Como agora temos duas variáveis, utilizamos uma combinação das duas para o cálculo da transformada (a combinação escolhida foi $f(x, y)=x y$, mas qualquer outra combinação levaria aos mesmos resultados).

Calculando o espectro de Fourier de uma linha magnética regular que se situa sobre uma superfície magnética que forma um toro fechado (fig.7.4.c), observamos que ocorrem apenas alguns picos espectrais discretos. O pico principal ocorre na frequência com que a linha magnética se desloca ao longo desta superfície toroidal. Ainda podem ser observados alguns picos muito pequenos associados à distorção deste toro, e à combinação da frequência desta distorção com a frequência do pico principal.

O espectro de Fourier de uma trajetória regular que se situa dentro de uma cadeia de ilhas magnéticas (fig.7.4.d) também apresenta apenas picos espectrais discretos. Neste caso o pico principal ocorre na frequência associada à cadeia em questão. Como no nosso exemplo numérico estamos sobre a cadeia $6 / 1$, temos que a frequência do pico principal é igual a

corresponde ao número de ilhas da cadeia. O denominador corresponde ao número de ilhas que a linha se desloca na direção poloidal a cada volta toroidal. De fato, o valor da fração corresponde exatamente à transformada rotacional das linas de campo sobre a cadeia de ilhas. 

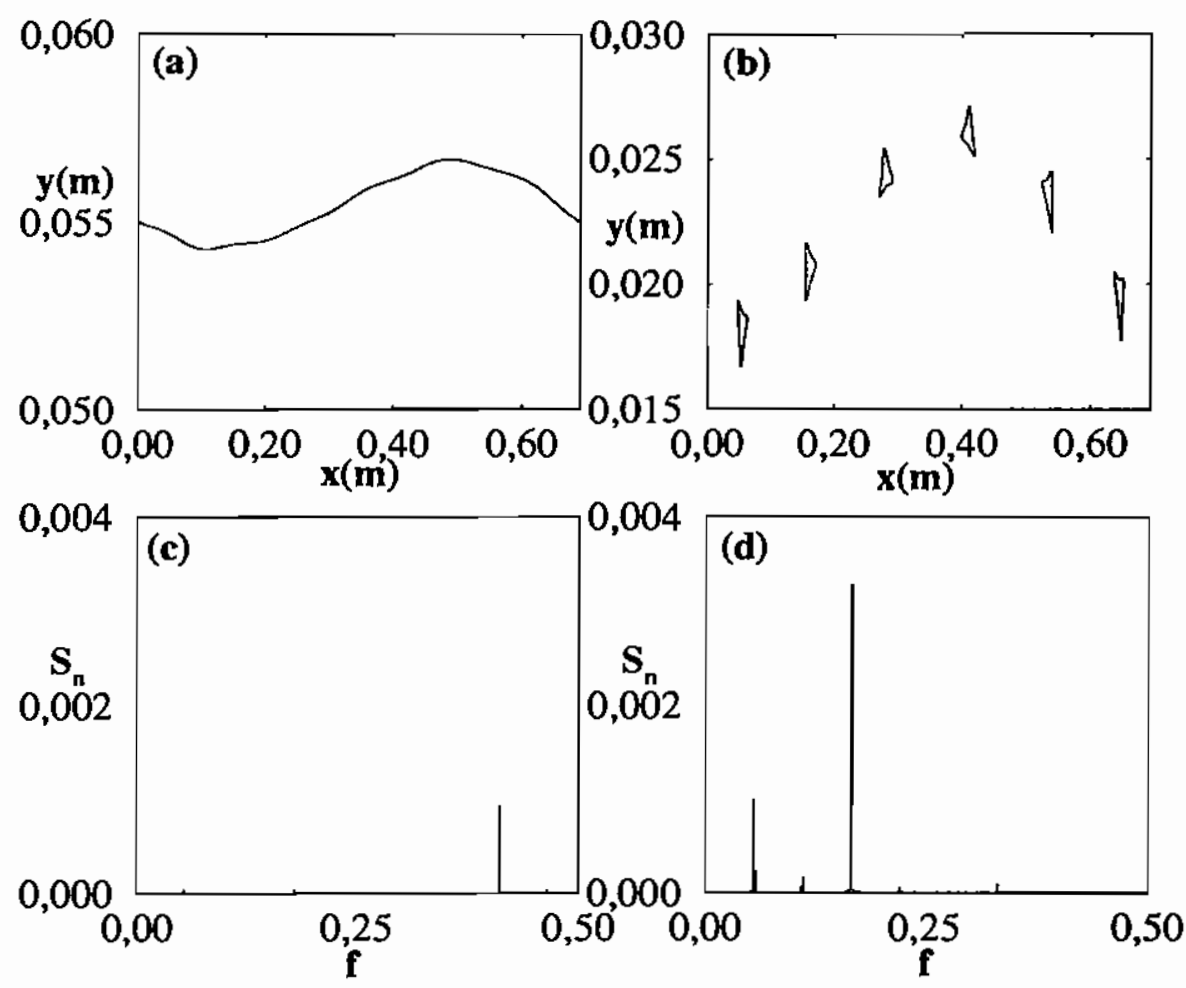

Figura 7.4: Trajetórias regulares do mapeamento bidimensional conservativo para $I_{h}=700 \mathrm{~A}$ e $m=6$ com condições iniciais (a) $x_{0}=0$ e $y_{0}=0,055 m$ e (b) $x_{0}=0,05 m$ e $y_{0}=0,018 m$, e seus respectivos espectros de Fourier ((c) e (d)).

$f_{p}=1 / 6$. Ocorre ainda um pico secundário bastante acentuado na frequência associada à "rotação" da linha de campo magnética sobre cada ilha $\left(f_{r}\right)$. E finalmente, temos uma série de picos menores devido à superposição destas duas frequências principais, apresentando frequências como $f_{p}+f_{r}, f_{p}-f_{r}$, e assim por diante.

Passando agora ao cálculo de espectros de trajetórias caóticas (fig.7.5), obtemos espectros de fundo contínuo que apresentam maior concentração em torno de algumas frequências específicas, ou mesmo picos discretos se superpondo ao fundo contínuo. Observamos que o fundo contínuo é sempre bastante elevado à medida em que nos aproximamos de $f=0$ (baixas frequências). Para uma trajetória caótica que se distribui em torno de várias cadeias de ilhas, sem ficar mais concentrada em torno de uma em particular (fig.7.5.a) o espectro não apresenta picos discretos acentuados, mas apenas uma banda contínua mais acentuada em torno das frequências associadas às cadeias de ilhas (no caso $f=1 / 6$ e $f=1 / 7$ - fig.7.5.c). Já quando a linha de campo magnético caótica tende a ficar mais tempo na proximidade de 

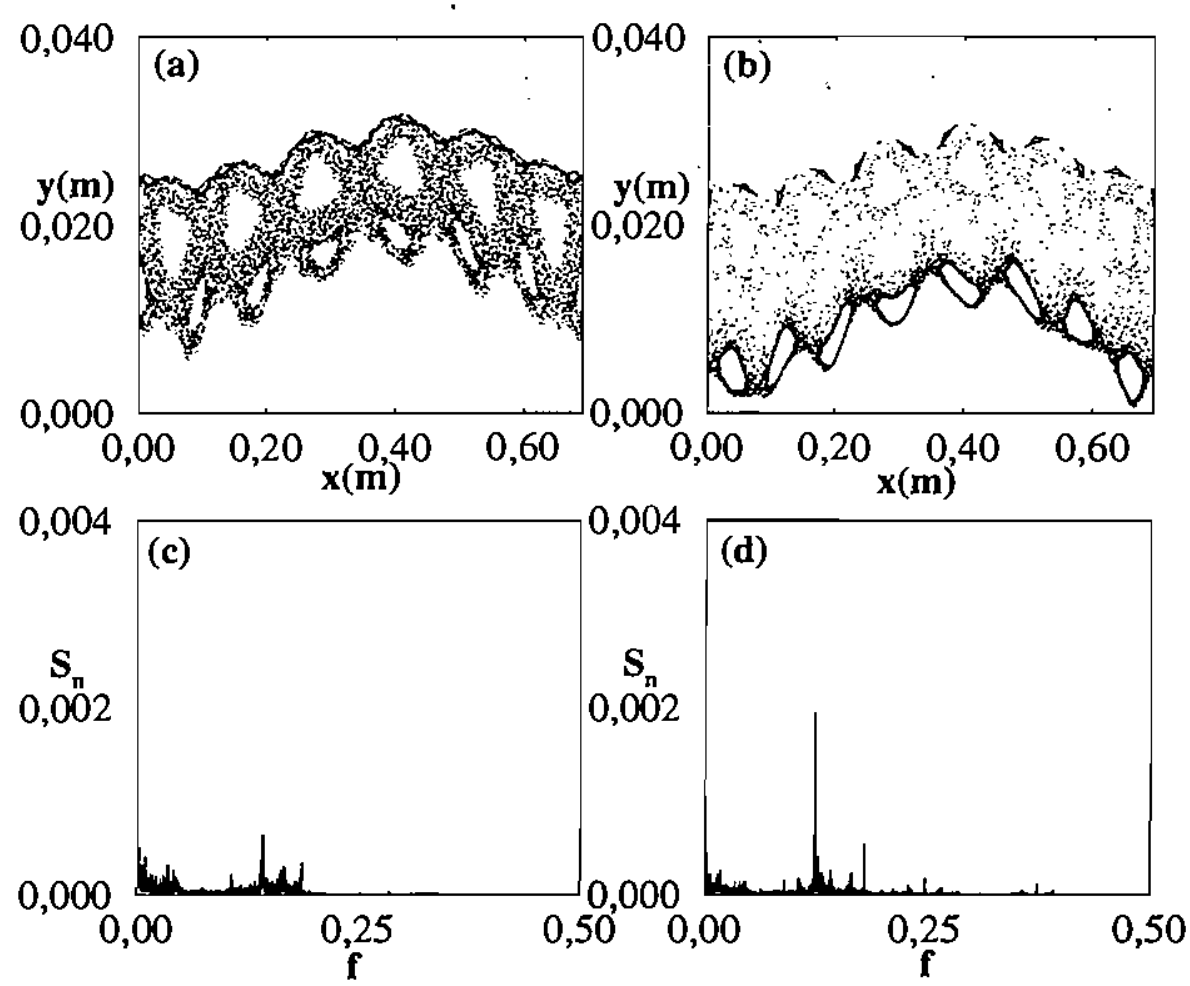

Figura 7.5: Trajetórias irregulares do mapeamento bidimensional conservativo para $I_{h}=$ $700 \mathrm{~A}$ e $\mathrm{m}=6 \mathrm{com}$ condições iniciais (a) $x_{0}=0$ e $y_{0}=0,020 \mathrm{~m}$ e (b) $x_{0}=0$ e $y_{0}=0,005 m$, e seus respectivos espectros de Fourier ((c) e (d)).

uma cadeia de ilhas, como acontece no exemplo da figura 7.5.b em torno da cadeia $8 / 1$, pode ser observado um pico discreto na frequência correspondente, no caso $f=1 / 8$ (fig.7.5.d).

Vimos então como uma linha de campo magnético pode ser classificada em toro fechado, cadeia de ilhas, ou regime caótico, de acordo com o seu espectro de Fourier, e ainda vimos que no caso caótico é possivel identificar as cadeias de ilhas magnéticas em torno das quais o regime caótico se situa.

\subsection{Expoentes de Lyapunov do mapeamento bidimen- sional conservativo}

Outro método para distinguir entre linhas de campo regulares e caóticas é o cálculo de expoentes de Lyapunov associadas a estas. Já vimos no item 5.6 que para um mapeamento 

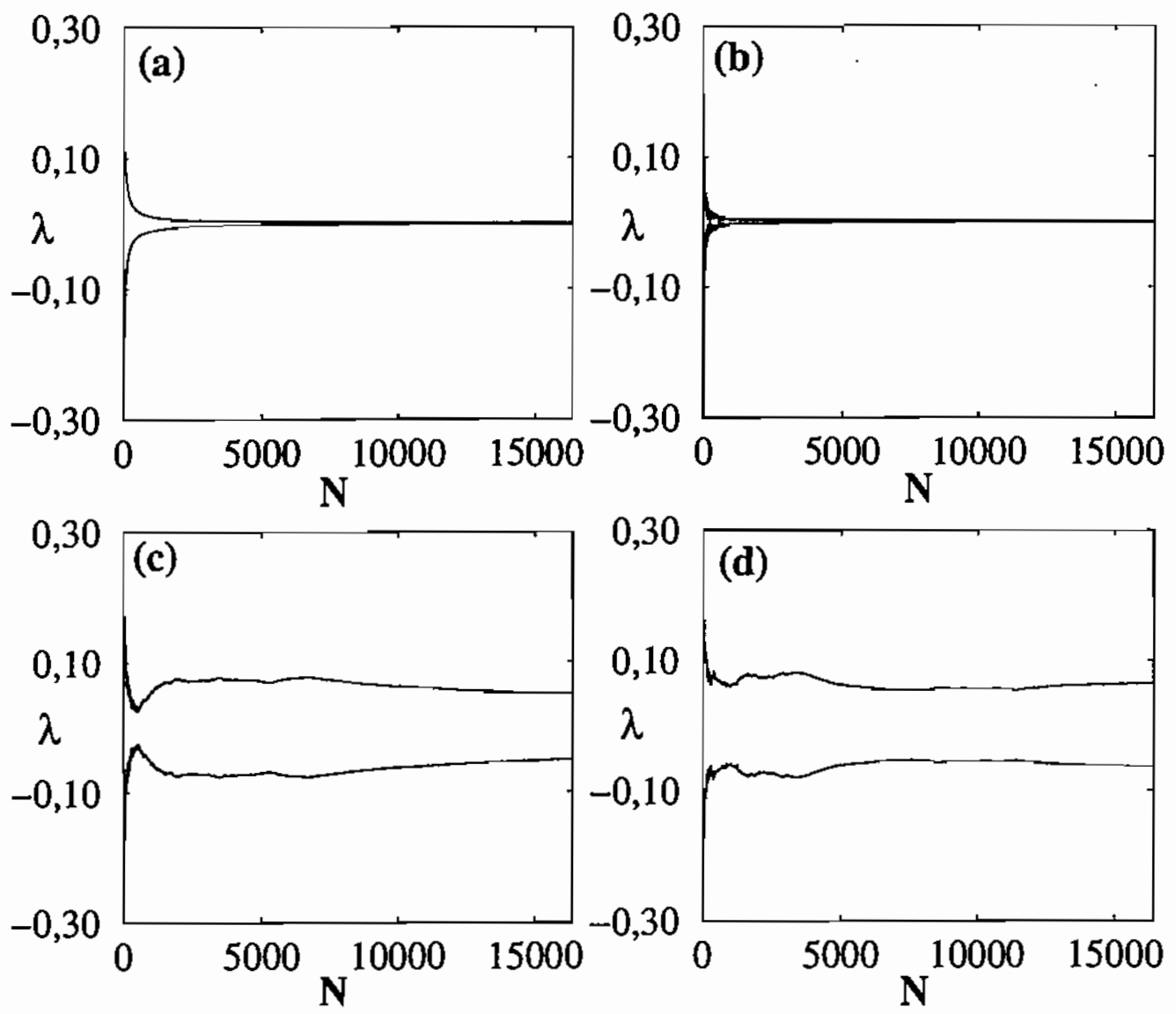

Figura 7.6: Convergência dos expoentes de Lyapunov para as trajetórias das figuras (a) 7.4.a, (b) 7.4.b, (c) 7.5.a, e (d) 7.5.b.

bidimensional os expoentes de Lyapunov de uma trajetória são definidos por[10]:

$$
\lambda_{j} \equiv \lim _{N \rightarrow \infty} \frac{1}{N} \ln \left\|a_{j}\left(\prod_{k=0}^{N} J^{k}\right)\right\|
$$

onde temos que:

$$
J^{k} \equiv \frac{\partial\left(r_{n+1}, \theta_{n+1}\right)}{\partial\left(r_{n}, \theta_{n}\right)}=\left(\begin{array}{ll}
\frac{\partial r_{n+1}}{\partial r_{n}} & \frac{\partial r_{n+1}}{\partial \theta_{n}} \\
\frac{\partial \theta_{n+1}}{\partial r_{n}} & \frac{\partial \theta_{n+1}}{\partial \theta_{n}}
\end{array}\right)
$$

é a matriz jacobiana da $k$-ésima iteração do mapeamento, e $a_{j}(M)$ o $j$-ésimo autovalor da matriz $M$. Sabemos ainda que para um sistema conservativo a soma de todos os expoentes de Lyapunov de uma dada trajetória tem que ser nula. Como temos apenas dois expoentes para um mapeamento bidimensional, temos duas possibilidades: (i) $\lambda_{1}=\lambda_{2}=0$, o que 
corresponde a trajetórias regulares, estejam elas localizadas sobre superfícies magnéticas fechadas, ou cadeias de ilhas magnéticas; (ii) $\lambda_{1}=-\lambda_{2}$ com $\left\|\lambda_{j}\right\|>0$, o que corresponde a trajetórias caóticas.

Como a matriz jacobiana do nosso mapa bidimensional conservativo não é triangular, como ocorria com o mapa do item 5.6, a princípio nós teríamos que calcular a produtória das matrizes jacobianas. Acontece porém que para trajetórias caóticas os coeficientes da matriz produtória tendem a crescer de forma exponencial, o que impossibilita o cálculo numérico para o número de iterações necessário. Recorremos então a um artifício[46]. Reescrevemos a matriz produtória dos jacobianos como sendo:

$$
\begin{aligned}
\prod_{k=0}^{N} J^{k} & =J^{0} \cdot J^{1} \cdot \dot{J}^{2} \ldots J^{N}=J^{0} \cdot\left(T^{0} \cdot T^{0^{-1}}\right) \cdot J^{1} \cdot\left(T^{1} \cdot T^{1^{-1}}\right) \ldots . J^{N}= \\
& =\left(I \cdot J^{0} \cdot T^{0}\right)\left(T^{0^{-1}} \cdot J^{1} \cdot T^{1}\right) \ldots\left(T^{(N-1)^{-1}} \cdot J^{N}\right)=Q^{0} \cdot Q^{1} \ldots Q^{N}
\end{aligned}
$$

onde $I$ é a matriz identidade e definimos as matriz unitárias:

$$
T^{k} \equiv\left(\begin{array}{cc}
\cos \theta_{k} & \sin \theta_{k} \\
-\sin \theta_{k} & \cos \theta_{k}
\end{array}\right)
$$

e as matrizes $Q_{k}$ que impomos serem triangulares:

$$
Q^{k} \equiv T^{k-1} J^{k} T^{k^{-1}}=\left(\begin{array}{cc}
a_{k} & b_{k} \\
0 & c_{k}
\end{array}\right)
$$

Para impor que as matrizes $Q^{k}$ sejam de fato triangulares impomos as seguintes condições:

$$
\begin{aligned}
& \tan \theta_{k+1}=\frac{J_{21}^{k+1} \cos \theta_{k}-J_{11}^{k+1} \sin \theta_{k}}{J_{12}^{k+1} \sin \theta_{k}-J_{22}^{k+1} \cos \theta_{k}} \\
& \theta_{-1}=0 .
\end{aligned}
$$

Com o auxílio desta decomposição podemos escrever os expoentes de Lyapunov como:

$$
\begin{aligned}
& \lambda_{1}=\lim _{N \rightarrow \infty} \frac{1}{N} \sum_{k=0}^{N} \ln \left\|a_{k}\right\| \\
& \lambda_{2}=\lim _{N \rightarrow \infty} \frac{1}{N} \sum_{k=0}^{N} \ln \left\|c_{k}\right\|
\end{aligned}
$$

onde os coeficientes $a_{k}$ e $c_{k}$ são, respectivamente, dados por:

$$
\begin{aligned}
& a_{k}=\left(J_{11}^{k} \cos \theta_{k-1}+J_{21}^{k} \sin \theta_{k-1}\right) \cos \theta_{k}+\left(J_{12}^{k} \cos \theta_{k-1}+J_{22}^{k} \sin \theta_{k-1}\right) \sin \theta_{k} \\
& c_{k}=\left(J_{22}^{k} \cos \theta_{k-1}-J_{12}^{k} \sin \theta_{k-1}\right) \cos \theta_{k}+\left(J_{11}^{k} \sin \theta_{k-1}-J_{21}^{k} \cos \theta_{k-1}\right) \sin \theta_{k} .
\end{aligned}
$$


Calculamos então os expoentes de Lyapunov, utilizando este método, para algumas linhas de campo magnético, tanto regulares como caóticas (fig.7.6). Para as linhas de campo regulares (fig.7.6.a-b) os expoentes convergem rapidamente a 0 , conforme esperado, sendo que para a linha de campo sobre a superfície toroidal fechada a convergência é uniforme, enquanto que para a linha sobre a cadeia de ilhas ela ocorre de forma oscilatória. Já para as linhas de campo caóticas (fig.7.6.c-d) a convergência não é tão boa, mas os números obtidos são distintamente não nulos. Este problema de convergência ocorre devido ao fato das linhas de campo ficarem presas em proximidades de cadeias de ilhas magnéticas devido aos cantori ${ }^{2}$ formados pelas cadeias de ilhas secundárias em processo de destruição.

\subsection{Fatores de segurança do mapeamento bidimensio- nal conservativo}

Outro expoente, bastante utilizado para a classificação das linhas de campo magnético do mapa bidimensional conservativo obtido, é o fator de segurança. $O$ fator de segurança de uma linha de campo magnético é definido como sendo[16]:

$$
q \equiv \lim _{k \rightarrow \infty} \frac{2 \pi k}{\sum_{j=0}^{k}\left(\theta_{j+1}-\theta_{j}\right)}
$$

e descreve o inverso do deslocamento angular médio por iteração, normalizado por um fator $2 \pi$. A linha de campo pode ser classificada como pertencente a uma das três categorias seguintes, conforme o seu fator de segurança: (i) se $q$ converge para um número irracional a linha de campo é regular e situa-se sobre um toro fechado; (ii) se $q$ converge para um número racional a linha de campo pode estar sobre um toro ressonante (para $I_{h}=0$ ) ou sobre uma cadeia de ilhas magnéticas (para $I_{h}>0$ ); (iii) se $q$ não converge, a linha de campo em questão é caótica.

Calculando, numericamente, o fator de segurança para algumas linhas de campo (fig.7.7), vemos que, de fato, para a trajetória sobre um toro fechado, ele converge, de forma praticamente imediata, para um número irracional (fig.7.7.a). Já para a trajetória que se situa sobre a cadeia de ilhas $6 / 1, q$ também converge, muito rapidamente, para $q=6$ (fig.7.7.b).

\footnotetext{
${ }^{2}$ Os cantori são formados pela ruptura de curvas fechadas nas seções de Poincaré, que para valores de corrente $I_{h}$ logo acima da sua ruptura constituem cadeias de ilhas secundárias de largura muito fina e com intervalos caóticos muito estreitos entre as extremidades das ilhas, dificultando assim a difusão das linhas de campo caóticas em sua vizinhança.
} 

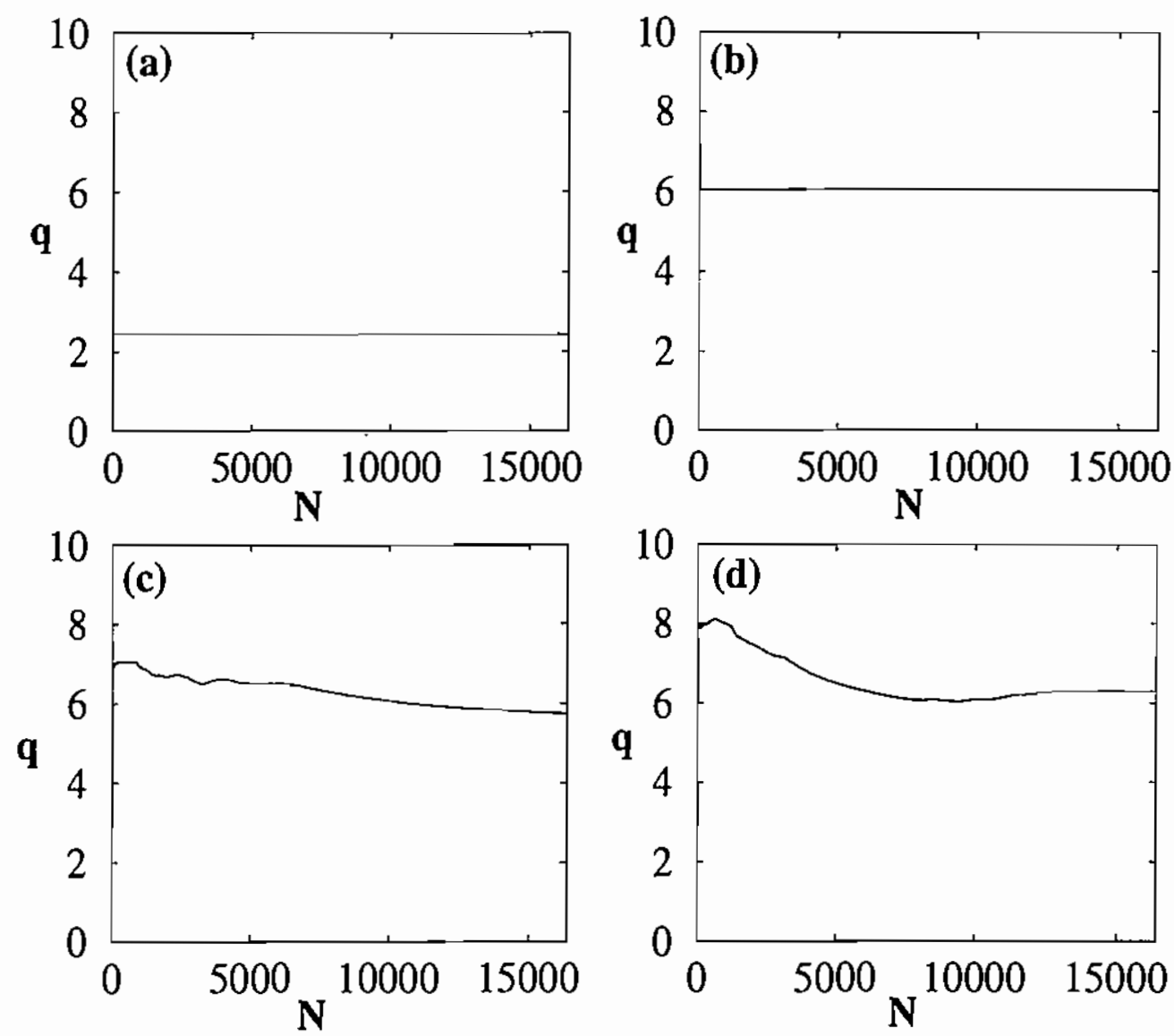

Figura 7.7: Convergência dos fatores de segurança para as trajetórias das figuras (a) 7.4.a, (b) 7.4.b, (c) 7.5.a, e (d) 7.5.b.

De fato, o valor de $q$ está diretamente associado ao número de ilhas da cadeia. Para uma cadeia $m / n$ temos que $q=m / n$. Para obtermos esta correspondência direta é que o fator $2 \pi$ foi incluido na definiçã்.

Já para as trajetórias caóticas vemos que os fatores de segurança não convergem (fig.7.7.cd), mas ficam oscilando dentro de uma faixa de valores delimitada pelas cadeias de ilhas imersas na região caótica percorrida. Se a linha de campo magnético ficar muito tempo próximo a uma cadeia de ilhas devido aos cantori formados pelas cadeias de ilhas secundárias rompidas, podemos até obter uma aparente convergência durante um grande número de iterações, mas esta é rompida assim que a trajetória se afasta desta cadeia de ilhas. 


\subsection{Dimensões de mergulho das trajetórias das linhas de campo magnéticas}
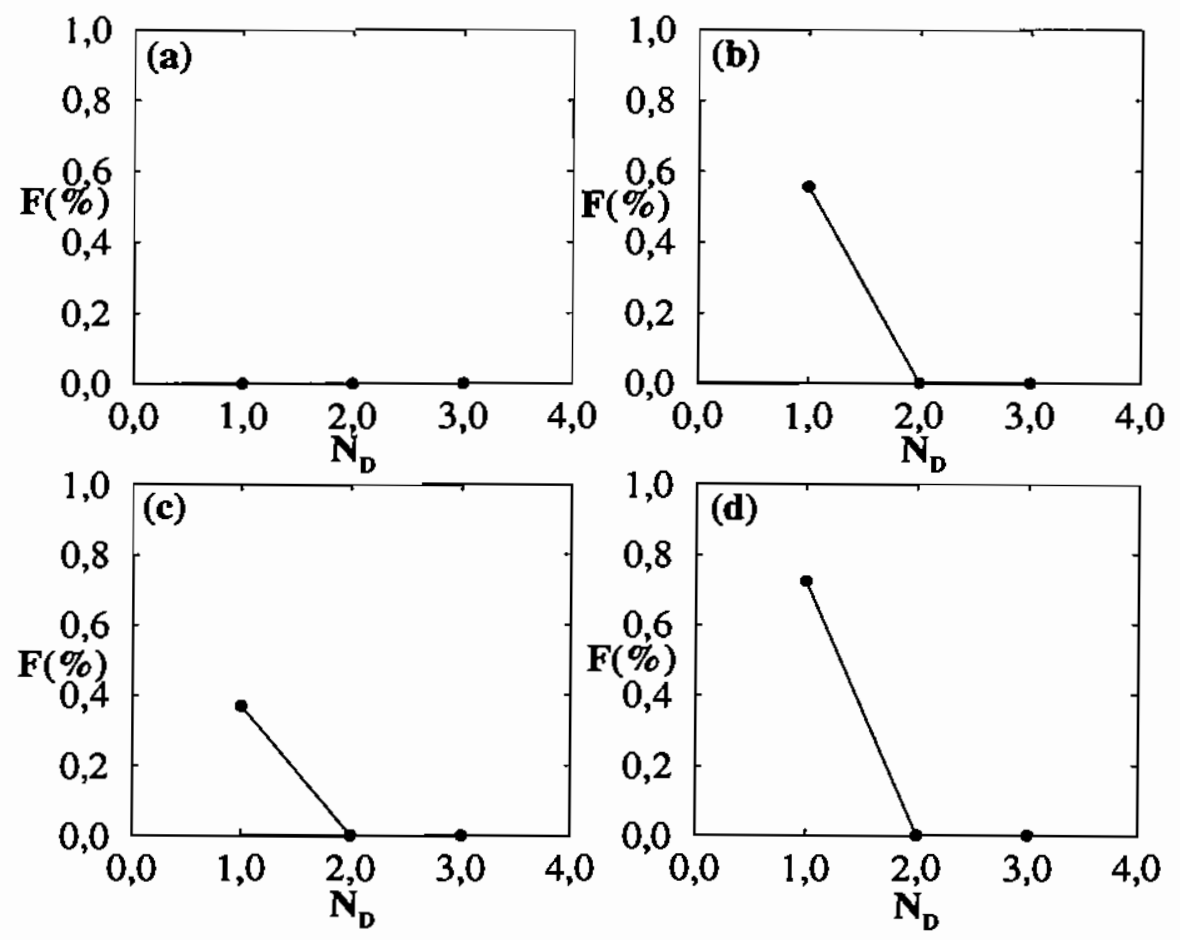

Figura 7.8: Porcentagem de falsos vizinhos para dimensōes de 1 a 3 para as trajetórias das figuras (a) 7.4.a, (b) 7.4.b, (c) 7.5.a, e (d) 7.5.b.

O último coeficiente que nós introduzimos para a análise dinâmica das linhas de campo magnético obtidas com o mapeamento bidimensional conservativo, é a dimensão de mergulho[33]. A dimensão de mergulho $\left(D_{m}\right)$ de uma linha de campo magnética é definida como sendo a menor dimensão inteira na qual esta linha pode ser reconstruída mantendo as suas propriedades topológicas originais. No caso do nosso mapeamento bidimensional, a dimensão de mergulho divide a trajetória em três tipos possíveis: o eixo magnético tem $D_{m}=0$; as linhas de campo sobre os toros fechados têm $D_{m}=1$; e as linhas sobre ilhas magnéticas e linhas caóticas têm $D_{m}=2$. Sendo assim, a dimensão de mergulho representa uma ferramenta importante para distinguir entre cadeias de ilhas e toros fechados, uma vez que ambos apresentam expoentes de Lyapunov nulos, espectros discretos, e fatores de segurança que convergem, se bem que no caso de ilhas magnéticas para números racionais, e no 


\subsection{Resumo da classificação das linhas de campo do mapa bidimensional}

conservativo

caso de toros para números irracionais. Mas numericamente é muito difícil distinguir entre estes dois casos, ainda mais para cadeias de muitas ilhas.

Para calcularmos a dimensão de mergulho de uma linha de campo magnético utilizamos um método conhecido na literatura como "método dos falsos vizinhos". Este método consiste em fazer a reconstrução do atrator em várias dimensōes $(1,2,3, \ldots)$ utilizando uma das variáveis do atrator (no caso do nosso mapeamento bidimensional conservativo escolhemos a variável $\theta_{n}$ ). Temos que o atrator reconstruído em uma dimensão consiste em um conjunto de pontos $\theta_{n}$, em duas dimensões em um conjunto de pontos $\left(\theta_{n}, \theta_{n+1}\right)$, e assim por diante. Pegamos então cada conjunto destes e procuramos todos os pares de pontos $(j, k)$ tais que $\left\|\left(\theta_{j}, \theta_{j+1}, \ldots\right)-\left(\theta_{k}, \theta_{k+1}, \ldots\right)\right\|<\epsilon$, onde $\epsilon$ é uma precisão a ser ajustada. Estes pares de pontos são denominados vizinhos. Em seguida acrescentamos uma dimensão na reconstrução do atrator e verificamos quantos dos pares de vizinhos calculados deixaram de ser vizinhos. Estes pontos são denominados "falsos vizinhos". A dimensão de reconstrução mais baixa que apresente uma porcentagem $F$ praticamente nula de falsos vizinhos é considerada a dimensão de mergulho $\left(D_{m}\right)$ do atrator em questão.

Calculando as porcentagens de falsos vizinhos para dimensões de 1 a 3 para algumas linhas de campo magnético (fig.7.8), vemos que no caso de uma linha de campo magnético regular sobre um toro fechado (fig.7.8.a) a porcentagem de falsos vizinhos é nula para todas as dimensões. Tomamos então a mais baixa destas dimensões como a dimensão de mergulho $\left(D_{m}=1\right)$. Já para linhas de campo sobre ilhas magnéticas ou linhas caóticas (fig.7.8.bd) vemos que a porcentagem de falsos vizinhos para a dimensão 1 é sempre distintamente não-nula, e portanto todos estes exemplos apresentam $D_{m}=2$, conforme esperado.

\subsection{Resumo da classificação das linhas de campo do mapa bidimensional conservativo}

Apresentamos, a seguir, uma tabela com o resumo da classificação das linhas de campo magnético do mapeamento bidimensional conservativo: 


\begin{tabular}{|c|c|c|c|}
\hline Linha de campo & Sobre toro fechado & Sobre cadeia de ilhas & Caótica \\
\hline & & & \\
\hline Expoentes de Lyapunov $(\lambda)$ & nulos & nulos & não-nulos \\
\hline Fator de segurança & irracional & racional & não converge \\
\hline Espectro de Fourier & discreto & discreto & contínuo \\
\hline Dimensão de mergulho & 1 & 2 & 2 \\
\hline
\end{tabular}

Tabela 7.1: Resumo da classificação das linhas de campo magnético do mapeamento bidimensional conservativo. 


\section{Capítulo 8}

\section{Análise do mapeamento conservativo do limitador ergódico}

Neste capítulo passamos a fazer a análise dinâmica do mapeamento bidimensional conservativo para a seção de Poincaré das linhas de campo magnético no vaso de um tokamak sob influência de limitadores ergódicos, obtido no capítulo anterior. Calculamos expoentes de Lyapunov em planos de parâmetros para observar o surgimento e alargamento de bandas caóticas com o aumento da corrente nas hélices, fazemos cortes nestes planos de parâmetros para estudos mais detalhados, e calculamos os planos espectrais do mapeamento.

Também passamos a estudar a difusão das linhas de campo magnético, introduzindo, para tanto, os padrões de escape, e fazendo uma análise dos coeficientes locais de difusão. Finalmente, fazemos uma análise da robustez do mapeamento frente a pequenas flutuações aleatórias na corrente do limitador ergódico.

\subsection{Planos de parâmetros do mapeamento bidimensio- nal conservativo}

Uma das questōes relevantes na análise do mapeamento do limitador ergódico é a análise do crescimento da largura das bandas caóticas entre as cadeias de ilhas, à medida que aumentamos a corrente nas hélices $\left(I_{h}\right)$. Existem trabalhos mostrando que, para baixas correntes, o crescimento da largura das cadeias de ilhas magnéticas tende a ser proporcional à raiz quadrada da corrente $\left(\delta_{I_{h}} \approx \sqrt{I_{h}}\right)$ e que as faixas caóticas correspondem, a grosso modo, às regiões em que estas cadeias de ilhas se sobrepõem umas às outras[47]. 
Mas ainda existe uma série de questões importantes em relação ao processo de crescimento das cadeias de ilhas magnéticas: o que acontece para correntes mais altas no limitador? Qual é a importância das cadeias de ilhas secundárias neste processo? Os centros de cadeias de ilhas principais são fixos ou se deslocam com a variação da corrente? Para analisarmos estas questões mais a fundo vamos observar alguns planos de parâmetros do mapeamento bidimensional conservativo.
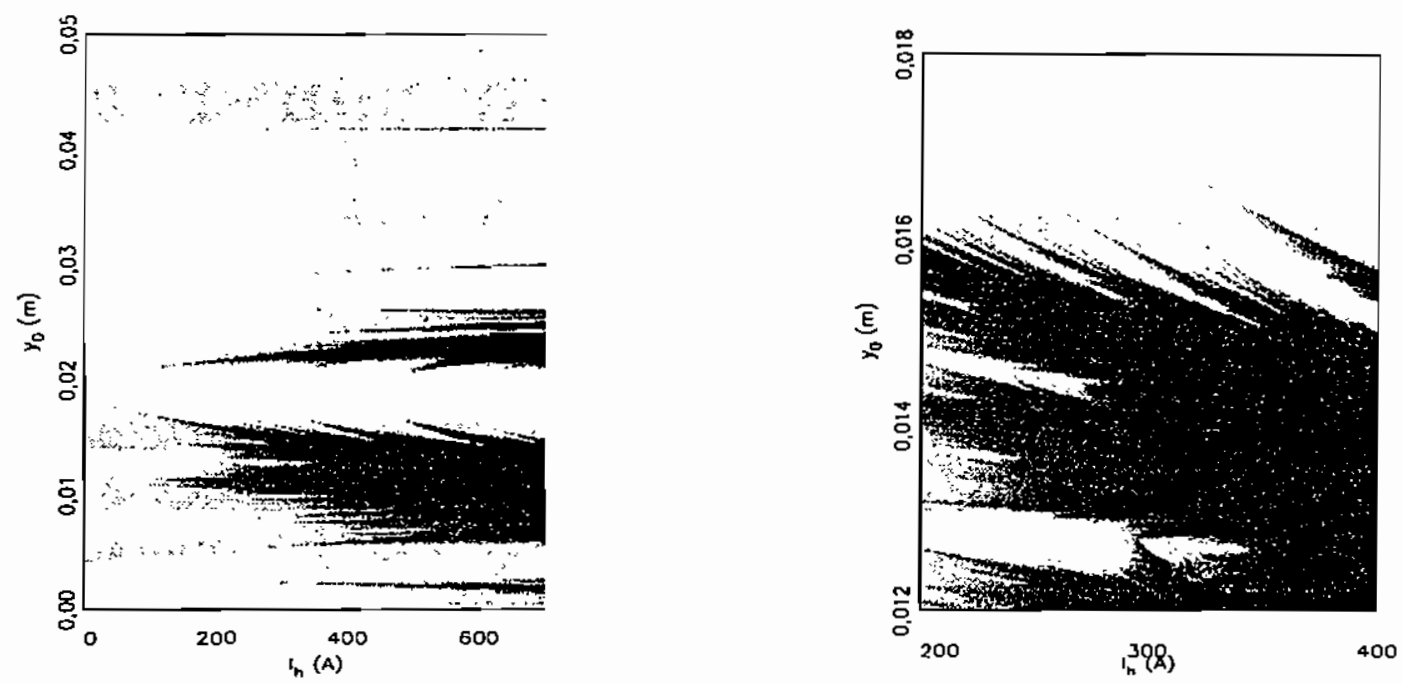

Figura 8.1: Planos de parâmetros com expoentes máximos de Lyapunov para o mapeamento bidimensional conservativo do limitador ergódico magnético com $x_{0}=0,05 \mathrm{~m}$ e $m=6$ pares de espiras. Quanto mais escuro o ponto, maior o expoente máximo de Lyapunov.

O mapa bidimensional conservativo a ser analisado tem, a rigor, dois parâmetros: a corrente do limitador $\left(I_{h}\right)$ e o número de pares de espiras $(m)$, sendo que o segundo é um parâmetro discreto que assume apenas valores inteiros. Sendo assim, não parece possível, a princípio, fazermos análise deste sistema em um plano de parâmetros, para o qual necessitamos dois parâmetros contínuos. Acontece porém que, ao contrário do mapa unidimensional dissipativo, no mapa conservativo a evolução e as características dinâmicas da trajetória (no caso a linha de campo magnético) dependem fortemente da posição inicial $\left(x_{0}, y_{0}\right)$. Podemos considerar então estes valores iniciais como "pseudo-parâmetros" para fins de análise dinâmica.

Calculamos então os expoentes máximos de Lyapunov sobre um plano de parâmetros $y_{0} \times I_{h}$, fixando os valores de $x_{0}$ e $m$, na borda do tokamak (fig.8.1.a). Observamos que para valores de corrente muito próximos de zero todos os expoentes de Lyapunov são pratica- 
mente nulos, o que já era esperado, pois as cadeias de ilhas magnéticas ainda não cresceram suficientemente para ocorrer superposição. Para $100 A<I_{h}<200 A$ começam a surgir as primeiras faixas escuras, ainda muito finas, de expoentes de Lyapunov positivos, correspondentes ao surgimento das primeiras faixas ainda muito estreitas de regime caótico entre as cadeias de ilhas.

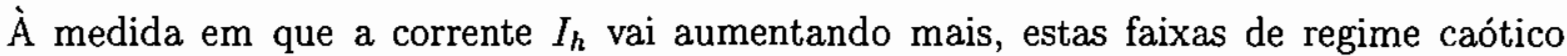
vão alargando e se fundindo formando algumas faixas largas separadas apenas pelas cadeias de ilhas principais. Estas cadeias principais de ilhas têm a sua largura aproximadamente estabilizada a partir de um certo valor de corrente em torno de $I_{h}=500 \mathrm{~A}$. Esta estabilização se deve ao fato de que as ilhas vão se alargando à medida em que a corrente aumenta, mas as bordas vão sendo destruídas e se tornam caóticas devido à superposição de cadeias de ilhas secundárias. De fato, observamos um grande número de "caudas" caóticas que se fundem com as faixas principais. Estas "caudas" são geradas devido à superposição de cadeias secundárias e a fusão com a faixa principal ocorre com a destruição da respectiva cadeia secundária. Este fenômeno dá uma característica fractal às bordas das faixas caóticas, conforme pode ser observado em ampliações (fig. 8.1.b).

Observamos ainda que as faixas caóticas são permeadas de pontinhos brancos correspondentes a "mini-ilhas" magnéticas que são geradas e destruídas logo a seguir, ou que "passam" pela posição $x_{0}$ fixa à medida que variamos a corrente, fazendo assim com que a estrutura interna das faixas caóticas também seja fractal. Observamos assim que as cadeias de ilhas secundárias desempenham um papel bastante relevante na formação das regiões caóticas, e que a partir de um certo valor de corrente ocorre uma estabilização da largura das faixas caóticas, ou seja, existe um máximo de caos que pode ser induzido na borda do tokamak, por mais que se aumente a corrente nos limitadores.

\subsection{Cortes nos planos de parâmetros}

Passamos agora a utilizar os métodos expostos no capítulo anterior (cálculo de expoentes de Lyapunov, análise espectral, fatores de segurança) para analisarmos com mais detalhe as trajetórias do mapeamento bidimensional conservativo ao longo de segmentos de reta dentro do espaço de parâmetros. Em primeiro lugar consideramos cortes sobre uma seção de Poincaré com $m$ e $I_{h}$ fixos (fig.8.2).

Começamos a análise ao longo de um segmento de reta de posição radial inicial fixa $\left(y_{0}=0,01 m\right)$ e variando o ângulo inicial em todo o intervalo $[0,2 \pi)$. Calculamos então os 


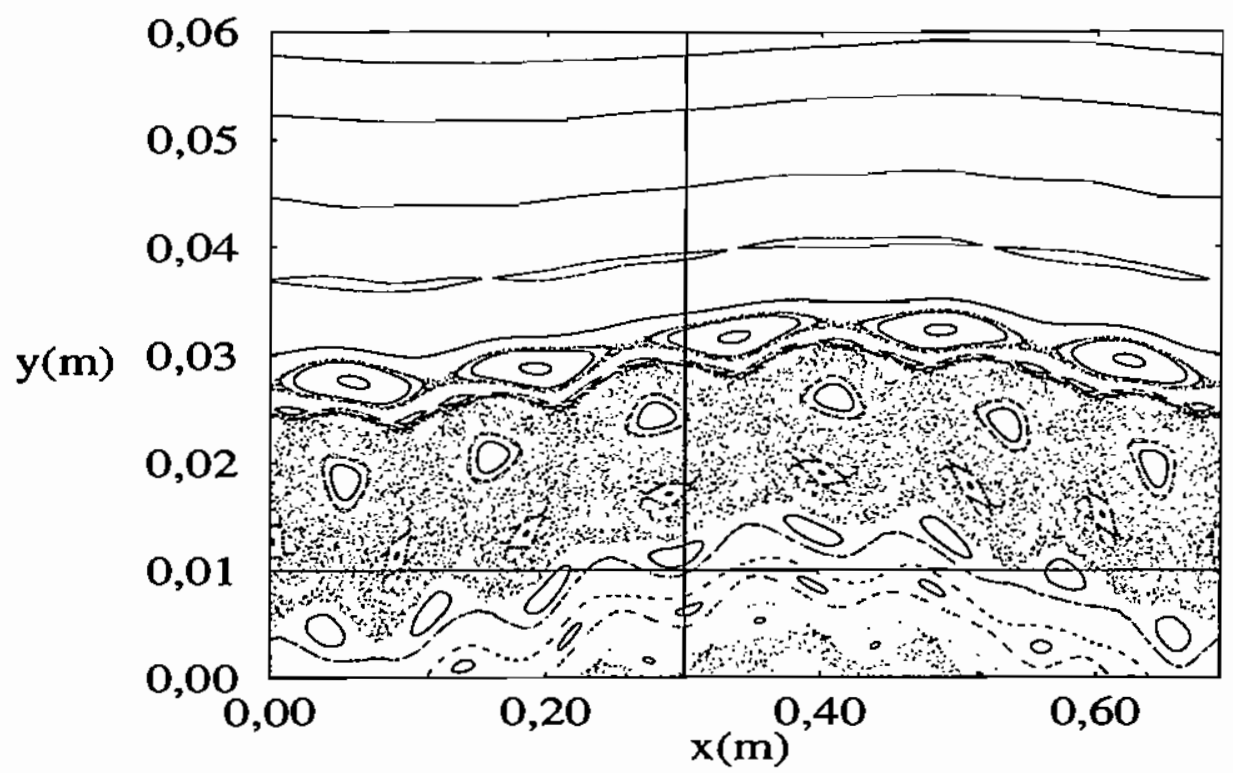

Figura 8.2: Seção de Poincaré do mapeamento bidimensional conservativo com $m=6 \mathrm{e}$ $I_{h}=600 \mathrm{~A}$, indicando os cortes vertical e horizontal a serem analisados.

expoentes de Lyapunov, os fatores de segurança, e o diagrama de bifurcação no espaço de frequências ao longo deste segmento de reta (fig.8.3). Observamos na seção de Poincaré que o corte efetuado começa na região caótica, ao sair dela passa pelas cadeias principais de ilhas $8 / 1$ e $9 / 1$, e acaba voltando à região de caos. Observando os expoentes de Lyapunov (fig.8.3.a), vemos que as passagens de regimes regulares para caóticos, e vice-versa, ocorrem de forma bastante abrupta, ou seja, há grandes saltos na curva dos expoentes de Lyapunov, diferentemente dos sistemas dissipativos, que muitas vezes apresentam transições com estruturas mais suaves. Já no gráfico dos fatores de segurança (fig.8.3.b) podemos ver de forma bem definida os patamares correspondentes às passagens pelas cadeias de ilhas principais, e ainda algumas curvas de passagem por superfícies toroidais irracionais ainda não destruídas pela perturbação.

A distinção entre regiões regulares e caóticas também ocorre de forma bem acentuada no diagrama de bifurcações no espaço de frequências (fig.8.3.c), onde podemos observar regiões com picos espectrais (linhas pretas) bem definidos e outras com regiões contínuas de 

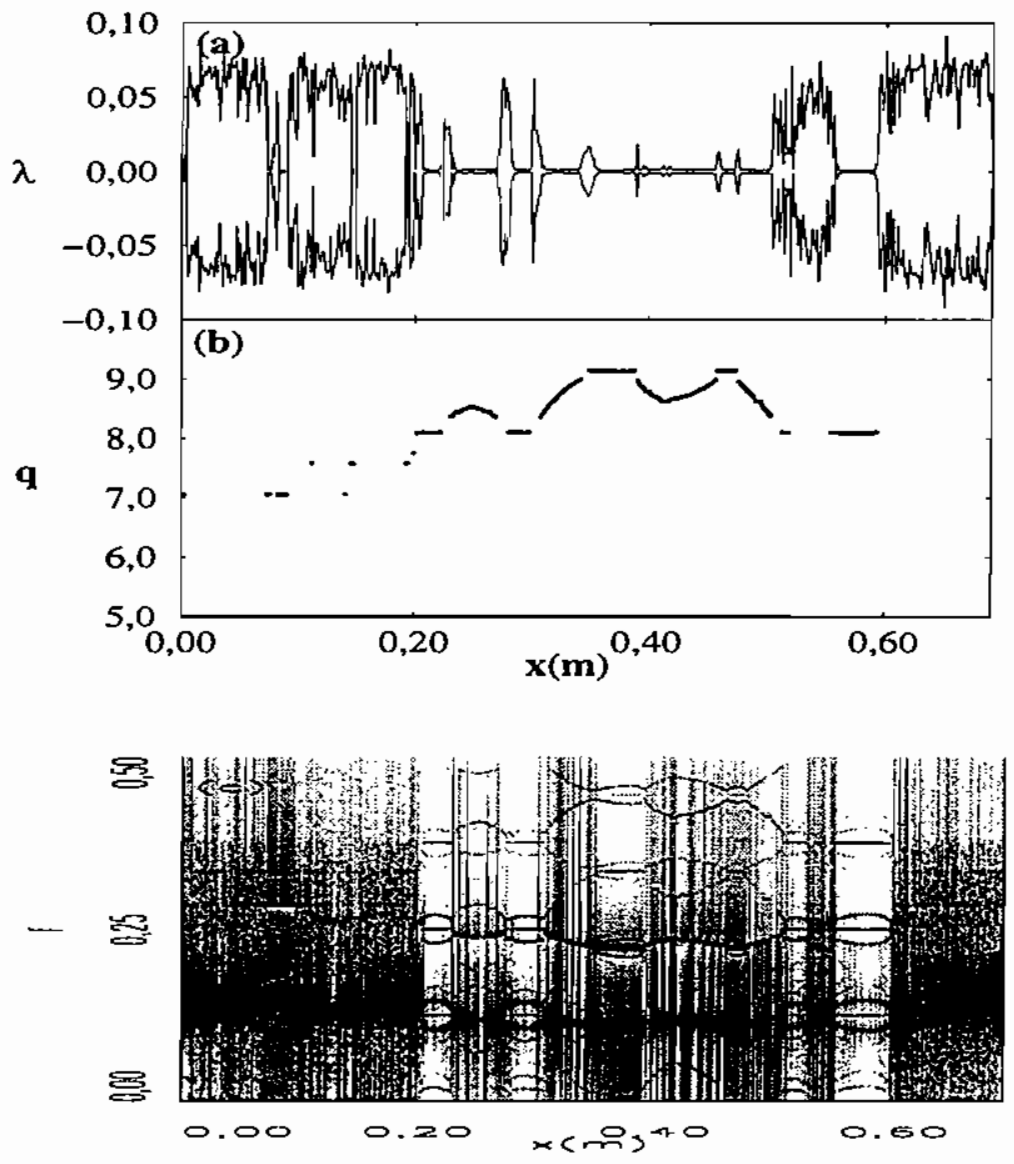

Figura 8.3: (a) Expoentes de Lyapunov, (b) transformadas rotacionais, e (c) o diagrama de bifurcação no espaço de frequências, para o mapa bidimensional conservativo com $m=6$, $I_{h}=600 A$, e $y_{0}=0,01 m$.

maior intensidade espectral. De qualquer forma, em todo o diagrama as frequências mais acentuadas estão na mesma região (em torno de $f=1 / 8$ ). Isto se deve ao fato de que mesmo no regime caótico as linhas de campo ainda estāo confinadas em torno das cadeias principais vizinhas e portanto apresentam, de forma mais acentuada, frequências próximas a estas.

Passemos agora a analisar o sistema ao longo de um segmento de reta com ângulos iniciais fixos e posições radiais iniciais variáveis, utilizando como exemplo o corte vertical com $x_{0}=0,30 m$ (fig.8.2) e calculando os expoentes de Lyapunov, os fatores de segurança, e o diagrama de bifurcação no espaço de frequências (fig.8.4). Este corte começa em uma estreita faixa de regime caótico na borda do vaso, passa em seguida pelas cadeias principais 

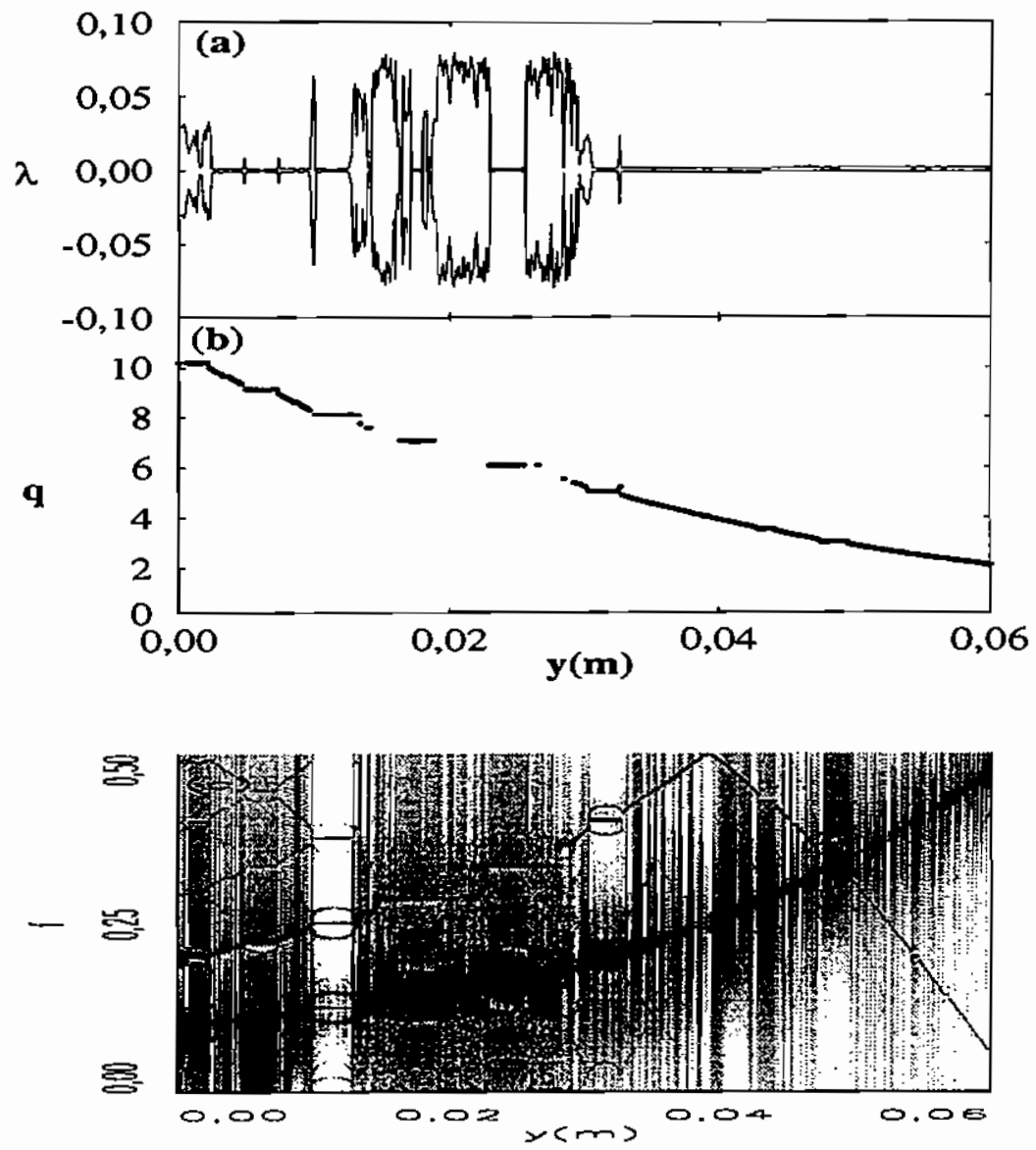

Figura 8.4: (a) Expoentes de Lyapunov, (b) transformadas rotacionais, e (c) o diagrama de bifurcação no espaço de frequências, para o mapa bidimensional conservativo com $m=6$, $I_{h}=600 A$, e $x_{0}=0,30 m$.

de ilhas, pela faixa caótica mais larga, e finalmente entra na região das superfícies toroidais fechadas. No gráfico dos expoentes de Lyapunov (fig.8.4.a) vemos as mesmas transições abruptas já observadas no exemplo anterior. Já no gráfico dos fatores de segurança (fig.8.4.b) vemos uma espécie de "escada do diabo" descendente, interrompida apenas por intervalos correspondentes às regiões de regime caótico. No diagrama de bifurcação no espaço de frequências (fig.8.4.c) observamos agora que as frequências principais percorrem todo o eixo de frequências à medida em que variamos $y_{0}$, formando curvas contínuas com pequenos saltos ao formarem os patamares correspondentes às cadeias de ilhas magnéticas.

Por último, consideramos um exemplo com posição inicial fixa no cruzamento dos dois 

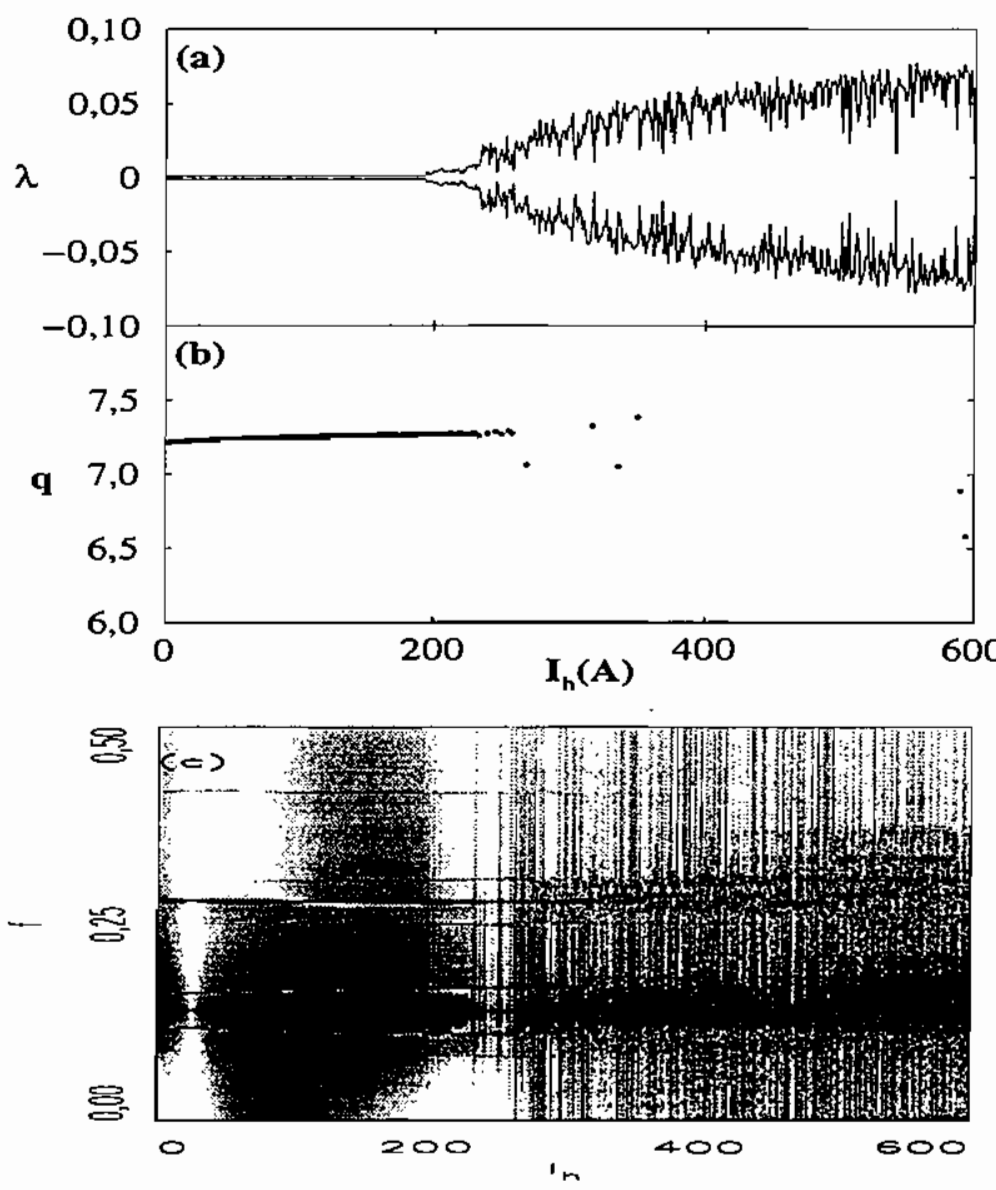

Figura 8.5: (a) Expoentes de Lyapunov, (b) transformadas rotacionais, e (c) o diagrama de bifurcação no espaço de frequências, para o mapa bidimensional conservativo com $m=6$, $x_{0}=0,30 m$ e $y_{0}=0,01 m$.

segmentos de reta anteriores $\left(x_{0}=0,30 m, y_{0}=0,01 \mathrm{~m}\right)$, e variamos a corrente nas hélices do limitador, calculando os expoentes de Lyapunov, os fatores de segurança, e o diagrama de bifurcação no espaço de frequências (fig.8.5). Os expoentes de Lyapunov começam com uma larga faixa de valor nulo, uma vez que não há caos nesta região para baixos valores de corrente, e uma vez que entramos no regime caótico (em torno de $I_{h}=200 \mathrm{~A}$ ) o expoente máximo de Lyapunov começa a crescer de forma irregular. Este crescimento se deve ao alargamento contínuo da faixa de regime caótico. O gráfico dos fatores de segurança consiste em uma curva quase constante para baixas correntes, que é interrompida na região inicial do regime caótico, durante o qual observamos apenas alguns pontos isolados correpondentes a 
mini-ilhas magnéticas dentro do regime caótico. O diagrama de bifurcação também começa apresentando uma estrutura regular de frequências bem-definidas, que é destruída de forma lenta e gradual ao adentrarmos a região de regime caótico.

\subsection{Planos espectrais do mapeamento bidimensional conservativo}

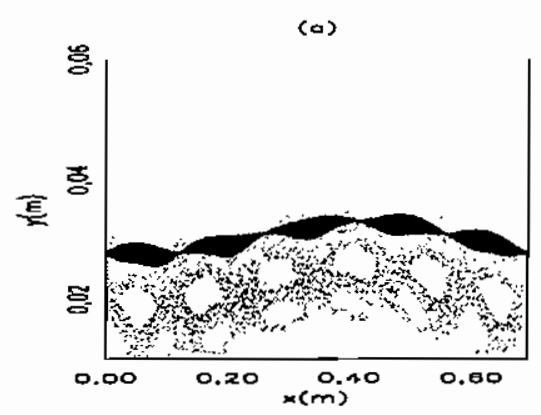

(b)

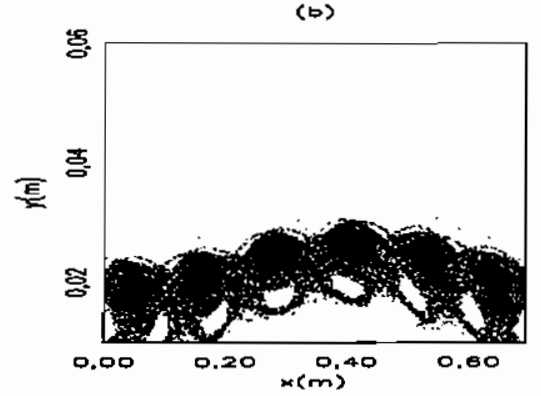

(c)

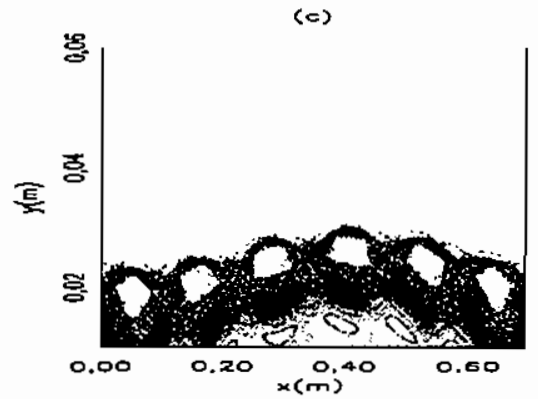

(a)

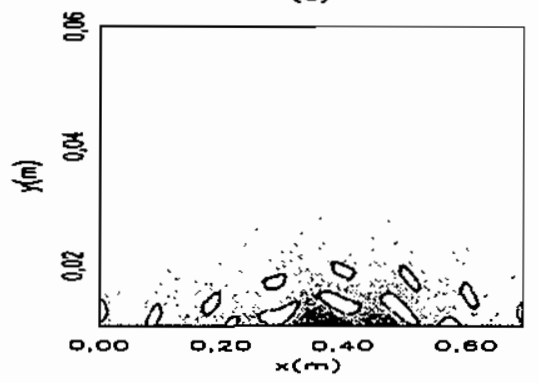

Figura 8.6: Planos espectrais do mapa bidimensional conservativo para $m=6, I_{h}=500 A$, e (a) $f=1 / 5$, (b) $f=1 / 6$, (c) $f=1 / 7$, (d) $f=1 / 9$. Quanto mais escuro o ponto, maior é a intensidade espectral da frequência analisada.

Os planos espectrais já foram introduzidos na análise do mapa unidimensional dissipativo, e consistem em uma série de gráficos no plano de parâmetros onde escolhemos a intensidade espectral de certas frequências mais relevantes para serem plotadas em função dos parâmetros. No caso do mapeamento bidimensional dissipativo escolhemos as posiçōes iniciais, angular e radial, como parâmetros.

Fazemos então uma série de planos espectrais para uma seção de Poincaré com parâmetros fixos (fig.8.6) e as frequências correspondentes às principais cadeias de ilhas da região analisada. No plano correspondente à frequência $f=1 / 5$ (fig.8.6.a) vemos que a intensidade desta 
frequência é muito intensa apenas sobre a cadeia de ilhas $5 / 1$, conforme era de se esperar, e de resto observamos apenas um fraco fundo contínuo nas regiōes caóticas, correspondente à intensidade do fundo contínuo destas.

Já para o plano correpondente à frequência $f=1 / 6$ (fig.8.6.b) vemos que a intensidade espectral é muito grande sobre a cadeia de ilhas $6 / 1$, conforme esperado, mas também é muito acentuada na faixa de regime caótico que envolve esta cadeia de ilhas. O mesmo fenômeno pode ser observado na figura correspondente à frequência $f=1 / 7$ (fig.8.6.c). Observamos assim que as frequências dominantes em uma dada região caótica são as frequências das cadeias de ilhas magnéticas que esta envolve.

Fizemos ainda um gráfico do plano correspondente à frequência $f=1 / 9$ (fig.8.6.d), e neste caso podemos observar que as maiores intensidades espectrais ocorrem não sobre a própria cadeia $9 / 1$, mas sobre a fina faixa de regime caótico imediatamente em torno desta cadeia de ilhas.

De forma geral, observamos então que uma determinada frequência apresenta intensidades espectrais acentuadas sobre a sua cadeia de ilhas principal e as regiões caóticas imediatamente adjacentes a esta, intensidades fracas em outras regiões caóticas, e intensidade nula em todas as outras regiões.

\subsection{Padrões de escape}

Um outro aspecto de grande relevância a ser analisado em relação ao mapeamento do limitador ergódico é a difusão das linhas de campo magnético, que influencia de forma direta na difusão de partículas, confinadas por estas. Para o estudo da difusão costuma-se escolher uma série de trajetórias com a mesma posição inicial na direção de difusão (no nosso caso a direção radial) e iterá-las, tomando uma média sobre o afastamento quadrático da posição inicial na direção de difusão ao longo do tempo. Define-se assim o coeficiente de difusão[2]:

$$
D_{0} \equiv \lim _{N \rightarrow \infty} \frac{<\left(r_{N}\left(r_{0}, \theta_{0}\right)-r_{0}\right)^{2}>_{\theta_{0}}}{2 N}
$$

onde \langle\rangle$_{\theta_{0}}$ representa uma média sobre os ângulos iniciais. Porém surge um problema nesta definiçāo: é preciso um número grande de iterações das trajetórias sobre as quais esta média é efetuada, para que ocorra a convergência do limite. Isto não apresenta problemas para alguns mapas como o mapa-padrão cujo domínio se estende infinitamente na direção de difusão ${ }^{1}$. Mas, no caso do mapa bidimensional conservativo que estamos estudando, a

\footnotetext{
${ }^{1}$ De fato, no mapa padrão ocorrem outros problemas de convergência, devido aos modos aceleradores [2].
} 
direção de difusão é limitada pela parede do vaso do tokamak em $r=b=0,11 \mathrm{~m}$. Depois que a linha de campo magnética passa por este limite não há sentido em continuar com os cálculos de difusão. Acontece porém que, nas situações em que as ilhas magnéticas na borda do tokamak estão suficientemente destruídas para que haja possibilidade de difusão, esta ocorre de forma tão rápida que para um grande número de linhas de campo bastam apenas algumas iterações para a colisão com a borda.
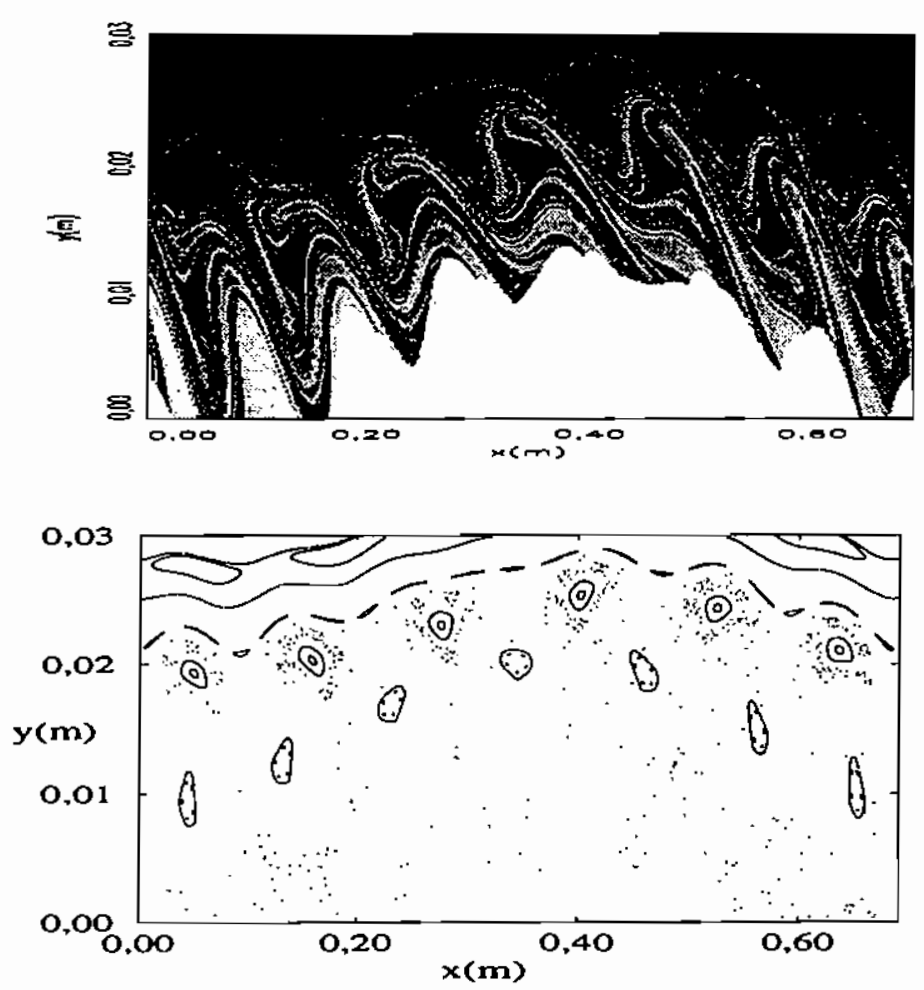

Figura 8.7: Diagrama de escape e seção de Poincaré do mapa bidimensional conservativo com correções toroidais para $I_{h}=700 \mathrm{~A}$ e $m=7$. Quanto mais claros os pontos, mais rapidamente a linha de campo magnético escapa. Pontos pretos representam linhas que não escaparam nas primeiras 100 iterações.

Para analisar este fenômeno mais detalhadamente, introduzimos aqui o que decidimos chamar de padrões de escape. Os padrões de escape consistem em planos de condições iniciais onde a cada posição inicial associamos um ponto cujo tom de cinza é proporcional ao número de voltas que a linha de campo magnético dá no tokamak antes de colidir com a parede, "escapando" assim do domínio do nosso mapeamento. Calculando o diagrama de 

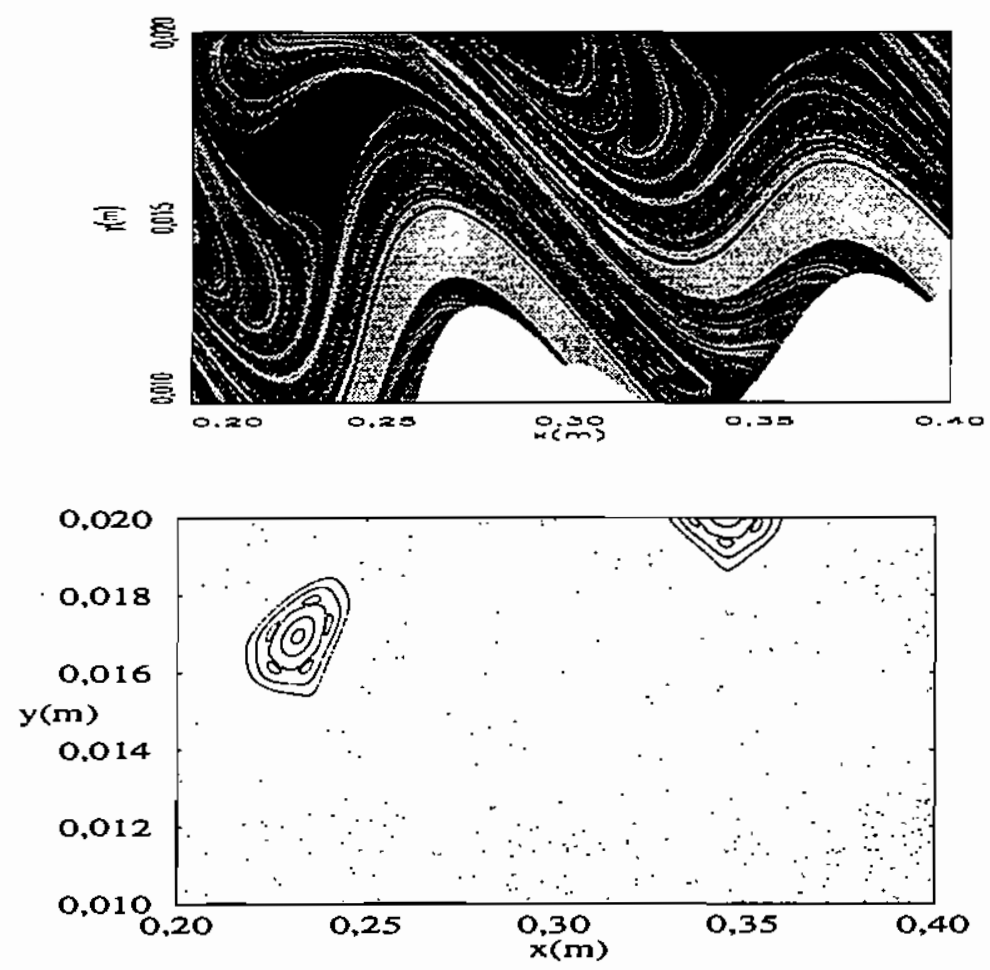

Figura 8.8: Ampliação de detalhes da figura 8.7.

escape correspondente à borda do tokamak de uma seção de Poincaré com uma grande região caótica na borda (fig.8.7) podemos observar as várias regiões de comportamentos distintos. Temos, em primeiro lugar, uma faixa imediatamente acima da borda do tokamak, onde as linhas colidem imediatamente com a parede (a primeira iteração já as tira do vaso). Esta região é contínua e o seu limite superior corresponde a uma curva suave, que nada mais é do que o segmento de reta $y=0$ iterado uma vez para trás no mapeamento. Acima desta curva observamos uma região bastante complexa, de caráter fractal, dentro da qual observamos grandes regiōes negras (não ocorre escape, ou este é muito lento) correpondentes às ilhas magnéticas. Destas regiōes saem pequenas "caudas" negras correpondentes às regiões em que as linhas são atraídas para perto das ilhas ficando presas por muito tempo pelos cantori formado por cadeias de ilhas secundárias, e demorando portanto a escapar. Finalmente temos uma região superior completamente negra, correspondente à região confinada pela superfície toroidal mais externa que ainda não se partiu, e para dentro da qual não pode haver, consequentemente, linhas magnéticas que cheguem até a borda. O complexo caráter 
fractal da região intermediária, formado por estreitas faixas esticadas, pode ser percebido em ampliaçōes (fig.8.8). De fato este caráter filamentado deve-se ao fenômeno de "stretching and folding"(em português "estica e dobra")[2], um mecanismo comum nos sistemas conservativos.

\subsection{Análise da difusão local}
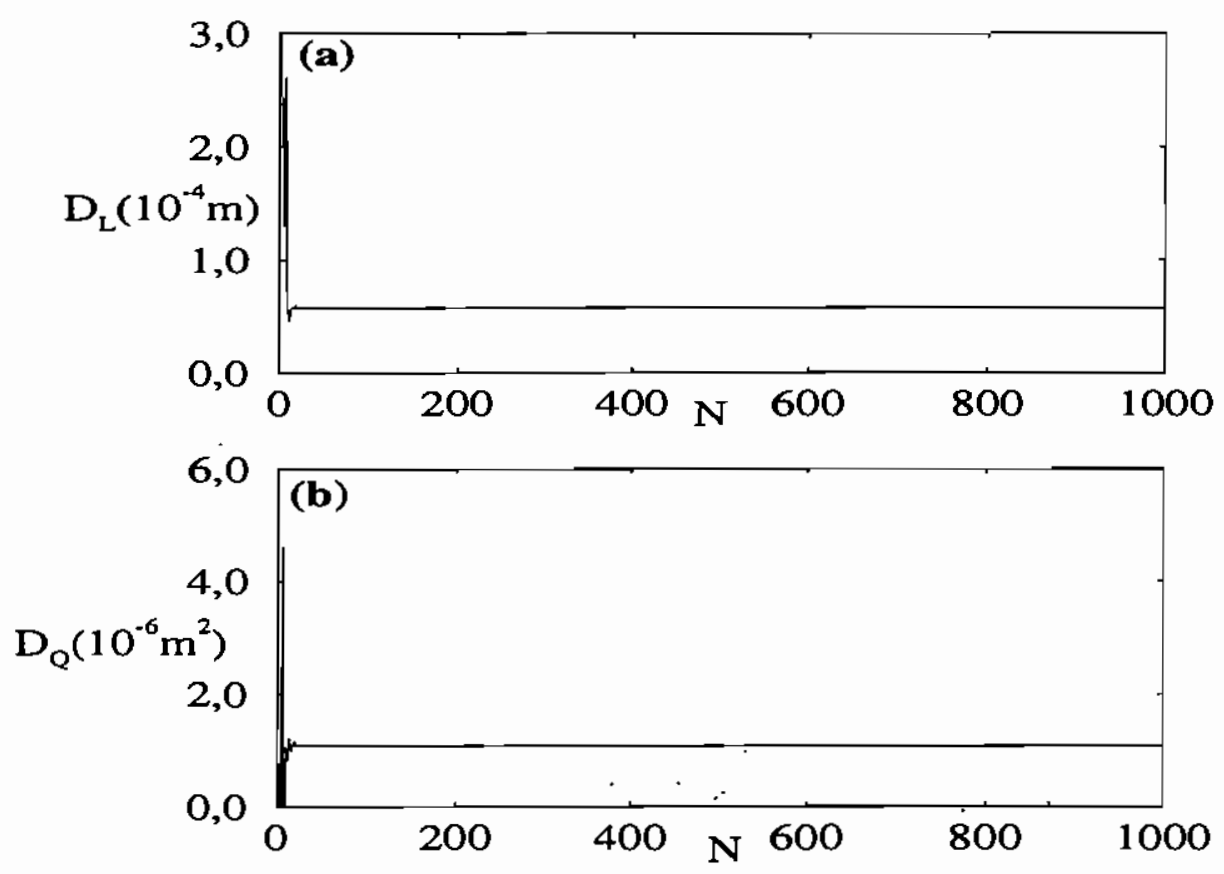

Figura 8.9: Convergência dos coeficientes locais de afastamento (a) linear e (b) quadrático para $r_{0}=0,10 m, m=7, I_{h}=500 \mathrm{~A}$, em função do número $N$ de ângulos.

Outra forma de se estudar a difusão em sistemas limitados é fazer um estudo local da difusão. Para tanto calcula-se não coeficientes de difusão que prevêm o que acontece a longo prazo, mas coeficientes locais que estudam o deslocamento médio das trajetórias na primeira iteração. Para tanto definimos o coeficiente local de afastamento linear[48]:

$$
D_{L}\left(r_{0}\right) \equiv<r_{1}\left(r_{0}, \theta_{0}\right)-r_{0}>_{\theta_{0}}
$$

e o coeficiente local de afastamento quadrático:

$$
D_{Q}\left(r_{0}\right) \equiv<\left(r_{1}\left(r_{0}, \theta_{0}\right)-r_{0}\right)^{2}>_{\theta_{0}}
$$


onde $r_{0}$ é uma posição radial inicial fixa, $\left\langle>_{\theta_{0}}\right.$ é uma média sobre posições angulares iniciais, e $r_{1}$ é a posição radial das linhas de campo após a primeira iteração do mapeamento. $O$ coeficiente local de afastamento quadrático mede uma tendência geral de afastamento, independente da direção, enquanto que o coeficiente linear é positivo para deslocamentos para fora do vaso do tokamak e negativo para deslocamentos para dentro, que não ocorrem no nosso mapeamento bidimensional conservativo.
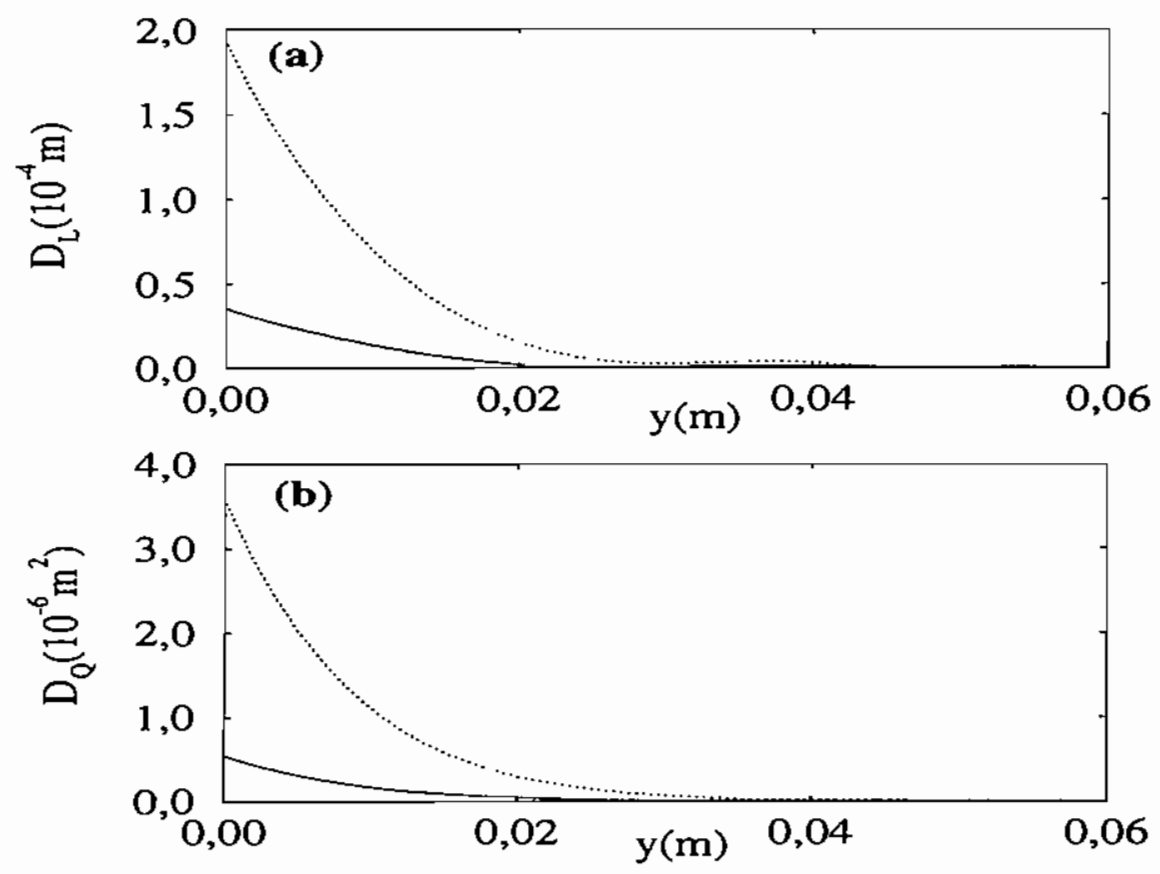

Figura 8.10: Coeficientes locais de afastamento (a) linear e (b) quadrático para o mapeamento conservativo do limitador ergódico com $m=7$ e $I_{h}=200 \mathrm{~A}$ (linhas cheias) e $I_{h}=500 \mathrm{~A}$ (linhas pontilhadas).

Fazendo um gráfico dos coeficientes de afastamento em função do número de ângulos iniciais empregados na média (onde sempre empregamos ângulos igualmente espaçados no intervalo $[0,2 \pi))$, vemos que ambos convergem muito rapidamente, e basta utilizarmos em torno de 100 ângulos iniciais para obter médias confiáveis (de fato este é o número de ângulos iniciais utilizados nos gráficos seguintes).

Passamos agora a calcular os coeficientes locais de afastamento lineares e quadráticos em função da posição inicial radial para correntes fixas no limitador (8.10). Observamos que mesmo para correntes baixas já há tendências muito fracas de deslocamento radial na borda. Quando aumentamos a corrente esta tendência de deslocamento aumenta e o afastamento se 

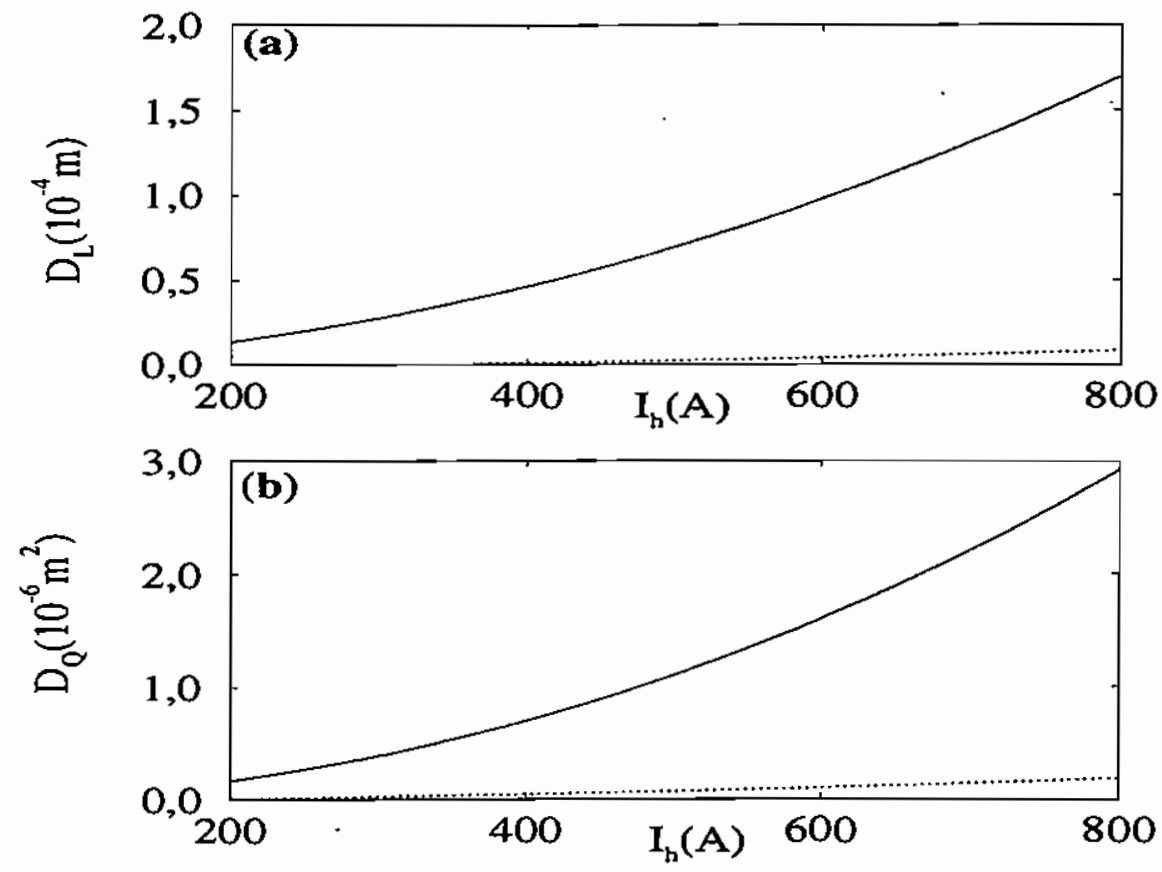

Figura 8.11: Coeficientes locais de afastamento (a) linear e (b) quadrático para o mapeamento conservativo do limitador ergódico com $m=7$ e $y_{0}=0,01 m$ (linhas cheias) e $y_{0}=0,03 m$ (linhas pontilhadas).

torna não-nulo mesmo para regiões mais internas. A dependência exata da corrente pode ser observada em detalhes na figura 8.11 onde calculamos os coeficientes locais de afastamento em função da corrente nos limitadores para uma posição radial mais externa, onde ele cresce rapidamente, e para uma posição radial mais interna, onde ele é muito baixo e só passa a ser não-nulo para correntes mais elevadas.

Os coeficientes locais de afastamento linear podem ser utilizados para estimar a ordem de grandeza do número médio de voltas que as linhas de campo magnético precisam para chegar de uma determinada posição radial até a borda do plasma, sendo que este número de voltas é, por sua vez, proporcional ao tempo de difusão das partículas. Sendo $N_{v}$ este número médio de voltas, temos que:

$$
N_{v} \approx \int_{r_{0}}^{b} \frac{d r}{D_{L}(r)} \approx\left(b-r_{0}\right)<\frac{1}{D_{L}(r)}>_{r}
$$

onde a média $\left\langle>_{r}\right.$ é efetuada sobre a região $r_{0}<r<b$.

Finalmente, fizemos ainda uma análise da robustez destes coeficientes perante pequenas flutuações aleatórias na corrente do limitador ergódico. A influência de pequenas oscilações 

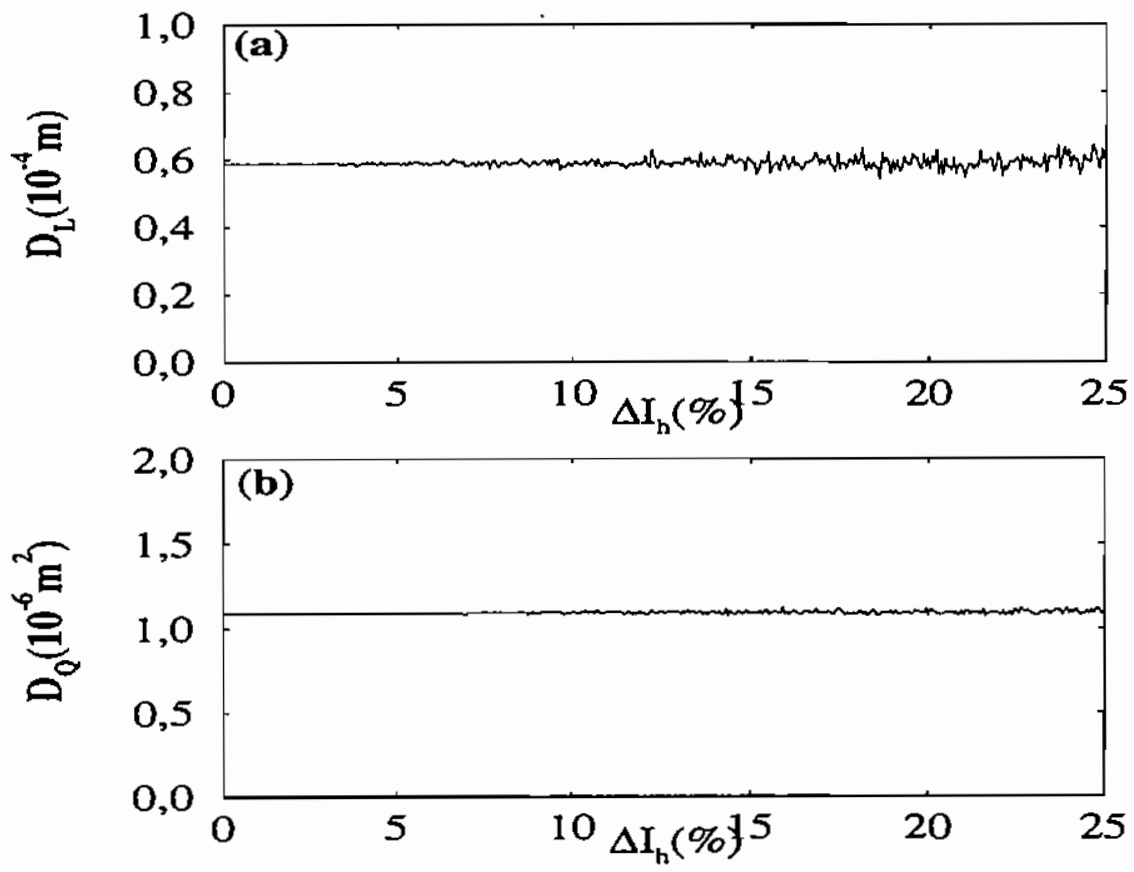

Figura 8.12: Coeficientes de afastamento (a) linear e (b) quadrático para o mapeamento conservativo do limitador ergódico com $m=7, I_{h}=500 \mathrm{~A}$, e $y_{0}=0,01 \mathrm{~m}$, variando as flutuações $\Delta I_{h}$ na corrente do limitador.

de corrente sobre o sistema será estudada de forma mais geral no próximo item, sendo que vamos analisar apenas a sua influếncia sobre o fenômeno da difusão. Considerando os coeficientes de afastamento linear em função da oscilação aleatória máxima da corrente no limitador (fig.8.12) vemos que para flutuaçōes de até cerca de $10 \%$ praticamente nada acontece. Mesmo para oscilações maiores o ruído percebido na difusão é muito pequeno, ou seja, pequenas flutuações experimentais aleatórias no limitador ergódico não contribuem de forma significativa para a difusão, pelo menos no nosso modelo.

\subsection{Pequenas flutuações na corrente das hélices do li- mitador}

No item anterior estudamos brevemente a influência de oscilações de corrente no limitador ergódico sobre a difusão no sistema. Passamos agora a tentar de forma mais geral a influência de flutuações experimentais sobre a validade do nosso modelo. Para isto, é 

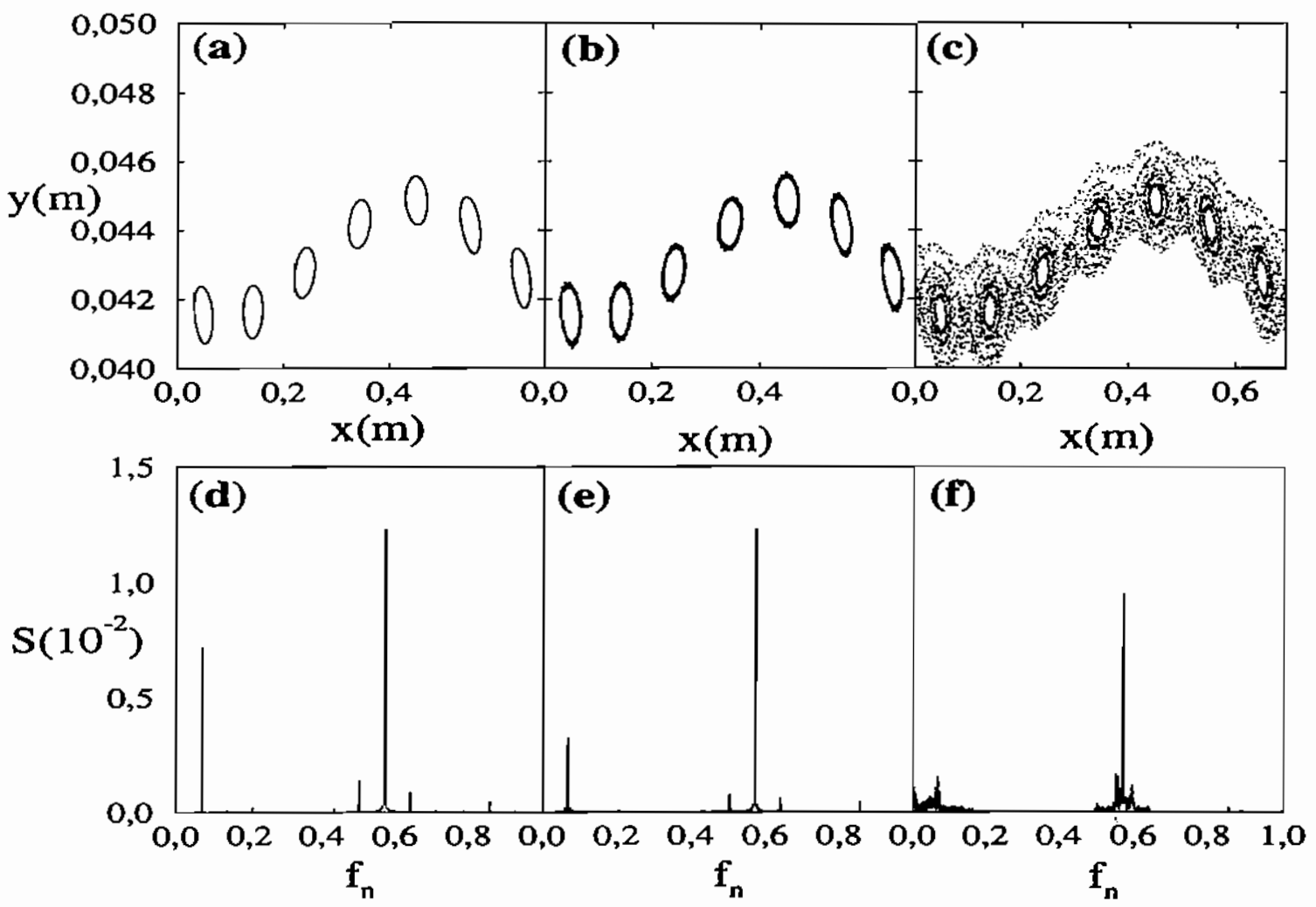

Figura 8.13: Linhas de campo do mapeamento bidimensional dissipativo do limitador ergódico com $m=7, I_{h}=700 A, x_{0}=0,15 m, y_{0}=0,041 m$, e flutuações na corrente no limitador da ordem de (a) $0 \%$, (b) $10 \%$, e (c) $20 \%$, e os seus respectivos espectros de Fourier (d), (e), e (f).

necessário fazermos uma ressalva. As iterações no nossso mapeamento para o limitador ergódico estão relacionadas a uma integração na variável espacial da direção toroidal $(\phi)$ que desempenha o papel de um tempo canônico, e não à integração em um tempo propriamente dito. Assim sendo, toda a linha de campo existe no mesmo instante de tempo, e como todas as perturbações estão, portanto, sendo aplicadas simultaneamente, não faz sentido, a rigor, falar em correntes flutuantes no tempo. O que nós queremos representar com isso é que, se houver flutuaçōes da corrente no tempo, há flutuações de toda a configuração magnética, e a trajetória de uma partícula se movendo dentro desta configuração vai ser influenciada pelas flutuações de corrente. Para simplificar o problema vamos nos permitir então, por um instante, confundir a linha de campo magnético com a trajetória da partícula, para fazermos uma análise da relevância de flutuações na corrente. 
Consideremos, por exemplo, uma trajetória regular que, a princípio, se localiza sobre. uma cadeia de ilhas magnéticas, conforme visto na figura 8.13.a. Aplicandö uma flutuação aleatória de $10 \%$ sobre a corrente e recalculando a mesma linha de campo magnético (fig.8.13.b) vemos que ela continua confinada sobre a cadeia de ilhas, aparecendo apenas mais "borrada". De qualquer forma, o espectro de Fourier da trajetória praticamente não é afetado, como pode ser observado nas figuras 8.13.d-e. Aplicando agora uma flutuação máxima de $20 \%$ e recalculando a mesma linha de campo e o seu espectro (fig.8.13.c-f) vemos que a linha de campo acaba escapando para a região de regime caótico e, consequentemente, o seu espectro passa a apresentar um fundo contínuo em torno dos picos principais.

Este exemplo mostra claramente a diferença entre perturbações aleatórias em sistemas dissipativos e conservativos. À medida em que para sistemas dissipativos muitas transições são suaves e o sistema transita entre os atratores, formando assim um atrator "médio" da regiāo de parâmetros compreendida na oscilação paramétrica, em sistemas conservativos este tipo de oscilação pode levar a mudanças bruscas, levando o sistema de regiões regulares a irregulares e vice-versa, uma vez que a transição entre eles é muito abrupta. 


\section{Capítulo 9}

\section{Conclusões}

Na primeira parte desta tese, introduzimos um mapeamento unidimensional dissipativo a dois parâmetros, que representa o comportamento de um protótipo de oscilador suave submetido a perturbações impulsivas no limite de relaxação rápida[8, 49]. Mostramos que as trajetórias deste mapeamento podem ser classificadas em periódicas, quase-periódicas, e caóticas, utilizando para isto vários algoritmos da análise não-linear, como o cálculo de expoentes de Lyapunov e a análise de Fourier[10, 18]. Verificamos em seguida que o espaço de parâmetros [14] deste sistema podia ser dividido em duas regiões distintas: a primeira, caracterizada por baixas intensidades de perturbação, apresentando apenas trajetórias periódicas e quase-periódicas, formando uma estrutura conhecida na literatura por "línguas de Arnold" [32], comuns a todo um grupo de mapas conhecidos como "mapas do círculo". A segunda região do plano de parâmetros, caracterizada por perturbações de maior intensidade, apresenta apenas trajetórias periódicas e caóticas, sendo que a fronteira entre estes dois tipos de regime apresenta uma intrincada forma fractal.

Passamos então a analisar os três tipos de transição entre regimes no plano de parâmetros: a transição entre regimes periódicos e quasi-periódicos, caracterizada por deslocamento contínuo dos picos espectrais ao longo de eixo de frequências nos espectros de potência, por curvas de expoentes de Lyapunov suaves e contínuas, e por uma estrutura de números de rotação conhecida como "escada do diabo" [13]; a transição entre regimes periódicos e caóticos, caracterizada por picos de frequência crescendo e decrescendo em posições fixas, por curvas de expoentes de Lyapunov com transições abruptas, e por diagramas de bifurcação cuja lei de escala é regida pela constante universal de Feigenbaum [10]; e a transição entre regimes periódicos de períodos incomensuráveis, caracterizada por oscilações abruptas entre diferentes expoentes de Lyapunov e números de rotação, distribuídas de forma fractal.

Para o mesmo mapa unidimensional dissipativo ainda fizemos uma análise das trajetórias 
periódicas instáveis que coexistem com os atratores caóticos, e mostramos que para um dado conjunto fixo de parâmetros o número destas tende a crescer de forma exponencial com o período, conforme previsto teoricamente [35]. Verificamos também que as órbitas instáveis de baixo período são em geral boas candidatas a órbitas optimais, justificando assim a utilização destas em métodos de controle de caos por pequenas perturbaçoes[28]. Encerramos o estudo do mapa unidimensional dissipativo mostrando que o comportamento deste é razoavelmente robusto frente a pequenas flutuações aleatórias nos parâmetros de controle, devido á forte dissipatividade do sistema que reforça a estabilidade dos seus atratores.

Na segunda parte da tese foi apresentada a dedução de um mapeamento bidimensional conservativo que descreve as seções de Poincaré das linhas de campo magnético no interior de um tokamak sob a influência de limitadores ergódicos magnéticos [16]. Através da utilização de expoentes de Lyapunov e espectros de Fourier, entre outras ferramentas, foi mostrado que as linhas de campo mangético podiam ser divididas em três grupos: linhas regulares confinadas sobre cadeias de ilhas magnéticas, caracterizadas por expoentes de Lyapunov nulos, fatores de segurança racionais, espectros discretos, e dimensão de mergulho igual a $D_{m}=2$; linhas de campo regulares sobre superfícies toroidais fechadas, caracterizadas por expoentes de Lyapunov nulos, fatores de segurança irracionais, espectros discretos, e dimensão de mergulho $D_{m}=1$; e linhas caóticas, caracterizadas por expoentes de Lyapunov não-nulos, fatores de segurança não convergentes, espectros contínuos, e dimensão de mergulho $D_{m}=2$.

Através de uma análise deste mapeamento bidimensional conservativo no espaço dos parâmetros, foi analisado o crescimento da largura das cadeias de ilhas magnéticas com a corrente nas hélices do limitador, e observado o surgimento de regiões caóticas devido à superposição das cadeias de ilhas magnéticas. Verificou-se também que para correntes mais elevadas nos limitadores ocorre uma saturação no tamanho das regiões caóticas. Em seguida, foi analisada um análise da difusão das linhas de campo magnéticas, e com o auxílio dos diagramas de escape, um método gráfico introduzido por nós, foi mostrado que devido á rápida colisão das linhas de campo difusoras com a borda do tokamak não é possível usar os coeficientes de difusão como são normalmente definidos, uma vez que estes dependem de um grande tempo de evolução do sistema. Optou-se então por uma análise local da difusão de linhas de campo magnético [2]. Finalmente, analisou-se a influência de pequencas flutuações aleatórias da corrente nas hélices do limitadro e verificou-se que estas não influem de maneira significativa sobre a difusão em nosso modelo, mas podem chegar a afetar de maneira significativa a evolução das linhas de campo magnético individuais, devido às fronteiras abruptas entre regiões de comportamento regular e irregular em sistemas conservativos. 
"De toute l'histoire vous ne retenez que certains mots qu'elle a dits dans le sommeil, ces mots qui disent ce dont vous êtes atteint: Maladie de la mort." - Marguerite Duras (la maladie de la mort). 



\section{Bibliografia}

[1] C. Sparrow. The Lorenz Equations: Bifurcations, Chaos, and Strange Attractors. Springer Verlag, New York, 1982.

[2] A.L. Lichtenberg e M.A. Lieberman. Regular and Stochastic Motion. Springer Verlag, New York, 1983.

[3] T. Matsumoto e L.O. Chua. "The double scroll". IEEE Trans. Circuits Syst., CAS32:797-818, 1985.

[4] M.J. Feigenbaum. "Quantitative universality for a class of nonlinear transformations". J. Stat. Phys., 19:25-52, 1978.

[5] J. Wisdom. "Chaotic behaviour in the solar system". Proc. R. Soc. London, A413:109$129,1987$.

[6] R. Lima e M. Pettini. "Supression of chaos by resonant parametric perturbations". Phys. Rev., A41:726-733, 1990.

[7] A. Azevedo e S. Rezende. "Controlling chaos in spin-wave instabilities". Phys. Rev. Lett., 66:1342-1345, 1991.

[8] E.J. Ding. "Analytic treatment of periodic orbit systematics for a nonlinear driven oscillator". Phys. Rev., A34:3547-3550, 1986.

[9] G.A. Cecchi, D.L. Gonzälez, M.O. Magnasco, G.B. Midlin, O. Piro, e A.J. Santillan. "Periodically kicked hard oscillators". Chaos, 3:51-62, 1993.

[10] H. G. Schuster. Deterministic Chaos. Physik Verlag, Berlin, 1984.

[11] K. Ullmann e I.L. Caldas. "Transitions in the parameter space of a periodically forced dissipative system". Chaos, Solitons \& Fractals, 7:1913-1921, 1996. 
[12] M.S. Baptista e I.L. Caldas. "Dynamics of the kicked logistic map". Chaos, Solitons $\mathcal{G}$ Fractals, 7:325-336, 1996.

[13] P. Bak. "The devil's staircase". Phys. Today, 39:38-45, 1986.

[14] J.A.C. Gallas. "Structure of the parameter space of the Hénon map". Phys. Rev. Lett., 70:2714-2717, 1993.

[15] F. Karger e K. Lackner. "Resonant helical divertor". Phys. Lett., A61:385-387, 1977.

[16] R.L. Viana. Problemas não-lineares com perturbação impulsiva e aplicações em física de plasmas (Tese de Doutorado). Universidade de São Paulo, São Paulo, 1991.

[1.7] T.J. Martin e J.B. Taylor. "Ergodic behaviour in a magnetic limiter". Plasma Phys. and Contr. Fus., 26:321-340, 1984.

[18] R.W. Hamming. Numerical Methods for Scientists and Engineers. Dover Publications, Inc., New York, 1989.

[1.9] H.D.I. Abarbanel, R. Brown, J.J. Sidorowich, e L.Sh. Tsimring. "The analysis of observed chaotic data in physical systems". Rev. Mod. Phys., 65:1331-1392, 1993.

[20] B.R. Hunt e E. Ott. "Optimal periodic orbits of chaotic systems". Phys. Rev. Lett., A76:2254-2257, 1996.

[21] R.L. Viana e I.L. Caldas. "Peripheral stochasticity in tokamaks - the Martin-Taylor model revisited". Zeitschrift fuer Naturforschung, 47:941-944, 1992.

[22] R.L. Viana e I.L. Caldas. "Comments on the magnetic field generated by an infinite current grid". Eur. J. Phys., 12:293-296, 1991.

[23] I. Percival e D. Richards. Introduction to Dynamics. Cambridge University Press, Cambridge, 1982.

[24] P. Cvitanovic (Editor). Universality in Chaos. Adam Hilger, Bristol, 1989.

[25] E. Ott. Dynamical Systems. Cambridge University Press, Cambridge, 1993.

[26] T. Kapitaniak(Editor). Chaotic Oscillators. World Scientific, Singapore, 1991. 
[27] J.P. Keener e L. Glass. "Global bifurcations of a periodically forced nonlinear oscillator". J. Math. Biology, 21:175-190, 1984.

[28] T. Shinbrot, C. Grebogi, E. Ott, e J.A. Yorke. "Using small perturbations to control chaos". Nature, 363:411-417, 1993.

[29] I.L. Caldas e H. Tasso. "Limit cycles of periodically forced oscillations". Phys. Lett., A135:264-266, 1989.

[30] J.L. McCauley. Chaos, Dynamics and Fractals - an algorithmic approach to deterministic chaos. Cambridge University Press, Cambridge, 1993.

[31] T. Bohr. "Transition to chaos by interaction of resonances in dissipative systems - I. Circle maps". Phys. Rev., A30:1960-1969, 1984.

[32] W. Yang e B. Hao. "How the Arnold tongues become sausages in a piecewise linear circle map". Com. Theor. Phys., 8:1-15, 1987.

[33] C. Beck e F. Schloegl. Thermodynamics of Chaotic Systems - an Introduction. Cambridge University Press, Cambridge, 1995.

[34] S. Bahar. "Chaotic orbits and bifurcation from a fixed point generated by an iterated function system". Chaos, Solitons \& Fractals, 5:1001-1006, 1995.

[35] F.A. Bajay. Órbitas periódicas em sistemas caóticos (Tese de Doutorado). UNICAMP, Campinas, 1996.

[36] S.P. Dawson. "Strange nonattracting chaotic sets, crises, and fluctuating Lyapunov exponents". Phys. Rev. Lett., 76:4348-4351, 1996.

[37] A.S. Pikovsky e U. Feudel. "Characterizing strange nonchaotic attractors". Chaos, 5:253-260, 1995.

[38] I.C. Nascimento, I.L. Caldas, e R.M.O. Galvão. "Tokamak research at university of São Paulo". J. Fus. Energy, 30:529-240, 1994.

[39] W. Feneberg. "The use of external helical windings for the production of a screening layer in ASDEX and a tokamak with material limiter". Proc. 8th Eur. Conf. Contr. Fus. and Plasma Phys., 1:3-8, 1977. 
[40] S. McCool. "Electron thermal confinement studies with applied resonant fields on TEXT". Nuclear Fusion, 29:547-559, 1989.

[41] N. Reggiani e P.H. Sakanaka. "The effect of the magnetic limiter current on the peripheral chaotic region of a tokamak". Plasma Phys. and Contr. Fus., 36:513-520, 1994.

[42] K. Ullmann e I.L. Caldas. "Dynamical analysis of the chaotic trajectories in a bidimensional symplectic mapping". Nonlinear Dynamics, Chaos, Control, and Their Applications to Engineering Sciences, 1:190-194, 1997.

[43] I.L. Caldas, J.M. Pereira, K. Ullmann, e R.L. Viana. "Magnetic field line mappings for a tokamak with ergodic limiters". Chaos, Solitons \& Fractals, 7:991-1010, 1996.

[44] M.Y. Kucinski, I.L. Caldas, L.H.A. Monteiro, e V. Okano. "Toroidal plasma equilibrium with arbitrary current distribution". J. Plasma Physics, 44:303-311, 1990.

[45] M.Y. Kucinski, I.L. Caldas, L.H.A. Monteiro, e V. Okano. "Magnetic surfaces in nonsymmetric plasmas". Plasma Phys. and Contr. Fus., 34:1067-1088, 1992.

[46] J.P. Eckmann e D. Ruelle. "Ergodic theory of chaos". Rev. Mod. Phys., 57:617-656, 1985.

[47] S. Matsuda e M. Yoshikawa. "Magnetic island formation due to error field in the JFT-2 tokamak". Jap. J. of Appl. Phys., 14:87-102, 1975.

[48] N.W. Murray, M.A. Lieberman, e A.J. Lichtenberg. "Corrections to quasilinear diffusion in area-preserving maps". Phys. Rev. A, 32:2413-2424, 1985.

[49] P. Hagedorn. Oscilações não-lineares. Editora Edgard Bluecher, São Paulo, 1988. 